
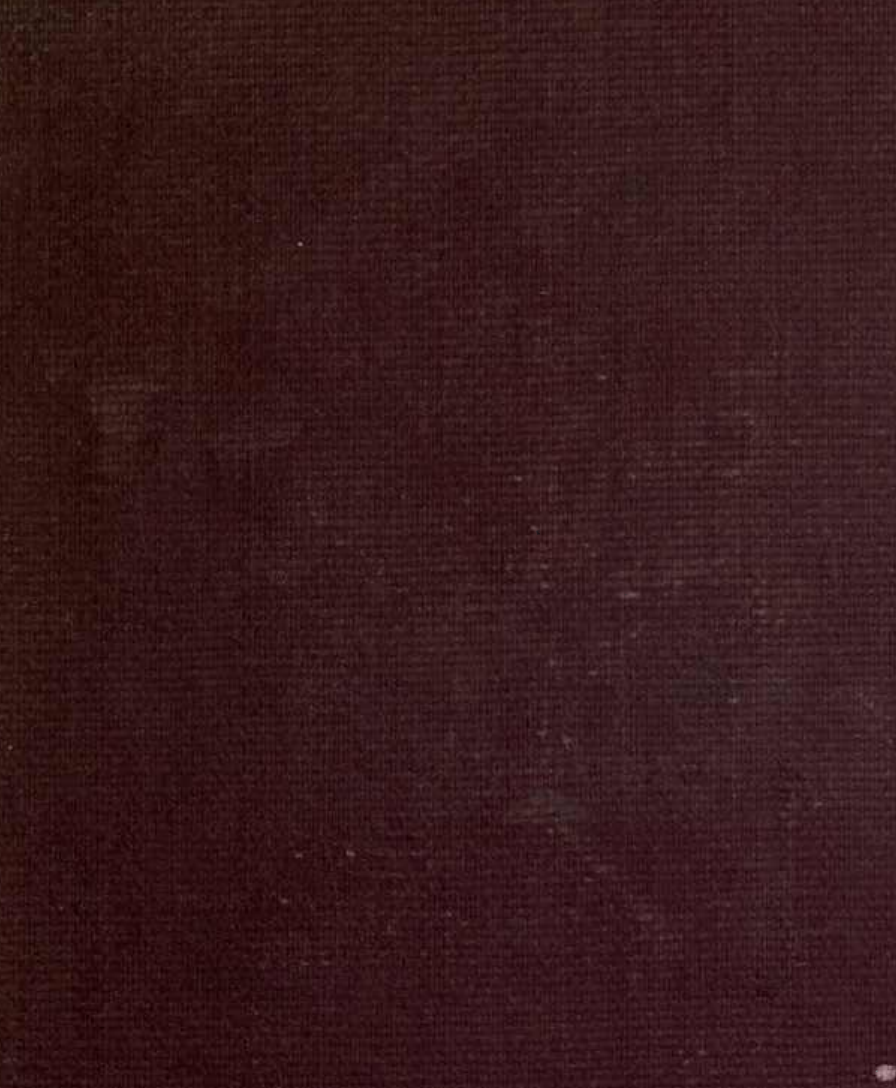


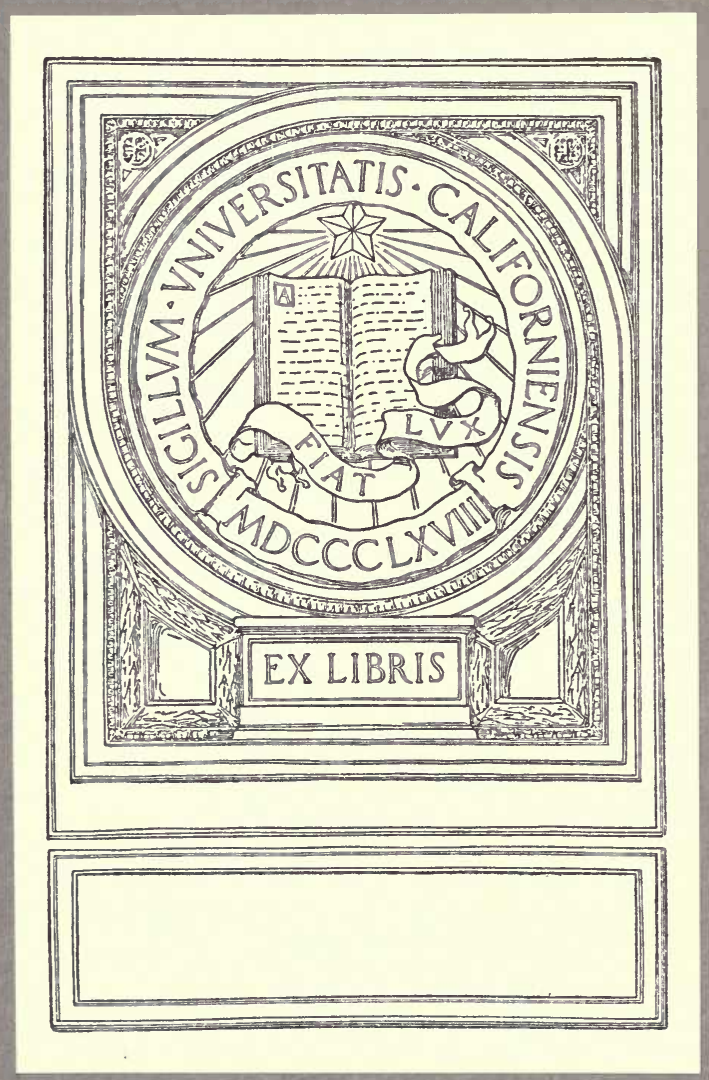



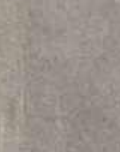




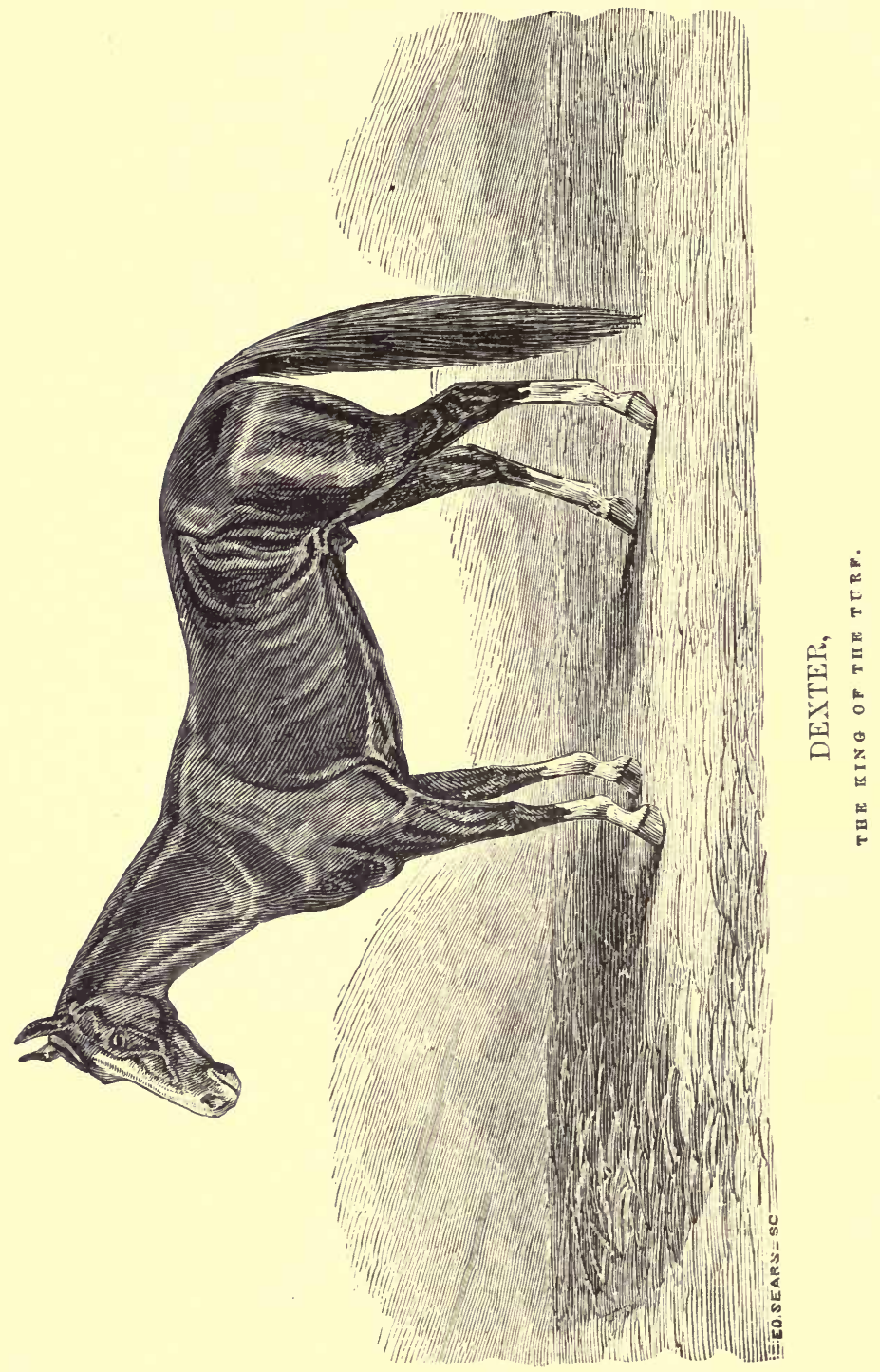




\section{H O R S E}

\section{P O R T A I T U E :}

EMBRACING

BREEDING, REARING, AND TRAINING TROTTERS, WITH THEIR MANAGE. MENT IN THE STABLE AND ON THE TRACK, AND PREPARATION FOR RACES; INCLUDING HISTORIES OF THE HORSE AND HORSEMEN.

\section{WITH AN APPENDIX} CONTAINING THE

DESCRIPTION OF DEXTER AND A PORTRAIT BY SCOTT.

BY

JOSEPH CAIRN SIMPSON.

NEW YORK:

GEO. E. WOODWARD, PUBLISHER. 
Entered, according to Act of Congress, in the year 1867, by

W. A. TOWNSEND \& ADAMS,

In the Clerk's Office of the District Court of the United States for the Southern District of New York. 
To

Hon. TAMES GRANT; Davenport, Iowa; and

M. S. PATRICK, Esq., Chicago, Ininois:

This work is dedicated, in token of the esteem in which they are held by the author, who enjojs their friendship, and has been benefited by their advice and counsel. 



\section{INTRODUCTION.}

I PRESENT this, the pioneer work of its class, to the public, with both trepidation and confidence. Aware of the many faults in construction, style, and the manner in which the ideas are conveyed, I claim the leniency of my readers, and can only advance the plea, that as no writer, more scientific, polished, and practiced, had attempted the task, the errors of a novice in literature would be overlooked and excused, that would meet with severe criticism in a Veteran Author. This book has been written in the hours intervening between the morning's drive and the evening's walk; and when the rigors of winter put an end to active training, the labor of composition, and care of the horses, about equally divided the time.

The practice recommended to be followed in these pages, in order that a horse may acquire condition 
and learn to trot fast, I offer with confidence. The treatment advised is no pet theory, but the result of years of practice, when the effects of any change in the work was anxiously watched for and carefully noticed. The system, as here exemplified, I have found the best that has come under my observation, and I do not hesitate to rest my name as a horseman on the award of those who will give it a faithful trial.

The chapters on sweating, food, and drink are not offered as being scientifically correct in a veterinary view. The want of a medical education would have prevented me from writing such a treatise, if I had been ambitious to do so; but the results deduced I know to be correct from the practical tests of every season's experience in training horses.

Should this effort meet with the favor and support of the public, I will be encouraged to follow the plan I have sketched, and continue the history of the trial stable in the journey from New York westwardly, through the main places to the Mississippi, and down that stream to New Orleans, describing the management when on the steamboat or railway car, with the care necessary to keep the horses in condition while traveling and frequently trotting in races, accompanied 
with descriptions of scenery, courses, \&c., and incidents illustrating turf sports.

The reasons why I have broached subjects other than breeding and training are the same that would induce a person not to work a favorite colt entirely on the track. Allowing him at intervals to jog through shady lanes, where the hawthorn would shower its white blossoms on his glossy coat, and by the sea-shore or the river-bank, where the ripple of the wavelets would moisten the hoofs parched on the dry, hard gravel, he would return with new life, and knock off a few seconds from the time it had formerly taken him to accomplish a mile. And so the writer felt refreshed after wandering, and returned to the dry details of training, in better spirits and with a keener zest, to impart what knowledge he possessed to those who join with him in enthusiastic admiration for "a fine horse and a fast trotter."

JOS. CAIRN SIMPSON. 



\section{SUMMARY OF CONTENTS.}

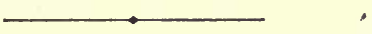

\section{CHAPTER I.}

INTRODUCTORY.-Arrival of the "trial stable".

\section{CHAPTER II.}

Description of Never Mind.-Merits and defects in his form.-Cutting his quarters.-Naming horses.-History and description of Jane.-Proper manner of driving.-Guarding against striking the knee.-Contrivance to prevent a horse

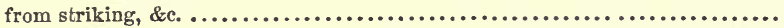

\section{CHAPTER III.}

Poor feeders, probably caused by want of food when joung, the stomach never recovering from the injury.-Camp life.-Smoking.-Old method of traveling with race horses.-Preceptor examines the Falcon.-His description of him.-Finds him nearly bis ideal of a model roadster.-Pupil recount. his history up to that time.-Bad driving.-Debt to the Falcon acknowledged.A home on the Mississippi.....................................

\section{CHAPTER IV.}

Patience required to teach a horse to trot.-Different breeds of trotters.-The pleasure there is in rearing fine colts.-History and description of Clipper.Admixture of French blood promotes higher action.-Dangers of a bolter.Best plan to drive one.-Contrivance that miglit be of benefit to stop a borse from "flying the track."--Manner of handling a horse in a break.-The appearance of the horses shows tbat they have been well wintered, being in proper order to commence work.-Preceptor's remarks on wintering trotters.Proper way to feed, and what the food should consist of.- Iocation of stable.Picture of a fine natural situation for a breeding farm.-The kind of stock to breed from.-Examples of pedigrees.-Treatment of the colts, weaning, win-

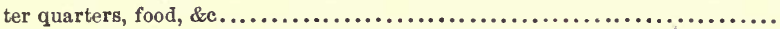

\section{CHAPTER V.}

3reeding farm continued.-Description of the house, and grounds surrounding it.-Ornamental planting.-Out buildings. - Yards.-Further treatment of the colts the iirst winter.-Brood mares, their quarters, food, and treatment during pregnancy.-The stallion used on the breeding farm.-A western prairieAdrantages possessed by Iowa for brecding fille horses $\ldots \ldots \ldots \ldots \ldots \ldots \ldots$. 


\section{CHAPTER VI.}

History of the colts in the trial stable.-May-day.-Hirondelle.-Disadvantages of a half-mile track for training.-Width of track.-Importance of a horse learning to recover from a break without swerving.-Best soil for a track.Mavourneen.-Oriole.—"Four white feet and a white nose."-Lexington and Sallie Waters.-Lexington at the St. Louis Fair.-Clamor about horses breaking.-Advantages gained in teaching a horse to go without breaking.-King.Pedigree and description.-Wildness when a colt.-Failure of knee straps....

\section{CHAPTER VII.}

Remarks about May weather.-The beauty of the American climate contrasted with that of England.-The walk to the blacksmith's shop.-A trainer's practice of giving his horses hard work.-Walking.-The reasons why horses are walked in training.-The benefits and damages from carrying it too far.Awount of clothing required when walking.-Remarks of the Preceptor on shoeing.-The plan he formerly followed.-The system adopted, and the reasons for the change.-The swedged shoe, and a "low hold" for the nails.-Proper form for the hind shoe to guard against cutting the quarters.--Preparing the foot to receive the shoe.-The wall of the foot only, allowed to be cut.-Blacksmiths not to be permitted to do a "finished job" by rasping the outside of the foot. - The weight of Never Mind's shoe, and the precautions taken against "grabbing."-Snatching a horse when in a break the frequent cause of cutting the quarters and striking the knee.-The evils of a short martingale. - The reasons for wearing a light hind shoc.-Difference between shoes and plates, and the effects of weight in the shoe on the action of the horse.Making the sides of the shoe of unequal weight.-The reasons for so doing.Treatment recommended for injury to the knee from having been strnck.Loss of a fine colt from the shoeing inducing the lock-jaw ................

\section{CHAPTER VIII.}

Hot ley to a punctured foot a preventive of lock-jaw.-Importance of stable management to forward condition.-Division and arrangement of the horses.Grooming. - Can be carried too far.-Value of a good groom.--Sweating facilitates the removal of the dandruff-A Arrangement of the stalls.-Furniture and necessary articles, and how to take care of them.-Rules to be observed by the stablemen.-Qualification and encouragement of the boys.Instance of cruelty in a groom.- Hair mittens.-How to rub a horse.Material for rubbers.-The wisp.-Skewers, and their uses.-Bandages.Thoronghbreds for trotters.-The use of bandages.-Wet and dry bandages.When the legs are swollen, how they should be applied.-Reasons for employing wet bandages - How th apply a bandage.-Uses of, when a horse is at exerc:se. -Benefits of pressure to reduce swelling.-Clothing.-The quantity to be nsed.-The kind needed for sweating.-Care of the clothing -Decoration..Order and sobriety essential in all those who are employed in the stableNecessity for condition in race norses imperative.-The effects of sweating nust be studied. - "Washy" and "kaked" horsts.-The setting muzzle.... thi 


\section{CHAPTER IX.}

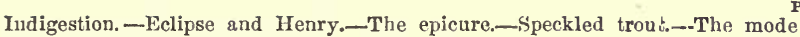
of cooking them in the woods. - A straight bit in a horse's mouth compels him to masticale his food better.-Kepler's story.-Breeding farm resumed. -Field for the yearlings.-Short herbage the best.-Feeding during the summer.-Salting.-IIaltering.-Examination of the feet.-The horn to be kert. in a proper shape.-Corn as food for colts.-A variety of grain recommended. -High feeding, prejudices against it.-Instances of longevity in thoroughbreds that have been well nurturcd.-American Eclipse.-His great age.Training two-year-olds. - Capacity of the well-bred one to stand work.-The fastest Cesarawitch.-The winner.-Mr. Sykes, a half-bred.-Letter from an Anierican breeder in England.- Iis astonishment at the size of the colts. Age of imported horses.-Instance of great speed in a trotter for a quarter of a mile.-His inability to "stay."-Reasons for the withdrawal of horses from the turf when young.-Betsey.-Malone.-Charmer.-Training stable on the breeding farm.-The location, and ground plan, showing the arrangement of the stalls, walk, and alley.-Deseription of the arrangements, and method of taking care of the provender and grain.-Capacity in cubic feet of the upper story.-Foreman's room.-Books, pictures.-Material for building. - Cost. -

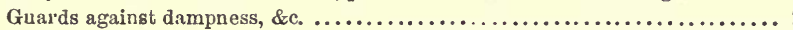

\section{CHAPTER X.}

The evening walk.-The benefit Clipper's legs would have derived from blistering.-Iudine recommended to be given him.-Bandaging and wet sponges Remedies for swollen legs,-Remarks on walking.-Necessity for discrimination. - Time required to get a liorse in condition.-The three stages of preparation.-The amount the liorses cat in the first stage to be increased as they progress.-Routine of feeding, work, and duties dnring the first stage, with the time they are to be fed, watered, and exercised.-Where to commence the walk.-Its effects on the muscles.-Working with colts.-The fight at the quarter race.-Shakespeare's description of the liorse of Adonis.- "Speed gives bottom."-Symmetry of form a quality of the blood horse.-Colt stakes.Danger of working them on a hard track - Colts playing in a pasture-field taking more exercise than would be required to prepare them for a 3 in 5 race. -Colt races more interesting than those of hackneyed performers. - Starring. -Hippodroming.-Mercury.............................. 135

\section{CHAPTER XI.}

The importance of good weather for horses to acquire condition.-Their work should be given if the weather is unfavorable.-Horses cannot be conditioned without work.-Directions for working in the mud.-Effects of moisture on the feet.--Injury done with the knife and rasp.-Govermental aid solicited to further the improvements of horses.-Argument in favor of a donation by Congress.-The necessity for better horses for military purposes.-General Grant at the Illinois State Fair.-Naming a colt.-Quotation from the "English at Home."-Female loveliness, and race lorses.-The horse and civilization.Stable tricks. - Crib-biting.-Weaving. - Pawing.- Dislike to go throngh s doorway. -Kicking the sides of the stall. - I stall that cured a kicker....... 148 


\section{CHAPTER XII.}

Building a track on the breeding farm.-The form, a parallelogram connected with semi-circles.-Reason for plowing it deep.-Form of a track scraper, and manner of using it.-Traek harrow.-Brush for sweeping the track.-How to make it.-Prairie soil an admirable material._Feneing._Close board._Wire, with growing cottonwood for supports.-Breaking the colts the fall after they are a year old.-Details of the method employed.-Lessons to be given before they are put in the shafts.-A practical exemplifieation.-The eruelty of the old plan of bitting.-Forming a mouth.-Allonging.-Breaking the check.-The Kemble Jackson check.-Commands to be distinctly given and rigidly enforced.-Style and fast trotting compatible.-Horses to be closely watched to apportion the feed rightly.-Teeth to be looked after ......... 161

\section{CHAPTER XIII.}

Bits._Snaffle.-_Bar._Chain.-Leather._-Curb.-The snaffle, the best adapted for all horses of any one pattern.-Neessity for frequent changes to find ont which suits the best.-The injury done to colts' mouths with the old appliances.-The chain bit can be made very severe.--Pulling horses.-Patents for controlling them.-The only eure is not to pull at them.-Chiffney's slack rein. -Not "taking hold of the bit." - The reason why they do not.-The bearing rein in the education of the trotter. - The Kemble Jackson check. - The advantages of the check and driving bit being distinct.-Illustration of the effects of the head check.-The wcight differently distributed by elevating the head, as shown by experiments of French veterinarians.-When the Kemble Jackson should be used, and when avoided.-Allonging with a small rope.If proper eare is observed, there is no danger to the feet and legs.-Instanes where a curb bit was of benefit.-Trotting on Michigan Avenue.-Carrying the tongue ont of the mouth, a large leather bit often cures the liabit.-Soreness of the angles of the lips, wash for it.-Contrivance to keep the bit in the lower part of the mouth.-Pulling on one rein.-Harry Hieover's advice.-Callosities. -Retrospect of the training.-Time to recuperate.-Inertness of the muscles. _Food._Fat forming necessary._-Walking exereise.-Roman bath._-Directions for working the colts, \&c................................. 175

\section{CHAPTER XIV.}

The return of the Preceptor from his country jaunt.-His description of Silver Lake and the residence of his friends.-The Falcon is harnessed, and driven by the Preceptor.-He is delighted with him.--Instructions for working. Difference between the track and road.-Never Mind is harnessed.-A habit of backing.- How a mare was treated "that would not stand for a person to get into the wagon."-Breaking King.-The mode adopted - The work the c)lts have had.-Green food, and bran mashes.-The benefit of allowing a iosse to pick grass. - Van Leer's method.-May-day, her form and action.The ent of her hocks and hind legs influencing her gait.--Cutting between the coronet and upper pastern joint.-IIow to remedy it.-The way a horse Luves his feet in the trot and gallop.- - Speedy cut.-Delie._Nervousness.... 


\section{CHAPTER XV.}

Preceptor relates his manner of life in the country.-Description of Mr. P-

and his daughters............................................. 20

\section{CHAPTER XVI.}

Oriole and Mavourneen.-A sylvan picture.-A love for the beautiful not incompatible with training horses.-Neeessity for a liberal education. Incipient lameness often shown by a ehange in the walk.-A divided nail in a horse's fogt.-Less liability to aecidents from the present system of shoeing.-Never Mind's manner of walking - The probable cause.-The necessity for sweating him.-Commencement of his preparation for the sweat.-Physic--Reasons for not using it.-How it aets._Lassitude following it.-How to get rid of superfluous matter witbout purges.-The more a horse eats the more work be will require.-The study of IIippopathology.-Remedy for looseness of the bowels. Colts scouring.-A homøopathie preseription.-Cruelty of quacks...........

\section{CHAPTER XVII.}

Harnessing.- How to harness a trotter.-The bad effect of the martingale being too short. - The method of different drivers to recover a horse from a break.The Preceptor's plan.-Horses pulling when scoring.-The advantage of "getting away from the score" well._Remarks about driving Jane.-Governing the temper.-A moment of passion may render nugatory the teaching of weeks.Messenger blood in Maine.-Driving on the ice.-How to shoe for ice driving. -Care of horses when driven in the winter. - Trotting on the Chicago rirer.-

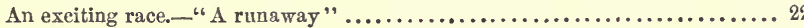

\section{CHAPTER XVIII.}

The after-dinner smoke.-Further remarks on the martingale.-Harry Hieover's and Carl Benson's views.-_Running and standing martingales.-Importanee of the first lessons._-Pulling horses, and those that are easily driven.-Fashion.Miss Foote.-Launeelot.-Blinders. - The proper adjustment of bridles. Cleaning and preparation of feed.-Mixing hominy and oats.-Horse commissary department.-Oats, hominy, corn, and bran.-Oatmeal and sago.-The amount of bran on oats, barley, and wheat.-The effects of corn on "washy

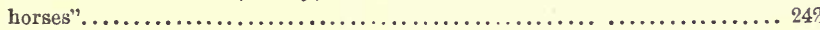

\section{CHAPTER XIX.}

Regularity in exercising.-The work of Nover Mind on the day preceding the sweat.-Conversation on sweating.-The objects of sweating.-Relief to the respiratory organs.-Benefit to the muscles.-Iforses not liable to "bake" when this plan of sweating is followed.-The action of the heart and lungs during fast work.-Greater increase of respiration than arterial aetion.-Difference between a fat horse becoming tired, and one in condition.-Powers of recuperation.-The diaphragm.-Fat within the ehest.-How fat impedes the action of the heart.-Change in the blood.- Its passage to the extremities.Fetting rid of the watery particles.-Oily matter in the perspiration.-Sab. traction of the fatty globules probably makes the blood easier to propel.Rhythm of the pulse and step.-Lungs, heart, muscles, and digestive organs, 
all benefited by judicious sweating.- Expansion of the chest. - Intercostal muscles.-Modifications of sweating. - Injury to the lungs permanent. - Fat, where deposited.-Change in the muscles from work.-Roman bath.-Increase in the size of the muscles as the fat is wasted.-The local effects of sweating.-Illustrations.-Benefit of a well sbaped neck.-Strain of the loin.-Interval between the sweats._- "Drawing" a horse.-Long and short races.Seasoning.-Effects of scoring.-Inducing perspiration between heats.-IIow to induce perspiration.-Manner of clothing.-A race where the favorite was beaten, probably owing to suppressed perspiration................... 256

\section{CHAPTER XX.}

An adventure in St. Louis-Intricacies of sweating.-Decarbonization of the blood tbrough the pores of the skin.-Purifying the skin.-Constant grooming produces soreness. - Dandruff.-The effects of sweating on the skin.-The veins of the thoroughbred prominent and large.-Insensible perspiration.Black Maria.-Mr. Stevens' training stable.-Advantages of scales to weigh horses after the sweats.-Haney's Maria.-Improvement in tracks, borses, and training.-Difference between sweating colts and old horses.-Not so necessary to reduce colts. - Mash previous to sweating.-How to make it.-Remarks on driving and shoeing May-day,-Directions for feeding Never Mind the night

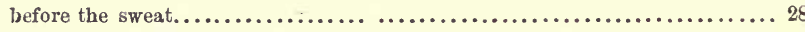

\section{CHAPTER XXI.}

The morning of the sweat.-Temperature.-The management when postponed.Muzzling. - Bedding.-Other material than straw.-Advantages of sand."Wallowing bed."-Never Mind's walk. - The preparation. - How he was clothed.-Guards against injuring himself.-How to prepare the drink.-The work he received. - Management in the stable.-Inducing a free flow of perspiration.-How to prolong it, and when to stop.-Scraping and rubbing.Adjustment of the clothes.-Restriction in his drink, and the reasons for it.The walk after the sweat.-His appearance, final care, and how to feed.Reasons for putting additional clothing on, when first bronght into the stable. -The manner of sweating will vary as the preparation proceeds.-Driving Jane. -Breeding trotters.-The teachings of the past.-Messenger.-Gcorge Wilkes, Dexter, and General Butler._-The Pilot family.-Andrew Jackson.-Jupiter.Rysdyk's Hambletonian.-Tabular pedigree.-His in-breeding.-Hambletonian's Andrew Jackson and One Eye.-Crosses of Messenger in the Falcon.-The Hambletonian, and American Star cross.-Cassius M. Clay.-Greo. M. Patchen. -Wm. T. Porter's description of Abdallah.-Mr. Morris' certificate of the blood of Mambrino.-Ariel, her exploits.-Tabular pedigrce showing ber in-

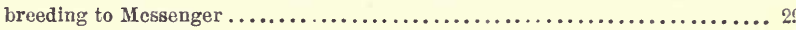

\section{CHAPTER XXII.}

Danger of smoking in the stable.-Care of Never Mind.-Loose bores and stalls. -llorses should not be disturbed. - Injury to the elbow while lying down.femedies. - Charles Lamb.-Quotation from the Turf Register about Messenger.-Partial history of him.-Dissemination of blood in the North-east.Grotters of the oldon time-Paul Pry.-Further consideration of the Messenger blond. - Goldsmith mare.-Major Winfield.-Squire Bingham.-Sir Archy._Planet.-Bonnie Scotland.-Horse Heraldry ................ 312 


\section{CHAPTER XXIII.}

Pedigree copied from an advertisement.-The importance of the weather in training operations.-A "green horse."-Pleasure and disappointment.-Trainer wrougfully blamed.-Jealousy.-The work the day after the sweat.-Signs showing that the sweating was not overdone.-Directions for driving the Falcon and Jane.-Precepts to be enforced in breaking horses.-Mental power.Clipper.-Firing.-Percival's remarks on firing.-May's performance in new shoes.-Changing the ground surface of horse's feet.-Directions how to proceed with the horses for the ensuing three weeks' work. - Sweating, feed,

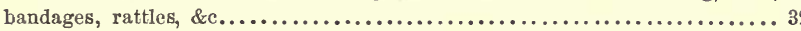

\section{CHAPTER XXIV.}

Day-dreams.-Scotch character.-An old nurse.-The food of horses in training. Hay.-Corn blades._Straw.-The best hay.-How to determine it.-The time to cut.-Mowburnt hay.-Corn blades, their advantages, and how to feed them.-Effect of diet on the respiratory organs.-Lord H. Seymour's stable in France.-The uses of straw as food, when training.-Prairie hay.-Prairie on fire.-Immunity from heaves in horses that are fed on prairie hay.-Objections to it.-Thick and thin seeding. - Table of relative value of different kinds of food.-Stemming corn-blades.-Pulling hay.-Tine for feeding hay.— "Craving " and delicate horses.-Oats.-Proportion of carbon and nitrogen in oats.Light and heavy oats.-The qualities they should have, and how to test them. -Corn.-Bran.-Lindseed-meal.-Oat-meal.-Sago.-Sago when horses are "baked."-Number of feeds in a day.-Time of giving them.-Grcen food.The benefits of it to horses in train.-Cutting grass, and grazing.-New way to give horses excercise. -Watering horses after driving.-Directions for driving Never Mind.................................................. 34

\section{CHAPTER XXV.}

Letter from Chicago.-Pupil recounts the work he has given the horses in the absence of the Preceptor.-Driving when the rattles are worn.-Knee action increased by driving on sandy roads. - Effects of snow on colts.-Allonging.Sherry wine between heats.-When it should be given.-Water.-Rain, river, and spring water.-Danger of change of water.-Airing.- Temperature.Acidulating.-Light feeders to be encouraged to drink.-The amount to be giren.-Frequency of watering.-Gruel.-Sponging mouth and nostrils:-The difference in sweating the Falcon, and Never Mind.-Sweating Jane.-Instructions for driving.-The work for the next two weeks.-Minute directions for the management for that period.-Capacity of swallowing $\ldots \ldots \ldots \ldots \ldots \ldots . . .363$

\section{CHAPTER XXVI.}

Cutting the quarters.-How to dress the wound.-Horses should not go out too early in the morning.-Preceptor examines the Falcon.-Remarks on his condition.-IIow to judge of a horse being in order.-The appearance of horses Whan in condition.-Pupil gives a history of the work the horses have had for the past three weeks.-Preceptor's comments.-Errors in Pupil's inanagement of Never Mind.-The benefit of trotting horses in races to further their condi- 
tion.-The Preceptor's ideas of the best form for a model roadster.-_" Points," and why a particular form gives superiority.-Nerve force.-How to detect it.Action.-The natural action a horse should have to make a trotter.-Long and short horses.-Driving colts.-How they ought to be worked, sweated, \&c... 378

\section{CHAPTER XXVII.}

Walking in the dew.-Hoof ointments.-Cracked heels.-How to dress them.Glycerine, and its uses.-Driving the Falcon, with instructions from the Preceptor.-Care after the drive, and how he is to be treated in the future.-The race, the best school to teach horses to trot.-How to manage a "dark horse."-The work of Never Mind.-How to drive him to keep him off his quarters, and manage him in a break.-Galloping a horse with a trotter.Driving Jane.-Her speed and length of stride.-Short and long striding horses.-The stride of horses, with diagrams showing the position of the feet in the trot and gallop.-Leugth of stride explained.-Advantages of measuring strides so as to know the reasons for a falling off in speed.-May's trial.Necessity for further care that she does not strike her pastern.-Skill more effectual in managing a horse than physical strength.-Running away.-The order horses should be in when commencing a campaign................ 400

\section{CHAPTER XXVIII.}

Trials. - Weather and track favorable for making fast time.-The way the horses were prepared for the trial.-The Preceptor recommands changes.-Time required for digestion.-Clipper's legs.-Symptoms of "breaking down."-Effects of weight.-Qualifications of a driver.-Trial of the Falcon.-Directions for driving.-Difference in the appearance of the sweat.-Instructions for driving Never Mind.-His first mile.-Scraping him on the track, and the reasons for doing so.- How to drive him in the repeat.-The timo made.-His distress.-How to recover him.--The after care.-Preceptor's instructions how to feed, work, \&c., till the morning of the race

\section{CHAPTER XXIX.}

Never Mind, trots in a race.-Minute instructions for driving.-Management before the race.-The treatment between the heats, and the care after it is finished. -The manner of feeding, making a mash proper for a horse to eat after a hard race. - Boots, $\&$ c.................................... 430

APPENDIX.

Dexter. -His Measurement and Description.......................... 416

Intex. . . . . . . . . . . . . . . . . . . . . . . . 459 


\title{
HORSE PORTRAITURE.
}

\section{CHA P T E R I.}

\begin{abstract}
INTRODUCTORY-ARRIVAL OF THE “TRIAL STABLE."
\end{abstract}
PUPL.-Good morning, my esteemed Tutor. You perceive I have taken you at your word, and have come with my whole family, bideps and quadrupeds, to avail myself of your kind teachings. Nature smiles on the commencement; I never remember a morning when everything looked more gay and cheerful. A choir of birds in every tree, making melody such as you cannot hear where gas pollutes the air, and the caller air exhilarating like champagne, the very poetry of breathing. Look at that black thoroughbred, the one with no ear pieces to his hood. He is telling you, as plainly as though he was gifted with speech, that he enjoys it, and wants you to know it. He is a physiognomist, and the first glance at you told him that you knew the next most difficult thing to a woman, a horse, as old Sam Weller says. Look at the beaming of the hazel eye, the expression of the long, slim ears-it would be a sin to cover them with ear pieces-the extended muzzle and expanded nostril inhaling the aerial treat, while his eye enjoys the beauty of the scenery. But I do not want to tire you at the outset; so come to the stable, where I will introduce to you the pupils of your pupil, 
telling you what is not apparent, history, pedigree, constitution, tricks, \&c.

Preceptor.-When I made you the promise of teaching you my craft of managing and training trotters, I hardly expected you would give me so good an opportunity, for I should judge, from the looks of your string, that you had nearly a specimen brick of all kinds, and I will wager a dozen of wine that I can give a good guess at their different natural qualities. What they have acquired from bad teachings would be harder to tell. Let us move to the stable, where we will become more particularly acquainted. Looking at a horse in his clothes is a good deal like telling what a book will be from knowing the author-you have a notion of his ideas; and you can see a horse's eye-a great part of the animal, for I never knew a good one that you could not see something of his character in the eye. Yet the spirit and will may be there without the capability of performing: that you have to judge of from the form and muscular development.

Trotters "go in all forms," as well as runners.

There would have been more truth in the proverb if it said a variety of shapes all tending to the same model. Some time I will acquaint you with what I consider the best form for a roadster; and what is more enjoyable than a drive, such a morning as this? A good horse, light, easy running wagon, with the road smooth, so that you can let him "g-long," and work off the superabundance of animal spirits that the fresh air you speak of gives a horse, as well as those birds that are giving vent to theirs in joyous song and animated flight. For youngsters like you, a gallop may be more congenial to the hot blood, but when you arrive on the shady side of fifty, then the smooth running wagon is the thing.

PupIL.-Fond as I am of mounting the back of a 
thoroughbred, and galloping over verdant turf, every bound of the horse sending the blood dancing through my veins,--as different from the sluggish stream in the arteries of the votaries of fashion, as the mountain brook is opposite to a Mississippi bayou,--yet I can enjoy the delights of the road as well as my elders. A bright morning ere the dew is off the grass; the sun's rays gilding the eastern slopes of the hills ; and you jog along listening to the measured footfall of your horse, musical in its cadence. Half a dozen miles are accomplished nearly in . half an hour, when you hear what appears like the echo of your steed's tramp. One ear is thrown back, the five minute gait is changed to something faster, a sharper hold is taken of the bit. You are hardly aware of the cause for the change, until some one pulls out for you, and away you go, neck and neck; the grade is little descending, and the weight of the one hundred and thirty pound buggy is not felt. Steady, my boy, you have got him skipping, he leaves his feet and is parving frantically in the air. You slide away a few lengths, and take your horse in hand ready for another brush. This is the excitement of the morning drive. In the evening the pair is harnessed; this time you have a companion, perhaps a friend with whom you talk horse, the salient points of the last race, the relative qualities of the roadsters you are both acquainted with, the benefit of a strong dash of blood for the road as well as for the turf, \&c. The halt at the frequented horse hotel, arguments as to which of the quadrupeds under the shed is the fastest ; the friendly match for a few hundred to test it on the Fashion or Union, and home again, with something else to think of than the rise or fall of gold, stocks or grain, or smoothing out a furrow or two made by what you think may turn out a bad investment. Or, in place of the friend who talks horse, your companion wears Number Three gaiter 
boots, a jaunty bonnet, with a stray curl for the wind to toss away from the "cheeks like lilies dipt in wine." You can hardly recall what has been said, 'but you never will forget the thrill, as the tapering arm was placed on yours, as you let them speed along the smooth road; and then in the winter-the same partner, a "duck of a sleigh"but hold, I am running away with myself, and have already said enough to convince you that I am as enthusiastically fond of a dash on the road, as a sail in the pigskin.

Preceptor.-Both are good; and though I have grown grey and old in the profession, as you may term it, of training horses, yet the same feelings come over me as when young, and I am only kept from showing them, for fear of the invidious remark of "what airs that old fool is putting on." Years are not the true test of age. For instance-you will pardon the comparison, but the horse is so intimately blended with my feelings I cannot help it-when you see some veteran of the turf whose youth and prime were a series of hard contests, led out of the stable, how hard it is to believe he is what would be termed old. Curving his neck and proudly caracoling, he has more sense than to be ashamed of his youthful feelings, but his master-while acknowledging his sense -is ashamed of copying from an animal that he stigmatizes with the name of brute. Without wishing to recall what I said about the smooth running wagon, there are times I would delight in a gallop that would stir the blood. There is enjoyment for me in rapid locomotion that I cannot well explain, and I have often envied the Englishmen their exciting sport of fox-hunting, which young and old follow with so much zest. My only acquaintance with it is from reading, and the enthusiastic reports of those who have taken part in the diversion. Yet I fancy there is more pleasure in it than 
any one but an ardent horseman would imagine from hearing the most vivid account of some celebrated run. There is a little piece of poetry, written by one of the titled sons of that country whose boast is that it surpasses all others for beautiful woman, fine horses and grand trees. I read it more than a score of years ago for the first time, and have read it so often that I still know every word of it. I will repeat it, but my rehearsal will not do it justice. It may not even be good poetry, I do not claim to be a judge of what the critics would call good, still it is fair to presume that what pleased me so well, will have some charms for you:-

Come forth, my brave steed-the sun shines on the vale, And the morning is bearing its balm on the gale, Come forth, my brave steed, and brush off as we pass, With the hoofs of thy speed, the bright dew from the grass.

Let the lover go warble his strains to the fairI regard not his rapture, and heed not his care ; But now, as we bound o'er the mountain and lea, I'll wave, my brave steed, a mild measure to thee.

Away and away-I exult in the glow Which is breaking its pride to my cheek as we go; And blithely my spirit springs forth as the air Which is waving the mane of thy dark flowing hair.

Hail, thou gladness of heart and thou freshness of soul, Which have never come o'er me in pleasure's controlWhich the dance and the revel, the bowl and the board, Tho' they flush'd and they fever'd, could never afford.

In the splendor of solitude speed we along, Thro' the silence but broke by the wild linnet's song;

Not a sight to the eye, not a sound to the ear, To tell us that sin and that sorrow are near.

Away and away, and away then we passThe blind mole shall not hear the light foot on the grass; And the time which is flying, while I am with thee, Seems as swift as thyself as we bound o'er the lea. 
PupIL.-Your declamation, I think, is superior to the poetry, while the subject is one that will stir the blood like the sound of a trumpet. The author, Sir E. Lytton Bulwer, has won a world-wide reputation by what he has witten-some of it certainly inferior to that. Still I am pleased that you recited it to me. I have read it, but was rather disappointed, looking for something superior from the talented author. Your recital was like Sir Walter Scott's acting a warlike, Scottish ballad-when, with walking stick in rest and brent brow, he looked the very impersonification of he ancient knight he knew so well how to portray. I shall always think you out of place sitting in the sulkey, "hick, haying" and making" all the uncouth noises imaginable to encourage your own horse and disturb your adversaries; but here we are at the stables. Ho! boys, take the clothes off. Lead out your horses. 


\title{
CHAPTER II.
}

\author{
DESCRIPTION OF "NEVER MIND" AND "JANE"-NAMES, \\ DRIVING, ETC.
}

PupiL.-Here is one raised "away down" in Maine. When three years old, he was taken to the fruitful soil and more genial climate of Illinois. Showing at times a great deal of speed, but generally single footing, and hitching, with other disagreeable qualities that severely tested the patience of his owner. One year he was placed in the hands of a man who had some celebrity as a trainer, but he utterly failed to improve him. In fact, he was worse than ever last fall, not being able to trot square a step, having been ingloriously beaten by a horse that could not trot better than fifty. I saw him two or three times while in this man's hands, and fancied there were several reasons why he had not done better. From some slight irritation in his throat, he is frequently troubled with a cough which was set down as heaves. He was strictly confined to prairie hay, selecting that in which there was the most resin weed. This being a powerful diuretic, affected his kidneys. Being in fine order and high spirited when the trainer first commenced driving him he became timorous, and feared his running away. This led him to give him more severe work than he ought to have done. A great share of this work was given under clothing, heavy blankets, hoods and wrappers, till the poor animal was reduced to a mere skeleton, looking like some veteran 
four-mile race horse, at the close of a hard season's campaign. He actually reeled in his wall, and I fancy he has never overcome the habit, and still walks as if he was strained in the loin.

His sire is said to have been thoroughbred, and from his appearance he is undoubtedly possessed of a good deal of breeding. I am very sanguine of his going fast, and hope, under your guidance, not to be disappointed.

Preceptor.-There is certainly nothing in his form to prevent him, and if his education has always been of the kind he was tortured with last summer, and he displays speed at times, we will give him a "fair show," trusting, by proper management, to overcome the faulty tuition, and take the crook out of the bent twig. His shape is certainly good, more so than the average of our fast ones; his neck and shoulders are very fine, his barrel first-rate, with good limbs. The worst points I see are a slackness about the loin, and narrowness of the head, betokening a foolishness which will require careful handling not to augment. The white stripe lights up his face, animating his countenance, relieving it in a great measure from the bad effects that would otherwise be apparent from the narrowness of the skull I spoke of. I agree with you that he shows a good deal of blood, which is all that probably saved him through the ordeal of blankets and rugs, scrapers and rubbers. I see from the scars, he has been grabbing his quarters, and I should judge he had some pretty severe wounds. This may have occurred from faulty shoeing or bad driving. Very few horses properly shod and handled will cut themselves, though there are exceptions. I have known several that nothing would avert the blow, save the best of boots made by Gibson, or some one equally well versed in the manufacture of that part of horse equipments; but that and shoeing will come more appropriately as we progress. What name do you 
call this high-headed brown? We will mutually have to know all their various cognomens, in order to understand which one we are talking about without circumlocution.

Popr.-_"Never Mind." No disrespect intended, for this horse is called Never Mind. The nomenclature of horses is something that might be greatly improved. I do not offer this as the result of my efforts in that line, and some other time will explain. We are too much given either to name horses after our acquaintance, until one is at a loss to know whether the biped or quadruped is meant, or follow some celebrity till the names are multiplied in the register, and we are equally puzzled to understand which of the many wearing the same title is intended.

Preceptor.-As a general thing the English are more happy in the christening of their horses than we, though Lord George Bentinck, and others, "not near so smart," gave some of them names that were neither appropriate nor poetical, as "All 'round my hat," "Here I go with an eye out," will testify. Yet, in a majority of cases, their Ayers have possessed very good ones, as Harkaway-that grand horse, unfortunate in being in the possession of one of the guerrillas of the turf. Beeswing, t'auld mare, whose defeat at Newcastle made strong, sturdy coal miners weep like children; but they were not often called on to mourn in this way, she winning fifty-one races out of sixty-four starts, a feat-or rather succession of themunparalleled in sporting annals; Touchstone, the progenitor of hundreds of winners; West Australian, marking an era by his triple victory, to be repeated by the colt bred under the sunny skies of France. Old Queen Mary's daughter, Blink Bonny, and grandson, Blair Athol, carr you to the blooming heather and bonny braes, where you can smell the perfume of the birk and hawthorn, where the gowan and the modest primrose are peering above the 
grass on the burnside, the lintwhite and mavis singing in the glen.

True, we have had Bonnets o' Blue, Flirtilla, Cassandra, Lady Lightfoot, Peytona, Charmer, Idlewild, Timoleon, Pacolet, Gracchus-all very good names, which cannot be said of Creath, the pronunciation of which caused almost as much discussion in this country as the famous Ilionea controversy did in England; Joe Blackburn, Geo. M. Patchen, Red Bill, Hornblower, Red Oak, \&c.

How happy Peytona must have been, when her name was changed from Glumdalclitch to the proud one the winning of the $\$ 150,000$ stake entitled her to wear. Under the former she never could have beaten the peerless Fashion, that vindicated her claim to be the top of the mode by re-conquering the Victrix, after being in a "little better fix."

PopiL.-I am well pleased to find that others have been giving this matter thought as well as myself, and when we come to the babies I have brought to commence their schooling, will be much obliged to have you assist me in giving them names they may wear with honor to themselves and pleasure to us. This lengthy bay mare I simply call Jane. Her life, like Nover Mind's, has not been one of strange vicissitude, but a sameness of bad management that would have made human subjects incorrigible. When I first got her, it was claimed she was by Glencoe, her dam by Bertrand, the mother of Andy Burt. Her glossy silken coat, strong muscular development, and high life, corroborated the statement; but her eyelids are heavy, her pasterns short, her shoulders rather too upright, while her mane and tail has a wave, almost a curl, that always caused me to doubt the truth of this assertion, and on making inquiry found that on her mother's si te alone she could claim aristocratic lineage.

In a cunversation with Mr. Frank Harper, of Midway, 
Kentucky, he informed me that he was her breeder, that her dam was by Bertrand, left with him by a man who had emigrated to the Pacific slope. Her sire was a French Canadian pacer owned by him. She was bought by a gentleman, who, after making a fortune in business in Cincinnati, bought a large farm in that beautiful country 'that surrounds Madison, Wisconsin, erecting fine buildings, and stocking it with animals that cost a "heap of money." Unfortunately, he had not sufficient knowledge of either farming or stock breeding to make either pleasant or profitable. After spending all he had made in fine buildings and foolish experiments, - as an illustration of which I was informed that in one season he grew one hundred and sixty acres of carrots; his large cellars were filled, new ones made, but they would not hold a quarter of his root crops alone-his stock and farm were sold.

He commenced teaching Jane to trot when she was three years old, driving an old trotting mare, and leading the colt behind the wagon. She was brolsen very easily, proving kind and tractable, but when aroused possessed of a very high temper.

He built a track, and employed a man who represented himself as being a competent trainer. The farm by this had become very irksome, and most of his time was spent in Chicago and Detroit. The self-recommended man proved not only worthless as a trainer, but a drunken loafer. His horses, of course, felt the effects of his bad temper, engendered by bad whiskey. This animal got to pulling, and finally ran away every time he attempted to drive her. As a proof of her sense, the gentleman's wife could drive her with perfect safety, which she did whenever she wanted to enjoy a drive on the banks of the clear lake which skirted their estate, taking her children with her, and feeling perfectly safe. When sold, she was only 
driven slowly on the road, as whenever started to speed, her pulling propensities returned in full force, and it took a strong arm to restrain her from running away. Again she went into the hands of a trainer of trotting horses. This man brought her home in a couple of months with a knee enlarged to twice its natural size; her mouth torn to pieces with severe bits, and a jaded appearance, as though she had been towing a canal boat the whole summer.

I heard she was offered for sale at a low figure, and succeeded in purchasing her. I have "great expectations" that, under your judicious directions, she will yet prove a good animal. I must own I am going to put your skill to a very severe test, as I have none but those who have been very badly handled, or young things that we can only surmise whether they will trot or not. To return to this mare's peculiarities, her gait is the reverse of the brown horse's, square as a brick, with a long open stride.

Preceptor.-I like the appearance of Madam Jane very well. She has evidently a fund of strength that can be made available for either good or evil. With proper teaching she would have been ignorant of exerting it to our prejudice. Now we will have to depend on gaining her affection, so that she will have the same confidence in us that she had in the lady who had the temerity to intrust her own and her children's lives to a horse that had ever run away. There is a subtle fluid, magnetism we will call it, between the horse and driver, the reins being the medium through which it is conveyed. How angry I become when I see a big brute tugging away for dear life at these leathern straps, his body braced as if a yoke of oxen were hitched to him to pull him from his seat, yelling at the top of his voice, self-satisfied that he is an expert. The horse has ten times more sense than he, and has 
learned that he must pull against the bit still harder, to stop the circulation of the blood in the sensitive bars, numbing them till the torture is unheeded. After a while the delicacy of feeling is gone, large calluses are formed, and the horse becomes perfectly useless. The knife is resorted to, the "bag's" are cut out. A brief respite, while the ugly wounds are healing; then again to be tugged at and spoiled. The reins should be handled as if they were a part of the animal endowed with sensitiveness, which would be destroyed by a continuous pull. A slight motion of them shifting the bit has often a magical effect in rousing the horse, when whip and spur would fail. This mare must be driven as an accomplished reinswoman would drive her. Light must be the touch, and no continual exertion of strength should be permitted. Her running out, the past winter, has probably restored her mouth to its normal condition. I will contrive a way she can be exercised without danger of her running away, till she will no longer want to.

I notice there is still an enlargement of the knee which must be reduced, or there will be more likelihood of her hitting it. Her formation is such that she ought to trot without touching. Like grabbing the quarters, it may have resulted from defective shoeing or bad driving. When it arises from natural action, it is one of the worst defects a trotter can have, and is generally caused by a wrong set in the elbows. We cannot change structural growth, but we can modify the effects of it by a little difference in shoeing, making the outside of the shoe a trifle the heaviest, increasing or decreasing the whole weight of the shoe, cutting away part of the iron, and rasping the corresponding part of the hoof. I once cured an inveterate "linee knocker" by making him wear an instrument similar to what hatters use to stretch their hats. This machine was confined between his fore legs and 
against his breast, by a strap running from the girth to collar. It was covered and padded to prevent chafing, placed on him when he commenced walking, in the spring, every day or two, lengthening the screw which gradually increased the distance between his knees as he travelled. He was kept at walking exercise for a couple of months, when he was jogged with the instrument on, till he finally acquired a different "way of going," and never hit his knees again while I had him. There are as many different patterns of boots to obviate this, as there are trainers or harness makers, each of whom claims his own to be the best. I have a perfect museum of all the varieties, which I will show you at some leisure time.

PupIL.-Here is a black thoroughbred.

Preceptor.- “Not a word an' you love me," scholar. Let me look at him without a word or gesture to interrupt. We will now go to breakfast; when we return I must again examine him. I want no clue to his qualities, pedigree, performances; till I have a good look.

PupIL.-All right. I was afraid I was tiring you with my disquisitions. I feel decidedly like doing justice to the pattern breakfast we will get at this snug hostelrie. We are of right particular about providing the sweetest old hay, blades, oats, hominy, bran, carrots, \&c., to keep our horses in good health, and should certainly be as careful of ourselves. 


\section{CHAPTER III.}

FEEDING - CAMP LIFE- "FALCON" - THE IDEAL OF A MODFL ROADSTER.

Preceptor.-You were right that we would get an enjoyable breakfast. It is a favorite meal with me, as my general custom is to spend an hour or two in the open air before partaking of the matutinal entertainment. The weather has to be severe, indeed, that confines me indoors, and I never need a morning cup to give me an appetite, which $I$ always indulge by eating plenty of the bounties our mother Nature has so plenteously provided for us. It is a difficult task to get a horse in order that is a delicate feeder, and I am inclined to think that nine in ten which trouble us by mincing over their feed, refusing to eat more than a quart or so at a time, owe this bad habit to rearing. Many think when the colt is weaned it is able to take care of itself, turning it out in the barn yard to fight for every mouthful of hay it gets, with older colts and all of the horned cattle of the farm. It manages to live through the winter and that is all. When the spring comes, it is lurned out as soon as the grass shows green. There is less sustenance in the short watery blades than even the straw possessed, which had been its principal food through the winter. The stomach loses its tone, and ever after is weak, not having the manseular strength to properly prepare the food in it, or gastric jroes sufficient to form the healthy chyle that 
produces the blood. The stomach needs exercise to neep it healthy as much as the limbs. Every one recognizes the fact that unless the growing animal has an opportunity to work them they will shrink away, but think that by making the colt "rough it" it will be hardier and more serviceable when its work is needed. However, the question of food will present itself as your horses are put in train, when we will discuss it in all its bearings.

PUPIL.-No doubt it will be as important as anything there is for me to learn.

Here is a cigar, which I will vouch for as being one of the best. I had it in a present from a friend who delights in keeping the best specimens of the Virginia weed. From long habit I prefer the pipe. The same kind friend always keeps me supplied with the most fragrant killikinick, which he superintends the manufacture of himself, selecting the very finest specimens of leaf, and is as scrupulously careful in the process of making and flavoring, as the old alchemists were in the preparation of the elixir of life. If he were still in business I would be tempted to give his address, so that all genial lovers of the tranquillizing herb would know where to get their supplies.

My fondness for a pipe was acquired by living in the woods through the summer. For many years I was engaged in surveying the mountainous section of Pennsylvania, where, twenty years ago, there were unbroken forests twenty miles in extent. For weeks we would never enter a house, but camp where night overtook us. The camping-ground was generally selected by the side of a swift running brook or erystal spring. Our supper ended, of speckled trout or venison broiled on a stic , with plenty of strong coffee that had a finer aroma than ever Turcoman drank on tapestried divan. The bed is made of the fine boughs of the hemlock; piled so high 
that there is a downy sensation as you sink in the fragrant herbage. Now pull off your boots, light your pipe and enjoy it. The stars are twinkling overhead, as if they had come nearer earth, looking like diamonds amid the sombre branches of the white pine towering a hundred and fifty feet above you. The camp fires throw a lurid light on the rocky banks of the little creek, whose waters are lulling you with their gentle cadence, as they glide over a miniature Niagara. The laurel and creeping yew look like the ivy on some old ruined castle wall. Puff! The talk of Sydney Smith or Sheridan would be a bore. You see visions brighter, fairer, rosier, than ever did the inspired author of the Ancient Mariner, and you fall asleep in that pure air to dream of still brighter fantasies. No doubt that smoking injures many a young man confined all day to a close counting-room, spending his evenings at the billiard hall or club, but to one whose life is mostly out of door, with exercise enough to engender a weary feeling at night, the moderate use of tobacco is certainly beneficial.

After carrying a knapsack containing thirty or forty pounds of provisions, a heavy compass, climbing hills, that rise with no gentle inclination, twelve or fifteen hum. dred feet above the rapid, rushing river at their base; stopping at noon time only long enough to eat a cold bite ; forcing your way through laurel swamps and tamarack thickets, impenetrable save to the skulking wolf and thick-coated bear, then the tobacco is a wonderful solace, and the best proof that it works no injury is the refreshed feeling you awake with next morning, conscious that there is no reasonable task you could not perform.

I look back on those days with a satisfaction I can hardly express, and have such a vivid recollection of every hill, intervale and stream, that without the help of compass, I could, after the lapse of twenty years, trace a 
line run at that time, and find every corner erected or witness tree marked on thousands of acres.

Preceptor.-Without being quite so enthusiastic in my devotion to tobacco as I find you are, I enjoy the perfumed breath of such a cigar as this. Your friend, the donor, who cares so well that your pouch be well filled, has my hearty thanks. Your camp life I know something about. In my boyhood's days I was with a stable of racehorses; at that time there were no railroads forming a net work of iron all over the country, and we had to travel our horses from race-course to race-course, often long journeys of hundreds of miles. It was rare that we found proper accommodations to pass the night, so we were prepared, like surveyors, to stop where our convenience dictated, or when the horses were thought to have walked far enough. A pair of mules was harnessed to a big wagon, in which was loaded hay, corn blades, oats, corn, bran, meal for bread, bacon, groceries, a hand-mill to prepare hominy, with all the necessary appendages to a race stable; we generally selected a pine forest to camp in, and the first business of us boys, was to gather the long pine leaves to form bedding for ourselves and horses. The ground would be thickly covered with them, so that it was no very long task. The cones were also plentiful, and of them we made fires, heating water to wash legs, whenever the trainer said hot water should be applied. The horses cleaned, legs rubbed, we prepared our own supper, and much as the breakfast we have just eaten would merit praise, the recollection of the fried bacon, corn-bread, and coffee drunk out of tin cups, comes back to me as being relished as well as the delicacjes I am now most given to like. It was a much more a duous task for the trainer of that day to keep his hore: all right than at present. A rainy night and we had no India rubber covers to keep out the moisture, but we used thick 
cotton, like sail-cloth, which answered a very good purpose. Our horses were "worked." so hard that the delicate ones were soon got rid of ; though I think, with the improved handling of the present day, many, rejected as worthless, would have proved very difierent animals, and as often winners as those whose temper enabled them to stand the severe drilling which they got. My cigar is nearly ended, so we will bring this conversation to an end. I am anxious to have a good look at that black fellow that so took my eye at first sight.

PupIL.-Here we are back to the stable; one of my rules is never to smoke in the stable, or suffer any ono employed there to do so. Visitors, of course, have to be tolerated in the bad practice. Boy, bring out the Falcon.

Preceptor.-All right, boy; give him his head; I want to look at him from a distance first. Turn him partly around. Now run alongside of him across the yard; come a little faster as you approach me ; that will do.

Well, scholar, I told you that sometime I would give you my idea of model roadster, and there stands neare: my ideal, than any I have yet seen. Before going into detail of his form, I will engage to make a trotter of him, no matter how much he has been abused in his training. I make this promise not only from the fine action he exhibited while trotting across the yard, but from that posuliar head, ear, and eye, that all show sense. Horses have just as many degrees of sense as men, and Daniel Webster's "dome of thought" never more palpably showed his superiority over the majority of mankind, than does this horse over his compeers. His head is large, yet you would not find enough meat on it to farnisin a pet kitten with his supper. Look how the cleariy cat nostril is just extended enough to discern the edge of the pink lining. There is an India rubber look about it that shows the orifice can be enlarged so as to admit all 
the air necessary to feed the lungs. The jowl appears as if carved, widening till you can thrust your clenched hand easily between the sharp jawbones. There is a corresponding widening of the Iorehead, giving plenty of room for a large brain, not alone the source of wisdom in a horse, but the centre of the nerve force, that wonderfu] something which we cannot explain, but which as surely enables the horse to do "great deeds of great renown," and places him far above his kind, as it supplies the hero with the stimulus that renders him immortal. The clear hazel eye, lustrous as a gem, shows his sagacity ; and the long thin ears placed just as I would have them, are perfection. How daintily the head is set on the neck; you could span the neck if it were detached from the throttle, which so nearly fills up the space between the jaws. Were it not that the neck is so perfectly formed, it would appear too long, but the crest rises so beautifully that it requires the length to give it such a graceful cirrve, while the depth it displays, where joined to the body, shows a mion of strength and lightness, admirable in its just prowortions. The breast has the rabbit formation, usually meen in the first-class race-horse. The shoulder blade ises well to the top of the wither, is broad, sloping, and falls back into the sway, just as it ought to, and the point of it is well thrown forward, so that the humerus or upper bone of the leg is oblique. The elbow is properly placed, neither tied in or standing away from the chest; this is what brings the fore legs so truly under him. As you stand in front of them, they are as true as a line, slightly converging to bring the feet squarely under the body, and the toes straight. The arm is long, the knee broad and strong, with the bony projection behind well developerl. The canon is short, the ligaments large, which gives the leg the flatness so much sought after. The fetlock joint is round, as if turned in a lathe, while the 
pastern is long, springy and oblique, so as to take the jar off the delicate bones below, without dropping enough to show any signs of weakness. There is no danger of ring bones or navicular disease in that formation. The feet are of a fair size, with good heels, and horn that will never shell if the nail is placed properly. There is a great deal of truth in the old adage, of "no foot, no horse:" these are not only naturally good, but I must congratulate you on having lept them so by judicious care.

This horse is very deep through the heart. When I first saw him I should not have judged him to be over fifteen hands two inches at the outside. When you stand beside him, you are satisfied that sixteen hands is, if anything, below his measurement. The barrel swells out, giving a good length of ribs, which are wide and have the right curvature. The back and loin are remarkably strong: The arch in the back is so high that it does not look as well as if a little lower, but there is a mountain of strength there when connected with the broad loin, braced with fillets as thick as your arm. The hip is long with slope enough. Were it more level, it would give him a jauntier air, but he would not be as likely to trot so well. The stifles are low, and placed the requisite distance apart to play freely, without being interfered with by the abdomen. The hock is large and so clean that you can trace the articulation of the joint. The great width of the gaskin arises from the bone, forming the point of the hock or oscalcis, being so long that the tendon comes up a long way before it is covered by the muscles. What was said about the canon of the fore leg will be appropriate to ciescribe the hind, only the flatness is more apparent. The angles, from the hip to the foot, are just what they ought to be to work the propelling hind legs to the best advaninge. His muscularity is just what I fancy, long, lean and dry ; they will come as near giving you an idea of perpe- 
tual motion, as is in the power of any animal to display. If he was only a little fuller in the quarters, I believe I would like him a very little better, but as they are heary enough, any thing more would give him a cloddy appearance, that would take away from his high quality. His coat is another mark of his high breeding; that and his hoofs would convince any discriminating observer, that his claim to blood was well founded. $\mathrm{He}$ is not properly black, but dark brown, with tan-colored flank and muzzle; this I prefer to a horse that is all black. His tail is magnificent, "fit for a Pacha's standard," as Willis once remarked of Lady Suffolk's, but fitter to ornament such an animal as we are looking at. Some would call him too short in the body, but I think, if measured, you would find it equal to his height-the best proportion in my opinion, to unite speed, bottom, and that compactness of form, so essential in a procreating animal, more especially the male parent.

I have, in this cursory manner, run over the Falcon's chief points. Many, of course, would differ with me as to what conjunction of them forms the best horse ; but my experience has led me to think a horse for fast driving on the road and track, able to keep going, up hill and down, or repeat his heats all day, must approximate the form I have just sketched.

PupIL.-You cannot conceive the pleasure you have given me, listening to the encomiums you have passed on the animal that I love. Yes, love is none too strong a term to express my feelings for that horse. After family and friends, he has the next place in my affections; and in order that you may understand how they became so strong, I will have to acquaint you with part of our-at least, to ourselves-eventful history.

His place of nativity was Central Ohio, a fine undulating country, which for fine horbage nearly equals the bluo 
grass region of Kentucky. His parentage is unexceptionable; his sire being Camden, by Shark, his dam a danghter of the northern champion, Postboy, thought, until his defeat by John Bascombe, to be the best horse of his day. He grew up a fine colt, taking the premiums at the local fairs, until three years old, when he was taken West by a boy who had no more knowledge of condition, than if he had never seen a horse. He ran him all sorts of races, from a quarter dash to two mile heats. As a specimen of the usage he got, I will relate the following story, which I was assured was strictly true. The boy having got in debt, an attachment was served on the colt, and he was locked up by the Sheriff in a log stable, where he was confined for three weeks. There were some races at a little town not very far off, and his owner managed to get him the day before the two mile heat race was to be run. He traveled him to the neighborhood of the racecourse, tying him to a tree ; during the night a violent thunderstorm gave him a thorough wetting. He had no rider, and in order to come as near the conventional scale as possible, rode him himself without a saddle; still he had to carry a hundred and thirty pounds-a pretty severe weight for a four year old, that for preparation had been a strict prisoner for weeks. He made a very good race, and it was the opinion of most who saw it, that had he been judiciously ridden, he would have been the victor as it was. That fall, I saw him on the occidental side of the Father of Waters, and was as much struck with him at first sight as you, thinking him the best formed animal I ever saw. I had long been of the opinion that just such a thoroughbred was the kind to make a number one trotter; but he had changed owners, and I did not succeed in getting him till the spring of another year. At that timo I was engaged in land speculations, selecting government lands in Iowa and Missouri, and being successful in mak- 
ing good locations, that I could sell readily at a greatly advanced price, my fancy for horses was only indulged as a pleasant interlude to the excitement of the land gambling. When I bought him I placed him in the hands of a trainer, who was reported to be the best in that part of the country. It was no trouble to break him to harness. On the first trial he went round the track hitched to a sulkey, on a trot that was as easy as the flight of a swallow. There was not much bending of the knee, and his action was so different from the spluttering little Blackhawks and Morgans-then all the rage in that section of the country-that the lookers-on ridiculed the idea of his ever making a fast trotter. I did not see him for several months, having been on an extended tour "land hunting:" That fall he trotted at a State Fair, in 3:05 ; which was certainly as fast, for the time in training, as I expected in my most sanguine moments, but no one else thought he would trot fast.

In the winter, he ran in a loose box. When spring time came, and the prairie roads got dry and smooth, I commenced driving him on them. He completely carried me away in a double sense. I thought I had owned and driven road horses very nearly as good as could be found, but I discovered he was so much superior to the best of them, that I took no pleasure in driving any other. Seventy miles a day was play to him, and he literally required no driving; a word would restrain him when most anxious to go. He never saw anything to shy at, but went along as straight as a line. His excellencies were so manifold, that were I to recapitulate them, it would be tedious. Unluckily, I again let his former trainer have him. The first time he went on the track, he trotted easily two miles in six minutes. The same day I matched him against a Blackhawk stallion for a couple of thousands, p. p. The match made a great deal of talk and 
excitement in the country, and my man was so anxious to have him trot fast all at once, that he ventured to whip him to increase his speed. This treatment his high spirit would not brook, and then began the contest between them, but the biped's arms was no match for the quadruped's strength of jaw, and when the day of the trot came he was utterly unable to hold him. I had not seen him from the day the race was made till the one prior to it. It was too late then, even to suggest anything, so he was driven in a long shanked curb-bit that had purchase enough to break the jaw of a mule. He was easily beaten. I cared not a straw for the money lost, but it was bitter to hear the remarks :- "I told you it wan't no use trying to make a trotter of a race-horse, they aint fit for nothing only to put a little boy on their backs and run over a smooth path," with hundreds still more ill-natured. I sent him home, and housed him again in his roomy box. Before the frost went out I started with him for Chicago. He was just as pleasant as ever, and I greatly enjoyed driving him the trip. Again I was unlucky in putting him in the hands of a man who did not understand the nervous organization of the descendant of a long line of illustrious ancestry. $\mathrm{He}$ hit him sharply with the whip when driving him down the road that follows the shore of the beautiful lake, which the Falcon resented by running away. The bit and reins were of no avail to stop him, but on he sped. The prairie was soon passed, and the driver thought of throwing himself out of the skeleton-wagon as they rushed through the timber. At last from sheer exhaustion he was forced to give up his pull, when a few soothing words was sufficient to stop him. The fright, however, deterred the man from getting behind the horse again, and the only exercise he got was from the son of the trainer riding him behind the wagon when his father was driving. I brought him home, thinking it 
was written in the book of fate, that the prophecies of those who were always ready with their "I told you so," were to be fulfilled. That season the great panic overwhelmed the West, leaving thousands, who had thought themselves well off, entirely penniless; it did not take long for me to realize that I was in that poor and destitute condition, for after selling every farm and acre of land I possessed, I was still five thousand dollars behind hand. The house where I lived, and which cost me nearly ten thousand dollars, one of my creditors took as a great favor to me at two thousand. I built a "shanty" on some land belonging to a friend of mine, moving thereon my family, this horse, and two of his colts. The land was entirely unimproved, but was beautifully situated, and laid so that very little expense built a good training track. To attempt training horses with the little know edge I had of it, was, to say the least, rather presum]tuous; but I had nothing else to do, and if my favorito ever made a mark on the trotting turf, this was his only chance for even a poor education in that useful branch of equine accomplishments. He lrept me in good cheer by improving so rapidly under my teachings, that those who had denied his having the least chance to make a fast one, now acknowledged the possibility of his becoming such.

I trotted him a ten mile race which he won easily. The stake money he had earned by his services in the stud before he left home, so I was doubly his debtor. The following season he had more business than he could do from March till September; still after three wceks' preparution I trotted him a race of heats of five miles. The first he lost by half a length in 14:21; and lost it entirely from bad driving on my part, for in place of letting him go along as he wanted, I pulled him back, which irritated him so that he worked unkindly the whole of the heat. 
The second he won in 14:33, and the third his antagonist gave out, dead beat on the thirteenth mile, but the slowest he could be made to go the last mile was $3: 20$, making the heat in 15:11. At the conclusion of the race it was a difficult job for two men to hold him till he was unharnessed from the sulky, not the least distress or even leg weariness being perceivable. The next day I started home with him; he bowled along the smooth road in such high spirits, that it appeared as if he was elated at the victory he had won, and was determined that no one should think he had anything but an easy task, by hiding the soreness he certainly must feel.

Never having seen him exhibit any signs of fatigue, I thought I would give him a trial, and for this purpose kept him to work a couple of weeks longer. I then drove him fifteen miles in 44:05, and on pulling him up, not a leg trembled, or even a long inspiration betokened the least distress. I then concluded to trot him twenty miles in an hour, which I am positive would be an easy task for him to perform, but have now changed my mind, and hope to see him doing his mile "low down in the twenties," which I fondly think him capable of, from the bursts of speed he has often surprised me with. I shall ask as the greatest favor you can do me, that in lieu of telling me how to drive, you will chaperon him yourself; I know he will please you when once acquainted. As you remarked about the.magnetic fluid traveling from driver to horse, this fellow shows it more than any I ever dealt with. If I got into the wagon ill-natured, he was sure to be cross too. At other times, on a fine morning like this, on arriving at the top of a hill, he would stop without any admonition from me; I know he enjoys beautiful scenery as well as I do. I have known him stop on a bluff overlooking the Mississippi-his eye would follow 
the course of the river for a while, but would finally rest where water, prairie and timber formed a harmonious picture that would have delighted an artist. There was no mistaking the look, or the nod of satisfaction he invariably gave, as he sprang off in the brisk trot to make amends for the lost time. I told you that next to family and friends I thought more of him than aught else. It may be foolish, weak and wicked, thus to speak of an animal, rating him above, and holding a place in my affections before many created in the image of the Great Architect; yet when I recount what he has done for me, you, at least, will understand the feelings that prompt me. From penury and a dark prospect, with a helpless family depending on me as their only means of support, he has raised me to comparative affluence. From a load of debt that would have bound me as with a three-fold cord in durance, that the results of even successful labor would have been unable for a long series of years to lighten, he has freed me. For a pleasant home, where the birds sing in the grand old oaks, where the bee sips the honey from the sweet scented cherry and the flowering fragrant crab-apple; where the sun shines so brightly in the windows of a morning, and gilds with refulgent glory the opposite bluffs in the evening; where the placid river runs so silently to the sea, with wooded islands on its bosom, that look like floating fairy gardens; where colts are gamboling in the green fields, where peace, contentment and happiness dwell-for all this I am indebted to him. Would it add to his happiness never to have a saddle or harness on his back, he should never wear the bonds of servitude again ; but active life is what he enjoys. No matter how large a box you confine him in, he frets like the prisoner of Chillon, and would soon wear even a stone floor in his uneasiness. He must acquire more than 


$$
\text { "FALCON'S" POSTERITY. }
$$

a local celebrity, and leave his posterity a record that will compare with the best, so that others shall know his great excellence as well as myself. This is what I have marked for him to do. For this I have studied, and for this I have come to perfect myself in the art, of which you are conceded a master. 


\section{H A P T E R I V.}

TEACHING TO TROT-BOLTERS-WINTERING HORSES-BREEDING FARMS, ETC.

Preceptor-I can well appreciate the feeling you have for that horse, and in place of considering it mawkish sentimentality, honor you for your gratitude to him, who has done so much to retrieve your bad fortune.

You are also worthy of credit for the pertinacity with which you stuck to him, determined that he should make a trotter. Patience is everything in our profession. Weeks, months, even years are necessary to make the most promising proficient in this partly acquired gait. The swift gallop of the race-horse is greatly improved by training. Perhaps if they were run without any weight on them, nature would be the only teacher they would require, but the action that is necessary to carry the weight easily is the result of practice. The swiftest natural trot any animal ever possessed is slow, indeed, compared with the speed exhibited by Dexter or Lady Thorne. If these two "Topsawyers" had never been subjected to a thorough training, their great speed would never have been known. In fact, they might have passed their lives without either being credited as even good travelers, by being placed in a position that would have rendered fast traveling un. necessary.

When a particular family of horses have become celebrated for great trotting powers, almost every colt belong. 
ing to it is placed in a position to show whether they have this family characteristic. Men pay long prices for Hambletonian, Membrino or Pilot colts that have never felt the weight of harness, because many of their relations have proved fast, and they are generally well repaid for their investment by subjecting them to long and skillful training. My predilections for the thorough-bred may have arisen from sleeping with them when a boy. My heart would nearly break when one of our stable was beaten, or burst with joy when any were victorious. These remembrances may bias my judgment, but I have often thought that, were the race colts placed in train as trotters, we would see as many of them first class performers as any of the strains I have just mentioned. IBoth the Hambletonians and Membrinos had their origin in the purest streams of the turf blood.

The admixture of Bellfounder, and other coarse strains, cannot have given them any additional qualities for rapid locomotion at a trotting gait, while, if the little black racing pony, Pilot, had been confined to mares of his own degree, we would never have seen one fit for a batcher's cart or balzer's wagon. But this is a subject we must take some rainy afternoon to discuss in all its ramifications, as it is one of great weight to you, expecting to breed as well as train trotters.

Pupic. - You again please me exceedingly, as I am well convinced that the better bred the trotter is; the more likely he is to perform great feats, and argue it so much that I am considered a monomaniac on that subject. There is no part of the business I am so taken up with as breeding and rearing the colts. The interest never flag's with me for a moment, from the time the young thing first gleefully capers round his mother till it is old enough to attract the attention of a purchaser ; even then the fecling of affection will follow, and I will rejoice in 
its well doings as much as if still the owner. I have only one more aged animal to show you, and he is a grandson of the little French pacer you were just speaking of, being by Pilot, Jr., his dam a well bred mare. These four specimens of bad management, will be, a sufficient test of your skill in teaching, and my aptitude in learning, as they have been as unfortunate in their early tutorage as generally falls to the lot of their species. With the young things we will at least have a clean page to commence on, which will be much pleasanter than if we had to use pumice stone and India rubber, before we could make a mark.

This grey horse we call Clipper, and he was considered as promising a colt as his sire ever got. His dam had produced a trotter that had gone exceedingly well, under the circumstances, and much was expected from the scion of a horse that boasted of Native American, John Morgan, Bull Run, and plenty of other good ones..

In his three year old form he gave further proof of his possessing the virtues of his line, by winning a three year old stake in a country where young trotters are as plentifül as blackberries in their season. When four years old, his trainer, a black fellow, owned by this horse's breeder, gave him an unmerciful flagellation, which knocked all the trot out of him. He took such a hatred to the track, that he could not be driven round it, and additional threshings confirmed him in this dislike, so that he had to be thrown up.

He was purchased afterwards by a gentleman, for his services in breeding, and when not in this employment, he drove him on the road. This gentleman, who had a strong desire to improve the stock of the section in which he lived, had spent a great deal of time and money to effect that object.

He first got a stallion, with a pedigree and form as good 
as could be found; and in order also to serve those who wanted a trotting strain to breed from, he selected Clipper. The blood Clipper drew from the veins of his dam and half-bred sire, gave him quite a share of that which would be so great an advantage to the cold blood mares, about the only kind kept in that region. The owner endured the irritation consequent on owning two public stallions for several seasons, thinking that when the progeny began to display their good qualities, it would stop the abuse that was so plentifully heaped on his pets, but it increased. Fifty good colts would be passed without a word of commendation, while a medium or poor one would be held up as a specimen of the horse's breeding.

$\mathrm{He}$ became utterly disgusted at the stock not being appreciated, made a present of the thoroughbred to a friend, and selling the Clipper for what we both thought was but a quarter of his value. $\mathrm{He}$ is as gentle as a horse can be on the road, a child driving him without the least danger, but on the track is quite a different animal. A sharp tone or flourish of the whip and away he goes for the fence. At times he will trot fast, but on making a break, will rush for the same place or jump frantically in the air, expecting a repetition of the beatings he has not yet forgotten. You will also perceive that he is as much out of condition as a horse can well be; every leg swollen; in the right hind foot a bad case of thrush, with a bowed sinew on the near fore leg that looks like the premonitory symptoms of a break down; this, however, was occasioned by a blow, so that it may not be as dangerous as it appears.

Preceptor. - Had I not my eye, full of the Falcon's faultless symmetry of form, I would have greatly admired the proportions of this one, though he shows but very little signs of his grand sire the "Canuck;" another proof of the superiority of racing blood. The five-eighths or 
three-quarters flowing in this horse's veins has completely obliterated the outward appearance of the remaining fractional part, and were this horse bred to fine mares, in all probability his colts would be still farther from showing it in acts and appearance. Were $I$ to open a breeding farm for the purpose of rearing trotters, expecting to sell my colts at an early age, I would not object to mixing a good deal of French blood with the purer stream. In my opinion the colts would come to their trotting gait earlier. They would bend the knee with less teaching. We have an exemplification of that in the young trotters Bruno and Brunette. That they would eventually prove as good horses, I have no idea.

As to the case in hand,--this fellow's bolting,-it is one of the most dangerous tricks a horse can have, and I would not knowingly become the owner of one that had acquired it. Your request for me to drive the Falcon I would grant with the greatest of pleasure, as I would take delight in driving him, but in order that you, as well as your horses, may be acquiring useful information, it will be necessary for you to do the tooling yourself. Should there be no nerves of sonse in your arms, telling you when to pull and when to ease away, I will give up the task ere the commencement of teaching you to drive. That you do possess this quality I have no doubt, as without it, you never could have met with the success you have already attained. Had you asked me to drive this bolter, I should have emphatically answered no, on my own account, and can only say that you will be lucky if you do not get hurt. The best advice I can give, is, that when you see he is determined to bolt, in lieu of trying to keep him on the track, pull him directly for the fence. If he keeps on he had better hit it with his head than the wheel. I have cured horses of shying with a contrivance tiat inay possibly be of some benefit to him, 
though I will have no faith in it till tried. For the blind or winker of the bridle have a sheet of Russia iron cut a little larger than the ordinary sized blind, and perforated with numerous small holes. The philosophy of the thing is that the horse sees so many bug-a-boos that he is confused, and results much the same as driving him in the crowded streets of a city, where so inuch strikes the eye that he has no time to be afraid of what is on one side, for the many objects on the other are just as fearful, compelling him to go straight along. This may multiply the fences to the Clipper, so that unless he takes a fancy for a steeple chase he may remain on the track. He will naturally associate the whip and bolting together, so we will discard it when driving him for a while. His going so frantically in the air, is from having his mouth so torn to pieces, and jerked when in a break. By letting him run till he will regain his trot of himself, or at least by a little motion of the bit pulling his head a little on one side, or a slight shake similar to what you would use to hook a trout, will in due course of time teach him a better system of brealing. It is true this will increase the danger should he bolt, the run being speedier than the trot. In the velocity of a moving body impinged on a heavy stationary one, and brought to quiescent state, everything movable will have acquired the momentum of the moving body, and will go till arrested by the laws of gravitation, or brought up with a round turn, coming down a purler, as our Inglish friend would say, or a sockdolager, as we would. He will not be likely, however, to leave the track running along at his ease, with the driver talking to him as he ought to. Should you pull and frighten him, the choking sensation would be an additional inducement for him to leave. His condition is certainly very bad, and it will be some time ere he can be put to work with the balance. I never believe in giving a well horse medicine, as I 
think all that is claimed to be gained by a course of physic, can be got at safer to the animal and easier to ourselves, than by balling and drenching; but in the case some aperient or alterative will be required. Your horses are just in the order I would like to have them to commence work, fat, but not overloaded with flesh. They show they have been well wintered, getting their rations of hay, corn and oats as regularly as the hour came for them to have it. The idea of starving or freezing out horses has long been exploded with me, and must have originated in some one who was so confoundedly mean that he grudged the horses the grain that was necessary for them to retain their stamina. My idea of wintering a trotter is to turn him in a large, roomy box, first having prepared him by taking off the clothes he has been wearing, putting lighter ones on, removing them so that he may get a good thick coating of hair that will protect him better than the artificial application of blankets; his shoes pulled off of course. Adjoining this box let there be a yard well littered with straw, and every day, that is not too stormy, give him the run of the yard for several hours. Have the best of timothy cut when the seed is just forming, or rather when the bloom is entirely off ; well cured, but not exposed to the sun and air till half of its nutritions qualities have been wasted. Have a large manger, in which the horse can turn this hay over, selecting the part of it that suits him best; but if good and properly cured all will be eaten. This manger should take up the whole end of the box, high enough that in rolling there will be no danger of getting in it ; built perpendicularly, so that if inclined to paw while eating, the knee will not hit it as would be the case were it sloping from him. On one end of this manger set a porcelain lined feed trough, or in lieu of that a common cast iron kettle that will hold two or three pails full. Give him, at regu- 
lar intervals, three feeds a day of good oats, every other day substituting a few ears of sound old corn-the dent varieties are the best-the amount will depend on the size or fat forming qualities ; but from six to eight quarts of oats daily, or its equivalent in other feed, will generally be found sufficient. The quantity of hay to be unlimited, so that the stomach will be filled, restoring the muscular power in that organ, which may have been impaired in the preparation for sweats and races the preceding summer. Once or twice a week give a bran mash, and place a box containing salt within reach. Through the winter change his feed by giving cut feed, carrots, wheat, rye, barley, meal, etc., and as the spring comes on, a little oil meal, flax, or sunflower seeds, will assist in shedding the old coat, and producing a soft, shiny new one to take its place. He should be watered three times a day. The litter in his box shaken up, and all the soiled portions thrown out once a day. No grooming will be needed; if plenty of clean straw is kept in his yard and box he will not require it, and for this much of the year, at least, he will be exempt from the torture-to a thin-skinned horseof currycomb and brush. In the temperature of this box I know of no better rule to observe than that, after proper precautions have been taken for thorough ventilation, it inay be made so close as to exclude the outer air. If this is clone by building a hollow brick wall or a wooden one, the aim will be reached. I have seen stables built of logs that were as good, and horses wintered in them as well, as when thousands of dollars had been lavished to rear a structure that has all the appliances of modern times to make its inmates comfortable. I do not mean, by this remark, to be understood that I find fault with the taste displayed by our wealthy men in building fine barns and stables. They are not only a great ornament to a fine villa or eity residence, but they are so comfortable for the 
horse, and so handy for those who have them in charge, that to one who had been accustomed to the best half a century ago, the change would be marvellous. For a country place or farm there is nothing that adds more of a home look than good outbuildings, and I would have the horse barn not too far distant from the house. In fact, I would have it so near that let the weather be as rough as it might, there would be no dread of going from one to the other. It should be a prominent feature in the picture, made up of the dwelling, lawn, orchard and paddocks, where the matrons of the stud and their offspring are sunning themselves. If not naturally protected, I would shelter it with belts of trees, evergreen and deciduous. To sum up, I would have it look as if its inmates were just as well taken care of as those in the more pretentious dwelling, and where horses, like the Falcon, would have their eye for the beautiful gratified whenever they looked out of the box window. For a training stable, there would have to be a change of site and arrangements that would differ, but the training quarters we will also discuss some other time.

PupiL.-You would have every one who kept a horse provide him with a comfortable home, and it is surprising that men of sufficient means are found who restrict their horses to a place unfit to confine a hog. Plenty of farmers, "out West," still crib them in a pen made of poles and straw, which answerod the purpose very well when first erected, and while the family was contented and comfortable in the shanty or log cabin; but large gaps have been made in the fragile material, where the cutting prairie winds blow through, seemingly more biting than where the snow drifted over the fence, and the cattle were cowcring beneath the blast.

These men have owed all their wealth and comforts to the faithful servants that brought them from their old home, 
where the soil was rocky and sterile, to that where it is as rich and fruitful as the valley of the Nile. They toiled at the breaking plow, late and early, to convert the flowery prairie into fields that were overladen with all the products the most provident farmer could desire; hauled the rails that protected these crops from devastation; reaped the grain, harvested, thrashed ; in fact, thanks to the inventive genius of the country, did all the heary work of the farm, and after that was accomplished, joined in the owner's pleasures, carrying him where he listed.

The excitement of the wolf chase could not have been enjoyed had they refused to follow the wily denizen of the grove and bluff over the rolling prairie, never making a mistake in the treacherous gopher holes, and knowing just where it was safe to cross the slough that trembles under their light feet.

For all these services rendered, they are requited by having to stand the cold night with no protection, while the owner has replaced the cabin with the good two story brick or frame, protected from every breath of cold air. Would that I had the power to make them change places. The burly farmer should shiver for a while till he acknowledged his indebtedness, and finally repaid it by making his horse as comfortable as his now ample means would render easy of accomplishment.

You almost frighten me from the determination to make this bolter forget his dangerous trick, but as there never was a steeple-chase rider that did not get a "purler" or "sockdolager," before he attained the requisite knowledge, so I will even brave the chance of being impinged on some heavy, ponderous object that will receive me at the risk of compound fractures, liberal contusions, and seeing stars generally. I cordially agree with you relative to the wintering, and have 
followed the plan you have advised, as far as my means would permit.

I cannot coincide in your opinion of even making the most money by the early sales of colts having the admixture of French blood, to make them learn their trotting lessons easier. If I were able to breed in the manner I would like, to secure the right location for the farm would, of course, be the first thing. I would look a long while before I made the selection, as it would have to combine qualities that are not found on every farm. Supposing it to lie north of the forty-first or second parallel of latitude, it would have to be in a sheltered situation, where no rough wind should have a long sweep. The soil should be rich, so that there would be a good growth of herbage, and suitable for the production of all kinds of grain. Without drawing on my fancy, I will describe a place I have often thought the very best I ever saw for a horse breeding establishment. It consists of six hundred and forty acres, being a square, each of its boundary lines a mile. Along its eastern boundary is a road that for several miles is perfectly straight, nearly level, and quite sandy. About half way there is another road running in a westerly direction, by the buildings, which are located very near in the centre of the whole tract. The eastern half of the section is very nearly level, yet undulating enough to cause perfect drainage. On this portion is found almost every variety of western land-that along the road having a mixture of sand; and as you go back, there is gravelly loam, heavy alluvium, clayey loam, all rich, mellow, and friable as an ash heap. This part was originally prairie, lying on the second bottom of the Mississippi River. The western part of the section runs part way up the bluff, which is crescent-shaped, and of a gentle inclination, rising about two hundred feet higher than the bottom. This bluff does not present a continu- 
ous line, but is divided into several hills by ravines, that gradually widen as they approach the bottom, till on tho skirts of the timber they are two or three hundred yards in width. The hills are covered with a heavy growth of timber, principally grand old white oaks, that interlace their branches overhead, while their trunks are such a distance apart as to suggest the idea of their having been planted by some skilled landscape gardener, centuries ago. This idea is strengthened by the grouping of the trees, which, in every case, are best arranged to suit the inequalities of the ground. As you approach the edge of the ravine, shrubbery takes the place of the large trees, making an appropriate border for these emerald bays so beautifully carpeted with the thick growing blue grass. These woodlands are very different from the celebrated wooded blue grass pastures of Kentucky, and much as $I$ have admired them at Woodburn, Ashland, and scores of other places in that favored region of the horse-paradise, still, to my eye, there is more beauty in these I am trying to describe. The Kentucky trees show that they have been a dense growth, and were forced to grow long boles that their tops might not be overshadowed by their high companions. The cutting away of part of this growth has made the lack of branches more apparent. Here the annual fires killed all the undergrowth, leaving those that were large enough not to be injured by the burning grass at a sufficient distance apart to develop their full beauty. Trees of two or three feet in diameter would scarcely rise twenty feet before they threw out lateral kianches approximating to the size of the parent stem.

What a crown of grandeur some of these old white and burr oaks possess, and to my mind the white oak is, par cxcellence, the lking of trees. I have a distinct recollection (though it is a long while ago since $I$ saw them) of some of the woods and parlss of the "old countrie." When a 
boy I bird-nested and gathered hazel nuts in Craigieburn Wood, "where sweet faa's the eve ;" guddled for trouts in the waters, and pou'd gowans on the banks, of the Even and Annan, rendered classical by the sweet lyrics my countrymen have written in their praise; wandered with awe around some of the old ruined castles whose thick walls and grated windows told tales of the old feudal times, and which needed not the funereal yew and dismal fir to make as ghostly as one could wish ; admired the wellkept parks, with the trees of centuries' growth springing from the verdant sod. Your remark that the Englishman's boast was of the most beautiful women, finest horses, and grandest old trees is true, since Scotland was joined by act of Parliament to the richer country. The finest horses, even a Scotchman will admit, they always possessed, but the bonnie lasses and grand trees would never be allowed. No one acquainted with the literature of the two countries, will deny that the Scot has been more felicitous in his description of female beauty, which can only be accounted for by his more frequently seeing it; but I have got away from the breeding farm and digressed merely to compare the trees on it with those of Kentucky and England, superior to the first and quite equaling the finest specimens in the English parks. The site for the house is about midway, in elevation, between the river and top of the bluff, on the summit of one of the smaller hills. To the east and south nothing obstructs the view, and a grand one. it is. The southward curve of the bluff, forming an arc of a great circle, encloses several thousand acres between it and the river. Where it meets the water, it ends in an almost perpendicular wall of yellow limestone, broken into deep fissures, where scrubby red cedars and creeping vines are the only verdure that can grow. On the summit of the precipice are gnarled oaks, throwing their branches in fantastic shapes 
athwart the sky. Away to the southeast and beyond the river, are blue, hazy looking hills, an undulating outline losing itself in the far off horizon. Directly opposite the house is a heavily wooded island. Above the dense foliage of the trees another rocky barrier rears its frowning bulk in broken crags, hundreds of feet above the water. This precipice is on the opposite side of the river, the course of which can be seen for miles from the door of the house. The plateau lying between it and the sheltering bluff is spread out, like a map, before you. On the farthest extremity is a neat little village. Between that and the observer are several cultivated farms, the buildings and fences adding greatly to the comfortable appearance of the whole. A steamboat is gliding along over the tranquil waters, and from another village on the eastern shore, a long train of cars is winding its way round the foot of the rocky bluff. A large spring breaks from the most northern ravine, and is running through the pasture like a thread of silver. From your seat, in front of the house, you can see where a mile course could be made that a cat would be visible on every "jump" he would make. You fancy now that you can see the embryotic trotters taking their preliminary lessons, and in another field to the right, but just as much under your eye, some of their kindred are more gracefully galloping. I am now presuming that $I$ am rich enough to keep raco horses, as I would advise every man of moderate means, whose fancy for the horse requires gratification, to sticis to the trotters. He will make money out of them if even unsuccessful in breeding top sawyers, the different grades finding ready sales and remunerating prices in the largo towns and citics, while the training expenses of the young race horse are three-fold of his more useful but less showy relative, the young trotter. I quite agree with John Randolph, that two tolerable things are intolerable, 
a tolerable egg and a tolerable race horse. I have now found a suitable farm, but the most important thing is yet to be sought, the stock that is to render all available ; and here I would probably differ from ninety-nine in a hundred who have given the subject much study. For a stallion (leaving all predilections or favoritism for an individual animal that would cause me to select the Falcon as a model), I would hunt up a thoroughbred of good size, say fifteen and a half to sixteen hands, possessing the requisite bone, or rather, tendon and muscle. Most all horses in my opinion have bone enough-a good many of them too much. His pedigree I would be just as fastidious about as if I wanted to breed race horses, and would not be suited without it contained several crosses of Messenger and Sir Archy. There may be other families that will prove just as successful, but these have been tried. I know of two imported stallions that will undoubtedly be celebrated yet as the progenitors of trotters.

To go back thirty years for an illustration. A colt from Ariel, by Henry, would suit me exactly as to blood. For instance, Ariel, by Eclipse, dam by Financier, g 'dam by Baronet, g g dam by Messenger ; Eclipse, by Duroc, dam by Messenger; Financier, by Tippo Saib, dam by Messenger ; Tippo Saib, by Messenger. This might appear as if too closely inbred to produce a good animal, but her performances - the best campaigner of her dayshows that it was not the case with her ; and by scrutinizing this pedigree we will find that with all these near crosses she was only about a quarter Messenger, but undoubtedly the preponderance of that blood over any other, enabled her to display its most valuable characteristies, and I have no doubt, that had she been taught to trot, she would have exhibited the wonderful feats since shown by the more remote members of this family. 
Henry, the celebrated antagonist of Eclipse, was the sire of the dam American Star, that got Goshen Maid, Bolly Lewis, and a great many other good ones renowned in the stud as well as the trotting course.

Post Boy, a son of the hero of $7: 37$, left many fine roadsters through Ohio and Michigan, ending his career in Dixon, Illinois, where he died in 1863, thirty years old, the last of his get a very promising trotting filly. I would prefer the stallion a bay or brown. My choice would be that rich, rosewood brown, a color often seen in the colts of imported Sovereign. It would be an additional induoement for me to buy him if he had been tried, and his eolts were found to color after himself, and it would be absolutely essential that he had good trotting actionthe faster the better.

For mares I would like to get good sized, roomy animals, with all the important points good ; strong constitutions and docile in their temper. I would not care if they had less quality than the stallion, but would much prefer one that had been a mother, proving herself a good millker, to one that looked a little better, but not known to possess this great desideratum for the well-doing of the colt. Their blood would suit me best to resemble that of the stallion, by having the remote crosses similar, with an admixture of Trustee or Boston, both of whose descendants I have seen trot fast. They should also have the clear trotting step that a majority of thoroughbred mares surely possess. I do not think the objection often urged against breeding from near affinities, is sustained by proof from the record-quite to the contrary, as was exhibited by Ariel. Many of the best animals on the turf have been thus bred. I would not advise incestuous crosses, though even that is less to be dreaded than many think. Virginia Taylor and Virginia Lafayette by Sir Archy, dam Coquette by Sir Archy, were both good 
mares, the best their dam ever bred from any other horse. Flirtilla, Jr., bred in the same way, was not as fleet an animal as her dam, but a better brood mare, producing Cassandra, one of the best of the noted Priam's get in this country. I think that to establish any point of excellence in a family, not usual to their race, but prominent in them, this system is far more certain than any other that can be pursued. 'Twas thus that Collins, Balewell and Webb built up almost a distinct race of short horns, Leicesters and Southdowns, and though we want our horses famous for something else than early maturity, large size and capacity to take on fat, the soundness of constitution necessary, ere they can possess these qualities, will likewise tend to the forming of muscle and adaptability for rapid locomotion.

These mares I would also select of a uniform color, which should be the same as that of the horse, having an eye to the progeny resembling each other, which would enhance their value both as trotters or carriage horses. Pairs are now much sought after, by those who delight in going fast on the road, and to one who can afford the added expense is certainly much more pleasant than driving one, if they are lucky enough to get together those alike in size, speed and action.

Having now got my stock; I would prepare the place by fencing those sheltered ravines into small sized fields or paddocks, in each enclosure placing a shed, tightly roofed and closely boarded on three sides. This would be for the accommodation of the mare, and foal soon after it was dropped, and where I would keep them till the fowl was old enough to wean. In this shed should be two feeding boxes or troughs, the one that the mare eats from large, but so low that her colt could also reach it, so that the little fellow would learn from his mother to nibble at the oats, and when the teeth got through the gums, eat his 
share from the smaller trough placed where the mare could not get at it. They should have two feeds a day of about three quarts each feed, not quite so much as that till after the mare was stinted again. When the colt is about five months old, say the first of November, I would wean him; first having broken him to the halter so that he would be as handy to lead as an old horse. The middle of August I would have one of the smaller fields of corn seeded to rye between the rows. Through one corner of the field runs the spring branch, its bed clean gravel and sand that has been placed there, so there shall be no mud for our little heroes to stand in as they quench their thirst. On the side near the house is a long shed with a trough, where the twenty colts we are now weaning, will have plenty of room to eat their ration of oats without interfering with each other. In this field we turn them, placing those foaled the earliest in first; but as a general rule, no matter about the age, it is best to commence weaning as soon as the first of November, before the succulence of the young rye has been injured by frost. The colts will improve in condition on that and the oats that are fed in the shed, and will also nibble at the ears of corn not yet gathered from the stalk. They will soon become reconciled to the loss of the mother by the company of each other, and it will be far better than any circus show to see them play, or come rushing through the corn-stalks, when you call them to the evening meal, always given by yourself or under your immediate supervision.

Here we will let them stay, till the weather becomes cold enough to require their being placed in warmer quarters at night and on stormy days. On the sunny side of the barn we have built a large shed; on the west side is a stone-wall which is banked up for half its height; the south side is boarded, and the east fixed with sliding 
doors, so that in case of very cold weather it can be closed entirely. Sliding partitions are aiso prepared to divide the shed into five compartments. The shed is littered deeply with straw. Overhead we have storage room for hay, corn-stalks and straw, and contiguous to the south side is a room for corn, oats, meal, bran, \&c., with a rootcellar in the high bank. The hay is clover and timothy, the clover cut while the flowers are in full bloom, and the timothy cut a week earlier than one woukd cut it for horses that are in train. The clover has been cured so that its fragrance is that of a fine morning, no blackness or mould, but a deep green; an armful of it thrown to the hogs is as greedily eaten as if it had just been cut. In the root cellar are carrots, with a few other vegetables, such as cabbages and sugar beets. The commissary is well supplied, and are near enough the head of the spring, so that we carry it in a pipe to the yard without danger of freezing.

These young things must be fed as regularly as the movement of a Jules Jurgesen watch, varying their feed whenever their appetite craves a change. But I must beg your pardon for taking up this subject, which you had tabooed till a rainy evening; but once on the subject of breeding and I do not know when to stop. I must pray of you to put an end to my loquacity when it becomes tiresome. I am not so conceited as to think that all of my plannings and dreamings will be conceded to, or even interest you, though I have had some experience in breeding on a small scale, and have visited some of the large breeding establishments of the country, but never yet have seen one that suited me in all particulars.

Precepror. - Well, my scholar and partly teacher, I have become greatly interested in your ideal farm, and will be much pleased to hear you continue it, till the colts have got to an age when they will be fit to go to sharp 
work. I have no doubt your knowledge of breeding is much superior to mine, as I never raised a colt in my life, and though nearly a score of years your senior, presume that your country life has given you facilities for observation, tenfold greater than could be enjoyed by one spending his days on a track near this great metropolis, which throws its shadow over what should be country, and requires quite a journey ere one can feel that he is entirely free from city air. It has been a cherished idea with me, that the time would come when I should own a farm, where I could retire in the evening of life solaced with the quiet joys a dweller in the country has to be contented with, but I have been too long acquiring the means that would enable me to fix myself satisfactorily. For a man of my age to form new habits, acquire new friends, change my whole manner of life, I am of opinion it is too late. It is true, my lifelong companions, the horses, could be retained, but ardent as I am in my affections for them, I could not be in the stable all the while. Had I a family, the case would be different. A wife to share my joys and griefs, to solace me in one and make the other doubly enjoyable, with children to watch over and establish, then any place would be cheerful; but, as with the farm, I waited too long, till the time for connubial felicity had also passed.

From my connection with horses $I$ have made friends that honor me by their friendship; men of strict integrity, who never think of a mean deed much less of doing one, whose fondness for the sports of the turf can not be destroyed by the rascality of those who would be rascals the same in any position of life they might be placed, and who bring the manly sport in so much discredit, that it takes a good deal of nerve in those men placed high in social position, the fruits of large means and well directed talent, to acknowledge their connection 
with it. I have scores of these friends to love and admire, and whose friendship will cheer me through life, if unfortunate enough to have neither home nor family to gild its declining years. I am sorry you have Jocated your breeding farm so near the setting sun as even the west bank of the Mississippi. It will be too far to go to see the results of your making trotters of thoroughbreds, and I am afraid ere you send the first installment to market my heats will be ended, and, gently as the ancient scythe-bearer has always treated me, he will undoubtedly leave me behind the distance pole at last, though I shall make a game struggle, and hope the closing event will bring no discredit on the many honorable contests that have preceded it.

PoPrL.-The Falcon?

Prectptor. - Yes, I know that the Falcon which I have been so foolish as to let you know how much I like, is thrown in my face as sufficient proof that the colts from your twenty-five mares will all, or at least a majority of them, trot fast. "One swallow does not make a summer," nor will one thoroughbred establish the claims of the whole race to trotting speed.

Pupil.-Did you not admit a short time ago, that if blood horses were trained as the trotting families are, they would excel them in their own branch of going.

Preclptor. - I did say if race colts were placed in the same thorough training as Membrinos, Hambletonians and Pilots, there would be as many trotters among them as among the colder blooded ones, but I did not want you to infer that in a breeding establishment to rear trotters, I would discard those families that had shown their adaptation for that gait. It would be well enough for some of our rich men to attempt the proof, who could pocket the loss, if it should prove such. In fact, I told you that I would have French mares, so that the colts 
would not need as much practice to acquire the necessary knee action, which every fast trotter must have. You dissented from the opinion, but as yet have not shown that I was wrong in the premises.

PupIL. - I had not come to that yet; I had only carried my colts along, till they were weaned and prepared for the winter, passing over a great deal I meant to say, in order to get to that point, but found that to make my plan intelligible, it was necessary to go partially in detail to be understood, and-

Preceptor.-All right, I was finding no fault with your description. As I think you weaned your colts, and started them into winter quarters in a very thorough manner, and will warrant that if dealt with in the same way till four years old, you will have the right kind of animals whether they trot or not. Nor do I find fault with your taking time to describe the scenery surrounding your farm. Were the best farm in the world isolated from others, with no beautiful surroundings, it would be no dwelling place for me. The blood you would select would also meet my approbation. The only trouble is in confining yourself to an experiment, which would be all proper in a man with abundant means, where failure would not result in pecuniary embarrassment, the worst of all loads to bear, excepting personal dishonor. After dinner I will be much pleased to hear a continuation of your experimental farm. In the meantime, we must not neglect the commencement of our duties to these animals that are to be put in active training. You say they have had a good deal of walk before you left home, so that they will only need sufficient to recover them from the long journey on the cars. Tomoriow, we will go to the shop, and see that they are shod in a proper manner. With the exception of the Falcon, they all want a change in their shoes, to guard 
against hitting somewhere, as I see the bolter has had some pretty severe hits on the shin, only now shown by white marks across the dark grey of his leg; but, as it will be sometime before he is ready, even to jog, there will be no hurry with him. As for the young things, when you finish your pipe, and I one or two of these cigars, we will look them over. 


\section{CHAPTER V.}

ORNAMENTAL PLANTING-OUT-BUILDINGS-BROOD MARES AND STALLIONS-WESTERN PRAIRIES.

Precepror.-You have been so fortunate in your choice of a stopping place, that I am afraid, while enjoying its comforts, we will be tempted to place too much importance on the good breakfasts and dinners provided for us, and grumble over their absence; making every one uncomfortable who has anything to do with providing or preparing our provender. The grumbler can make himself more disagreeable to those who are unlucky enough to be brought into contact with him, than any other species of "the miserables" attendant on this life. I have known some unmitigated types of this class, but, on making their acquaintance and finding this to be their true character, have got out of their way and kept out, not caring for any benefit that might accrue from their friendship, so much overbalanced by having to listen to their fault-finding diatribes. But if you will favor me with another of those finely flavored cigars, I will not bore you at present with grumblers, or the mischief they do ; and shall listen with pleasure to the continuation of the history of - Farm. Your Scotch proclivities ought to have led you to have named it before the first paddock was built or the first furrow turned.

PupiL.-And a very good plan the Scotch have of naming every farm, no matter how humble. How much better to refer to a place as Burn-braes, Heathery 
Haugh, Rosebank, Hall-dykes, than Smith's farm, Jones's place, \&c., the only way we have of distinguishing the most beautiful places in the country. Should a person name a little farm which he looks at with more fondness and pride than does the owner of the estate of several thousand acres, his æsthetic taste is laughed at, and he is ridiculed. by men who have not many ideas above those of an Esquimaux, so far as the beautiful is concerned. I will continue my ideal history of the breeding. The place is no fiction, and I have admired it a thousand times, always considering it the best natural farm I ever saw. The present house, situated on the grandly wooded eminence, is a large, massive stone building, with no pretensions to taste. However, the arrangement and size of the rooms are such as to be comfortable for the sheltering of a good many people. It is in the form of an $\mathrm{L}$, but unfortunately the angle is on the back side towards the wood. It is placed so near the eastern slope of the hill that all those magnificent trees are in the rear, excepting some of the finest that flank it on the north, forming a second screen as an additional protection from the north wind, which is more effectually shut out by the bluff making an abrupt bend to the east, running in that direction very nearly to the eastern boundary. A few straggling black locusts are the only trees in front, and the fine slope is bare of everything save garden vegetables and current bushes. The road is at the foot and winds round it, so that to an observer, familiar with Western road-making, it looks like a private one, all the others he has traveled following the section lines over hill and dale. The summer has not alone been occupied by watching, feeding and weaning colts, planting crops, and so on. The bare walls have been hidden by a wide verandah on both the eastern and southern sides. The roof has been carried over it so that it projects two or three feet beyond the 
pillars supporting the structure. On the second floor it forms a commodious balcony, and the small windows have been enlarged and cut down to the level of the floor, so that when the window is open you step at once on to the balcony. The color of the yellow limestone walls is in harmony with the scenery and the prairie rose, ivy, honeysuckle and woodbine that are just beginning to climb up their supports will hide the wood work, resembling the natural festoons that drape the distant rocky bluffs. The slope has been planted with rare specimens of trees and shrubs. The sombre hues of the cedar and hemlock, are relieved by the brighter green of the Norway spruce, its branches hanging in graceful curves from the ground to the summit. These young trees have been planted in groups, which when better grown will be in keeping with the natural growth, forming a foreground to the picture - a wide contrast to the massive oaks in the background, yet appropriate, as there is no glaring incongruity to offend the cultivated taste. There is no formal, stiffly laid out flower garden, nor even beds in geometrical figures, but patches of flowers spring up where least expected, greeting you with their bright colors and sweet fragrance. There are a few pots in which are growing those that need the protection of the conservatory in the winter, which has been added to the house on the west side, part of the wall having been removed so that there is a communication with it from the library and living room. Ornamental vases are distributed about the grounds, not placed there to be admired for their beauty of design and richness of sculpture alone, but every one further decorated with some plant that gratifies the eye with its unique appearance, or shrouding the pedestal with a mass of foliage and flowers drooping from the rim. That old stump, from which the tree has been barbarously eut, has been formed into a sun-dial. We do not expect to time our 
colts with it, but it has a useful duty to perform in giving us the true time, by which we can regulate our watches, and see that they do not mislead us in the division of our time or the speed of the colts, when they have become so fast that a fraction of a second is of importance. The source of the spring being higher than the house, we have conveyed it there in pipes, giving a plentiful amount of pure water. From its abundance, we supply the fountain in the green-room. The fruit and kitchen garden has been removed to the rear of the conservatory. The barn is back of this, and a little further east ; approaching the house from which we conveniently reach it under cover of the wood and carriage houses. The sunny yard for the colts is not the only one, there being several separated by close board fences, the boxes of the brood mares opening into them, and one is for the use of the cattle, the gazelle-eyed Alderneys predominating.

Beyond the yards there is an opening in the heary timber, of several acres, which had been planted to fruit trees; but the rabbits reveled there, and it was never replanted till the present season. They are growing finely, and have been protected from future attacks by a wire fence, the meshes so closely interwoven, that the rabbits will be compelled to satisfy their taste for bark with the hazels and sumachs outside. Now that we have noticed the improvements to beautify and make comfortable our home, we will take up the colts started into the winter, as you admit, under favorable auspices. The routine of the winter season has been explained, and assuming there has been no deviation from the time they got their meals or were turned out for exercise, you may have found it necessary to divide them into four or five lots, some of them being so timid, that the bolder ones drove them away from their feed, and generally showed an arbitrary temper to those who would give way. With all our care, 
some of them may have got lousy, infested with parasites that will attack, though rarely, the well fed, well cared-for animal. Those that are found in this situation, are placed by themselves. Many object to the use of mercurial ointment; I have never found any danger in its use or anything' so effectual to remove them. Rub it along the roots of the mane, and down the back, being careful you do not put it, where in biting themselves, they would be likely to get it. Keep them dry and warm, and a very few days will be sufficient to rid them from these pests, that would soon reduce them to a skeleton if not attended to.

The twenty-five mares-twenty of them being again with foal-require much the same treatment as the colts, though it is advisable that they should not acquire too much fat. Each one has a box stall for herself, with nothing but a manger and feeding box, and this placed so there will be no danger of the mare injuring herself when rolling. The water is also conducted through the yards, so that all may drink at their pleasure. Their feed is the clover and timothy hay, with corn fodder to increase the secretion of milk when they have-foaled. Bran mashes we would not give, but plenty of carrots and occasional feeds of wheat, which I have known the use of to prevent mares from slipping their foals that had always done so before they were thus fed. They should have their feed with the same regularity as the colts, the amount of grain regulated by their condition. Some will need nearly double as much as others, but in no case should enough be given them to accumulate much inside fat, which will surely be detrimental to the foal. We have noted exactly the time of being served; but as there is a wide difference in the period of gestation of not only different animals, but of the same in different years, it is only a partial guide, and there is no rule known any way near infallible. Some mares will secrete a great deal of the lactic fluid, 
and days before they foal the mills will drop from their udder. Others foal before the secretion talies place. By close observation it is noticed that the depression in the hip is more apparent just before foaling; this, and the uneasiness of the mare, will be the best tests to rely upon. They should be very carefully watched, but if their box is roomy enough, and the mare is healthy and sound, there is very little danger attending parturition. As in everything pertaining to horses, we will find a great dissimilarity between the mothers; some it is almost dangerous to approach, their affection for their offspring being so great that they are in an agony of fear whenever they perceive any one coming near. Others will not pay any attention to them, while there are still others that will not let the foal suck unless compelled; and I have known a twitch on the nose requisite before they would succumb. Here is one that, though willing enough, has not a drop of milk to furnish. The Alderney is now our dependence. We take some of the rich milk, dilute it with water, add a little sugar,-and a very little patience will teach the partorphan to drink.

One of Clipper's colts the past summer lost his mother, when ten days old, by falling through a bridge. His owner brought him up on cow's milk, and I never saw a better' grown, better developed. four months' colt in my life. He went the round of the fairs, and at every one took the first premium in his class. He could be led on a steamboat or railroad car with no more difficulty than a pet dog, and he exhibited more sense in every position than any one would have believed an equine baby could possibly show. He had a bountiful supply, and his capacity for drinking was as deep, though his potations were milder than the famous Knight of the Whistle. After drinking a bucketful he would neigh for more.

Our stallion, the descendant of aristocratic parents, has 
hardly been treated with the consideration he deserves; but he has been as well cared for as any other part of the stock. We found him in a southern clime, where he had figured as a good second-rate performer on the turf, running long distances better than short, and from his size, able to carry his appropriate weight in a satisfactory manner. He possesses most of the attributes we were looking for, and only fails in minor points that were not considered essential. In selecting the mares, I was very particular they should be such as were likely to "nick" well with his form. The blood, as we said before, in some of them, being rather closely allied, one or two being halfcousins and all very similar in their remote crosses. He was eight years old when bought, and though very kind under saddle, he had never been harnessed. When he was brought here, and after having been walked a few weeks, part of the harness was put on while in the stable, adding it by degrees till breeching, traces and collar were all familiar to him. The reins were put on, and he was accustomed to a check, tightened by degrees till he could not get his head below a certain position, not high enough to be a constraint that would annoy him. He was driven every day for a week with the harness dangling about, and for which he never exhibited any signs of fear. $\mathrm{He}$ was then placed in the shafts, and went as quietly as if that had been the place to which he was always accustomed. I took the precaution to have a kicking-strap put on, though the security was needless so far as he was concerned. Every day the roads were not too muddy he was driven for an hour or two, and whenever a smooth part of the road was found, he was trotted as fast as he could go. Under this system, the fine trotting step he exhibited has increased so much that I am confident he can trot a mile close to three minutes, and expect before the close of the next season to see him go still faster in 
proportion, as the track will be made and the exercise he will get there will be more likely to benefit his speed than all work on the road.

I find I am talking just as if this farm and stock were no longer an imaginary one, and until I made the pause, was so much carried away describing it, that it was as vivid as if real.

Preceptor.-There must be some magical properties in this cigar, akin to the wonderful eastern plant that made captive the senses of those who inhaled it. I have been completely transported to the land of plenty where your colts are frolicking. That grand country has been opened since my active days have passed, or rather its capabilities were not understood till a comparatively recent period. I always associate the Mississippi with the bark canoe of the Indian, and the prairie as a marshy plain almost limitless, where tall grass and flowers conceal the rattlesnake and venomous Massassagua, with the buffaloes, in countless myriads, roaming over a waste recking with malaria that totally unfitted it for the abode of civilized man. Of course, these crude ideas may be far from the truth, but I find it difficult to replace them with others, and cannot but think you might more advantageously have located it nearer some of the great horse marts of the country.

PopIL.-Those prairies that are to you flat, marshy grounds unfit for anything save reptile life, are one of the grandest sights God has vouchsafed to us poor miserable sinners. But you will have to go still further west than the right shore of the mighty river, to see them in their glory at this late day. Man has spoiled their beauty in one sense, in cutting them up into farms, and disfiguring them with fences and plowed fields.

Fancy yourself on an eminence overlooking miles of waving billowy verdure. Near you the deep green of the 
grass is relieved by flowers of brilliant hue, scattered over the wild expanse. Streams are glistening in the sunlight, their banks fringed with elms, the drooping, spray-like branches resting on the willow tops, that seem to be springing from the crystal flood.

" The mild waves bathe the woods, the woods the wave o'ershade."

You can mark their course for miles by the green bor- dering. The distant outline of the hills looks like a dream of land when in mid-ocean. A herd of deer are quietly grazing, apparently so near, from the clearness of the air, that you mark every line in their graceful forms. A solitary bald eagle is wheeling in circles over your head.

The few fleecy clonds that are sailing along so majestically before the western breeze, throw deep shadows that chase each other adown the slope and across the valleys. You are lost in the immensity of space, the earth appearing as boundless as the sky.

But you have not seen half the beauties of the prairie, unless so fortunate as to behold a sunset; and to fully appreciate this you must be alone.

When looking for land on the waters that empty into the Missouri, I frequently got so far from habitations that I was obliged to spend the night on the prairie. My horse shackled and turned out to graze, I have sat and watched the sun as it lit up the western horizon in a blaze of glory. Sometimes large masses of cloud would lie in huge fragments, their edges at first only gilded, when, as the sun sank, the dense foreground became gradually lighted up, till the whole was of such a gorgeous hue that the eye was pained looking directly at it. The reflected light, mellowed as it fell, gave the whole prairie the semblance of being no longer of earth, but happy hunting grounds lit up by the shadow of God.

In this dreamy, golden air, things could be seen nearly as distinct as in the blaze of noon-tide, only everything 
would have a weird-like appearance. The groves would seem no longer dark-green masses of foliage, but floating in the distance, as if the topaz-colored clouds had descended from heaven and were resting on a sea of amber, into which emptied rivers of molton gold.

I will not tire you with my dreamings on the prairie, but give you some solid reasons for preferring the rich soil of Iowa to that of any other Northern State, as a place to breed fine trotting horses.

The surface of Iowa is generally rolling, in some places it might be termed hilly, which not only insures proper drainage, but the difference of level permitting the subterraneous reservoirs to break out in springs,- - the most convenient way of obtaining a supply of pure water. A rolling surface is also better for the production of the finer varieties of grasses, which hardly ever grow on an extended level. These are not the only advantages. Horses bred on the fens of Lincolnshire, and other countries similar to them, have large flat feet with thin horn, their bones are porous, and the carcass too heavy for the legs. The dry soil gives the reverse - well-shaped feet, with the horn smooth, tough and elastic, the bones dense as ivory, and the muscles, all being called in service running up and down the hills, well developed.

Though nearly all the very fast horses eventually find their way to New York, there are other markets where remunerative prices are given for those of every grade.

Chicago is conveniently reached,--that wonderful place that has grown upon the marshy shore of the lake so rapidly, that men now living, of middle age, have hunted wolves and shot ducks where now stately edifices reach for miles. The marble walls of the magnificent Operahouse enclose ground where, forty years ago, the fringed alder sheltered the nest of the aquatic fowl. Chicago, however, will merit more attention than can be given 
now. When we get our horses ready, I must insist on your accompanying me to the races at that place, where I will insure you a hearty welcome from the losts of admirers the fast horse has there; when you will "see sights" that no city on the face of the globe can equal.

The river that almost washes the eastern line of the stud farm, furnishes the easiest and safest method of transporting horses, and it does not require a map to remember the grand towns lying along its shores. St. Louis, the "King City" of the West, with its miles of levee and hundreds of steamboats ; Memphis, New Orleans, \&c., \&c. But as all these places have been marked to be visited during the fall and winter campaign, I will say nothing at present about them; and as our stipulated nooning is now ended, I am anxious to show you the juvenile division now awaiting your scrutiny at the barn.

Preceptor.-I shall certainly take great pleasure in making the trip you contemplate, if your horses turn out good enough to travel with. All my ideas are associated with the Atlantic seaboard, and it will be a novelty to see the portion you extol so highly; and though I can see nothing that will overbalance the benefits easily obtained here, will look with a favorable eye on the country where you have located your home. I remember, many years ago, falling in with an old sallow-faced woman who had just returned from the West. She summed up a not very flattering description of the country with the remark, that "it was an amazin' fine country for men and dogs, but an onkimmon hard one for wimmin and horses." 


\section{CHAPTE VI.}

THE COLTS-TRAINING TRACKS-ABOUT HORSES BREAKINGPEDIGREE AND DESCRIPTION OF KING.

PuprL.-Boys, bring out the colts. We will have them all out at once where you can take a general view; and withøut wishing to appear egotistical in praising my own stock, must say they are of better appearance than a majority of trotters. They are all half bred, and some of them have as pure a pedigree, if not as fashionable, as either Asteroid or Kentucky. This one may have seen too many summers to be fairly termed a colt. In fact, the question of "can a filly have a foal?" once propounded by "a young turfman," can be settled in her case, as she was a mother before shedding all of her milkteeth. This circumstance prevented her being trained, and with the exception of a little work when three years old, she is not much better acquainted with how to handle herself in a trot than the others, several years younger.

As I previously remarked, I will be obliged if you will assist me in naming the neophytes, though I have done so usually on the spur of the moment, not expecting they would always wear their titles. But as with the young aspirants in chivalry, the names would answer till they had shown by their devoirs that they were worthy the fitting ornaments of golden spurs and a distinctive rame. On a beautiful morning the first of May, I found this mare standing by her mother. The bright natal morning suggested a name of itself, and May-Flower, Queen of the May, May- 
Queen, May-Day, all presented themselves. The last was finally settled on, abbreviated to simply May. She was the first of the Falcon's get, and I had awaited with a great deal of anxiety to see how his first-born would appear. She was a crooked, big-jointed foal, with the head and eye of a gazelle, and I need not add, pleased me, though many called her too long in the pasterns, and a homely, ill-shaped brute every way.

Preceptor.-This is truly a very fine lot of colts, and I do not wonder you take pride in showing them. Had I not been better informed, I would have taken them for a stable of stake colts, and would have expected to see the paraphernalia of racing hung up in their stalls. No one would ever have thought from the appearance of this mare that she had performed the fond and pleasing duties of maternity.

She certainly is no discredit to her sire, though she falls greatly below him in perfection of form. Her forehand is superb, but the loin lacks in strength, her ragged hips making it look worse than it really is. The worst fault $I$ see is her hind legs below the hock: they are a trifle cut away, and have not the set that quite pleases me. They are a little too crooked, and too much after the pattern called "cow hocked." The hock itself is good, which also can be said of the canon, pastern and foot.

I shall be agreeably disappointed if we do not need the protection of boots on these crooked shanks. As to her name, "handsome is as handsome does," and we will let her keep her appropriate title till we think her worthy of a better. The name itself is good enough, and I would not suggest a change had it not been given to several before her lay.

PupiL. - You came very near the truth, thinking this animal would need some protection. In the little $\mathrm{I}$ have 
driven her she has troubled me by cutting between the hoof and pastern joint. I ascribed it to breaking on a half-mile that had four rather sharp quarter-circles for tuzns. When going round these she would sidle against the near shaft, trotting as you frequently see a dog, placing the off hind foot between the fore-legs, being more inclined to do it when not at full speed. I have tried a variety of boots, but none seemed eflectual. I am convinced the sharp turns were the cause, as I drove her for a time on the road when she never brushed a hair.

This one next her is also by the Falcon, her dam by a Morgan horse, her grand-dam an Ohio mare with some pretensions to breeding. You will not be able to discern any of the Morgan taint in her appearance, the purer stream having quite obliterated the mongrel. She skims over the ground so easily, and with so little apparent effort that I have named her Hirondelle. Delle is her stable-appellation. She is very highly strung, but docile as a pet dog.

The only trouble she has occasioned me is her anxiety to overdo herself. When asked to trot fast she will rush at it as if she were emulating Flora Temple in her electrio flights of speed; of course, not having the same control of her limbs, the brush is only a short distance, when she goes with the same determination into a run, and a person not acquainted with her would be sure she was going to run away. A strong pull will keep her from breaking for a little while, but I was so fearful of getting more of these torments that I never would pull against her, hoping that time would correct the bad habit.

Preciptor.-This little brown is certainly a beauty, and a rare feather in the plume of Falcon. Her form is almost as faultless as his, although so widely different. The name is very good, though if I had owned her, she should have been called Fenclia, after the sprite who was so airy 
in her movements. You have acted judiciously in not tugging at her, as with her resolution she would have been desperate in her efforts to get rid of the torture of the bit. We will "bide our time" with her, and my word for it, she will well repay for the probation.

There is no doubt but the short turns of the half-mile track had a good deal to do in teaching May the provoking dog movement you speak of. These half-mile courses are the bane of many a good trotter, and unfit as they are for a horse that has acquired his gait, they are still worse to teach a colt that, as yet, does not know how to handle his feet. In making private training tracks, there is not much necessity for paying great attention to grading. So that the surface is smooth, the undulations may be beneficial, and the work that is generally put in a half-mile track would make one double the length. Neither is there any need of emulating the courses where mariy horses are expected to start in a raco; and if a man wel: $\Theta$ to offer to build me one for nothing, I would restrict it to a width so that there would only be room for two horses to trot abreast. The advantage of a narrow track is that you are compelled to teach your horses to recover from a. break without being swung over a width of forty feet. This capacity for catching the trot without deviating from a straight line, is of vital importance in a race, giving immense advantage over a horse accustomed to be snatched and yawed all over the track. On almost every farm fit for breeding purposes, there is ground sufficient to get a mile, provided the maker is not afraid of going up and down moderate elevations and depressions. It is immaterial about the distance being exactly the mile, and should be governed by and adapted to the configuration of the ground. The best form is to have the sides straight and parallel, connected by a semi-circle at the ends; the curve as easy as can bo got, the outside raised 
a good deal the highest. The soil that would suit me best for a training track would be a sandy loam, free from stones and gravel.

PupIL.-Wait till you visit the glorious West, when I will show you the soil, of all others, best adapted for a track. I will defer my description of it till we come to making the track on the place where I am turning the thorough-bred into trotters. The slight antipathy you have to the experiment, I hope will be done away with as you become better acquainted with these colts and their performances before the summer is ended. This filly is by Endorser, dam by Boston. She ran very creditably when two years old, and has now just been broken to harness. She shows a trotting step that is a good deal like the one described in the old English song:

"Come, I ride as good a trotting horse as any in the town,

Trot you sixteen miles within the hour, I'll lay you fifty pounds,

He gathers up his knees so smart, and tucks his haunches in," \&c.

She is as handsome as Delle, and has the advantage of being a color that is much more showy. It is rare indeed, common as chestnut horses are, to find one of this bright golden color that looks like sun-painting, the gor-

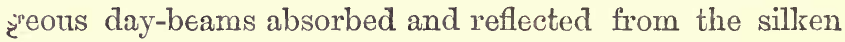
hair. The two white hind legs, and the broad stripe running so truly down the face, relieve and make the brilliant color still more to be admired.

Before leaving home I was showing her to a friend, who takes great delight in driving the finest and fastest trotters, - and, by the way, is the one who gave me the cigars you pronounce so good,-remarking to him what he would consider her worth if she could trot in " thirty." His answer was, if he owned her, and she could trot in that time, or a little faster, there was no man in the United States rich enough to buy her. He had often argued with we on the uselessness of the race horse, but he had to 
admit that, for beauty of form and the high quality exhibited by this filly, it was necdless to look for them in any other family. My asking your aid in naming these colts you will thinls like an invitation to dinner the day after the event, all of them being already known by some title, yet as they have never figured in record or story, I will be glad to change them, should you oblige me by offering anything fitter. I call her Mavourneen.

Preciptor. - A very appropriate and significant name for this young beauty-a type of equine harmony, as you truly remarked, only found in the thoroughbred, with ten generations of pure blood flowing in its veins.

She appears as conscious of her noble ancestry as the tartaned chieftain, whose pedigree runs back to the days of Fingal, and who stalks over the heath of his native mountain, as if all the heroic deeds of his illustrious progenitors were within his own reach, and could be outdone by the strength of his arm and valor of his heart, requiring only another Ossian to sing him to glory.

Should this filly's temper be in keeping; with her form, the name will be still more suitable, and she will then be our darling.

PupIL.-This is another coit of the Falcon's. Her four white feet and blazed face induced me to call her Oriole, and certainly no animal was ever more fancifully marked. The old prejudice against "four white feet and a white nose" has been so effectually done away with by some of the most noted horses, that I am not afraid to admit my fondness for it, when so beautifully penciled, as is the case with this filly. When Lexington run his match against the famed Sallie Waters, some would-be wit shouted to take him off the track, quoting the old couplet. He took off the track many a dollar which the mare's backer's so livishly loaded her with at a hundred to fifty. I saw him in the show-ring at the St. Louis Fair in 1859, and have 
lately had the pleasure of reading a piece of poetry to commemorate that event. The perusal of that pleased me, finding I was not the only one who had been struck with the grandeur of his appearance, heightened by the darkened orbs, which was the only reason given for investing an inferior, though still noble, animal with the blue ribbon. His groom tried to lead him in alone, but he dashed about so wildly among the trees outside the amphitheatre, that the restraining force of two stalwart men was necessary to keep him from injuring himself; and when the multitude greeted his appearance with tumultuous shouts and frantic clapping of hands, he stood a moment immovable, every muscle quivering with energy, his glossy coat glistening in the sunlight, flecked with spots of white foam; the swelling veins appearing as if they would break through the thin covering which hid neither them nor the tension of the muscles, now rigid as steel bars. It was hardly for the space of a second he thus stood, striving against the loss of vision as if he would strain the useless eye-balls out of their sockets, when he bounded as though the trumpet had sounded to start him in another victorious race. These shouts to him were familiar, as they had before reverberated on his ear on the springy Metairie or Classical Association grounds at Lexington, and he could only associate them with victories won, knowing the power was still in his sinewy limbs to repeat the feat. The darkened veil hid that vast assemblage from his sight, but as the garlands of bright flowers woven by the fair fingers of the daughters of the sunny South were placed on his neck, and chaplets of every hue graced his brow, he became quieter, as if aware it was the guerdon due his former prowess. He strode out of the ring with elastic step, his unrivalled pasterns enabling him to walk as gracefully as though he could see the way. 
This filly's dam I knew nothing about, she having been found astray on the large bottom at the junction of a river with the Mississippi. As you will perceive, her form is good, though her temper is more sluggish than any other of her sire's get. When first harnessed, she seemed to know just what was wanted of her; and anxious to obey, she takes very naturally to trotting, possessing a right handy step; but when forced to go faster, will roll and hitch, trying her best to go as fast as wanted, before she leaves her feet.

Preceptor.-I would not be surprised if this strongly made, quiet filly, made the fastest or rather the most reliable trotter in the string. From her general appearance she has undoubtedly plenty of resolution when aroused. Her docility of temper is a great assistance already gained, as those that are as nervous as Delle and Mavourneen require very careful usage to overcome its bad effects. You must be careful not to spoil the naturally handy step by forcing her to what you yet cannot expect her to do. A good breaker is a great advantage in a race when you can force him along at the topmost rate without being fearful of the consequences of leaving his feet, which if he does is no detriment. But we all know how trying it is for the judges to withstand the clamor of, "See him run;" "He gained every time he broke;" "Set him back according to rule, and he will not win the heat." I am well aware that very few, even among the good breakers, gain anything by breaking, if the drivers do their duty by endeavoring to eatch them at once. Yet it is a matter of great annoyance to owners, and judges as well as drivers, to listen to the complaints of those who, having at the outside five dollars invested in the race, make more noise and disturbance than others losing thousands. I therefore always try to teach my horses not to break, but to depend on a steady, constant trot, that will carry them 
to their more ambilious rivals before they get down the home stretch. This filly, if judiciously driven, will never know anything about breaking, and time must be taken with her as well as the headstrong Delle, so that she will not roll and hitch bebind,-a gait easier acquired than forgotten. As to the christening, it is easier to find fault with a thing than to mend it. I suppose, as you say, the white and black coat gave you the idea of Oriole, as well as keeping up the ornithological names in the family. Not being familiar with a science that delighted Wilson and Audubon, I cannot say how appropriate it is. She is marked more like a bobolink than any other bird with which I am acquainted, but that name would not sound as smoothly as the one she wears. The next colt is rather a differcnt looking customer from the rest; he has not shed his coat yet, and is very thin. Quite a difference from the others, who are so plump and well fed. You must have picked him up where feed was scarce.

PupIL.-This rough-coated, starved looking three-yearold is, after the Falcon, my chief favorite, and in place of picking him up at some cross road, I watched for his appearance into this world with as much anxiely as the lover does for the approach of his mistress. When his mother was bred to the Falcon, I made up my mind that the product would not only be A No. 1, but would be a practical exemplification of the theory I have advanced for many a year. She is a bay mare, of rather more than the average size, say $15 \frac{3}{4}$ hands, and is very high form. Her sire was Alex. Churchill, a horse that had a high reputation in Kentucky, and well he might, having run a four-mile heat in 7:41-with one exception, the best time ever made there up to this day. He was by imported Zinganee, dam by Bertrand. The mare's dam was by Cherokee; her grand-dam a mare that always threw a winner. This pedigree shows her to have several crosses of Sir Archy; 
and as the Falcon also runs back to the same distinguished source, through Lady Lightfoot, Henry, Bacchus and young Janus. She was a race nag of no ordinary capacity, beating, among others, Little Flea, Lithgow and Diamond. Her trotting step is very fine, swinging off with such a loose, open gait that only needs cultivation to make fast. When this fellow eventually made his début, my anxiety was put at rest so far as shape was concerned. There never was a better made foal dropped. It being my usual custom to handle the foal from the very outset, I made my approach cautiously, but never deer or untamed stag was more frightened than he. He rushed at the sides of the box as though he would break them down. Thinking, if once cornered and caught, he would be likely to forget his great fright, I got hold of him and sincerely believe if I had held him ten minutes his heart would have burst. His efforts were as frantic as the struggles of a madman, and after releasing him his heart beat so violently, that it shook his frame. As he grew older he becarne worse, and if a person went into the stall, no matter how cautiously, his excitement was intense. When the mare was turned out to pasture, he would not mingle with the other colts, and if he chose to play, it was always by himself. When his mother was brought up to feed, he stalked majestically in the rear, every motion showing that he was fearful of falling into an ambush, and was on the alert to prevent it. His dam proved a poor suckler, and though bruised oats and carrots were fed her, she would not even nibble at the tempting food. That fall he was thin in flesh, but rather above the ordinary size, and as the mare was not in foal, I determined to let him suck through the winter. The box was roomy, and, after he became familiarized with living there, I placed a feed box out of the reach of the mare, and fixed her own too high for him to reach it. He would 
never touch the food if he thought he was observed, and I have watched him from a position where I knew he could not see me, but never during the whole winter detected him feeding. The mess that was put in the box would be gone by morning; and the amount increased till be was eating as much or more than any colt on the place, though he still kept poor. The following summer was much the same; he keeping up his dignity by never joining the other colts, feeding alongside his mother; when she went among the other mares, he kept aloof, as if there was degradation in the association. That winter he had the box to himself, but no change took place in either his appearance or habits.

Towards spring, I made up my mind to halter-break him, and taking advantage of a deep fall of snow, so that he would be less likely to injure himself, I had to get the assistance of two men to get the halter on him. We thought it the best way to Rareyize, or rather, to place the merit where it belongs, follow Dennis Offut's plan, but here was a case where it was apparent it would not do. When laid down, after the most tremendous struggle I ever witnessed, you could see he would never succumb till life was extinct. Every muscle was swollen, the eyes bloodshot, and his whole appearance like a horse suffering with lockja's. I undid the straps, put a long rope on the halter, determined that if he cnuld not be broken without these much vaunted appliances he should remain as he was. He sprung away as far as the rope would allow, and when found he could get no further, he commenced walking in a circle, his eye never for an instant neglecting to watch my movements.

I continued this treatment from day to day, until he would follow, but always at the extreme length of the rope. Spring-time came, and I was away from home till July. It was not thought safe to allow him to run in the 
tield, so he was confined to a small paddock, and fed all the grain and hay he would eat: When I came home, I led him out with the long rein, and he would pick the clover blades if you kept at a proper distance, but as yet would not suffer the least approach to familiarity. Now he has so far relaxed his vigilance that you can place your hand on his neck, but any further advances are repelled with a resentment that is determination itself. The long journey in the cars has proved beneficial in partially subduing this refractory temper. The novelty of the situation has given him some new ideas which I hope can be taken advantage of. While in the cars he would suffer a surcingle to be laid on his back, a proceeding which would have made him frantic at home. I am convinced that it is neither timidity nor fear, as he never even started at the approach of the locomotive, and preserved his equanimity on the most trying occasions. I am well satisfied that, when once broken, he will be reliable, and the very qualities that have troubled me so much will prove of vast benefit when placed under proper control. One great argument advanced against the thoroughbred is their irritability and high temper. That they possess the last qualification, I am ready to admit, and without it, would not be of the same value. Their vices and irrascibility have, in ninety-nine cases in a hundred, resulted from improper breaking. I have full faith we ean teach this colt what we want him to learn, and have brought him along, as I would not trust him in other hands. My youngest little girl dubbed him "King of the Ghosts," and when asked the reasons for naming him, said he would not play with the other colts, and looked just as the horse did that was buried under the big cottonwood tree; that the fairies must certainly have brought him, as he neither looked or acted like a human horse, being determined that mortal straps or harness should never interfere with his free mo- 
tions. We have retained the King part, and I am not without hopes that "of trotters" may yet be added. I have now paraded all the inmates of the trial stable, and, if the description has been tedious, you may congratulate yourself like tlre man just recovered from the small-pox, that although he was badly scarred and seamed he would not have to go through with it again.

Preceptor.-I do not say from courtesy alone that your descriptions have not wearied me. Your enthusiasm in all that pertains to the horse, even your fervid admiration of the blood horse, that leads you to such a length that some of your positions will be untenable, please me. When we have leisure time, as we sit on the verandah and smoke, you must continue your history of the Iowa farm. As for this young scion of nobility, I have been examining him more closely while you were recounting his history, and find him a very different animal from what my first impression was. There is certainly no flesh in the way to hide the study of the osseous structure. He will never equal his sire in justness of proportion, though he has more of his peculiar build than any of the rest of the colts. I will not offer a word of advice as to breaking him: convinced that your experience in that line has been greater than mine. I will look on with interest, as he is undoubtedly as hard a customer as could be found; and if you succeed in making him "gentle and reliable," there is nothing in the way of making him a trotter.

I must now bid you good-bye, having business in town. By the time the horses have had their morning walk I will be here, when we will take the Falcon, Never Mind, and Jane, to the shop, and have shoes put on that will do for them to commence work in.

Have the boys wet some tow and place in their feet to soften the horn, and only walk them an hour. 


\section{CHAPTER VII.}

WALKING AND SHOEING.

PrecEPTOR.-Good morning, scholar. Providence has again blessed us with another fine morning,- -so fine that my heart responds with gratitude to the Great Father for the many beautiful mornings he has permitted us to enjoy. This "sweet habit of existence" is doubly sweet when the merry month of May proves so lovely. I have thought the English poets have given it too much prominence over the month of June. There is probably a difference in their climate that gives it the precedence, or they would not have been so unanimous in their expressions of fondness. One of the grandest of that grand body thus apostrophises it :-

"For thee, sweet month, the groves green liveries wear, If not the first, the fairest of the year;

For thee the graces lead the dancing hours, And Nature's ready pencil paints the flowers."

PupIL.-I shall certainly coincide with you in preferring June to May, in our northern latitudes ; but the air is as balmy and fragrant this morning as could be wished, and the budding flowers and springing leaves are greatly to be admired. The remembrance of the stinging blasts of winter is yet fresh in our memory, and the contrast heightens the enjoyment. In England, the spring opening earlier than here, May has usurped all of the praises due its flowery reign. Ancient customs have marked this month as proper for the return of gaiety, partially suspended during the dreary period of winter. The Christmas fes- 
tivities partake of a religious character; but now Venus and Flora are the presiding deities, when young hearts pay their orisons at the shrine of the first and seek the aid of the latter to be more refined and tasteful in the display of their devotions. To continue your quotation from "Glorious John :"-

“The sprightly May commands our youth to keep The vigils of their night, and breaks their sleep: Each gentle breast with kindly warmth she movesInspires new flames, revives extinguished loves."

One great advantage we possess in our climate is, that there is no time of the year that a reasonable man can well find fault with. Foggy November is one of the mosi enjoyable months in the year-at least in the West,-and, in fact, the biting cold of the winter is only for a few days at a time ; in the intervening portions, the air gives a zest to the sleigh-ride, mantling the cheek of beauty with roses that outdo those of the growth of this genial month.

We have followed your directions, and the horses are now ready to start for the blacksmith shop. If it is a distance that will be inconvenient to wall, we will harness Falcon to the road wagon.

Preceptor. - It is only a short mile from here, and the walk will do us as much good as the horses. The walk will also enable me to give you my ideas in regard to that exercise. When in my boyhood's days I was with the stable of race horses, all the exercises were more protracted than at present, more especially the walk. One trainer I was acquainted with hardly gave his horses time to eat or sleep, but kept up a continual round of exercise from early in the morning till sundown. I have frequently seen his horses in such a state of exhaustion from this continuous labor, that they could not run a mile in 2:05. He was quite successful, however, notwithstanding this bad treatment. A week or ten days before they had to run in a 
race, he would throw them up, giving only short gallops and very little walk, thus bringing their foot back without enough time elapsing to accumulate inside fat. It was a perilous system to follow. I knew several to attempi it, and the result to them was always failure. He knew just how far to go, and when to ease them before their powers were to be tested in a race. I have seen one of his horses, after having concluded the work marked out for him to do, neigh before leaving the track. Another mile or two, with sharp work in the stretches, was sure to be the sentence,- - this display of exuberant animal feelings being always certain to be followed by extended work till the time came for the cessation.

The general custom then was to walk three times a day, no matter what the animal was. The gallops would be varied according to the different requirements of the horses; but it never entered the trainer's head that the slower gait needed variations on account of difference in temperament or form-the flighty, narrow-waisted, delicate feeder getting just as much as the sluggish, heavy made, phlegmatic individual, that took everything as quietly as if he had no care or ambition to do more than he * was absolutely compelled. Races, either running or trotting, are short periods of violent exertion, when every muscle is called upon to perform to its utmost endeavor. The training, then, is to enable the animal to accomplish this as easily as possible.

In ancient times, Hercules and Mercury were associated as patrons of the Olympic games to show that force must be accompanied by address. Our aim, then, should be to balance force and address so that their proportions will harmonize, and while we increase the strength, be cautious to employ means that will not interfere with agility. Walking has a great part to perform in fitting a horso for rapid locomotion. 
Should all the exercise be at a fast pace, the machine would soon fly to pieces. There can be no rule laid down to say how much of this exercise must be given; as the requirements for different constitutions will vary nore than is generally thought. The practice most followed is to send the horses all out at once, and bring them in at the same time, which is certainly erroneous. I have often asked trainers, why they walked their horses; and nine out of ten could give no reasons, only that such had been the custom. The walk, if not carried too far, gives suppleness to the muscles, increases the appetite by giving tone to the stomach, furnishes pure air to the lungs, so that the blood is thoroughly oxygenated and the nerve force augmented in a way that I cannot explain, but which is evident in the general increase of health. If the exercise is too much prolonged, the ligaments are strained and lose their elasticity. The sensitive membrane is inflamed that covers them, and the joints are injured by the continual strain. The monotony of the walk must be overcome by changing the ground so often that the horses may be relieved by seeing different objects to attract their attention. The custom of clothing a horse heavily during these diurnal rounds I also think is wrong, and in my practice I have discontinued it. 'I cannot understand why it should be beneficial, and have often asked those who follow it to explain the advantages. This has never been done satisfactorily to me. Some say that it hardens the flesh. This is much better done by exercise. Others, that the horse must be protected from taking cold. If it is necessary to wear a heavy blanket, thick kersey cover and hood to do this, I am much mistaken, and think the fancied prevention only causes the animal to become more delicate. Men who clothe in the stable according to the exigencies of the weather never think of changing the walking garments so long as perspiration is not induced. 
The disadvantages are, that, when it becomes necessary to sweat a horse, the number of blankets required is in an increased ratio to what he has worn in the stable and while walking, the system having adapted itself to this artificial covering, like men who wear their winter habits throughout the summer, professing no more inconvenience than those who resort to linen and nankeen.

How beautifully Nature works for the welfare of her children, is exemplified in the care with which she changes the horse's covering, to suit the changes of temperature. The thin coat of summer is shed in the fall, to give place to one that is more of a protection again st the inclement air. With the advance of spring there is another change, and when the hot summer days come, a third molting takes place, and the thinnest of covers is all that is granted.

My remarks have been applicable only to the walk, as a means of exercise, previous to commencing faster work. When the pace is quickened, and the walks are necessarily shortened in the morning, even in some cases done away with, we will discuss while the horses are actually engaged, and we can note the effect. The walk, then, has a still more important duty to perform, viz :- obviating the danger attending "cooling off." Having now arrived at the smithy, we will proceed to the business in hand. If you have studied the works of the various writers on shoeing, you will perceive I follow an entirely different plan from any they have recommended. I do not want you to take my dictum as gospel, and will give you the reasons I have for shoeing horses after my plan. It was formerly my custom to have the shoes for the front feet made flat and wide on the ground surface, with a small steel calk in at the toe to prevent wear. The web of the shoe was tapered from the toe to the heel, and the fuller or crease cut deeply, so that the heads of the nails would be on a level with the 
surface. The inner part had a flat bearing of about half an inch in width for the nail to rest on, then made concave, so that there would be room between it and the sole to introduce a picker, and that the sole in its descent might not be bruised. The shoe being properly fitted, was fastened to the hoof with nails driven about the center of the crust, the points "getting a good hold" by coming out about an inch above the shoe. The hind shoes were made narrower and lighter, with both heel and toe calks. The plan I now follow, is, to have the fore shoes swedged with a tool that leaves a rim all around the shoe of three-eighths of an inch at the base, coming to a dull edge at the apex, being about the same depth as it is wide. The remaining part of the web is concaved on the inside, and on the outside the crease is cut where the web and rim join, with an inward inclination. The nails are driven from the inside of the crust in place of the middle, with a slope that will bring them out half an inch above the shoe. The reasons for adopting this system of nailing are, that, as the hoof is composed of a great number of thin plates or laminx overlaying each other-the fibers running up and down the foot-when a nail is driven in the center, it has a tendency to divide the layers, and either split them asunder or cause an undue pressure when driven higher than the insensible sole. By starting the nails from the inside of the crust and taking more of a horizontal direction, the laminæ are not divided, but perforated, giving a far better hold for the nail, with no danger of either wounding the sensitive parts or pressing on them to cause pain. When the nail is driven through, the point is twisted off, and in lieu of taking the rasp and filing an ugly crease that weakens the hoof by destroying the enamel, a very small gouge merely removes enough of the horn to hide the clinch riveted with a punch, and of course, entirely out of the way of 
doing injury. The clinches "cannot raise," as the heads of the nails are completely protected by the swedged rim. There is a small clip at the toe with the additional security of a nail driven in that strongest part of the foot; three nails on each side giving ample assurance that it cannot be displaced. These nails only go back as far as the widest part of the foot, leaving the quarters unobstructed in their motion. The hind shoes differ in being a great deal lighter, and in place of the swedged rim are so concave that they have an angle or bend of about fortyfive degrees. The crease is cut in the rim, and when the nails are driven they are filed away till the whole shoe is left so smooth that if even a horse "grabs," it slips off the quarter without doing an injury. The back part of the web of the hind shoe is what gives the wound when a horse cuts his quarters, and when turned over the horn of the anvil-as is the customary plan-is almost as sharp as a knife. You can satisfy yourself that this is the part of the shoe that does the mischief, by observing the wound, which is always triangular, the point being the place where first struck, and the flap or torn skin falling back and attached at the lower end or base of the triangle. But still the most conclusive proof is, that with the shoe made as I have described, with no toe call, sharp web or nail heads, there never will be a wound. The quarter may be bruised by a blow from the iron, but even that will be mitigated by the smooth surface. There are, of course, horses that could not be shod in this way, from their feet being diseased or defective-some requiring round or bar shoes, others with a gutta-percha or leathern sole, and still others with a great part of the horn and shoe cut away to guard against the result of faulty action arising from wrong shape, \&c., \&c.

A natural, healthy foot is the one I am now directing to be shod, so as to do the work in the best manner re- 
quired, and keep it in its normal condition. Those who still stick to the first shoe I described will say that it is the only one for a trotter, without deigning to give any reason why it is so. The advantages I claim for the continuous rim or calk, are, that it is more like the natural unshod foot, bringing the support where it is required, directly under the wall; that it gives a firmer hold of the ground, enabling the animal to retain every inch he progresses, and adds to the confidence he has of not slipping, so that he strikes out boldly to the limit of his stride. Should the track be very hard, there is less concussion than where there is an inch and a half of flat metal to meet it. Should it be inclined to cup or give, the concavity gives a far better traction than the flat, with less tendency to "pick up." In the mud, no one will deny its advantages over the customary way of placing the points only at the heel and toe. In preparing the foot to receive this shoe, I may still be thought singular. I will give my reasons, and until some one converts me to another plan, by force of argument, I shall continue in my own without the fear of ridicule, which has no better logic than a laugh to carry its point. I suffer no part of the foot to be pared, only the wall, and that is cut till it rests on the floor in a natural manner. Great care must be taken that the proper amount be cut from toe and heel to effect this. I think the general error is in allowing the heels to be too high. When it has been cut with the rasp and knife, a smooth file finishes the preparation, so that there are no inequalities to keep the shoe from touching every place. When nailed on, the shoes must come exactly to the edge of the hoof, in no case projecting the least beyond it. If this fitting has been properly done, there need be no rasping or filing the horn to injure the outward coating and destroy the elasticity of the hoof.

The sole is left just as nature made it, and we will try 
and keep it. It has a rugged appearance that will mortify the blacksmith, but will retain the moisture better than any stopping, and when the surplus portion needs removal, will exfoliate before it comes in the way. Many blacksmiths will need watching, in their anxiety to do a finished job, which consists in paring away sole and frog, opening the fissures between the bars and frog, and rasping the outside of the horn to within an inch of the hair. The natural mechanism of the horse's foot is beautiful. His domestication requiring of him artificial duties necessitates artificial aid. How much it ought to be our study to ameliorate the ills forced on him, and make the willing servitude, as much as lies in our power, a pleasure! In no way can there be so much unnecessary suffering relieved as by attention to shoeing. Any one who will take his station for an hour on the crowded streets of a city will be convinced of this. How rarely do you see a horse stepping out with the free, grand motion, resulting from sound feet and limbs. They come hobbling by, some of them with dauntless spirit, enduring torture, partially hidden by a jaunty air, that would make the most heroic biped grate his teeth with pain.

"Never Mind" we will have shod with a shoe weighing about twelve ounces. From the description you give of his manner of going, he has, probably, rather an excess of knee action, and by putting on rather a light shoo we will remedy it. His hind shoe should not weigh over a third as much; and to guard against getting on his quartors, we will have them made as I described, and set a short distance back from the toe, which must project over the shoe about half an inch.

Bad driving, as I said before, has as much to do with horses striking their quarters as anything else. When a horse breaks and is jerked from one side of the track to the other with all the strength a man possesses, there is a 
great danger of his hitting somewhere ; and it is fortunate if it is the quarter instead of the knee. When to this snatching is added a short martingale, the tendency to hit is still greater. The head being pulled close to the breast, the horse has no freedom of action left; and I have known horses hit themselves between the knee and pastern when thus tangled.

The Falcon shall wear what I term a medium weight for an ordinary sized foot, viz: each fore shoe weighing a pound. I have always found an advantage in making the hind shoe very light. The hind legs are the propelling power, throwing the body forward, while the fore legs support it and are merely rolled out of the way. In order that they may do this, the knee requires to be well doubled, to ensure a proper length of stride corresponding to the force of propulsion of the hind legs. The hind feet, however, cannot be carried too close to the ground, as there is less expenditure of strength than when raised higher. The light shoe, therefore, interferes less with this skimming motion than one heavier. That a few ounces' difference in weight of the shoe of so powerful an animal as the horse should make so much difference in the speed, can only be accounted for by the change in the action of the animal. Turfmen will tell you that there is from three to four seconds in time between shoes and plates in running a mile. The one set will weigh say forty ounces, the other ten. This small decrease of weight, though placed where it exerts the most influence, can never be sufficient reason for making fifty yards' difference in a mile.

To carry this argument still further, with an illustration that is to the point: a trotter can go faster with the shoe as usually worn, than if plated, like the race horse. So the disadvantage of increase of weight is more than 
counterbalanced by the action being better calculated for rapidity of trotting.

Jane we will have shod a little heavier, adding a couple of ounces to each shoe. If I thought she had hit her knee from her own fault, I would put the two ounces on the outside of the shoe. But as I am satisfied the injury arose from bad handling, we will make the shoes to balance. It is reduced to a certainty with me that a horse's way of going can be greatly modified by an unequal shoe. I had one horse that hit himself violently on the shin with the outside of the forefoot, and on weighting the shoe he escaped the blow on the shin, but did what was worse, hit his knee. While Jane is working slow, we must try to reduce the enlargement, and bring: the knee to the natural size. To effect this, we will irritate the cuticle with oil of cedar, and then apply mercurial ointment, or some preparation of iodine. I have been very successful with this mode of treatment.

In case of a recent injury to the knee, a very different course would have to be followed, by placing the feet in a tub, and giving a thorough bathing with hot bran tea, applying it for an hour or longer, then swathing with flannel bandages wet with the tincture of arnica, reduced by adding three parts of water to one of tincture. Should the infiammatory symptoms not be abated the next day, apply pounded ice, to be followed by a strong decoction of mullein leaves-of course, dispensing with all fast work, lessening the feed considerably, and giving acidulated dirink. If at a season of the year when grass or green corn blades can be got, give a plentiful supply of them, with a bran mash not too often. I am in favor of giving green food more than mashes, and will give you my reasons for the preference at a future time.

We can leave this blacksmith safoly, as I will warrant him to do the shoeing as directed; so we will walk back 
to the stable and see to the arrangement of things there. Much work can be saved by having a place for the "traps," and making an imperative rule that each article shall be returned where it belongs.

PuPIL.-To say that I have listened with attention, while you have been talking of the walking and shoeing, would be a poor return for the information I have received in so short a space. The ideas are nearly all new to me, but I can give no reason why they should not be followed. I have had an illustration of the danger of driving nails too high in the horn, even when there was no direct injury to the sensitive parts when first shod, and which resulted in the death of one of the finest animals I ever saw.

Early in the spring of 1863, I accompanied a gentleman to Kentucky for the purpose of purchasing a few colts. We got to Cincinnati at the time Mt. Sterling was captured by the Confederates, and, of course, there was great excitement all along the line of the Lexington and Covington Railroad. Paris was supposed to be the next point of attack, and the railroad officials debated some time before they would send out a train, finally concluding to do so. By this conveyance we reached Lexington, and spent a short time there, looking at the stock of Jno. M. Clay, and others in the vicinity. There were Lodi, Kentucky, and many other fine specimens of the blood horse; but, unfortunately, Mr. Clay was not at home, so that we could only admire the horses and everything about his well-kept establishment-to my mind, the most perfect of any we saw. We were kindly received, however, by his trainer, who showed us all in his department, and he certainly deserved the credit of having his horses well advanced in condition; and the arrangement of the training quarters was admirable. That morning we breakfasted with Mr. E. E. Eagle, who not only gave us a genuine Kentucky welcome, but accompanied us in our 
visit to the other places. When we left Mr. Clay's, we came back by the way of Ashland; and my enthusiastic admiration of the great man, whose home it had been, was gratified by seeing the place, so beautiful by nature, still further adorned by the plantations which he had superintended. But I must not be tempted to describe any of these places, as our walk is too short to admit of even a sketch of their beauties. We took the afternoon train to Spring Station, and I greatly enjoyed the twomile walk over the verdant blue grass sod to Woodburn. The next day was occupied in glancing at the stock on that vast domain; but there was so much of it, that the mind got confused by the number seen, and it was difficult to get a correct impression that could be retained by the memory without mixing up different animals together.

There were two, however, that struck my fancy more than any of the others : a bay colt, by Lexington, out of Nebula, the peerless Asteroid, and a bay colt by Knight of St. George, out of Miriam. They were both rated at the same price, and I finally settled on the son of the conqueror of the dragon. I will only describe him by saying he was the most finished specimen of horse-flesh I ever saw; powerfully made, yet showing quality of the highest character. I have a print, copied from Herring, Sen., of Beeswing ; I have admired it as coming exactly to my idea of what a horse should be, and I often point it out to visitors as being a model, in my estimation, as it is in the opinion of those much more capable of judging. This colt's similarity of form to the picture was remarkable. Mr. Alexander sent us, in his carriage, to pay a visit to "Uncle Ned," where we were so agreeably entertained that the evening shades were falling ere we regained Woodburn. We found every one much excited, there being a report that Breckenridge was within six miles, 
with a large force under his command, conscripting all who came in his way. A gentleman from Ohio accompanied us on our way to Equiria, intending to take the cars at Spring Station; but they had passed laden with soldiers and artillery.

This looked as if the Federals were evacuating Lexington, and increased the excitement. Mr. Alexander kindly offered to send us in his carriage to Georgetown, where we could get a conveyance to Cincinnati; but I had fallen so completely in love with the colt, that I was determined to take him home, if I had to lead him through the woods to the Ohio river. At my urgent request, Mr. Alexander delayed sending us off till a boy could go to Midway and get a reliable report from the telegraphic operator at that place. He came back in a very short time with the news, that the Confederates were no nearer than Danville, some thirty miles distant. This relieved the party of their fears for their immediate safety, and led them to stay over night.

Mr. Alexander agreed to send some of his men with the horses purchased to Cincinnati, and in order that they might have an early start, the colts were brought up before daylight in the morning and shod. This was necessary, as the hard rock roads would have worn their feet to the quick, if they had not been protected. They got to the Queen City, looking jaded, but no other bad effects from the journey were visible. I accompanied them myself from Cincinnati to Chicago, talking the Air Line Road, -and I cannot pass further without remarking that the roads between these two cities are cursed with the most disobliging set of officials I ever had to endure in all my travels. The journey that ought to have been made in tnurty-six hours, at furthest, occupied five days. I was well prepared with hay, feed, blankets, \&c. ; and having the whole car for tinree colts-two two-year-olds and a 
yearling, had plenty of room. When we laid up, which was every night but one, and a great part of the day also, I could not prevail on the conductor to draw the car to the platform, where I could take the colts off to exercise; so, when not in motion, I turned them loose in the car. After the first night, they would lie down and rest as comfortably as if in a stable. The second day I discovered the Knight was lame in one of his hind legs. After the closest scrutiny, I could not tell where it was seated, and came to the conclusion it must be in the foot. $\mathrm{He}$ was in a good deal of pain, holding up the foot, or resting it on the toe.

Before I got to Chicago, the lameness was less apparent; and leading him from the cars to the stable, he went as sound as ever. I took the colts to the blacksmith shop, had all of the shoes pulled off, and after a good grooming, put them in roomy box stalls with comfortable beds, gave them a warm mash, and felt that they were well cared for.

When I woke up the next morning, it took me some moments to realize I was not on the railroad; but the luxurious hair mattress and the comfortable room at the hotel recalled me to a knowledge of the true situation. As I did not expect to continue my journey for a day or two, I was in no hurry to get up. The deprivation of all comfort for the last few days made my present position the more enjoyable, and I felt inclined to make the most of it.

I lay building air-castles in which the half-brother to Mammona and Magenta took a conspicuous place. He must be run till four or five years old, leaving the legitimate turf, crowned with bays, to gather fresh chaplets on the Union and Fashion Courses, the meed of victories won at the less graceful trot. My reveries were cut short by the ostler coming to my door and telling me one of 
the colts had the "belly-ache." Which one? I eagerly enquired. The pretty bay, was his answer. All three were bays, but I knew which he meant. I jumped out of bed, hurried on my clothes, and found my worst fears more than fulfilled. It needed but a glance to arrive at a correct diagnosis,-lock-jaw. I led him a few blocks to a veterinarian, who frankly told me that he had not one chance in a hundred to live. He applied chloroform till insensibility was induced. This was some relief, as, when lying under its influence, the pain of looking at him suffering so intensely was done away. All the man's skill availed not: he died.

The conclusion that forced itself on my mind was, that, in the hurry of shoeing by the dim light of a lamp, the nail was driven too near the quick; that the jarring of the car after journeying over the Macadamized road caused the lameness. The pulling the shoe off did still further injury. The nerve was wounded, resulting in the loss of an animal that would have been of incalculable sorvice to the stock of the section where I lived. Crossed on mares, the get of the Falcon, would have produced liotters to a certainty. His trotting step was as fine as siny colt bred expressly for that purpose ever had. His blood, form, and quality, being of so high a character, I despair of ever looking on his like again. 


\section{CHAPTER VIII.}

STABLE MANAGEMENT-GROOMING-SWEATING-BANDAGES--

CLOTHING-RULES FOR THE STABLE.

Preceptor. - That was a very unfortunate case, losing your colt, and I have no doubt the reason you give for the attack of tetanus is correct. If, when the shoe was pulled off, you had put the foot in a bucket of hot, strong ley, made with wood ashes, the fatal result would probably have been avoided. Horses take the lock-jaw without having been wounded. Yet, when it occurs without a wound, it is easier managed, and does not generally prove so serious.

The stable management of horses is of the greatest importance, and the strictest attention is required in order that their condition may be advanced, which all our skill will not effect if they are neglected there. I do not intend, at present, to give you a lecture on stable economy, but merely to assist you in having the stalls arranged so that the least work possible will be required to take care of the inmates. This stable is not what I imagine either of us would have built; still it can be arranged so that the horses may be very comfortable.

It was my intention to have given you a plan of a training stable that would meet my ideas; but as you have not yet erected one on the Iowa Farm, will await your description, and suggest such changes as may appear beneficial. Your nine horses we will divide into three classes, viz. : Falcon, May-Day, and Delle, will take the three stalls 
that are in one compartment; we will put them under the charge of one man, with a boy to assist in rubbing: legs, walking, \&c. The next division, in like quarters and with the same number of attendants, will be Never Mind, Jane, and Mavourneen; while we will expect one man to take charge of Clipper, Oriole, and King. The "old Virginia" plan in racing stables was to put a man and a boy to every horse; and I have seen the services of two men detailed to take care of one of our fastest trotters. In my opinion, so much help is unnecessary, and in some cases injurious. Grooming, as well as exercise, can be overdone. When the results aimed at are attained, what can be the profit of carrying it further? The benefits arising from grooming are cleanliness, and keeping up the circulation of blood to the extremities by the friction. The horse's skin is like the human, exudation removing impurities from the system, which, if confined, would do injury. The dandruff or scurf closing the pores has to be removed, and it is astonishing the difference in the appearance of the horse between having this duty performed thoroughly, and having it slighted.

A good groom is of great value, and, simple as the operation appears of cleaning a horse, there are very few adepts. The curry-comb in the hands of an artist is used only to keep the brush clean. A bungler rakes away with it against and across the hair, torturing the horse without affecting any good. The brush, if properly used, will effectually remove the scurf, while the wisp gives the polish to the hair, and removes the dust from the surface. Fast work, while it makes extra care necessary, decreases. the labor of keeping the horse clean, the frequency of perspiration loosening the dandruff, and lodging it on the outside, where its removal becomes less troublesome. It is very true that, in the commencement of training, this perspiration is of an oily nature, which, if suffered to dry, 
becomes sticky as wax, matting the hair together. This, however, when the stable is situated close to the track need never occur, the scraper taking it off before it is allowed to cool. There is one drawback to the benefit sweating confers in lessening the labor of grooming. The perspiration not only removes the dandruff, but also the oily matter that gives the gloss to the hair. A fresh secretion takes place, the wisping or rubbing stimulating the vessels and encouraging the flow. Should this be neglected, the hair has a harsh feel and a dry appearance, which, if it does not arise from a neglect of grooming, betokens a want of condition, the source of which will be - often difficult to discover. There are times when the labor of two men is required on one horse, when giving a sweal, a trial, or after $\approx$ race. We will arrange the days of sweating so that we can call in the help of our other classes, and the men mutually assisting each other, there will be no lack of help.

I spoke of grooming and rubbing being overdone. When horses are fussed over too much, the time they ought to be at rest is broken in upon, and more injury results from this than benefit from the extra care. The want of box stalls in this stable is partially compensated by there being plenty of room for three in each compartment, divided by partitions that are strongly put up. These partitions are deep, so that there is no danger, when a horse is lying down, of the hind legs getting beyond the heelpost. The feeding boxes are hung on staples driven into the wall, so that the box can be removed when the animal has eaten the feed. The hay we place on the floor, where it will all be picked up, and suits horses better than when put in a manger. The stalls are so wide that the horses can be dressed in them, and there is a space eight feet wide between the heel-post and the wall. The furniture consists of a cot bed for the man to sleep in, which can be 
doubled up and set by during the day. There are ropes stretched along the sides to hang blankets and clothing on; hooks screwed into the wall for the harness, each one having a hook. Bridles, surcingles, rubbing cloths, chamois skins, are hung where they can be conveniently reached. There is a cushion for skewers and a piece of flannel, the heads of the nails projecting that fasten it to the wall, on which we hang the bits, the flannel protecting them from the dampness. We will need quite a collection of bits, as you will find a great advantage in different forms for different horses; or the same horse will need a change to keep his mouth from getting sore; or you will find him working best to-day in a plain snaffle, perhaps next week showing his predilection for a bar or a snafile of another pattern. Lantern, muzzle, curry-combs, brushes, foot-picks, hair mittens, bandages, sponges, combs, scissors, soap, tincture of arnica, glycerine, rack for whips, are arranged where they will be least in the way, yet handy to get at; while we have on hand-hoping not to have to use them-knee, shin, and quarter boots, buckskin rolls, rattles, hand pieces, \&c. With forks, shovels, brooms, foot-tubs and baskets, we are pretty well supplied with necessaries, and as we have a feed-room and shed for the sulkies and wagons, we can find no fault with our present quarters, even if they could be bettered. One article must not be omitted: a good clock with an alarm, that will waken the most inveterate sleeper. This placed in the foreman's room will enable him to be up in the morning and regulate the feeding, which is very essential. Impress on the minds of your men certain rules, the violation of which will be followed by positive dismissal. The first and most important, uniform kindness to the horsesnever to strike or lick one under any circumstances; to cultivate a kind tone of voice, trying to obtain the affection of the animals; never exhibiting fear; $2302^{\circ}$ 
using profane or vulgar language; to put everything when done using it in its appropriate place ; to wipe the lits before hanging up, and rub the sweat off the harness; to follow implicity your directions, and, in your absence, those of the foreman; never to smoke in the stable, or lieep a light burning after the usual time ; drunkenness, or even "getting a little tight," to receive condign punishment, no matter if there are extenuating circumstance; to be neat in personal appearance and in the arrangement of the stable. Other minor regulations will present themselves.

To look for these qualifications in "rubbers" may be thought useless; but I never keep a man unless he possess them, and I am happy to state they are obtainable. To encourage young men who work for me, and raise their aspirations to fill their places well, is one of the chief aims in my intercourse with them. I furnish them with all the turf and horse literature that is worthy of being read, and not only find it to their advantage, but also a great furtherance of my own interests.

The spare time, of which they have a good deal, is thus profitably employed. They take pride in performing their duty well, and the information acquired from reading will never be obliterated or useless, whatever station in life they afterwards occupy.

PupIL. - The first man who drove the Falcon taught him another bad trick, which your remarks on grooming bring freshly to my mind. He would tie his head up with a rein on each side of the bit, elevating it into a very uncomfortable position, and handling the curry-comb, as you remarked, to give the most pain, when he came to where the hair was the thinnest, he would bear on with additional force and energy of movement, driving the horse nearly frantic, who would cringe almost to the floor, and lash out his hind feet in a desperate manner, requiring a 
good deal of agility on the part of his tormentor to keep out of his reach. The stable where he was kept was in a small village, and there was usually quite a crowd to see the horses exercising and watch the movements in the stable. I believe this man thought it heightened his consequence to be seen grooming so desperate an animal, and took delight in aggravating him to the display. A brush drawn across a curry-comb will put him out of temper the moment he hears it. I found in a drug store a different kind of hair mitten from any $I$ ever saw. In place of the hair being woven in with the material composing the mitten, it was fashioned like a card, which was sewed on the palm. It is very effective in removing dust or dandruff from a horse with as thin a coating of hair as Falcon has, and I have never suffered anything harsher to be used in cleaning him since I obtained it. By placing one on each hand the work is not only expedited, but by brushing them together they are kept clean.

Falcon's temper is so much better than it used to be, that I am inclined to think the doing away with the torture of grooming has caused him to look on men as pleasanter companions than he formerly rated them, and is on his good behavior as long as he is exempted from the annoyance.

Preceptor.-The irritation consequent on the preparation of a horse for fast work cannot be done away with, as the necessary amount of rubbing inflicts pain. When this is increased to positive agony, from the want of sense -as shown by the man you mention and by plenty more of the same stamp-it is no wonder that the horse's temper becomes spoiled, so much so, that there is often actual danger in dressing them. See what a difference there is between men not only in using the comb and brush, but the soft piece of linen called a rubbing cloth. The bungler bears on as if drying the hair was to be accomplished by 
pressure, as juice is squeezed from the cane; the little bulbs at the root of the hair are made sore, and the job is not so quickly or effectually done as with the light motion that absorbs the moisture and leaves a glow over the whole body that is pleasant to the recipient. There is no material I have tried for rubbing cloths better than old salt sacks that Liverpool salt is imported in. The salt has given them properties, not possessed by the cloth before being used. They are heavy and soft, taking up the moisture more readily than any others. Turkish towels are the next best, and after they have been used awhile, are capital articles for the purpose. The wisp is very effective in the hands of a good groom, and when I see a new hand. make one, I can give a shrewd guess of his skill in the stable. The soft wisp when rightly made takes off the loose dirt. With a little more twist to make it harder, it polishes the hair and keeps up a circulation better than a cloth or brush. Skewers, or "skivvers," as the boys persist in calling them, will be found very convenient, trivial as they appear. The blankets, if furnished with strings, will do away with their use in a great measure, though when a horse comes in "boiling hot," and it is of great importance that the wind should not strike him, then the skewers are better than strings to fasten the blankets just where we want them. They should be made of tough, hard hickory, shaped so as to retain their place, with strength enough not to break easily. When a horse has to work in clothes, as in a sweat, they should be used very sparingly, and great care taken that they are placed so as not to wound with the point, or abrade the skin with the friction. The head ought not to be larger than the bulge. The bandages, of which there should be a set for every horse, are made about three yards long, and four inches wide, using soft strong flannel, with strings of the same material. The color is not important, though I 
must acknowledge a penchant for red. The uses of bandages are very little understood by many trainers, who use them on occasions when they are actually an injury, and neglect to apply them when good would result. Like the shoeing, where I differ from others, I will give my reasons for being of a contrary opinion. If they are not cogent according to your belief, show me their falsity. Converse with others, even those whom you think not so well informed. There are points where they may be likely to know more than both of us, - and let not the meanness of the source detract from the merit of the position. We are prone, after establishing a favorite theory, to build up every weak point; to search diligently for anything that would substantiate it, and as scrupulously avoid everything that would tend to weaken the structure. As an illustration of this, we will take your favorite hobby of the superiority of the thoroughbreds in making fast trotters. How carefully you dwell on what gives strength to the speculation : their superiority of form for rapid movements ; their capability of enduring protracted exertion; their being better supplied with nerve force; their recuperative power that enables them to "come again," disdaining to yield when every muscle and tendon has been strung to its utmost tension, commanding victory when defeat was booked as a certainty.

You see all this. Do you see as clearly the effects of generations of habitude to a different gait? The young grey-hound, by suckling the pointer, and subjected to the most thorough breaking, will never be of use to point game. The high temper, will it brook being kept, in the excitement of a race, to a pace that the animal knows is not the most speedy, and suffer others to lead? However, I do not want to open the question, only to put you on your guard against accepting that which I have concluded to be right, without scrutinizing closely the reasons I advance, 
giving them no more weight, because you are favorably impressed with my skill, than if they had been uttered by some one not familiar with the subject. A person must think for himself, and education is only just commencing when we put our knowledge to a practical test.

Bandages have many duties to perform. To a horse that has good sound legs that do not swell from the work he receives, their only use is to prevent evaporation, and keep the legs warm. They would be unnecessary even for this purpose, if, after the legs were washed, each could be rubbed dry at the same time, though I am not so much given to hand-rubbing the legs as many are, and would prefer the loosely applied bandage. Should the work have been very severe, bandages dipped in hot water, and left on all night without being permitted to get dry, will be found a great preventive of soreness. If the legs are inclined to tumefaction and tenderness, wet bandages are almost indispensable. Bear it in mind, that dry bandages will increase the inflammatory symptoms, and are never to be applied when inflammation exists. Warm water, the degree of heat being regulated so that you can just bear your hand in it, is just as good as any of the medicated compounds so much in vogue. I prefer the bandages to fomentations, not that they are better, but are less troublesome to apply.

The reasons for my preferring wet bandages to dry, and warm water in place of cold, are, that the moisture acts as a poultice, and the heat of the water, confined by the flannel, keeps up a perspiration that relieves the parts. When applied in the stable, dry bandages should be put on loose, so that when the string is tied, you can slip your finger easily between it and the leg; wet ones bear being a little tighter. It is quite a knack to put on bandages properly, particularly where a horse has to take his work in them. Have your bandage rolled up smoothly, 
and commence a little below the knee or hock, winding it carefully, so that there are no creases, till you reach the coronet; then go back with another fold, till you come back above the place where you commence, and tie with the same care, keeping the strings flat as they cross over each other, and fasten.

The uses of bandages when at work are to support the ligaments and tendons, enabling you to keep a horse in train that would otherwise have to be thrown up, and to recover from a strain that might become serious if he was exercised without their support. That there is danger of needing them when the horse becomes well, I think is unfounded, if their use is discontinued as soon as the leg has regained its normal condition. I broke the covering of one of the small ligaments in my hand, the sinew puffing up to the size of a hazel-nut, and my fingers almost completely paralyzed. I could not have lifted ten pounds. I immediately applied a bandage, with a small flannel compress over the rupture. The relief was instantaneous, and I kept at my work, nearly as if nothing had happened. I wore the bandage for some time, and on removing it, found no inconvenience for the want of the support. When there is much tumefaction, the pressure can be increased by tightening the bandage. This assists the absorbing vessels to take up the matter that causes the swelling, and expels it through the natural channels. As the application, in actual practice, is a far better method. of learning than either oral or written instructions, you will become familiar with my bandaging system before the season is through.

The clothing of horses is also a subject on which there is much difference of opinion; the advocates of either extreme being confident in the wisdom of the plan they follow. While I differ from both, I must say, if compelled to adopt either, I would go with those who discard the 
blankets. There is a medium that will suit me better. Clothing has its uses that can hardly be dispensed with in this variable climate, and the question is, how will we apply it to the best advantage. By the use of reasonable clothing there is less trouble in the ventilation of the stable, as slight changes of temperature are not felt when the bodily heat is partially retained by the application of a cover. The changes in a day or night range frequently through several degrees of the thermometer; and a horse that may have been comfortable with a linsey in the stable, and while taking his afternoon walk, will need the protection of kersey from then till morning. This is the furthest I would go, from a linen sheet to thick kersey; the addition of one or two blankets being, in my opinion, detrimental. If the training is carried on till late in the fall, the horse must be allowed to start a growth of hair that will compensate for the increased cold. The clothes that are used when sweating should be of an entirely different character from those intended for daily wear. They cannot be too thick, if soft and pliable. They need to be soft and porous, that they may absorb as much of the perspiration as possible,-and pliable that they may not injure the skin when brought in contact with it by the harmess. The quantity will be in accordance with the design of the sweat. The first that takes place in the preparation is to get rid of surplus fat, not expecting as yet much advantage to the lungs. A slow pace and heavy clothing will accomplish this purpose. As we advance, lighter clothes-with some horses none at all-and a fast pace are required. Sweating is of so much importance that we will have to give it great consideration; and as the time for your horses to go through the fiery ordeal is yet distant, we will postpone the discussion till we bring it in actual practice. The cost of clothing, at the present day, is one of the heaviest items in the expenses of 
training. Much of this will be saved by your man knowing how to takie care of the clothes. Cleanliness is the first and all-important lesson. The bedding must be arranged so that there will be no soiling of the clothes. The horses must be taught to stale outside the stable, the droppings removed as soon as they fall, and the most fastidious will not detect any of the ammoniacal scents that are thought one of the essential disagreeabilities attendant on keeping horses. The decoration of horses is a matter where a good deal of taste can be exhibited by the groom. We have scissors, but I never suffer them to be applied to the fetlocks. Your horses, I see, are not disfigured with any long hairs (this much, at least, being accomplished by blood). Those that have these unsightly appendages had better retain them. No amount of clipping or shearing will give them a high-bred look, and it certainly increases the danger of cracked heels. The mane neatly braided and tied up with ribbons, a clean well polished harness and vehicle, when a horse is going into a race, looks well, and is due your own character for care, and gratifies the spectators. A horse that comes on the track neither too high or low in flesh, a blooming coat, bright eye, and elastic step, needs very little aid of a decorative character to attract admiration.

PUPIL.-I thank you for the hint to scan closely the reasons for a distinctive plan in the training of trotters. I heartily coincide in the idea that our education only. begins when we think for ourselves, in lieu of the teacher finding all the brains. I shall leave the answering of your remarks about my predilection for blood, till I resume the history of the breeding farm, only begging your leave to call attention to the well-authenticated fact of a black sow making a famous pointer, showing all the enthusiam for the sport of the best trained dog, and when her owner would not go to the field, traveling several 
miles to the house of his brother, knowing he would accompany her.

Careful attention to the minor duties of the stable is very material, and one of the most difficult things for me to find are grooms that will attend to them. "Order is everything" in all kinds of business, and nowhere more important than in the training stable. Sobriety cannot be expected of the men if the trainer himself drinks too much; and it would be an insuperable objection with me to place horses in the hands of a man who ever got drunk. The results of one spree might do more harm than a year's careful handling had done good. Inciting a taste for reading in those who have the care of horses is one of the most effective ways of making valuable men. Ideas are fastened on the mind while pondering over the views of others, as expressed in writing, that are more difficult to obliterate than if received orally. We read and compare with our own views, either eradicating erroneous impressions, or strengthening those that were correct. I am very glad that you are going to make the subject of sweating one of major importance. The little knowledge I possess of training horses has been acquired more by reading and study than observing others. It is true $I$ have watched those who were in bigh repute as masters of the art, but have often failed to see the force of the plan they were pursuing, and no part of the system has been so blind to me as "the scrapes" they gave their horses. I have seen them put blankets on a horse every day for two weeks, without preparation or after care, thus negativing the benefit derived from the flow of the fluids.

Those who train race horses have to be in a manner proficient, as the best race horse in the world is easily beaten if he falls much short of the mark in condition. With the trotting horse, while it is more of a science to overcome natural bias, keeping a horse in the excitement 
of a hotiy contested race at a pace that he knows is not his fastest, still the want of condition is not so apparent, and a horse will make a very creditable performance trotting, when one in the same condition would fall immeasurably short of his true form on the racing turf. My idea is, that horses are oftener got out of condition from injudicious sweating than all other causes combined; and it certainly devolves on any one who intends to prepare horses for fast work to master this part of the subject, and become as familiar with the necessity for sweating and the effects of it as patient study and thought will permit.

Preceptor.-All fast work has a sudorific tendency, which can be either augmented or diminished by means within our reach. A horse that does not sweat after sufcient exercise is in a very bad plight, as much as those that perspire very freely with little exertion. One is said to be burned or baked, the other washy. I can only say that I am pleased that you realize the importance of this part of training, and shall look for mutual benefit when we come to discuss it. The morning has so far been profitably occupied with the shoeing and stable arrangements, we will now go to dinner, and while we enjoy the repose of our usual post-meridian smoke, I will listen to the continuation of the breeding department, and will give you a history of how I became a "trotting trainer." I have neglected mentioning a very dangerous instrument we left hanging so quietly on a hook, - one that we cannot possibly get along without; and as it is too late at present to give it the attention its merits and demerits deserve, I will postpone the subject till your horses require its use, which I hope will not be the case till we prepare them for their first sweat, unless there happen to be a gross feeder among them. I allude to the muzzle. 


\section{CHAPTER IX.}

A BACKWOODSMAN'S STORY-THE BREEDING FARM-FEEDTNGLONGEVITY-TRAINING-STABLES, \&C.

Preceptor.-How much the welfare of mankind depends on trifles, has been illustrated by Napoleon's losing a battle in consequence of an indigestion. The "Napoleon of the turf" was unable to manage the race between Eclipse and Henry on account of a lobster supper eaten the night before. Many confidently gave this as the reason why Henry was beaten. Men dislike to acknowledge their favorite has been conquered by meeting a superior horse, and ransack their brains for excuses, rather than admit the fact, apparent to an unprejudiced observer. We will have to be gluttons indeed if the food prepared for us here does any injury. The excellent cooking gratifies the palate, and preserves all nutritive qualities of the food.

There is no one who despises more heartily than I do he man who lives only to eat, who is only gratified by the sensuous delights of the table, and is unhappy himself and disagreeable to others, when some dish he delights in is omitted, or falls short of the standard of perfection of which he is a good judge. While I contemn the epicure, I pity the man who does not care what he eats so long as hunger is appeased. He goes through the world deprived of one of the means of enjoyment as much as if he had lost the sense of hearing, though not in so great a degree. You have one thing to-day for dinner, speckled trout, that is the choicest of all food to me, save fruit.-I will have 
to place a curb on mv desire, or I will certainly do myself injury by eating too many.

PuprL.-You need not fear any injurious effects if you should gorge yourself with them, unless the mode of cooking give qualities not possessed when made edibls by the simple plan I have followed in the woods. Venison and brook trout I have known men eat to repletion without the least inconvenience, save that of the skin being too tight to hold the supplies comfortably. The preparation was very simple: they were broiled on the cnals under the drippings of a small piece of salt pork. Whenever I started for a trip in the woods, I engaged a man to hunt, fish, and superintend the preparation of the camp. One thus employed was an old hunter by the name of Kepler. He owned a farm and saw-mill on the bank of the West Branch of he Susquehanna river, yet seemed delighted to embrace the opportunity of joining our expedition.

He was a very successful hunter, and the first night of our stay in the woods he brought in a deer that would dress from sixty to eighty pounds. Nine men completely demolished it before we left the camping grounds the next. morning. Some were roasting tit-bits nearly all night. I had eaten heartily, and was lying on the bed of hemlock boughs, enjoying. the quiet solace of the pipe. Kepler was telling hunting stories, and had an attentive audience in the members of the corps. To most of them forest life was a novelty, and the tales were listened to with as much avidity as they had devoured the venison. One of the stories appeared to me highly dramatic, especially as the scene was located near our present camp, and in the earnest manner it was related by the old hnnter, the truth was guaranteed. With your permission, I will repeat it, without expecting it will strike you as forcibly as it did me.

Preceptor.-I shall be delighted to hear it. Hunting 
stories were always favorites of mine, and we are in no hurry to get through our meal, having plenty of time that cannot be more profitably employed than eating leisurely, thereby making ligestion easier. When I have a horse that bolts his feed, as if he were afraid of losing his oats before he could eat them, I always place a large straight bit in his mouth, which compels him to better mastication. When I am too much hurried, I postpone eating till the hurry is past.

PuPII.- - Here goes, then, for

\section{KEPYER'S STOORY.}

"Fifteen years ago this fall, five on us started out on a bar hunt, and we fixed our camp a little lower on the crick. While we wur makin' our cabin, Sam Kurtz, one of our best hunters, said he would go up the hill and kill a venzon, that we might have something fresh for our first supper. Sun was near about an hour high, and it wan't long till we heerd the crack o' Sam's rifle. By-and-bye we heered it agin, and we wondered some, as we knew he never missed, and one blue coat was all we wanted at a time. We kept busy on our work, lookin' every minnit for Sam to come in with his deer, as it was only a little way off where he shot. Not comin' we hollod, but couldn't get eny answer. This kind o' skeerd me, and I was afraid something had happened. I jest told the other three to keep on, I'd go and help him to bring in the meat. I shouldered my rifle and started for where I heerd the shots. Afore long, I struck his track and followed it up the brow of the hill. Directly I found a young painter cub shot right through and through; he laid in a little thicket of beech staddles, and right on t'other side of it there laid another. This made me step mighty keerful and look well to the priming of my rifle. Pretty quick I 
heern a pumin kind of a noise, and looking up saw a sight that raised every hair on end and set my heart thumpin' as it would break throug my wawmus. In the crotch of a big white-oak that leaned a little katerin to me, sat a big painter right straddle o' poor Sam, and I knew by the limsey way he hung it was all day with him. The second look set my blood boilin', and every cord in me was as stiff as steel. I coclred my gun-didn't look for' nary rest-and drew a fine bead right atween the critter's eyes. I saw by the whippin' o' her tail that she was not satisfied with what she had done, but wanted more blood. I drew a long breath and pulled trigger; down she came, falling within ten steps of me, and the way she made the leaves fly was awful. Sam laid there,-he had got wedged into the fork so hard that the painter falling didn't dislodge him. I hollod like mad, and heerd them answer me from the cabin. When they came up I couldn't say a word, but pointed to the tree. They looked at Sam and then at the painter, and their looks told me they understood it all. How to get him down was the trouble, as we didn't want to fall the tree for fear of jammin' him ; so, after a good deal of bother, I climbed up to where he was, and stannin' on a limb, hoisted him on to his feet. The whole back of his head was crushed where the varmint had bit him. I took the belts o' my huntin' pouch and his'n, and puttin' them under his arms buckled it crisscross of my shoulders so that he was right agin' my back. 'Twas a queer feelin' that ran through me as his weight came on me when I started to come down the tree; but I knew Sam would have done as much for me, so I didn't mind it more than he had bin alive. We took some of the staddles, laid him across them and carried him to the camp. I tell you, boys, there was no supper eat that night, an' if there was a man lying here now who'd been killed by a painter, you wouldn't be toastin' bits o' deer- 
meat on a stick. Next morning I skinned her, and we stretched the skin on two poles and laid on it all was left of the best hunter from Lockhaven to the mouth of the Sinnemahoning, a man as true as the rifle he carried, never missed fire or took the back track of friend or foe. We followed the branch to where it jined Shintown run, and then crossed the pints and over the edge of the mountain home. The bad news spread quick, and afore long the whole settlement was at my house. I took the painter-skin for a shroud, wrappin him in it and puttin him in the coffin, laid his rifle and huntin' knife on the top of it, and buried him under the big tree on the bank of the river. I had no more heart for huntin' that fall, though the bar war very thick, but just tinkered round the mill an' helped the boys get out lumber. But lots o' times since, when lying in the woods alone, I have seen Sam hanging so limber like in the big white-oak."

Every one was still at the conclusion of this story, and nothing was heard but the dash of the waters and the murmurs of the tree-tops. Having no inclination to sleep, I refilled and lit my pipe, listening to the music of the water and the song of the wind drawing through the ravine, making Elian harps of the twigs, and singing a grander requiem for Sam Kurtz than ever echoed through vaulted cathedral for mighty conqueror or renowned statesman.

Precepror.-I should not have slept any sounder for being in the neighborhood of such lurking "varmints." As there are a couple of hours before we revisit the barn, we will adjourn to the piazza, and I will listen to your continuation of the breeding farm. I will have to retract my promise of giving you so much of my history as relates to my adopting the profession of driving trotters, postponing it to a future period, as I am not at present in the humor. You can rejoice over escaping the in- 
fliction at present, as I shall have many a long story to tell before the summer is ended.

PUPIL.-In place of rejoicing, I will lament that you have resolved to postpone the relation, having a good deal of anxiety to learn the reason why you forsook the graceful gallop of the young thoroughbred-the very poetry of motion-for the rougher gait of the trotter. I shall resume my own history wit pleasure, as I hope soon to convince you of the points where, as the lawyers say, we "join issue,"- the profit of raising thoroughbreds for trotters, and failing that, the finest carriage horses in the world. I left off with the first colts a year old, fields laid out, paddocks and barns built, but with neither track nor training stables erected. We will first put our yearlings in a suitable pasture and then build the stables and track. The field selected is one lying on the side of the bluff, where the herbage is the shortest. This is chosen for the reason that we want their supply of food to be mainly grain, as tending to form more muscle and tendon, and a denser, fine: bone, than if living on succulent food. They are fed regularly twice a day, three quarts apiece in the morning of oats, and in the evening six or eight ears of sound corn. The slope of the bluff is quite at a sharp angle from the level field at the foot of it, in many places steep, with patches of hazel bushes along the hill-side. The frolicsome spirit of the colts leads them to gambol up and athwart the hill, leaping the smaller clumps of bushes, and bringing every muscle into full play. They are salted twice a week, at which time the halters are put on and their feet examined, to see that the horn is not breaking away unequally. There being no stones to wear the hoof, it requires more care than it otherwise would, and we will have to cut away the extra supply that threatens to give a wrong set to the pastern. Should they not, keep in as good order as we would like, the grain must 
be increased. The prejudice existing here against using corn as food for horses may have arisen from good causes, as there is a vast difference between the flint varieties, and the larger, softer grain grown at the South and West. I am well satisfied that good horses can be reared on dent corn, having seen many that were called on to go both "fast and far" that never were fed a pound of any other kind of grain. Still my plan would be to feed a variety; and as all kinds can be grown in Iowa with a tithe of the labor bestowed in the East, we need not restrict them to either corn or oats. With one of the two horse corn-plows, now in general use, one man and a pair of horses can plant and cultivate in the best manner eighty acres of corn.

I find there is also a belief here-sanctioned by the writings of a man who has long stood at the head of the list as a driver of trotters-that feeding grain as practiced by the best feeders of racing colts is detrimental.

In proof of which, the withdrawal of horses from the running turf, when comparatively young, is instanced, claiming that, because they come to maturity earlier, they will likewise sooner decay. This is not in accordance with proof from the record, which will distinctly show that the thorougllbred lives longer than members of any other family of the equine species, owing to an inherent heartiness of constitution, and the care taken to nurture him well when young. I remember taking from the old Turf Register of 183-, the first twenty names from an obituary list of blood stallions. Their average age was twenty-two years. In the same magazine, there was a history of American Eclipse from the pen of his breeder. IIe gave the amount of grain he was fed daily from the time of weaning till he was put in train, and it was a very liberal allowance. As he lived to nearly forty years, it will not require long arguments to show that the feed did 
not shorten his days. It would be tedious to follow the record, although those familiar with the celebrities of the turf that have figured within the present century, will agree with me when I assert that a majority of them have lived to old age. It would be an idle waste of time for me to tell you the reasons for horses leaving the turf when young, being better informed on that point than I am. I will advance an idea, however, feeling confident of maintaining it with proofs of the most irrefragible kind,- - that no thoroughbred colt, even if put to trotting work when two years old, will ever be injured unless the exercise is prolonged to an extent that would kill two or three dunghills. When two-year-olds will stand the necessary training to run a dash of a mile in 1:50 or less, there need not be much apprehension of hurting them with trotting work, unless pounded to pieces on a hard track. Take an aged horse, of some of the breeds in vogue for trotting, one that has speed enough to run at the rate of a mile in that time, and before his trainer could get the length in him by sufficient work, his machinery would be worn out, and still this animal might stand a preparation to trot mile heats, 3 in 5, if he ever had the foot, to place them "low down in the thirties." I hope yet to see a thoroughbred. that will be able to speed with Dexter, Wilkes, or Toronto Chief, for a quarter of a mile, and you will see a trotter that will finish a race and make play of it. Why, he would bowl along the home stretch of a seventh heat as if he were at exercise. I do not intend to imply injustice to the hero of the fastest time on record. Nothing but the good blood derived from the patriarchs, Sir Archy and Messenger, ever enabled him to do the deed; and if the rest of the vital fluid that courses through his veins, were of the same stirling kind, the wonderful flight of the first half-mile would have been kept up to the end, and a 
mark left that no part-bred horse might ever expect to excel.

Preceptor.-I must call your attention to one fact that will upset all your arguments, "that none but the thoroughbred does it quite well," as Fanny Kemble said. The fastest Cesarewitch ever ran was won by Mr. Sykes (halfbred), in 1855. He was five years old, and carried ninetytwo pounds, running the two miles two furlongs and twenty-eight yards, in 3:55=to a mile in 1:43 $\frac{3}{4}$. Prioress, a year younger, and carrying one pound more weight, was 4:09 in running the dead heat, and 4:07 the deciding one. So the half-bred Mr. Sylkes must have run a quarter horse clip, and kept it up for over two miles and a quarter. Should not Dexter-having at least as much blood as that - keep up his rate of going for a mile, as well as one with a pedigree as clear as the Moon of the Mountain?

PurIL.-You have lost sight of an important fact in the case of Mr. Sykes. The English call a horse half-bred if he has only one part in sixty-four of other blood. Not knowing the pedigree of the horse, only that he was got by a St. Leger winner, Sir Tatton Sykes, I am unable to say how much blood he possessed. Yet it was a wonderful performance, even for a thoroughbred. The English system of raising colts is still more on the forcing plan than is followed in this country, adhering to the Yorkshire motto, "that half a horse goes down his throat." An eminent American breeder thus writes from Doncaster, in 1840, to the Old Spirit: "The first striking difference which presented itself between these and American bred horses, of corresponding ages, was the size of the English horses. I think I saw foals eight months old as large as our yearlings, yearlings as large as our two-year-olds, and two-year-old colts as large as our three-year-olds. I was much astonished to find that colts a few months old had shoes on, and gave evidence of having been care- 
fully groomed from the time they were old enough to bear this attention. Whilst I could not withhold the expression of my astonishment at the extraordinary size of the colts and fillies, there was but one in this number that elicited anything like surprise from any Englishman present, and this was a brown yearling called Artful Dodger, whose pedigree I have forgotten. But for this I should have supposed the largest and choicest colts had been selected from each stud for sale." The record of imported horses that have been reared in a manner to gain a year in size at two years old, will show that their lives have been prolonged beyond the usual term of horse life. Leviathan, Priam, Trustee, Roman, Sovereign, Glencoe, \&c., \&c., are proofs of the truth of this statement.

I may be wrong, thinking that part-bred horses are not able to keep up great trotting speed for even a mile; or rather that when the trot becomes almost as speedy as the run, none but the purest will be likely to do it without great fatigue. I have seen a horse that could trot a quarter of a mile in 31 seconds, the half-mile in $1: 05$, but could not trot the heat in $2: 35$, to save his worthless life. Now a blood horse that could go the first quarter in 31 seconds would trot the mile in 2:05, as far as tiring is concerned. He might be unsteady and fractious, but if such a horse as the one mentioned, if he did not break in his last quarter, would be as good or better than in the first.

Preceptor.-I will certainly not argue that colts, if allowed room to exercise, can be fed too much grain, as I am satisfied the best horses, and those likely to live the longest, are reared in this way. As to the withdrawal of them from the turf when four or five years old, the reasons are patent to any one at all acquainted with racing. Inability to carry the scale of weights, as now regulated, is one of the most fruitful sources. Those that 
have been well fed when young are far more certain to have the stamina to do this than others not so fortunate in their breeding. Neither will I contend against your claiming so much for the thoroughbred. But you, just as certainly, will not acknowledge the merits of those which have half or more of the same blood. Half or threequarter bred horses for trotting, answer every purpose as well as if they had the full modicum necessary to remove the h. b. stain in the English Stud Book. Not only trotters, but some of the very best racers, could not boast of more. Look at old Betsey Malone, the "traveling terror," never losing a race but when she fell down, winning twenty-one in succession, at all distances, leaving the turf when five years old, from an accident that resulted in blindness.

Her daughter, Charmer, winning sixteen three-mile races, emulating her mother by never losing one at this distance, and in the aggregate number, recording nearly double as many as any of her illustrious sire's get, never handing in her checks till ten years old-her valedictory a second four mile heat in $7: 43 \frac{1}{2}$. The first named mare, by Stockholder, dam by Potomac, with the Glencoe added in her nearly as celebrated daughter, is not a very extensive pedigree, and has one advantage of not requiring a horse memory, like that of Dr. Weldon, to remember it.

PUPIL.-I have not succeeded in making myself understood, as I never intended to take away any of the well merited honors won by the part-bred heroes and heroines. Yet, I fully believe the better bred the horse, the better performer he will be at anything requiring speed, and will fortify myself with illustrations that are not remembered quite as clearly as I would like to have them, before adducing them as proof. Betsy Malone, I am in hopes, will be rescued from the obloquy that has always rested 
on her and her descendants. I am informed by a friend, that he had made a discovery that her grandam was by imported Diomed, and the only flaw was that derived from the Potomac strain.

I will now proceed to build my training-stable; hoping from your kind promise, that, if the fitting-up is different from what you would recommend, you will inform me. The location I have chosen is where the trees flank the

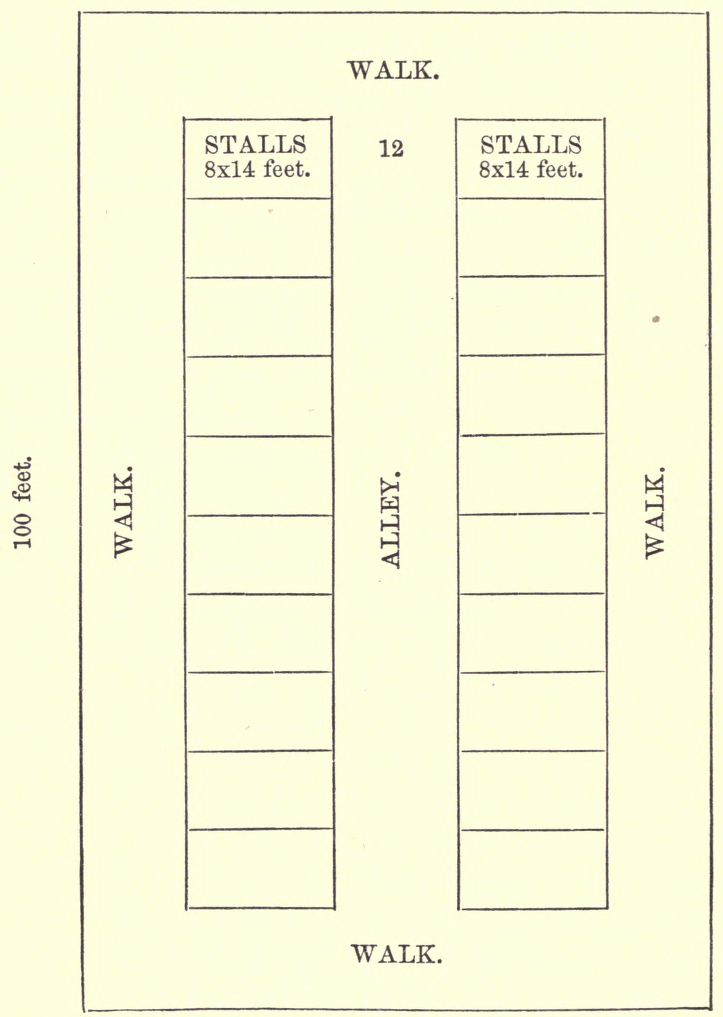

60 feet. 
house to the north-east, and under their shelter. There is a little knoll there that will give perfect drainage, and the track will approach within one hundred yards. Twenty stalls will be as many as we will need for a time, and the form is such that they can be added, without detriment to comfort or appearance.

I have drawn a rough sketch of the ground floor, which will aid me in making my ideas intelligible. The whole area enclosed is sixty by a hundred feet. Of this space ten feet in width is taken up for a walk, the benefits of which will readily be seen. By having this walk sheltered from storms we never miss the advantage of having the horses exercised, no matter how bad the weather is; and in this northern latitude, by having it well littered with straw, we can gain a month in preparing the horses, equalizing our chance in the spring races with those living: farther South. The outer wall is so arranged that there are large openings to both doors and windows; hence, when the weather requires it, there can be as free a circulation of air as if entirely open. The height of this story is ten feet, with the same distance to the plate, making the post twenty feet high. There is a double row of box stalls, with an alley between twelve feet wide; each stall is $8 \times 14$ feet, sealed with matched boards, presenting a uniform smooth surface. Well seasoned black walnut is the material used, which can be got in this section of Iowa nearly as cheap as pine. There are two doors in each stall, one opening to the walk, the other to the alley. There are openings for ventilation at the top of the stall, with others at the base to pass off the heavy, impure air, that otherwise would not escape when the door is closed. The feed boxes are arranged in one corner of the stall, sliding through a place cut in the wall, and when not in use are leit projecting into the alley. The hay is fed by placing it on the straw forming the bedding, 
so that the horse has nothing in the way to injure himself. Should he want to roll, there is plenty of room for him to do sa, and it is impossible to get himself in a position where he will be hurt. There are, of course, no halters used, as that would negative the benefit of our boxes, and reduce them to the level of a space six feet by ten. The window is at the top of the stall, and the doors are divided so that the upper portion can be left open when desired. The whole of the feeding and bedding is supplied from the alley. The hay, straw, and feed, are stored in the upper story. There are spouts that bring the oats and cracked corn into receptacles convenient to the feed boxes, and shutes to slide the hay and straw where it is required. There are stairs that can be slung to the joists overhead when needed to be out of the way, as we drive the wagons loaded with grain through the alley, and discharge the load, by the help of a block and tackle, into the bins overhead. This upper story can be divided so as to meet our wants. Upwards of one hundred thousand cubic feet from the floor to the ridge-pole is accommodation sufficient; and after storing all the hay and straw required for the season's use, we have plenty of room left for grain bins, harness room, sleeping apartments, \&c. The foreman's room should be large and nicely fitted up, adorned with prints of the most celebrated horses, and plenty of books and papers to foster the love of reading, which you and every one who has tried it with the boys, have found so advantageous. As more room is needed, it can be added by merely making the building longer.

Preceptor. - Your stable is a novelty to me, and before I condemn it, I will have to follow your plan of studying the record to adduce proof that it might be bettered. It corers a good deal of ground to get twenty stalls, but has advantages that will probably overbalance the added 
expense. You will need more room on your farm than would be required if the grain, straw, and hay, had to be purchased, as you will haul directly from the field, and will save re-handling by having storage enough for a season's supply. A very convenient.stable of six or eight stalls can be built on the octagonal plan, and some day I will show you a drawing a friend gave me, which I think is very good.

I have thought that, on a farm where the material would be convenient, concrete could be used, securing a cheaper building than stone, brick, or wood. The material you would use in the construction of yours, you have said. nothing about. I presume it would be a frame.

PoprL.-I would build the outside walls of the yellow lime-stone, a quarry being opened at only a short distance to obtain the stone the house was built with. A wall eighteen inches thick would require five hundred perch, and can be built there for $\$ 1,500$. By using the teams and men employed on the farm, and burning the lime on the place, the cost would be greatly reduced. The interior should be after the plan of framing at first termed in derision "balloon," but which has taken the place of the heavy timber once in vogue. By using stone for the exterior, the building will not only be far more permanent, but the expense of paint is done away with, and a more agreeable temperament is secured. The only drawback is that it would interfere with making more room, if required.

Preceptor.-The dampness consequent on the use of stone would be obviated by the walking-space between the walls and the stable proper; and when it can be built as cheaply as $\$ 12$ for a hundred cubic feet, I can see no good reason for not using it. As to the want of room, the twenty stalls will probably be all you will need for a long while, unless the proportion of trotters among your thoroughbreds is far greater than I expect. I sup- 
pose those looked for to make the finest of carriage horses would do to have their quarters assigned them in the boxes vacated by the brood mares.

PUPIL.-It is very true that the room in the trainingstable is only intended for those we hope to dignify with the name of trotters. The proportion can only be found as the man was going to discover the race horse, by "sarching."

I am glad that you have placed yourself in a position at the outset to admit that there is a likelihood of once in a while getting a trotter from the source I have such great expectations from, as I have found plenty of men who were so bitterly jealous of the praises awarded the thoroughbred, that they could not bring themselves to acknowledge there was any good in them; foolishly thinking the merit admitted would detract from the fame of other breeds in which they had some interest.

The prices that are now paid for stylish, good-sized carriage horses would warrant the outlay I have contemplated in the purchase, stock, and fitting-up of this breeding farm, even if we never produced a fast trotter. I look to these, as a means to compensate us, as much as to those with the more attractive quality of speed; there being a good deal less outlay in fitting carriage-horses for market. I have not time for the disquisition now, and will also have to put off building the track, as I have already taken up the allotted time. 


\section{H A P T R $\mathrm{X}$.}

COLTS IN THE FIRST STAGE OF PREPARATION-ROUTINE OF WALKING, FEEDING \&C.

Preceptor.-We will now proceed to the stable, and see the horses take their evening walk. It has always been a pleasant scene for me to observe them performing this very necessary exercise. How gaily the young things move along! Their joints and tendons are as pliant as those of a deer; yet a few years of usage will make them lounge in their movement as well as the veterans.

Have one of the boys lead out Clipper, to pick the grass and gnaw the ground, which will assist the aperient medicine we are giving. It would have been well during the winter to have applied a light blister to fine down the extra tissue that has been formed so long. As it would be too great an inroad on the time now allotted to bring him in condition, we will have to adopt a plan that may answer, but not with the certainty of a vesicant. To the alterative medicine we will add daily doses of iodine in small amounts, say five grains, which will act as a glandular excitant, and aid the local treatment, consisting of poulticing with hot water, and applying dry bandages over the wet sponges, gradually drawing them tighter to assist the absorbent ressels in taking up the extraneous morbid matter, and removing it from the system.

Blistering, a remedial agent of vast power, has fallen into disrepute from the empiricism of those who have applied it, right or wrong. The legs of this horse would 
have been very much benefited by the application of an irritant, as nothing would be so likely to restore the skin to its proper functions. It now has an unnatural closeness and tenseness, arising from the adhesion of parts underneath, caused by a deposit in the interstices, the effects of acute inflammation at some previous period. The emollient tendency of the hot water may relieve this, and the treatment will be such as to render the cure of the running thrush a work of some little duration. We would defeat the end we have in view, were we to stop the offensive discharge from the frog, before the system is relieved from the taint which causes the disease.

The walk your horses had before leaving home will shorten the time required now in fitting them to enter the second stage of the preparation. In my remarks on walking, while we were going to the smith's shop, I left much unsaid that ought to be fully understood at this stage of the training, and while reprobating the practice predominant many years ago, of walking horses too much, think it very essential that a proper time should elapse before they are called on to "jog." We will find a great difference in the amount of work even members of the same family are able to stand; still, there will be less variation in the time allotted for walking than when the gait is faster; that is, the walking given in this proliminary stage. As we progress, and it becomes an adjunct to the trotting, we may find a great dissimilarity in the members of your stable. Now, we will walk them all, with the exception of Clipper and King, two hours and a half in the morning, and one and a half in the evening. The old members of your horse family we assume to have acquired the step necessary for fast trotting. The essentials with them, then, is to obtain condition, and forget bad habits. We shall be forlunate if we have them in proper order for a race in three months. This, therefore, 
will be the shortest time to which we will limit ourselves. We will divide the preparation into three stages-the first occupied with easy work; the second, somewhat faster, called jogging; and the third, calling at stated intervals for as high a rate of continued speed as the animal is capable of showing. In these three divisions, or stages of preparation, we will have to vary the feed as well as the amount of work. They are now eating, on an average, eight quarts of oats each, with as much hay as can be eaten heartily. As we proceed, we will not only have to increase the amount of oats, but will have to add hominy or corn, which my experience has taught me as being needful to keep up the stamina of a horse, called on for severe muscular exertion. The first stage will now merit all our attention, and the plan we will adopt will be the following: At five o'clock, we will expect the boys to open the stable, give the horses a few swallows of water, and their first feed, two quarts of oats. When eating this, the bed to be shaken up, and all soiled portions and droppings thrown out. After this is done, a careful light dressing, when the clothes are replaced, and the boys go to their breakfast, having tied the horses' heads up, so that they cannot reach the litter. The breakfast finished, the string will go to the walking ground at seven,o'clock, where they will walk at an easy, natural pace till halfpast nine. They must be kept some little distance apart, and when one stops to empty, the others must wait till he moves. When brought to the stable, a light brushing and whisping is gone through with, a bucketful of water given, two more quarts of oats, and four or five pounds of hay. The litter forming the bed is arranged, the stable locked up, and they are left undisturbed till three o'clock, when the next feeding time comes. This feed consists of three pints of oats, followed by a little water, after which they walk for an hour and a half, return to the stable, are 
thoroughly cleaned, dressed, their feet picked out, the sole and horn washed, and their legs lightly hand-rubbed, followed by their bed being properly arranged. At seven o'clock they must have their full supply of water, the balance of their daily quantity of oats, and about six pounds of hay; after which the stable must be closed, not to be entered, unless some accident occurs, until the following morning.

The walk is commenced in the small yard adjoining the stable, that a little of the exhuberance of animal spirits may be worn away before going into the field, where the increased space may tempt the colts into a frolic. When this walking has been prolonged to a suitable length of time the muscles will have acquired some firmness, the joints set, and the whole economy of the frame in a position to undergo the second stage with increased advantage. The training of race horses, while it necessitates more care to bring them to the post in proper condition, has the advantage of the distance being regulated to what the trainer thinks is right. With trotters, after leaving the slow and medium work, we cannot exactly foretell what the distance will be. The brush that was only intended to have been of a quarter or half a mile, has been changed by the horse acting badly, so that, in order to give a lesson in brealking, the work has been prolonged more than was anticipated. Hence it is good policy to have the animal doing rather below the mean, so that the lengthened exercise his temper obligates will not be detrimental. Your rough-coated favorite, King, not being amenable to ordinary laws, will not, I suppose, deign to walk in company with any of the others. I hardly know what shall be done with him.

PupIL.-My high bred protege has lately given an inkling of making a companion of Oriole, in the absence of his mother, and I think I can teach him to take his walk 
in her company. I will first put the long rein on him, so that he can follow in the rear, till the novelty of the situation is gone, when I imagine he will not trouble us in this particular. Your former remark, that patience is everything in the formation of trotters, is doubtless correct, and must be accepted as an axiom by those who would be successful in teaching young roadsters how to trot. You cannot look for them to "keep pace with our expectancy, and fly," unless we are reasonable enough not to look for the acquirement of speed till they have a fair chance of showing it, after years of patient teaching. It requires a good deal of enthusiasm for the business to make trotters of colts, and no one will be highly successful who has not a great fondness for them. They are very trying to the temper at times, and it is of the first importance that we should school ourselves never to show the ruffling. Neither must we be discouraged by the jeers of others, "that we are throwing our time away in attempting to make something of a brute that never will go fast enough to carry the mail." "Once upon a time," at a quarter race, I saw two men strip to fight out some grudge that had culminated in the excitement attending on the running. One was a big, brawny six-footer, called Barney : his opponent, a much smaller man, yclept Sam. The feelings of the assemblage ran very strongly in favor of the larger, and whenever he hit a telling blow, he was cheered on, "Now you have got him, Barney," "Hurrah for Barney!" "He's nearly licked," with numerous phrases calculated to keep up his spirits. But Sam was a nervous, wiry fellow, and needed a good deal of "punishment" to cook his gruel; and, notwithstanding the shouts of encouragement to Barney, he finally came out conqueror, the big fellow having to be carried to a neighbor's house, where he did not get out of bed for several days. On congratulating Sam on his victory, 
which for a long while looked so hopeless, he told me that several times he was on the point of "hollering enough," and if the crowd had been equally divided in their expression of sympathy, he would have done so, but he was not going to gratify them, and every time they shouted to Barney, a new courage would revive, his failing strength would return, and he would determine to die rather than yield. This is the spirit to ensure success in the handling of colts. I have already signified my ardor of temperament for them, provided they have some good blood in their veins; the only thing to rely on when it comes to the struggle, like that of the fight at the quarter race. The often quoted stanzas from Shakespeare, "Touchstone" says, delighted Jno. Scott, the great English trainer, so much, that he had a copy framed, glazed, and hung up in the room for the boys to commit to memory, and declared, that with such a horse as there described, he could win every Derby and St. Leger. The picture shows that at that early day the thoroughbreds had their prototype in old England before Arabs or Royal mares were introduced.

\footnotetext{
"Round-hoofed, short-jointed, fetlocks shag and long; Broad breast, full eyes, small head, and nostril wide; High crest, short ears, straight legs and passing strong: Thin mane, thick tail, broad buttocks, tender hide,Look, what a horse should have, he did not lack, Save a proud rider on so proud a back."
}

Nearly three centuries ago this was written, and it would be remarkable indeed if the immortal poet had drawn on his fancy for this perfect description of a blood horse, or could so faithfully have described one without an intimate acquaintance with his points and capabilities. It is claimed that on the poet's advent in London, the only means he had of gaining a livelihood was holding horses at the door of the theatre. This would give him ample opportunity 
to study "the well-proportioned steed" he has so faithfully "limned." I have always a great fancy to see the horses walking, and my business must be very pressing if I do not watch them through the whole course. Look how majestically the Falcon leads the string, and is contented nowhere only at its head! "Never Mind" stumbles along with that queer gait, placing each foot exactly in line, and playing with May every step he takes. I hardly ever knew a horse that was so much attached to his companions. If you put May in another stall, where she is out of his sight, he will mourn until she is returned, refusing to feed and drink till her presence gladdens his heart. $\mathrm{He}$ is one of the horses that will require, in my opinion, very little walk when once put to fast work. His wonderful speed will enable him to overcome faulty conformation, and if brought to the post in the bloom of condition, shall look for him to live the race through, if not more than two mile heats.

Preceptor.-The adage that "speed gives bottom" is only true in a relative sense. The possession of speed is of course the first great consideration to be looked for, and it gives an animal possessing it in a degree over an antagonist a superiority that is hard to counterbalance by mere endurance, when the race is of the kind now most in fashion,-mile heats, best 3 in 5. Shakespeare's description would have suited me better if he had not put in the short ear and straight leg; still, it is remarkable that he should have given so true a description at a time when it was thought there were so few first-class specimens in Great Britain. There are very strong arguments adduced that our present horses are more indebted for their preëminence to the Arabian and Barb than any other crosses ; but I must say my belief is to the contrary, and that the native breed were superior to the animals crossed on them. I have read that a brother to the reigning King 
of France tried, over two hundred years ago, to get a bill through the parliament, which would enable him to export mares, but it failed to pass. The privilege that would not be granted shows the importance English horses had at a time prior to the advent of either the Darley or Godolphin Arabians. What a dissimilarity there is in the walk of the race horse and the rest of the equine family! He swings along with a low, long step, his tail vibrating like the pendulum of a clock, hung careless and loosely, a consciousness of power in all his movements.

I will join in your enthusiasm for the royal blood, so far as to admit there are no others that can vie with them in grace or beauty of form. How often have I admired their symmetrical proportions, when I have seen them in the first flush of youth stripped to start in a colt race! That is a part of the running usages that might be well to adopt with the young trotters, more than is practiced now. I mean open stakes for three, four, and fiveyear-olds, and would suggest that the amount should be moderate, say two hundred dollars entrance, half forfeit, with fifty dollars declaration. Entries to be made a year before the race, with the time to declare forfeit extended to within three months. This would stimulate breeders to increase their endeavors to raise trotting horses, not only giving a chance to win a stake that would be worth a good deal of money, but would attract purchasers looking for fast stepping colts; and any that made a good show would find a ready market. People are very much afraid of trotting three or four year-colts, and a great deal has been written and said about the danger of injuring them at that early period of thoir lives, by the training requisite to make them trot fast enough to be of any service. I cannot see that the risk of injury is so very imminent, if they are handled with proper judgment, 
and not made to exert themselves to the point of extreme exhaustion. One great error is that a hard track is considered essential to train a trotter on. An inch or so of loose dirt would lessen the concussion; and though the drag of the wheels would require a little more force to overcome the friction, the advantage resulting to the limbs would far more than counterhalance this slight evil.

PupIL.-There is where my favorites would show their superiority; and admitting that they do not acquire the trotting step as readily as some others, their stamina would warrant them in being worked harder, without endangering their future welfare. Any one who will take the trouble to watch colts, when running in a field, will coincide with me in the belief that they take more exercise of their own accord, than would be sufficient to learn to trot and endure the fatigues of a 3 in 5 race. I have spoken before of the enjoyment there is in watching a lot of colts playing in a field, their manœurres being so varied that I never tire of observing them. At first they will trot off in divisions, throwing their heads up, their tails curving over their backs. What a grand quadrille they are performing,--now advancing among each other, wheeling in circles, and mixing together in seemingly inextricable confusion, yet in harmony with the stately step and flashing eye! This is only the prelude. Soon the lofty trot gives place to the simultaneous charge, and away they go to the extreme range of the inclosure, only to rush back with accelerated speed. There is no need of whip and spur to stimulate them to their utmost effort: every one except the veriest dunghill is emulous to excel; and the most exhilarating "trials of speed" I ever witnessed have been on the vernal sod of a large pasture field. It needs no one to pick out for you the blood in these assemblages. A few courses, and some will cry 
enough, when long afterwards those of pure lineage are gamboling with undiminished spirit.

I shall impatiently wait for the time to come when we shall sit under the umbra of the oaks, on the knoll where the old stone house is keeping watch and ward over the quondam hunting-grounds of the Sioux and Chippewa. The placid river looks like an inland sea, the mountain snows in the far-off north swelling its waters till it is miles across. The brilliant foliage of the islands floats on its surface and is reflected from the flood. The waters extend to the very foot of the hills, that looked so hazy and indistinct in the orange light of the Indian Summer. Now they appear as if drawn closer, and you can see the white farm-houses that nestle on their sides. The yellow limestone bluffs frown like giant fortresses, massive and gloomy, on the eastern shore; those on the west glowing in the morning sunlight. The blue-grass carpet is fringed with the flowering crab-apple, the calm air laden with their sweet fragrance. The brown thrush and robin are singing a duet, and the prairie chickens are cooing their songs of love. The colts turned out from the stable are wandering listlessly about, inhaling the perfumed atmosphere, till one gives the signal, and away they go. What energy and grace of movement! Their lissome limbs seem endowed with a spirit that compels them to rush along, rivaling the roar of the avalanche, as they drum music out of the springy turf. The play of the muscles is dictinctly seen under the pliant skin and silky hair, which takes different shades like the changing hues of the pigeon's neck. No matter how long they keep up this exciting pastime, you will feel disappointed when they cease, and hope that after a short respite they will again go on with the play. When you see this repeated day after day through the whole summer, you will agree with me that the work well kept colts take for their own enjoyment is 
more than that which would be necessary to teach them to trot, and be in condition sufficient to live through a race without injury. One great object to attain in training is to have the colts engage in their exercises with the same spirit and glee that they join in play; and by watching them closely we will be ablè to keep up that feeling in a measure. If the task is not too arduous, they will learn to like it, and bowl along the track or road with a zest that will nearly equal the pastoral gambols. There has arisen a feeling that a race to be worth seeing must be fast. Associations and proprietors, of course, have recognized this by doing everything in their power to have the fastest horses in the country grace their tracks, no matter if one was so much faster than all the rest that there was no show of a contest. This has led those having the management of courses to throw obstacles in the way of colt races, which would lack the speed considered so essential. The interest to me in a race lies in the closeness of the contest. I would hardly walk a mile to see a horse that could go a mile in 2:15 if pitted against one that took five or ten seconds longer, not quarter that distance, if $I$ had seen the actors performing before. To see half a dozen or more colts engage in a trial which was to determine a bonâ fide stake, and settle which is the best, would take me a long way, and be of far more interest than those hackneyed races now so much in vogue.

Preceptor.-This starring system which has been so fashionable for a term of years, has, without doubt, been a source of great injury to the trotting turf, not alone by making fast time the only attraction to draw people to the course, but inaugurating the hippodroming evil that has done far more injury. The large purses advertised meant only a division of the gate money; and people that had been induced to visit the arena, expecting to see a 
true struggle for the thousands of dollars said to be at stake, went away dissatisfied when the transparency of the humbug was made apparent.

PupI.- - The copartnership existing between the ancient patrons of the Olympic games has been dissolved, so far as the stars, or rather those managing them, are concerned. The God of Strength has been discarded, and they have enrolled themselves as the disciples of Mercury, without deigning to copy the adroitness which gave his stealings the charm of being so skilfully done that the victim's admiration nearly compensated for his loss. We are told by those conversant with the habits of one of the western tribes of Indians-the Blackfeet-that stealing is a weighty part of the education of the young. The junior dusky warrior is unmercifully punished if detected. and as highly applauded if undiscovered. This is akin to the story of the Spartan youth, who denied, with unchanged countenance, the theft of a fox. The savage animal, covered by his mantle, gnawed flesh and bones till he reached the vitals. The stoicism shown by enduring this terrible torture rather than be convicted, is certainly to be admired. The corresponding thief, who makes the noble horse the vehicle of getting his hand into other men's pockets, is not the possessor of this redeeming quality of manliness. However, my acquaintance with the class has been limited, and they may possess attributes which I have never seen, though it will take conclusive proofs to have me believe there is any good in them. It is a pity the Indian and Spartan method had not been employed in finishing their education; and while they learned to be adepts sufficient to conceal their depredations, it would have saved the obloquy from resting on the whole fraternity by the evil-doings of a few.

Precepror.-It is a matter to be forever regretted that there should have been those who were willing to degrade 
themselves by the practices you mention. My experience has led me to believe that there are very few who have erred, yet there have been enough of them detected in their villainies, to throw blame on all connected with this chief of sports.

The matter, however, is working its own cure, and will forever be banished from all respectable courses, and those with a dirty record will be watched so closely, that certain ostracism will follow a relapse into former bad habits. 


\section{CHAPTER XI.}

EFFECT OF WEATHER ON CONDITION-GOVERNMENT AID IN KNCOURAGING BREED OF HORSES-GENERAL GRANT-STABLE TRICKi'

PRECEPTOR.-The morning is again beautiful. How much we ought to prize the fine weather that is meted to us by the goodness of the Great Father! We repine if a shower or mist interferes in the slightest manner with our business or pleasure, and give no thanks when the skies are as propitious as now.

Favorable weather is of great importance in getting our horses in condition, and rain and sudden changes often render nugatory the care we have bestowed upon them, and upset all our calculations. My plan is to work, no matter what the weather is. Of course, the amount of labor will not be the same; but it would be a tempest indeed that kept my horses in the stable twenty-four hours at a time.

Condition is much sooner lost than acquired; and as condition cannot be reached without continued work, it must be lost when we cease our exertions. It is not pleasant for either driver or horse to work on a muddy road or track, and the groom's duties are more onerous then when everything is dry and pleasant. The mud can be kept off in a great measure by using a cotton cloth, similar to a belly-wrapper, with strings to tie over the back. The tail is tied up and enveloped in a bandage, when the legs will be about all that is exposed. There are some cases when muddy roads are beneficial by saturating the feet with moisture, although horses with good feet, and shod in the 
manner I have directed, will never need this pluvial ministration. It is agreed upon by both advocates and opponents of the Arabian horse, that his feet are always good, the dry climate and the scorching sands showing that water is not essential to his well-doing. The knife and rasp do the mischief, which no soaking can repair.

PupIL.-This weather is truly enjoyable, and I will try and leep it in remembrance when inclined to repine at that which is less favorable. I was reading an article last night, that has filled me with "vast ideas" which I am anxious to disclose to you for criticism or commendation. It was an editorial from the Spirit, advocating the appropriation by the General Government of one hundred thousand dollars a year, to be applied in purses for races, and distributed equally among the States. It struck me that if the measure was carried out, the benefit to the whole country would be immense, and the outlay would return to the treasury a hundred fold increased, through channels opened by this appropriation. The plan pro posed was to give the amount into the hands of the respective governers, who should select a central place where it could be run for under such conditions as Con. gress might impose. What an impetus it would give to breeding a better class of horses in States, now wofully deficient in those adapted for either pleasure or service! There is no country in the world, of the same extent, so well calculated for breeding good horses as the whole of the United States. The extremes, both North and South, require that more care be taken than in that portion favored by a more equal temperature; the South not being so favorable for the culture of the grasses and small cereals, and the North requiring a greater outlay for warm stables, and a larger supply of fodder and grain. But neither is a bar to profitable breeding and rearing; and the stimulus given by this contemplated movement would 
quicken farmers to prepare themselves with all the requirements necessary for the propagation. My idea would be to confine the government purses to horses owned in the States where the trial was to be, and, after a proper lapse of time, to those bred there. The reason why I would confine it to horses owned in individual States is, that the object to be gained is the improvement of stock over the whole country, and not in one particular section where breeding has been established, without other aid than the fondness of the inhabitants for turf sports, coupled with a climate and soil favorably endowed by nature for breeding the best horses with the least outlay and care. With this assistance from government, there is not a North-western State which would not soon be filled with the blood from those localities where the race horse is now prevalent. The demand would enhance the value, and create a market that would remunerate the breeders far better than if they were allowed to make a circuit with their best animals, and sweep the board of every purse offered. You will pardon me for again introducing Iowa; I only do so from being more familiar with her people and resources than those of any other State. I removed there when a mere boy, soon after she had been admitted into the sisterhood of States, before the clatter of a locomotive had been heard within hundreds of miles, when her population was mainly confined to the river counties, and the only market was down the Mississippi. We can point with pride to the position she now occupies, and may be pardoned if we provoke a smile at the magnitude of our anticipations for her future. The few thousand doliars Iowa would receive as her proportion of the race furd would work wonders in the introduction of blood stock.

There are several gentlemen of my acquaintance who would delight in owning and training race horses, if there 
were an opportunity of running them for adequate purses within the limits of the State. Should the contests be confined to those horses actually owned there, and after a suitable lapse of time to those bred there, thoroughbred stallions would be located in nearly every county. These State contests, determining which was the best, would enhance the interest in the general race meetings by bringing together the State victors, and afterwards the conqueror of the West would meet the Eastern champion at Saratoga, Paterson, or Westchester, the winner making good his title to the premiership.

The small amount donated by Congress would set the ball in motion, not so much from the money value, as the effect it would have to popularize the sport. Should the Governor of Iowa say to the various smart little cities within her boundaries, "I have such a sum put in my hands for the encouragement of breeding a better class of horses than now exist in our State. It is conceded by those conversant with the matter, that the best way to appropriate this sum to effect the object in view, is to give it in prizes for horses running long distances. Which city will build the best course, put up the necessary buildings, and add an amount sufficient to ensure a variety of races suitable for all classes, on a guarantee of having it located for ten years at that place?" There would be so many liberal offers that the difficulty would be to discriminate between them, and select the most favorable; for to my knowledge there are half a dozen places that would give all needed, to have two good meetings a year. Confining the races for the government money to borses owned in the State, would ensure the colts being kept for breeding purposes; and the rivalry between those determined to own the best, would lead them to select for nurchase animals that are ranked high in places where tho thormglibred has been reared for long periods. It 
would not be long ere the good effects would be visible; not only in improving horses for cavalry service, but road, trotting and carriage horses would be more plentiful and of a great deal better quality. I have thought so much of the scheme since reading the article alluded to, that I am full of the subject; and to follow it in all its bearings for the good of the horse stock would be a trial to you patience more formidable than $I$ am inclined to punish you with. However, it is so intimately blended with the breeding of trotters that I hope every effort will be made to have such a project become a law. There are enough influential men in every State interested in the welfare of the horse, who, if united in their endeavors to press the matter on the members of Congress from their respective districts, could render its success sure. I feel confident General Grant would recommend it, even if ten times the amount were asked for, for the benefit that would follow to the improvement of the cavalry alone. During the last Illinois State Fair, the General, attended by a brilliant company of general officers, was present. Though he paid great attention to the various departments, it was soon evident which was of the most interest to him. An -)ld man, whose appearance was striking from the peculiarity in his manner and apparel, came in upon the judge's stand where the General was seated, and asked his permission to name a favorite colt, then on the ground, after him. The request was courteously acceded to by the hero, with the promise of visiting his namesake before he left the ground. The old gentleman withdrew to prepare the colt for the distinguished company, and on the approach of Grant, led him to the front of the stall. Well did he merit the encomiums bestowed on him by his breeder.

The whole group was striking, and as I looked at the few comprising it, I would have given a pretty good trotter 
to have had a faithful picture of the scene. The old man was apparently verging on that period of life allotted by the psalmist as its close, but possessing all the vigor of manhood. His form was tall, spare, and sinewy, the right arm gone, yet with the left he controlled the bounding motions of the vigorous colt easily, the grace of whose movements was rather heightened, than otherwise, by the constraint. His hair was white, hanging in long locks down his back. His clothing was home-made, a kind of blue jean, that set off the tendinous frame to far better advantage than the smoother broadcloth would have done. The fire in the grey eye was as brilliant as ever flashed from beneath the silky veil of the most radiant belle. The animal was of course thoroughbred, a deep chestnut, with lithe limbs and glossy coat, his form possessing the symmetry due his breeding. The General's square, massive face expressed pleasure more than I had ever seen it while receiving the ovations of the most demonstrative crowd. General Logan, with one or two officers of the Agricultural Society and Driving Park Association, were the only persons present. The colt's bridle was decorated with knots of blue ribbons, betokening the first premiums he had received. The old man, after allowing a few minutes to elapse for the General to scan his beautiful proportions and lightness of movement, said, "There is your namesake, General. I have bred many a good colt, but this is the most likely one I ever raised. He has taken twelve blue ribbons, and nary red one."

The General very handsomely signified his admiration, and the old man replaced in the stall the colt whose elastie step was not a whit more bouyant than that of the man who had owned his progenitors for many a generation. I am quite a hero-worshipper, yet I thought more of General Grant for the unassuming way with which he granted 
that old man's request, as if he were the party honored, than for all the battles he ever gained.

Preceptor.- That was a beautiful trait in the character of the successful military chieftain whom a whole peoplo are anxious to honor,-escaping from the plaudits of a crowd to gratify one humble individual by the admiration of his colt.

The plan you speak of, if forced upon the attention of Congress, would do even more for the improvement of horses than the most sanguine supporters claim. Politicians, however, will not see the benefit, as there is nothing to be gained by them from the appropriation. Incorporate with this bill a whole army of useless offices, with rich salaries, and it will go through the House like a "prairie on fire," as that would make places to reward adherents and relatives for their aid in elections. Farmers are the most indolent men in the world in looking after their interests not immediately connected with their bit of land. They never will learn the lesson taught by the faggots resisting all efforts to break them when united, but which is so easily accomplished when unbound. Broach this subject to them, and nine out of ten will admit its merits-not one in a hundred second it with an effort, or sign a petition, if you have not pen ready to place in their fingers. Once make it popular, and the Hon. M. C.'s will vote for it, even if lacking the essentials I have before remarked. How are you going to do this? Not through the political press; their columns are filled with stuff disgusting to a man not biased by party drill. The agricultural press, in their advocacy of fat bullocks, swine, and sheep, ignore the horse that has speed enough to carry one comfortably to mill or market, from a feeling of jealousy at the prominent place occupied by horses and "jockeys" at the fairs, these very horses, enabling managers to pay premiums to cattle 
which were it not for the interest taken by the multitude on the very animals thus decried by the cattle-breeders, they could never do. Our Government, at an outlay of several hundreds of thousands of dollars annually, publishes a work, called the "Report of the Commissioner of Agriculture." One year it was of vast importance to the horse-breeding interest, the result of an article written by one familiar with the subject. The last issue has an account of a mongrel, only amounting to an arvertisement for one individual horse; and the volume preceding the one containing $\mathrm{Mr}$. - 's first-rate article, contained one written by a prominent agricultural writer, yet so devoid of truth that the merest tyro in horse breeding would not have been misled by it. How then will you effect the popularity requisite to carry the bill you propose through Congress and on its intrinsic merits without adventitious aid?

PUPIL.-By each man that subscribes for a turf paper constituting himself an agent and canvasser to increase its circulation, till the masses become acquainted with the efforts that are making for the benefit of the country at large through the improvement of the stock; by calling the attention of people to the course pursued by other countries in encouraging by governmental aid the production of the true type of animals from which to breed; by invoking influential men in every State to enforce their views through channels open to them,-subscribing to truths with which they are familiar, and which would need no further guarantee than their proper signature. I could name hosts of the very foremost men all over the country interested in this project, whose concerted support would insure its success. I read a notice in a paper that has a bearing on this, and reminded me of our former conversation regarding the English women, horses, and trees. I transcribed it, as every country there mentioned 
lends its influence through money appropriations to the advancement of the breed of horses. It is copied from "The English at Home."

"England produces three cljects which are met with everywhere, but which in this island are remarkable for their marvelous beauty-the women, the trees, and the horses. Moreover, every place which raises a race of horses worthy of admiration is also peopled by pretty women. What is the cause of the coincidence is not easy to say; but this strange correlation is not the less real. Georgia rears the best horses of the East. The plains of La Camerque in the neighborhood of Arles, famous for its lovely girls, preserves the blood of the Moorish coursers in a state of nature. The Andalusian maid attains her perfection of form by the side of the most symmetrical steeds of the Peninsula. At Mecklenburg you behold the purest blood of Germany; and when a phalanx of Amazons gallops along the avenues of the London parks, the dazzled eye cannot fix itself with indifference either on the écuyeré or the animal on which she is mounted. Let a young girl draw up her horse under a lofty tree, and you will contemplate, grouped in a single picture, the three marvels of England."

The comparison will hold good in our own country, as will be readily admitted by those who are familiar with the beauty of the females in those regions most remarkable for fine horses. I will not try any more than the author above quoted to account for the parallel. It is very true that the beauty of the thoroughbred is nearly akin to the highest type of female loveliness. The flowing: lines made up of curves identical with Hogarth's line of grace and beauty; the highbred look, the lustrous eye, the silken, glossy hair, the grace of movement, the pliability of limb, and the rounded form free from all grossness. Hang up a picture of the Venus de Medici, by the side 
of that of Beeswing, and you will find more than one point of resemblance.

Preceptor.-Without seeing the resemblance, I will cordially admit that they are both very much to be admired, and after a handsome woman, a handsome horse has the next place in my favor. But all this will not help the passage of the bill through Congress. With the co-operation of the influential horse admirers, both East and West, the thing would be easier of solution. This certainly looks like the most feasible way. I know of hundreds who would do everything in their power to assist in getting such a law enacted. Horse races having become the fashion at Saratoga, would materially advance the cause. Yet it wants to be looked at in a higher light than merely the means of aiding a listless crowd to dawdle away their time. The very existence of a country may depend on the quality of the horses; and if those used in the late war had been of a higher grade, the cavalry would not only have been more effective, but the cost to our government would have been much less. In time of peace the merits of the horse, if not so apparent are equally of the same importance; the horse, more than any other animal, belonging to the highest civilization, and aiding more than all others the development of a country.

This talk has rather led us away from the animals immediately under our charge. As their treatment will need but little variation for a week or two, till they commence jogging, the only thing required is to see that they are regularly fed, groomed, and walked, watching things that may appear trivial, but which often grow in magnitude till they are difficult to eradicate. Idle horses, or those not working very hard, are apt to acquire habits that are very annoying-as crib biting, weaving, pawing, disliking to go through a doorway, kicking the sides of the stall, \&c. 
The first is considered by many an unsoundness, as well as a disagreeable habit, and they would reject a horse, nu matter how good, or ever so well suited to the business they wanted him to perform, if he possessed this trick. I do not look at it in this light, and apart from the annoyance of listening to the sound usually made by those addicted, am not aware that it injures the animal. The idea that they "suck wind" enough to make them any more liable to colic or rupture of the intestines, is certainly false in all that have come under my observation. One of the finest "Gentleman's Horses" I ever knew was a confirmed crib biter. He was a large, brown gelding, nearly sixteen hands high, stylish and showy, had trotted in $2: 28$, could pull a wagon almost that fast, gentle and reliable in every place. If there was anything he could lay his teeth on he was sure to crib, yet always kept easy ; would stand an immense amount of work, and trot long distances, but was never, to my knowledge, sick a day in his life. The last I knew of him, he was owned by a gentleman in Cincinnati, who valued him very highly for his many good qualities. When horses have once acquired this habit, I doubt if they ever forget it. By having a box or stall sealed up perfectly smooth, they cannot get hold of anything, and few horses will crib if thus kept, though some press their teeth against the smooth side and accomplish it. There is a muzzle made, through which horses can pick up their feed without being able either to bite or get hold of anything with their teeth. It is made with two small iron bars, joined to the nose band of the halter, far enough apart to allow motion of the lips sufficient to pick up their food.

Weaving is another very perplexing habit, acquired from, I know not what, and when once learned I never could cure it. Fretful, high tempered horses are most prone to acquire it, and when at full work generally quit 
of their own accord. Some horses cannot be easy till they have pawed their bedding quite out of the way, leaving them the bare floor to lie on, soiling their clothes and liair in a manner not very agreeable to the groom, his duties thereby being much increased. Turning them loose in a box, fastening a elog above the knee, will sometimes cure this evil. When the latter is tried, there should be a pad applied to the shin, to keep the clog from injuring the very sensitive membrane covering the tendons. From having been led carelessly through a doorway, where they have been injured, horses are afterwards fearful of attempting the passage, and when urged to do so will go through with a bound that adds greatly to the danger. Compel the groom to get the horse square with the door before leading him out, holding him firmly by the halter, so that the leap cannot be made, never urging him to go faster than the slowest pace; in no case permitting a blow to be given. Rather than use force, either blindfold or back him out, until the fear is overcome by judicious usage.

Kicking the sides of the stall is a very unfortunate custom some horses possess, and no amount of punishment will cure one that has become determined in the practice. Clogs and whips are of no avail, and it seems to be almost a species of insanity, compelling them to kick away till their legs are bruised and swollen from the blows. I liad one very fine horse that I had tried every method of cure I could hear of without effect. When he was shackled, of eourse he could not kick, neither could he lie down, and I have kept him standing for a week, when in less than an hour after the straps were removed he would fall to kicking as furiously as if the lost time had to be made up. I cured him by putting him in a stall about the width usually made in livery stables, the sides of the same length of the horse when standing with his head at the 
manger. A bar was dropped behind his quarters to keep him from backing. Through the sides of the stall a slot was cut large enough to admit a plank two inches thick and eighteen inches wide. This plank came within half an inch of his loin, and of course he could not raise himself to kick. It was amusing to watch the rage he would get in at finding his most violent eflorts frustrated. I looked for him to strike with one foot, and intended, if he had done so, to let a shelf extend on each side as high as his gaskins, which would have prevented it. The plank over the loin, however, cured him, and I never heard of his relapsing into his former bad practice, although going from my stable into a stall that had not these appliances. 


\section{CHAPTER XII}

CONSTRUCTLNG THE TRACK-BREAKING COLTS.

PuprL.-Stable tricks and vices are very annoying; and the old adage of prevention being tenfold better than cure, is worthy of being accepted as saving an immensity of trouble, by nipping in the bud habits that become incurable when allowed to seat themselves. Idleness and confinement are a source of most of them, and when horses are in sufficient exercise there is not much danger of their acquiring them. Having now a little spare time before dinner, I will take up the history of the Iowa farm, broken off when the training-barn was built. We will now construct the track, and begin the education of the colts, by this time well advanced in their second year. The field where we will build the track has already been partially described; lying on the north side of the road that divides the estate in nearly equal portions. I find an old habit-so old, indeed, that it is one of the very first of my recollections-still clinging to me, and which I will never be able to rid myself of. My life has been twofold: the actual, made up of rather more stirring scenes than falls to the lot of every one, in which I have exhibited a fair share of energy and determination; the other has been an inner life, which has more than occupied its due half of my years, - a dreamy, inactive one, where fancy has taken place of reality, affording day-dreams, mure entrancing than the rosiest visions, dreams seen while the 
spirit was freed from its gross material covering, rambling untrammeled through every clime, and witnessing wondrous things, the recollections of which have never been effaced. These fantasies now make up a definite period of my existence. It requires a strong effort of the memory to separate the ideal from the actual, and I have often detected myself recounting some adventure which was a mixture of both lives.

I remark this, to account for my talking about the breeding-farm as if it were a thing tangible and real, with the brood mares, colts, fields, paddocks, and buildings, just as I have described them. When I return to Iowa, there will be times when I shall walk over the pasture field on my own little farm, saunter along past the church and school-house, and be disappointed, in climbing the little elevation between these and the stone-house, not to see the colts gamboling in the field, or the prairie rose and woodbine draping the house, relieved now by nothing: save the shade of the oaks in the background.

The field is slightly undulating, and of sufficient extent to get any shape we may desire the track to be. We will adopt the one you recommend,-two parallel sides of a quarter of a mile each, joined with semicircles of the same length. The soil is just what is best adapted for the purpose,-a dark sandy loam, the proportion of sand being small. The richness of it is attested by the corn growing so high that there are stalks where the ear is almost out of a man's reach, with the tassels waving fifteen feet above the ground. We commence by plowing deeply, either using a double Michigan plow drawn by four horses, or make two teams follow each other in the same furrow. The advantage of deep plowing, is to get a stratum of this easily pulverized soil that can be leveled without leaving hard places near the surface, causing inequalities that will be hard to get rid of. The plowing accomplished, the 
harrow and brush are used till it is in as fine tilth as would be necessary to raise a premium crop of onions. We will now commence walking the horses on it, which will destroy the even surface and tread it into holes. A. scraper will then be needed, and according to my idea, the best is constructed on the following plan: Talke iwo oak planks, fourteen feet long and a foot in width. They are placed together so as to form two sides of an equilateral triangle, the apex joined by strong iron hinges. Bars are framed in near the base, fastened only at one end, so that the planks can be brought together or separated as wanted. The plank on the right hand side, as you stand behind it, is faced with a thin plate of steel, extending half an inch below the wood. A chain runs from the point two-thirds of the way along this plank, so as to change the line of draft as required by the spreading of the instrument. At the very end, a handle is bolted on, by which a man guides it, and allows the dirt pushed away by the steel-plate, to be deposited wherever desired, by lifting on this handle.

We commence on the turn, closing the scraper till it is six feet across the base of the triangle, the left-hand plank running in the furrow, which prevents it sliding to the left, and the other side carrying all the loose dirt the width that the instrument is set to the right. We keep on, cleaning out the ditches the same way as on the stretches, only that we close the scraper still more as we want a level surface there, while the turns should be formed so as to have a gradual slope rising from the inside. The outside of a track twenty feet wide should be raised two feet. Having followed the inside furrow once round the track, we open the wings of the scraper, keeping the draught chain regulated so as to carry the dirt on the semicircles further towards the outside; while on the stretches it is drawn in such a maniner that the loose soil is leveled 
only, a very small proportion of it finding its way outside. As the track becomes hard, we load the scraper, to enable it to cut off the inequalities, depositing the surplus in the depressions.

We will also want a harrow, built after a different plan from the approved agricultural pattern. The teeth should be made of steel, a quarter of an inch thick, and one and a half inches wide, hammered to a point, and the edge sharpened. These teeth are set in a frame and inclined a little backward. They are placed in three divisions, arranged so they will cut the space in which they run into inch strips. A pole is necessary that it may follow the team, which is further controlled by handles like those of a plow. Should the track become hard, this instrument cuts it up very effectually to the depth required, leaving a light coating of loose dirt, which has a great effect in moderating the concussion consequent upon the rapid motion of a horse, also filling up the space between the shoe sole and frog, the benefit of greater elasticity in yielding to the jamming force of the blow thus secured. We will find the constant use of the harrow, brush, and scraper needed during the first year; after that the track can be kept in order with a great deal less work.

After a rain, the track should be harrowed when it has become dry enough not to clog the teeth. This keeps the surface from drying and cupping out. The brush spoken of, I make by having an axle ten feet long placed in the hind wheels of a lumber wagon, with holes bored in it two inches in diameter, and six or eight inches apart. The holes are sloping, so that, when the wheels are on and the brush fastened in these holes, it will be held firmly against the ground. Elm or birch is the best, the pliant twigs lasting a long while before they need renewing. This levels the newly harrowed surface admirably, and I have never known any other instrument needed to keep 
a track in first-rate order. There are, of course, exceptions. The Chicago Driving Park Course is on a level, sandy prairie, which cuts up in dry weather till horses can only wallow through the loose soil. A coating of clay was used, but it was of a character that slaked, the track becoming nearly as bad as before the application. It was then covered with a thin coating of coal cinders, obtained at a neighboring rolling-mill. These, when properly pulverized by a very heavy roller, made a great improvement. Wet weather, which before the application of the cinders would have precluded work upon the track, now scarcely affects it.

On this rich prairie soil, there is not much difficulty in either building or keeping a track in order. The team does the whole work, and I have seen as good a trainingtrack as any one could desire, where there never was a spade or shovel used. The drainage is effected by the slope of the track, carrying all the water to the inner ditch, two small culverts being sufficient to convey it to the outside, where the natural depression makes a channel for it to flow into a little stream that carries it into the Mississippi. As I remarked when locating the stable, the track runs almost to it-so near that the shed for the wagons and sulkies takes up nearly the whole space between them. The track is fenced around, the first curve with a board fence, the boards close together, and so high as to present a formidable barrier, should a colt try to bolt as he approaches the barn. The rest of the distance the fence is of wire, and the newly planted cotton-woods are expected to take the place of the posts; acquiring sufficient size long before the present ones decay. The cottonwood was certainly created expressly for the prairie, its quick growth and hardiness making it the very tree needed for many purposes. It can be trained to almost any form, either throwing out its branches near the 
ground, making a perfect pyramid of verdure when in full leaf; or, by pruning the lower branches, it shoots up with a top not large enough to injure vegetation by its shadow, or prevent the sun evaporating the water on the course. This makes a fence that will last for many years; the galvanized wire being nearly indestructible, while the living posts will be good for generations to come. The trees are planted only six feet apart, and the wire will be fastened to them by staples driven into the wood. The only care needed will be to cut these staples as the tree increases its growth, and replace them with others. If this were neglected, the rapidly growing tree would soon enclose wire and staple, and the swaying of the tree in the wind might break them, which the play of the wire in the staples will prevent.

We are now ready to commence breaking the colts in a business-like manner, and as the pleasant Indian Summer days arrive, we will give our pupils the second lesson in the horse "rudimans." They are all thoroughly halterbroken, never having been allowed to go a week without being led and tied up. The head-stall of a bridle, with a small snaffle bit, is put on over the halter, accustoming them to wear it by leaving it on when they are fed. Very soon the novelty is acquiesced in, and they become familiar with the bit. We now lead them with the reins attached, in lieu of the halter, accustoming them to turn to either side as required. The harness, or rather the pad and girth, is placed on them, and the driving reins are applied, without passing them through the terrets, so that, if a colt turns around quickly, we still have the reins in a position to control him. Each colt is practiced thus till he acquires a mouth, that is, till he will obey the least touch of the bit, without bending his neck or sidling his body. It requires command of temper, and great patience, to wake this part of the training effectual. But when 
once thoroughly accomplished, the benefit will well repay the time thus employed. It is not pleasant to walk day after day behind a colt, watching his slightest motion; now touching him with the whip to straighten him or make him answer the bit, compelling him to stop at the word of command, and to move in a straight line till you signalize him to turn with the rein. This is not as pleasant as to sit in a sulky, and have him draw you while administering the lesson; yet you teach him this way far more thoroughly. If placed in the shafts before he knows what the bit means, or what is required of him in this now situation, he will be far more likely to get in trouble. Should he move sideways till he strikes the shaft, he is frightened, and throws himself violently against it, upsetting the sullky, or he becomes sullen and will not move at all. The sharp single blow of the whip that you can give in the former situation with impunity, cannot now be ventured on without risk. You lead and coax till he plainly understands he has got the advantage, and will keep it. I can exemplify this by recounting my "experience" with a young mare I was training. She had been broken when I got her, and the first notice I had of there being any thing wrong, was her refusal to go past the barn, which was within twenty yards of the track. If led for a few rods, she would go on till she came around, only to be more determined in her obstinacy. A touch of the whip showed she had been coerced in that way, and knew how to resent it by wheeling so abruptly as to endanger upsetting the vehicle. I took her out of the shafts, took a long whip and gave her the word to proceed. She shook her head when a light touch of the whip was given. The moment she attempted to wheel I hit her with all the force I was master of in one blow. She retaliated by kicking as violently as I had struck. I straightened her into the track, and on her refusal struck her the one severe blow 
again, giving her time to go on and never repeating the blow till she was placed properly to go straight past the barn. It was not long before she became satisfied that her best course was to do as she was wanted, and passed and repassed the barn without any hesitation. Had I attempted this lesson when she was in the sulky, confining her with kicking-straps, in all probability she would have thrown herself, breaking the shafts, or doing mischief of some kind.

After the colts are thoroughly broken to the bit, the rest of the harness is put on, and as soon as they become familiarized with the breaching dangling about their quarters, they are placed in the shafts, taking the precaution of using a kicking-strap, though in all of the colts I have broken but one or two have needed this safeguard. By the time the snow and frost have followed the golden autumn, our colts are all broken, and are wintered much the same way as the preceeding season, fed all they will eat heartily, and allowed plenty of opportunity for exercise. They are now nearly as handy as old horses, having been driven single and double, without requiring them to show more speed than their natural trot. When brought safely through the winter, so well grown and furnished, that they look like three-year-olds, nearly all of them being over fifteen hands, and "thick through as a hay-stack."

I beg pardon, as I find I have been talking as if I were the master, in place of the scholar who hopes to profit so much from your instruction.

Preceptor.-There is no need of offering any apologies, as I have previously told you that your experience in rearing, breeding, and handling colts has been much more extensive than mine, and that you are therefore capable of teaching me this branch of the business. I never broke a colt in my life, though I have had horses that I would much rather have had in a state of nature than as they 
were, possessing all the bad tricks a faulty education could engender. There is one part of your conversation that I want you still further to explain,-the mouthing, as you termed it. Am I to understand that this is to take the place of bitting, and if so, how it is effected, by merely driving with the pad and reins?

PuprL.-I am glad you have questioned me on that point, as I have had frequent arguments with those who hold to the barbarous practice of bitting, when done by the old appliances, which is to have a wide surcingle, or rather leathern roller, with rings, buckles, and loops, in every place where there was room to sew them; a strong crupper and bridle, with a half-dozen reins attached; a large snaffle bit, with three or four little pendants joined to the ring in the centre, like those worn on Mexican spurs. These are put on the poor colt, the bearing reins tightened till his head is thrown in the air, when the side reigns are buckled, so as to compel him to bring his muzzle as close to his breast as the check will permit. $\mathrm{He}$ is now turned into a yard, and his tormentor takes a whip, and forces him to run around in this confined space till the man becomes tired. The victim is not released then, but is left to fight against the bit, and endure the horrid punishment for hours at a stretch. When asked the reasons for thus cruelly treating him, you will be answered, " that he may give way to the bit, get a proper, elegant carriage, set him on his haunches," \&c., \&c. There is not an iota of sense in all this talk. The sensitiveness of the mouth, on which much of the pleasure of riding or driving a horse depends, is destroyed. The constrained carriage of the head is anything but elegant, while the throwing on the haunches, carries no meaning with it at all. It is very true that when a colt is first put to work, he has a slovenly way of going; his head is carried low, and his whole sppearance is very different from one that has ac- 
quired the graces of the manege. You see no lack of beauty of motion and carriage in the same animal when playing in the field; and only give him time enough to learn the lessons that cannot be hurried by a few days suffering in the bitting bridle, and he will surpass those with tempers spoiled by that persecution. The first lessons our colts received were given before they were any more afraid of mankind than they were of their dams. King is the only instance I ever knew of a colt when first foaled, being terrified at the approach of a man, who took the proper method of making his advances. These colts - have been groomed, fondled, accustomed to have their feet taken up, and hence are like old horses in these particulars. During the summer, when the halters were put on, they were allonged by attaching a strap to a ring in the front part of the nose-band, which I think much better than performing the same operation with a bridle or cord put round the lower jaw, as that is apt to make the mouth unequal by a greater pressure coming on one side. When we commence driving them in the manner recommended, a check or bearing rein is applied, so loosely, however, that it will not be felt unless the head is thrown down lower than the level of the withers. This is made shorter by degrees, accustoming them gradually to the constraint, but it should never be allowed to interfere with an easy carriage of the head.

I have found in some headstrong colts a propensity to try to rid themselves of the check by throwing their heads violently down, in some cases succeeding in breaking the check rein or crupper strap. A judicious touch of the whip will generally reform this conduct, and an additional prevention will be found by using what is generally termed the "Kemble Jackson check." I prefer using separate bits for the driving reins and check, if even applied in the customary manner. The check bit is drawn too much into 
the corners of the mouth, while, by using one untrammeled, the horse heeds its suggestions quicker, and the driver is not met by an opposing force which often counteracts the effect intended. The muscles of the human arm are far better than any dumb jockey, St. Andrew's cross, or other contrivance used to mouth horses, and keep the sensitiveness and delicacy of the bars uninjured. The force is regulated by attending circumstances, and one thorough lesson given in this way, will effect more than any one not familiar with the plan would believe possible. I do not believe in talking much to the colts when breaking them. A pat on the neck, or the hand passed caressingly over the face and nostrils, is much preferable to many words or. much fussing. The commands should be distinct, and the tones of the voice, when giving them, as little varied as possible. Every command must be enforced, and hence the greatest caution must be observed that we do not require what the colts cannot yet be expected to perform. There is no question but that much benefit followed the teachings of Rarey, though I am just as positively certain that the injuries resulting from charlatans, who have traveled. over the country exhibiting their ignorance and brutality has more than counterbalanced the good. I saw an instance of this lately where a fine young mare-the get of the Falcon, and out of a thoroughbred dam-was the victim. She had been suffered to grow up without handling, and being a large, powerful animal, her owner disliked to commence with her education himself. A pair of these traveling knaves who advertised to out-Rarey Rarey, and claimed to know all of his method of "horsemanship," and a good deal more, tools this mare in hand. The battle between the noble animal and the base bipeds was severe. They had tied a rope round her hind pastern and into the bit, and the result was what any one of sense might have expected. She tore her mouth to pieces, and injured the leg 
so that there will be always a permanent enlargement of the upper pastern joint. They effected nothing, and when I saw her she could not be led out of the stable, if strangers were present. I am very peaceably inclined, and after a quarrel, feel exceedingly uncomfortable till time obliterates it from my mind. But had I happened along when these fellows were ill-treating this daughter of the Falcon, there would have been a case of assault and battery, sure.

Preceptor.-Your reasoning is, that bitting, as ordinarily practiced, is prejudicial ; and not having much knowledge of the subject, I am unable to say. It is certain that a horse with a faulty configuration can never be taught to carry himself in a proper manner. It would also be hard to say which carriage is the most proper for a fast trotter, as there has been as much difference in the celebrities in this particular as in others. Some have argued that style is incompatible with speed of the highest rate. That species of style which is shown by high, faulty action, and a peacock demeanor, does not, it is true, comport with fast trotting. Style, the result of proper form and good breeding, is quite a different thing. The neck justly attached to the body, springing from the sloping shoulder, and ended by the right setting-in of the head, requires but little artificial aid to have it carried in a way the most favorable to appearance, and not in any way antagonistical to speed. The bearing or check rein, is of great importance in trotting, and the one you have alluded to as the Kemble Jackson is little understood, being used right and wrong by those unacquainted with what it is intended to effect. It is a powerful auxiliary in handling turbulent horses, or those that require to be more "thrown on their" haunches," - though I agree with you that that term, so long in use, does not rightly express what is meant. I 
will not introduce the subject of reins and bits till after dinner, when we can give it the attention it deserves.

To-morrow, I intend starting on a trip that I had contemplated making later in the season, but have concluded that you will miss me less now than after your horses commence the other stages of the preparation. They will need watching, to see that their feed is regulated to suit the appetite and keep them in about the same flesh as at present. When feeding time comes, every horse ought to signify his desire by neighing; and if he does not express his anxiety on hearing the sieve rattle, his rations should be diminished; and those that unmistakably show that their appetite has not been satisfied must have theirs increased. The colts' mouths will have to be examined frequently, to see that, while undergoing the process of dentition, their mouths are not made sore from the old teeth not being shed at the right time. The mills teeth are partially absorbed by those growing to take their place, and often hang by the integuments adhering to the side of the tooth, and preventing proper mastication of the food. Old horses frequently suffer from the grinding teeth not wearing away evenly, leaving sharp, jagged points to wound the inside of the lips. The file must be used to reduce them to a proper shape. Horses that are suffering from this cause will signify it by partly chewing the hay, which will fall out of their mouth, in consequence of holding their head on one side to allow the food to come under the pressure of the teeth on the well side, \&c. A decayed tooth may be the cause, though generally it is the sharp one wounding the tender parts adjacent. With the file made on purpose for this section of horse dentistry, and which is guarded from injuring by being made round and smooth on the back, the job is easily accomplished, though I have seen cases that were neglected til] 
the wounded check became ulcerated, making a sore that was very difficult to heal.

By the time I return, the Falcon, Never Mind, and Jane will be ready to be harnessed. The colts you may begin at once with, as the more practice they get, the quicker they will learn; and not expecting them to trot fast enough to require first-rate condition, we will make the first consideration to teach them as much of their harness education as the time will permit. This is a matter we also discuss after dinner. I feel that my digestive organs are in proper order, and when the time comes for me to take my feed, I require no stimulas to eat with a relish.

PuPIL. - I am sorry to hear that I am to be deprived of your company, though I am pleased you have made up your mind to absent yourself when your instructions will be of less importance than in the future. I regret, however, that my affairs have caused you to change the time of your trip from that contemplated; and you place me under renewed obligations by neglecting your own interests to further mine.

Preceptor.-You need not mention the obligation, as perhaps I will leave you again at my ordinary time of transmigration. I have some friends in the country with whom I spend a couple of weeks semi-annually, and have always timed my visit in the winter to the holidays, and in the summer to the middle of July, when my horses could be advantageously thrown up for a while, and recuperate their health and strength; all parties benefited by laying in a fund that will carry us triumphantly through the fall campaign. 


\section{CHAPTER XIII.}

BITS, SNAFFLES, CHECKS ; CURE FOR PULLING HORSES, FOR CALLOUS AND SORE MOUTHS; TURKISH BATH, \&c.

Preceptor.-I find that after eating heartily it takes a little time before the ideas flow as readily as when digestion is further advanced. The subject we are going to talk about is of importance, requiring full use of our reasoning faculties, unobstructed by the over-indulgence in the good things we get here. Smoking, though, certainly assists in collecting the scattered reins of thought; and through its soothing influence the mental faculties throw off the lethargy induced by hearty eating, and ideas soon coming faster than one can find words to express them.

A person not conversant with horse life in all its phases would be surprised when shown a full collection of bits,-many of them useless, some worse than useless, testifying that their inventors would have been in their appropriate sphere if the old Spanish Inquisition still needed their aid in devising instruments of torture. The snaffle, in its various sizes and forms, is the most useful; and were we restricted to one pattern, that would be the one chosen. But as we can pick and choose throug! these and through all the varieties of the bar, chain, and leather, it will be very hard if we cannot suit our horses' mouths. The curb is generally thought inadmissible for trotting purposes, though I have seen one or two instances where its use was beneficial. It will be almost im- 
possible. to prescribe, merely from hearing how a horse performed, or even by driving him, which style would be best to use. Experiments will be the only guide to direct us, and we will find many trials necessary to know which is the best for each horse under our charge.

Colts' mouths are generally greatly injured in the first lessons given, and the delicacy of feeling destroyed, by the use of the machinery you spoke of. Many seem to think this is a great point gained, and offering a horse for sale, will tell you that he has a first-rate mouth,-meaning that he has learned to pull against the bit with all the force of the masticating muscles, regardless of the pain to the lips and bars. When I commence driving a horse that has not been injured in the mouth, I always use a medium-sized steel snaffle, with long check pieces and stout rings. Should he pull too much on this, or drive on one rein, I change it for a bar bit, again taking the medium-size. If he shows a disposition to run away, I put a chain bit in his mouth, which is as easy as any, if his perversity does not force me to punish him with it by "sawing.' Persistency in pulling generally compels me to use the high check. Should the horse's action not be ajuriously affected, the application is generally effectual. Before using it, I try the large leathern bit, with which I have cured the most obstinate cases. Pullies or slip reining are only admissible when there is actual danger of running away. The method lately patented will usually stop the most obdurate. I have long been acquainted with the effectiveness of having the power to throw a horse's head up when he attempts to kick or run away. Still there is an advantage in the novelties that are now protected by patents. There is no cure for a pulling horse, however, like that of not pulling against him; though it adds to a person's steadiness of nerve to know that he has the applicances to stop a horse, should gentle- 
ness not prevail. A horse can never be radically cured. of this propensity to pull, unless the driver is determined not to gratify the morbid habit, but to ease away whenever he rushes for the bit, and teach him that his comfort and ease of going is dependent on his ceasing to pull. The celebrated English jockey, Chiffney, wrote a treatise on riding a race horse with a slack rein. I have never been fortunate enough to see it; but, judging from the success he met with in "his mounts," his practice indicated the truth of this theory. Before leathern bits were in general use, I made one with a silk handkerchief. I did not transmute the silk into leather, but wound the handkerchief through two rings for check pieces. A pulling mare that I made it for was reconciled, and worked as kindly as any I ever drove. Some horses will not take hold of the bit, not even bearing enough on it to keep the reins straight. In some, this results from want of condition; others seem to be afraid of pressure at all times; while with others, it only occurs when they are very tired. The bit is frequently the cause; and when a horse has this very troublesome failing, I shift the bits, and sometimes find that he has a liking for some peculiar pattern, and will pull sufficiently to steady him, which is all that is required. The bearing-rein has a great deal to do with the education of a trotter; and though, like many other things, fashion has proscribed it for a time only to sanction a more stringent use of it at another period. Very few horses require to be checked alike. A difference of a few holes will sometimes make a variation of ten seconds in the time for a mile.

When a horse requires his head to be elevated very high, then the "Kemble Jackson," or head check, is most proper. Having a ristinct bit for the check rein, allows the one attached to the driving reins the right position in the mouth, which would not be the case if it were drawn 
as far up as the angles of the lips would permit. Some object to this check on the ground of the pressure on the poll. This is not so great as is imagined; neither is it heavier than when checked to the same altitude in the ordinary way. The horse not being able to lower his head by curving his neck, he cannot get so much purchase, either on the bearing rein, or those that we drive with. This gives the advantage in managing turbulent horses I spoke of before dinner, as we get them in a position where they cannot use their strength. To illustrate this : grasp me round the body with both arms, and at the instant you apply your whole strength to throw me down, I push up your head with a slight touch of the hand on your chin, and you will fall as if shot. This check was invented, or at least used, to cure the celebrated stallion, from which it derives the name, from throwing his head down when in a break, and when he could not be made to recover his trot with his head in that position. The rapid improvement in this horse's gait, which placed him at the very top of the list as a weight drawer, is ascribed to its use, as well as his going into the hands of the "Field Marshal." This title, applied to Hiram Woodruff as a driver of trotters, is hardly right. He should be called the Emperor of the Knights of the Whip and Snaffle,-the Field Marshals consisting of those who have a secondary renown. Frequently there is a marked change in the action of horses driven at first in this check, as the weight of the body is differently distributed by the position of the head. I have read an account of a series of experiments made by French veterinarians in weighing a horse. The scales were made in two compartments, or rather two platform scales were placed contiguous, so that the hind feet were on one, and the front feet on the other. It was surprising, the difference between the weight of the forehand, when the head was elevated or depressed. 
A horse that has a long dwelling stroke is compelled to shorten it when his head is thus elevated, and, being quickened in his recovery in a greater ratio than what he loses by shortening his stride, of course goes faster. Horses that have the reverse of this action would in a corresponding manner be injured by the appliance. When an animal is narrow between the jaw-bones, pulling compresses the throttle, and the result is roaring, high blowing, whistling, according as the area for the passage of air is diminished. The outstretched nose makes a more direct route from the nostrils to the lungs, and the breathing is easier. The Kemble Jackson check is proper, then, when a horse throws his head down in a break, and refuses to catch his trot only at his pleasure, when the head is thrown heavily on the bit, "hogging," as some term it. There is a modification of this check for an animal needing an additional restraint to the usual paraphernalia, for his proper government, but being so narrow between the jaws that the breathing is impeded, and whose action will be benefited by raising the head. The reins run over the forehead, and through the loops between the ears, similar to the Kemble Jackson; but in place of running to the water-hook, is furnished with gag runners through which the ordinary bearing "rein is run. I never could see that there was much advantage gained, but I have known men, very successful in training, who hold it in high favor.

The allongeing you mentioned as part of the system of breaking the colts, I have not viewed very favorably, and have imagined that many horses drove on one rein owed the habit to having been so used by calouses forming on one side of the mouth, while the other was natural. I have thought, with other objections, that are perhaps of not much weight, that there is danger to the legs from the violence of the animal, when confined in so small a space. 
PUPIL.-To avoid giving this one-sided mouth, is the reason I use the halter with a ring in the noseband; and when I want to tame an obdurate, headstrong animal that cannot be handled with the halter, I employ, in lieu of a bridle, a small rope about half an inch in diameter. This I form by making a loop that is large enough to go round the lower jaw, tying a bowline knot that will not slip. The rope is placed over the neck, and the end run through the loop on the left side of the jaw. The pressure then is equal on both sides, excepting so much as is produced by the friction between the loop and rope. Soft ground or snow is indispensable, especially when teaching the colt to run around in so small a circle; but it is astonishing how soon they learn to go with safety to themselves. They find out to a nicety how far the rein or rope will allow them to go, and will just keep it straight without trying to enlarge the circle in which they are moving. I have practiced colts in this way for many years, and have never been able to detect any injury to their legs from so doing. You mentioned having known the curb bit used to advantage with some trotters; and I have known one at least that got a good deal of his trotting education in one of that character.

A celebrated western horse, that ${ }^{\circ}$ has trotted low down in the twenties, and is thought by many enthusiastic admirers to be able to cope successfully with the best of the eastern flyers, commenced his career when he could neither trot fast, nor be relied upon every time to do what he could, having a failing of buck-jumping whenever called on to go a little faster. He was sold for a trifle, very few recognizing him as a horse of any promise. The first races he trotted he was easily beaten, through his proclivity for going into the air. His owner, whose silvered hair and beard betokened that the vigorous days of manhood had. passed, drove him on the road the following winter, and 
till late in the succeeding spring. In order to drive him easily, he used a curb bit, dashing down Michigan Avenue in a sleigh, taking the lead of all the speedy ones that congregated on that street of fashionable resort. No matter how icily the wind blew from the congealed surface of the lake, he was always on hand, and his "take care, _-," reverberated above the merry tintinnabulation of the "bells, silver bells." When the frigid barrier was removed, and the clear liquid "broke into dimples, and laughed in the sun," from the perfumed wind that had not yet lost the aroma of the orange-blossoms on its way from the fervid South; when the sails of many vessels loomed white against the horizon, and dark columns, like that which preceded the children of Israel by day, towered upward from the gallant steamers that were plowing their way from the harbor; when the birds were pairing, and the prairie-flowers making their first appearance, _ would be seen jogging leisurely through the sand on Wabash Avenue down the road by the "ribbed sands," where snug cottages nestle in the shade of fir and spruce, and where the climbing rose was showing its green leaves on the trellis, soon to shine resplendent in its gorgeous blossoms. The sleigh has given place to the light wagon or sulky, but no change has taken place in the bit. Here is a good piece of road, and "take care, -, is heard above the sounding of the surge, or the rattle of the wheels. The old man is waving his cane over the horse's back, like the baton of a leader of the grand orchestra. His white hair and long beard are flowing behind, like the streaming pennon of the propeller in the background, and his gesticulations are as violent as ever Julien displayed when the crash of cannon and the rattle of cymbals were keeping time to the brazen throats of a hundred instruments. Truly, the horse is going at a fearful rate; nor has he time to buck-jump. The swing- 
ing cane is remembered, and he knows that a mistake will surely change its direction from the horizontal to the perpendicular, leaving its impress on the black and shining quarters. Predictions were rife that what little good was in the horse would be cramped out with the curb, or beat out with the cane; but all such prognostications proved false. He never afterwards lost a race; and when rushing down the stretch a twenty "clip," I always thought he recked little of the whip or the " $g$ "lang" of his former drivers. It was visions of the waving cane and streaming hair that carried him along, impelled by the recollection of a power he had been made to acknowledge. I would not take away a jot of the well-merited reputation the successful drivers of this horse have earned; but I cannot quite shut my eyes to the importance of the lessons he got from his owner, though administered in a way not considered the best by "horsemen."

Preceptor.-Your episode is the best exemplar of the difficulty of saying what kind of a bit is best calculated to use, while trying to improve the trotting speed of a horse. In fact, when I commenced this conversation, I expected to be able to impart a great deal of information, but find that actual practice will be the only thing that will illustrate the effect of different bits. What a variety of inventions I have seen, to cure a horse from carrying the tongue out of the mouth or over the bit, and all of them failures! The best remedy that has come under my observation is the largest sized leather bit, filling up the mouth so that the horse is glad to keep the tongue in its proper place. When the mouth becomes sore in the angles of the lips, it is often a very troublesome matter to cure it. One of the best remedies is a wash made with a few drops of creosote, combined with diluted aqua ammonia; and it is of great importance that the pressure of the bit should be removed. To effect this, I have the noseband of the bridle 
made of a thin steel plate, well padded, and covered with soft leather. On each side, a small steel pin makes a joint for another plate that extends down the cheek, and is attached to the bit, leaving a free motion forward and backward, but effectually stopping the bit from rising above where we intend it to stay. This is also a capital contrivance where horses pull on one rein. When this arises from one side of the mouth being sore, or from the callouses I spoke of, horses generally bear on the side that is sore, and, by lowering the bit into a well portion of the mouth, not only gives the mouth an opportunity of getting well, but greatly enhances the pleasure of driving.

The celebrated writer, Mr. Brindley-“Harry Hieover"-when appealed to for a remedy to stop a mare pulling on one rain, recommended a snaffle, plain on one side, the other very much twisted, placing the twisted part on the side she pulled to, so as to punish that side, and render it as sensitive as the other. This advice I deem wrong; and any one can convince himself of the fallacy of it, by observing that the animal tries to modify the pain of the pressure of the iron on the wound, by pulling till sensation is not so acute. Should the habit arise from one side of the mouth being calloused, then, by compelling the bit to stay in another part, an opportunity is afforded for the thickening integuments to soften, just as the hard, horny palm of the blacksmith becomes soft when relieved from work. We will now take a retrospective glance at the first part of our training exercises, which is soon to be followed by a stage that will require still more strict attention. Training is not alone, what some have defined it the art of increasing the bodily health and vigor to the highest pitch. If this were the case, the system would be benefited by continuing the exercises for an indefinite period; and, barring accidents, a horse would become faster and stronger the longer he was kept in train. This is true 
in a relative sense ; for, if the work is given judiciously, the animal will keep on improving till the summit is reached. Yet this is far short of the time a horse could be kept in robust health, if not called on for the display of his utmost speed and endurance.

English trainers claim to be able to have the horse at his topmost rate, the very acme of condition, on a designated day, but will not engage his staying there fortyeight hours longer. When this point is reached the bent bow must be unstrung, and that very carefully, or the recoil will be more dangerous than the bracing required to bring it to bear the necessary strain. Training, then, is to enable the horse to do deeds, without injury to his health, that, before the preparation he was utterly incapable of performing, and, by giving a season of rest to recuperate the taxed faculties, render him capable of repeating the feat, till the time comes when years abridge his power to perform. Again : the trotter has the advantage of the race horse, in not requiring so long a time to recover; the exertion of nerve and muscle not being so great. It is useless to argue that a fast-trotting gait is as tiresome as the run. Many claim so without having taken steps to prove it; like those who argued that a live fish would not increase the weight of a pail of water, when immersed in it, but that the "four-pounder," water and all, would only be the same as before the addition. All their arguments were of little avail when the test of the balance was applied; and any one who will bring trotting and running to a practical test will be satisfied which is the most arduous.

It is very probable that Dexter could run in 2:18 1-5 easier than he trotted in that time; but run him nearly at his best speed for the same distance, and I will warrant the distress will be more apparent. This first stage, as I 
remarked previously, is a required probation, to enable the succeeding ones to be endured with benefit.

Air, food, exercise, and a strict attention to cleanliness, are the great adjuncts in bringing all stages to a successful termination. While walling, there is less liability to get wrong, in comparison with the stage requiring faster work; but walking can be prolonged till every muscle is inert and inelastic. The coal-heavers or heavy porters would need a good deal of attention and time to bring them to a point to show a speed in a foot race they naturally possess. The muscles, though capable of contracting with powerful effect, take time to do it; and though strength is gained by walking, rapidity of action is lost. As all parts of the body are nourished and sustained by food and drink, it is of the highest moment that those kinds be used that are not only nutritious, but of the quality that give the characteristics we wish to develop. If fat only were required, the variety of food containing the most starch and sugar would be sought for. Fat is of essential service to a horse when commencing training, but only as a surplus that cannot be built up into muscle. That superabundance of food which has been deposited in all the interstices between the muscles, coating, and internal viscera, loading the lungs, has uses which, if we only avail ourselves of, will help us get the animal into condition. While we diminish this, we must do it in a manner that will leave the muscles fuller and more pliable than they possibly could have been if it had been absent. The getting-rid of this fat will be the work of the succeeding stages of preparation. In the preliminary stage, we must watch that it is not decreased, as that would denote want of health, or an insufficiency of food to meet the wastes of the system. Almost every horse or colt should be able to take the amount of walking exercise yours are now getting. Some fretful, irascible ones, that would rapidly lose flesh from worry. 
ing, dancing, and fuming, would have to be walked by themselves, or in a small enclosure. There are others with legs so weak, or having been injured, that give way from very little walking. If known to possess great speed, I would train such animals; otherwise they would poorly pay for the trouble. The most powerful auxiliary to aid us in treating these is the Roman or Turkish bath. With its aid, we are enabled to get rid of superfluous matter, and can train horses that would be exceedingly troublesome by any other method. The Turkish bath, however, is rather an expensive adjunct to a training-stable intended for the preparation of trotters. The tight room could. be made, by taking extra pains in the construction of a box stall, by having matched double partitions, thus leaving a space for dead air. The furnace, and pipes for con . veying the heated air, would he expensive, and their man agement a source of trouble. If we train horses with shaky foundations, some other method will have to be devised to keep them from giving way. What that course will be can only be determined by the wants of the patient, and the exig'encies of the case. The hot-air bath, the virtues of which were so highly extolled a few years ago, has undoubtedly been the means of bringing horses to the post fit to run and win, that could not have stood the ordinary preparation. I do not think it is of any service in horses that are sound and strong. I never look for it to come into general usé, and in a trotting-stable, there would be less necessity for it than in cases where a speedy unsound horse was wanted to merely run a dash of a mile or so, the winning of which would ensure a good deal of profit. A more proper time to enter into the discussion of this question will be when we are giving the horses their first sweats. At that time we will have the subject-matter fairly before as, and will endeavor to examine it in all its ramifications. PupIL.-At which period I will be all attention, as that 
has been the point that has troubled me the most. Often, when putting the sweaters on a horse, have I asked myself the questions: What are you going to accomplish? Have you not carried this drain on the system far enough ? He goes the distance without showing undue labor of the lungs. It is true, many will say, he is not "drawn fine ennugh ;" but do not his performances show this is a mistake? However, I will not trouble you with questions now, awaiting the time when I can see the advantages practically exemplified. I am aware-though I thank you for the reminder-of the importance of this preparatory stage, and shall watch closely each member of the stable, to see that his appearance merits your approbation when you return. The colts I can be driving, and hope, when you see their action, that you will be as favorably impressed as you are with their form.

Preceptor.- - The few days' walk they have had, since the (') mpletion of their long journey on the cars, will be sufficient to remove the soreness incident thereto; and they ought to learn something every time they are driven, that will bring them much nearer being trotters. So it is best to neglect no opportunity of tuition. The plan I would recoinmend would be to drive them, on the road, to a skeleton wagon, and when you come to a smooth piece where the grade is descending, let them rattle along merrily, striving to keep them as nearly at their top speed as they can go without breaking. If you fall in company with some one who is willing to drive along-side, so much the better; but never extend the brush farther than a quarter of a mile. They may be anxious to go along, yet, by restraining them, vou will keep up that feeling of pleasure, which will encourage them to "try again," and at a better rate of speed. King, I hope to find more amenable than at present. He has been quite a study to me ever since I received so unfiuvorable an impression of his appearance; 
He is like some of those old pictures, - the work of a master hand, that never fairly display their beauties till patient study has discovered in them perfections of art, that appeared at first sight a mere confused mass of colors. The colt requires the same study in order to bring out points of speed and durability.

I will now bid you good-bye. On my way I will drop into the stable to give the Falcon my valediction. In two weeks I will return, and he will be the first horse I shall want to see harnessed. 


\section{CHAPTER XIV.}

FALCON AND NEVER MIND ON THE ROAD; THE COLTS MAY AND DELLE ON THE TRACK.

PupIL.-Well pleased am I, my worthy master, to see that the country trip has been of such great benefit to your personal appearance. You seem quite rejuvenated, and look as if the ravages of time for at least the last decade of years, had been obliterated. I can hardly believe your late asseveration, that all thoughts of matrimonial felicity have been banished from your mind, and think that some entrancing enchantress has fascinated you, till the return of youthful feelings has been accompanied by the resemblance of manhood's prime. You would be set down by shrewd observers as still being on the sunny side of forty, and I only know one feeling that can work such a metamorphosis.

PRECEPTOR.-Your surmises are quite wide of the mark, though there are sufficient reasons why the two weeks' absence from the "sea-girt shore" has been attended with such beneficial results, and I can assure you that my looks do not belie my feelings. I feel like a four-year-old race horse, and walk as if fifty pounds of useless flesh had been removed, almost enabling me to rival the old lightness of step when tag and base ball were so keenly relished.

When I left here, I took the boat to Piermont, and thence the New York and Erie cars to the pleasant village which my old friend "Rex," of Knickerbocker fame 
has enlivened with his presence for so many years. The scenery along the line I will not try to describe, as you are familiar with it, and will agree with me that the journey is well worth taking, if for no other reason than to enjoy its beauties. I was conveyed by a friend the ten miles that intervened between the village and the place of my final destination. This was the first time I had soen the spot at this enchanting season of the year; and, much as I had admired its beauties in midsummer, and the grandeur of the winter display, I was totally unprepared for the marvelous splendor that now greeted my eye. Your Mississippi bluffs, rolling river, floating islands of verdure, towering oaks, and fragrant crab-apples, may show on a larger scale, and your seat that overlooks the plateau of thousands of acres of billowy grass and prairie flowers may be very fine; but for quiet beauty and harmony of detail, there is no place that will equal it on the Father of Waters from the Gulf of Mezico to the Lake of Itasca. Imagine a little lake-so small, indeed, that its length hardly rivals the width of your majestic streamnestling among emerald hills. The hill in the background is covered with a dense growth of hemlock, the dark green of which is relieved by the bright hue of the deciduous trees, now in their most brilliant garments, while tall pines shoot their spires from the summit away up in the blue firmament. The hill to the right is carpeted as thickly with grass as the famed pastures you have described; groups of scattered trees breaking the uniformity, with large dark-colored rocks beetling from the side in bold relief. Large flocks of sheep are grazing on the sides of the hill, the lambs playing and gamboling as if every minute of their existence were too precious to be lost. To the left, the hills slope gradually, forming a little valley through which the outlet runs. Away in the distance, as far as the eye can distinguish, the hills swell into magni- 
tude enough to be called mountains, and it is difficult to tell where land and sky meets.

Not a breath of air ruffled this fairy sheet the morning of my arrival; and hills, woods, and sky were reflected from it, as faithfully as the most polished mirror gives back the form that stands before it. The few fleecy, snowwhite clouds that hung motionless away in the zenith looked just as distant in the depths of the water, and almost gave you the sensation of being above the clouds, looking down on terrestrial scenery.

The beach is white sand, almost rivaling the snow in fairness; its contour on the wooded side is a sweeping curve, while that towards you is broken into bays and inlets. All the way round the lake, the underwood is of dense growth, and both the broad-leaved and common laurel extend quite to the water's edge. I cannot picture the bloom, though I doubt if the Vale of Cashmere ever equaled the brilliant display. Large crimson masses of flowers in gorgeous profusion, alternated with as abundant blossoms of snowy white, so heavy that they fairly laden the twigs, and rest on the silver water. At the foot of the hill, where the cattle and sheep are grazing;-or rather on a slight eminence this side,-is an irregularly constructed Italian villa. The irregularity of the structure makes it more in harmony with the scene. The western wing is surmounted with a dome and cupola. To the east, the building is not so high, and about the centre is a large conservatory, the glare of the glass mellowed by the climbing plants inside. On the very eastern extremity rise two square turrets, between which is a colossal statue of an antlered buck, the attitude being that of watchful rest. Along the south wall of the building is a sort of battlement, forming supports for marble statues, representing nearly all the gods of Heathen Mythology. They were sculptured in Italy, having been captured by a pri- 
vateer when on their way to adorn the park of some English nobleman, and are of rare workmanship. The lawn in front of the building extends to the coppice that makes such an appropriate setting to the pellucid water. A carriage-road is cut in a sinuous form through the turf of the lawn, and vases and statues are interspersed beneath the trees. The road leads to a summer-house on the bank of the lake: the house is ornamented with representations of fish and fruit beautifully carved. Towards the lake there is a ballustrade, several steps leading from it to the water ; tiny boats are moored there, the white sails hanging listlessly against the masts. A walk leads from this summer-house adown the bank, the laurel meeting overhead, and forming an arch of wondrous beauty. Looking up, there is nothing to be seen but a canopy of brilliant colored flowers, intermingled with polished darkgreen leaves. The walk leads to the point of land that forms the bay on the eastern shore, which sweeps round in a sharp curve to the left. At this point is another ornamental summer-house, but on a different plan from the larger. The lower part of it is hidden from the house by a group of pines, though when you ascend the stairs to the upper story you are more entranced than ever with the different views seen from that point. Every inch of the lake is under your eye, and through openings in the trees detached pictures-any of which, if truthfully depicted, would make a reputation for an artist-are visible. The house is only partially in view, the portion seen being that which makes the most beautiful background to the sylvan picture. The section of the lawn seen through this vista is perfect in its details,-trees, shrubs, flowers, vases and statuary, all being in the very best places for effect. You turn to another opening in the pines, and the turrets, dome, and images on the house stand in bold relief against the western sky. To show the master's hand that 
planned all this, a circular group of Lombardy poplars lose their stiffness and come in for their share of admiration, which I could never award them in any other situation. In the rear of the villa, and between it and the public road, farm buildings and offices give the place still more the look of repose, beauty, and fitness, that so eminently belongs to it. But if I try to describe all the beauties of this cherished spot, you will still think I have seen some apparition that has made me romantically crazy. So I will not say a word more till we take our accustomed smoke on the piazza after dinner, when I will give you an insight into the pursuits that have obliterated the marks of years, and left my feelings so youthful. So have the Falcon harnessed,- -he must have had his morning's walk by this time,-and I am very anxious to see how he will deport himself.

PUPIL.-The boys have had him harnessed for some time. The wagon has been run out from the shed, awaiting your orders. I shall anxiously look for the continuation of the history of your trip, as I am still more certain that I have divined the right cause. Either this is the case, or you have viewed no mortal scene, but have been transported to that land where the famous Christian Knight was held in thrall by a garland of flowers. In the place of the Erie Railroad, and the wagon from B you not encounter all old man with silver hair reaching to his girdle, who took you in a boat, fashioned like a seashell, which drove with you on "without a wave or wind?" Or, did you meet with a damsel-

"With long, rich tresses curling 'round her brow,

And garments beauteous as the bird of Ind,-

She through the ocean swifter than the wind, Or wing of eagles, did direct your track."

Preceptor.-This silver lake and scenery, far beyond my powers of description, actually exists, and is no more 
of a myth than your Iowa farm. We will have no more talk on the subject, however, till the time appointed. How gently Falcon consents to be harnessed and hitched to the wagon! From his extreme nervousness I supposed he would not be so docile at first.

PUPIL.-Six months have elapsed since the harness was on him; and to give you further proof of his natural docility, I will be much gratified if you will get into the wagon and give him his first drive.

Preceptor.-To that I have no objections, though I shall insist on your being the reinsman in future, unless I want to know from actual trial how a horse handles. Whoa! my boy, a little more to the right. These skeletons are not the handiest things in the world to get in. Now, sir, you can go along at your leisure.

PupIL.-I need not ask how you like him, as I see satisfaction in every line of your countenance,--though that may be attributed to the recollections of your late visit.

Preceptor.- Like is hardly a strong enough expression to convey an idea of the pleasure there is in driving such a horse as this. He has the form of my model roadster, as well as every other quality that could be shown in so short a drive, though I have done one thing I should have scolded you for doing. Jogging down the road for a few miles about a six-minute gait, from which he never varied, going along as true as a first-class piece of machinery, I came to a place that was as smooth as a well-kept track. I could not resist the temptation to see if his motion was equally precise when going faster. I never saw so true a mover; he appeared only to be gliding along; and had it not been for the buzz of the wheels through the air, I should have greatly underrated the speed we were going. He missed not a step, and was as obedient to the slightest touch of the reins as the best family horse that could be found. I will venture what little reputation I have, on 
making « Number One trotter of him. There is nothing to direct about his management at present. You can gauge him to åny gait you wish, and the next two weeks we will give him ten or twelve miles a day, at the rate of about a mile in five minutes; towards the last of that time, moving him somewhat faster.

PupiL.-When he is driven on the track, I am afraid he will change your opinion, giving further proof of the effect of bad management in the first part of a horse's education. The road, to him, has been a pleasant interlude to the tortures of the course, and all his remembrances connected with it are of a pleasant character. There he has been treated with uniform kindness, and when he has been allowed to extend himself in a little burst of speed, it has been done without pulling at him; or, if he happened to leave his feet, there was no jerking or sawing, allowing him to recover as suited his own humor. Of the track, his recollections are not so pleasant; pulling, snatching, and fighting are his most vivid reminiscences of that period.

Preceptor.-For that very reason we will confine him to working on the track, and will only vary it with road work when the course is too muddy to use. I know he will jog there as kindly as on the road; and by letting him time the short brushes to suit his own notions, we will get him to reconsider the verdict that pronounces the track a place especially invented for the torture of horses. I now want to see Never Mind in the shafts; and in order to give him as fair a chance to make a true impression as the Falcon, will also drive him.

PupIL.--He also has not been harnessed in several months; and before you get behind him, I want to observe that he never has been much used on the road. I tell you this, so that you will not be prejudicẹd against him. He is not a good road horse, and goes stumbling along at a road gait that is very provoking. When on the track 
at full speed, he makes a fine appearance, carrying his head high, and going in grand style every way.

Precepton.-I perceive you are afraid I will get a poor opinion of the horse, with his queer name. You promised me the reason for thus calling him, and I have had it on the tip of my tongue to ask you to gratify my curiosity. You need not fear, however, that I will condemn him without a fair trial. I do not look for first-class trotters to be necessarily of the same excellence on the road. Many of the best are not pleasant to drive there,-most of them for want of practice, and others from being badly driven.

PuPIL.-When you finish your description of your recent trip, I will recount why this fellow was called Never Mind. Before he is hitched to the wagon, I must acquaint you with another bad trick he has, though luckily he has not had frequent opportunity to practice it. When harnessed, if not allowed to start right off, he will rush back at a tremendous gait, and it is astonishing how fast he can perform this crawfish movement. If the wagon or sulky hits anything, he is sure to break it or the harness. When I had him at home, the inside of the track was planted in corn. At the time I speak of, it was just high enough to commence tasseling, - say six or seven feet. In making his retrograde rush, he backed the sulky into the corn. The slight resistance led him to think he could break it, and back he threw his whole weight in the breeching. Hearing nothing but the crushing of the corn, and not the crash he expected, he kept backing at a "right lively gait" and never stopped till the entire field was traversed, nearly three hundred yards. As the sullky struck the back-stretchand there was no longer any resistance from the standing corn, he was fairly nonplussed; and stopping a moment, as if cogitating on the probable reason why the sulky was not broken, he swung round, and jogged off as if nothing 
unusual had taken place. We had no more trouble with him the rest of the season. I do not think he will make the attempt now, as by never punishing him, or trying to force him forward, always hitching him where he could have leeway, and trying to attract his attention till everything is ready for him to go, he has nearly forgotten it. In connection with this, and brought to my remembrance by recounting Never Mind's memorable backing-out scrape, I will relate a circumstance something analogous.

A neighbor of mine had a bay mare that would match one of mine. Both were good steppers, and I finally succeeded in trading for her. On the completion of the deal, he told me that the mare had only one failing, which was, that she would not stand when a person was getting into the wagon. I told him that was annoying, but I had cured several of the same habit. The next day I harnessed her to a road sulky, and drove eight miles and back. The trip was made satisfactorily. The day following, a friend was to accompany me a few miles to see a quarter race. We put the mare to a top wagon by the side of a steady old trotter; I threw the top back, the mare standing very quietly, though as soon as I took up the reins, she wanted to start. I said whoa, very gently, and accompanied the command with a slight pull. Down she dropped, as though she had been struck on the head with an axe, lying quietly, and apparently comfortably to herself. I could not help laughing, provoking as the situation was. My friend did not see the reason for being amused, telling me he would give her a good thrashing in place of laughing at her. I told him I was not laughing at the mare, but at my own ignorance. The man I got her of told me literally what she would do, and I had not sense enough to understand him. I supposed she would rear and fret when restrained from starting; it never coming into my head that she would drop down, and lie perfectly quiet. 
We unhitched her from the wagon; and from the sullen way she laid, it was apparent she expected a beating, and was going to endure it like a stoic. She never offered to rise while we were divesting her of the harness, and I made up my mind what to do before the last strap was unbuckled. Old Quaker, her companion, looked on surprised. We had broken many a colt by his side, yet this was something new to him, as his looks plainly showed. We strapped both the mare's fore legs up, fastening the pastern to the arm, brought both hind legs up against her belly, securing them there so they could not be moved in the least, put a strong bridle on, the bit having long check pieces, drawing her head up and on one side, where that was also fastened. A bundle of straw was put under her head so that it would be supported without pulling on the rein. When all was completed she could not move an inch, though she never made the attempt. We put another horse in by the side of Quaker, leaving strict orders for no one to go near her, and went on our way to the quarter race. Four hours elapsed before we returned. The straps were removed, and she was bid to arise. She did not need a second invitation, looking very foolish when she regained her legs. This was the most cruel operation I ever subjected a horse to; but in her case it was effectual. I kept her some time, and she never showed any desire to repeat the trick. She afterwards went to New Orleans trotting in forty, acquiring a good deal of celebrity as a safe and reliable road mare.

Preceptor.--That was rather severe, yet not so bad as beating her as severely as some would have done. I should have misunderstood her case, too, and would have been bothered to know how to cure a trick of that description. Horses frequently throw themselves; this mare, as I understand the case, was not so violent, and the stolidity she displayed showed a stubbornness that would have 
been hard to conquer in any other way. The account you give of Never Mind's propensity is not very flattering to his breaker, and I hope we will not be compelled to devise any other ireatment than that you have pursued. The boys had better not put up his check till after I get in the wagon. Don't hold his head to awaken his suspicion that we are expecting him to do something wrong. Now I am ready. That start is certainly quiet enough.

PupIL. - Your drive this time has been of longer duration. I presume you have gone over the same ground ais you did with the Falcon.

Preceptor.-I made the same trip, but jogged slower, and did not require him to show anything faster than a very moderate gait. He jogs like a fox trotting, and for anything $I$ have seen is worthy of more commendation than I was led to infer from your remarks. When I turned him around, he was in something of a hurry to get back, yet was very bidable, and seemed to enjoy the drive. He will be the first one we will scrape, being fatter, and requiring longer time to rid him of his superfluities. Jane, we will not drive till to-morrow. I promised to rig her so she could be jogged without requiring any very great outlay of strength to restrain her. The plan we will adopt will be to keep her walking till she is harnessed, starting her the reverse way of the track, using a chain bit; and whenever she goes faster than wanted, bring her to a full stop. It will require some patience for her to learn to go slow, though it is of the first importance she should be taught. After a couple of months' steady work I have no doubt she will be all we can ask for in that respect. The colts we will work in the track, so that I can watch their action. Clipper, I am glad to see, has improved wonderfully. He looks as though he had also made a trip into the country. King, too, has "come out of the ashes," and is not only looking better, having nearly got rid of 
his long coat, but his prominent eye has a calmer look. I have missed seeing the mode of operation that has thus transformed him, and will have to be contented to hear how so much has been accomplished.

PupIL.-I have worked with him every spare moment since you have been gone, and now think there will be no further trouble in either handling or driving him. It has resulted, as I expected, in one way. He will now grow and thrive, and I venture to say his most intimate acquaintance will fail to know him three months from now. The journey down partially tamed him, so that he would stand while a surcingle was laid across his back. After due caution, I got a roller buckled on him that had a billet and buckle to fasten the check-rein to. A blind bridle, with a long pair of driving reins, just as $I$ have described in breaking the colts on the breeding-farm, was used. When first brought, out he did not like the idea of taking the precedence, but wanted to be where he could watch every one that was around him; so another rein was put on, one of the boys going before to lead him, while I took the reins and let him feel a very slight pressure on the bit. The blinds preventing him seeing in the rear, he soon learned to heed the suggestions of the bit, and would go wherever directed. I will venture to say I have walled miles enough behind him in the last two weeks to carry me to the spot where the Erie road and spring wagon took you so much more easily. In a few days we were able to partially clean him, the good effects of which are so plainly visible. As he will now suffer himself to be held by the bit, wear the whole harness, and allow the crupper to be put on, I shall have no hesitation in placing him in the shafts of the breaking-sulky, taking every precautiou, of course, that we can to prevent injury to himself or the vehicle. The other colts I have driven regularly, either on the road or track, and as the weather has continued so 
fine, have worked them more on the track than you recommended, it being more convenient and occupying less time than when going on the road. None of them have given me any trouble, all eating and drinking heartily. I increased their feed a little, and have also added an ear of corn to their evening meal. Clipper has had a run every day to get quite a bite of grass, and the others have been allowed to graze a little twice a week.

Preceptor.-A very good idea, which I like better than giving so many bran mashes. Both keep the bowels open; the bran irritating the mucous membrane of the stomach, causing a greater flow of the gastric juices, while the grass effects the same object in a milder manner. English trainers lay great stress on keeping their horses full of "good hard meat," which probably in their climate is essential to bring them into proper condition. That they understand the art is undeniable, as the appearance and performances of their horses prove. Our hotter and drier climate requires changes. Nearly all of our trainers practice giving at intervals small quantities of succulent food; grass and green corn blades being in general use. Van Leer, who trained Peytona, Liatunah, Saartain, \&c., practiced taking his horses out of the stable at unseasonable hours-often in the night-to graze. He was successful, the benefit of the grass being greater than the ills resulting from breaking in on their rest. The question of green food, mashes, etc., we will talk about when we have more time. The morning is wearing away. Get your colts out, and let me see them move.

PuprL.-We will commence with the oldest,- the same as in my younger days, when the sulphur and treacle were dosed out in the spring, and all the children, comprising a large family, were placed in a row, none escaping their share of the compound. I will jog May twice around; and let her step up and down the stretch at her best gait. I 
want you to see her move both ways of the track, and how she changes her feet when she gets round the curve, and has straight work before her.

Preceptor.--She has a singular movement indeed. Part of the time her gait could not be bettered, which is especially the case when she trots fast down the stretch. She has more speed than I looked for, and showed at least a thirty-five gait. We must discover the cause why she does not keep that stroke up, and when once found, can devise some remedy. She has not cut herself anywhere, and we cannot have that guide to direct us, though, in all probability, fear of doing so is what induces her to change. If all your thoroughbreds had such knee-action as she has, you might well look for them to make trotters. Perfection of form in a horse is rarely to be found; and we often hear the remark made, "I do not care how he looks, if he can only go fast enough." A few crooked, ill-shaped brutes go fast, though very seldom it is that they both can go and stay. This mare exemplifies the necessity there is for shape as well as blood. Her forehand is superb; nor do I see a place you could change her configuration, till you come back to her loin. Hence, the action of her fore legs and the carriage of her head, is admirable. The ragged hip and sloping quarters, though offensive to the eye, are not detrimental to speed. She is wide across the stifles, and they are low enough to insure a free motion of the joint. The hock is wide and strong, and the muscles of the thigh and gaskin are all that could be desired. The hocks, however, have a wrong set; they stand too close together, while the feet are thrown quite a distance apart, the toes very much turned out. The consequence is, that, when going around a turn, she cannot. avoid hitting herself with the fore foot. To remedy this, she throws her quarters around, placing the off hind foot between the front ories, and loses the length of stride she 
has when going straight. We will try what a change of shoes will do for her, having those for her hind feet considerably heavier than the ones she now wears, hoping the higher action they will cause, will in her case result beneficially. When these are put on, we will have to watch her action very carefully; and if that does not effect a cure, boots will have to be resorted to. As I have already told you, I do not like to use boots when they can be got along without; they cramp a horse when going fast, and much care is required in their construction to prevent them chafing the skin. Unfortunately, there are cases when they cannot be dispensed with, and many that require a great deal of ingenuity to fit them properly to the place intended to be covered. Cutting between the coronet and upper pastern joint is very bad; that place being so difficult to protect with a boot, the motion of the joint, united to the tenderness of the skin, causing abrasion almost sure to follow. I think a very light buck-skin roller, made large, and stuffed with deer-hair, will also be of advantage. The wound-when she cuts on the place you mentioned-is probably made with the inner edge of the shoe on the near fore foot; and as an additional protection, we will have that part of the shoc rounded, and set a little inside the erust. You tell me she never cuts when driven on the road; and I noticed, when coming towards me, that her motion was regular. She necessarily must do the damage, then, when going round the turn; and by using: the heavier shoe she may be enabled to go clear. Ask any horseman how a horse moves his legs in the trot, and the ready answer will be, that the left fore foot and right hind one move simultaneously, and when they strike the ground the others are elevated, carrying the body along. This is very true when the pace is slow; when it becomes fast, and a horse is stretching from sixteen to twenty feet, there must be a bound similar to the running horse, as no horse 
can possibly have that immense stride otherwise. It is apparent, then, that all the feet must be off the ground at the same time. I have often watched to see if I could determine whether the feet passed each other when off or on the ground. I am inclined to think the latter position is correct, though I cannot say positively. In a gallop, each foot strikes the ground in rotation, followed by a bound. The sound a running horse makes can be imitated very accurately by placing the hand on a table, striking first with the little finger, and at equal intervals with the others, dwelling a little after the fore finger has been brought down, which answers to the spring that marks the duration of each stride. The hind legs, in galloping, must be thrown forward when the body is in the air, touching the ground very nearly as soon as the fore ones, and, at the moment of contact, being in a proper position to propel the animal along. Horses sometimes, when running, cut themselves on the inside of the hock, frequently between that and the pastern. This is termed speedy cut, as it is evident that a horse must be malking violent efforts when the hind legs are thrown so much in advance of the front feet. Should May cut, as I suppose she does, thrusting the hind foot between the fore feet and partially under the near one, it will show that the legs are not moved at the same instant; and if we make the stroke of the propelling limb from a higher curve, she will either avoid having it wounded, or the injury will be in a different place, where I hope it will be easier protected.

PuPIL.-I think your surmises are correct as to the cause of the injury. When experimenting with the different kinds of boots which I have tried on her, I daubed her pastern with white paint, thinking it would show the place that gave the blow by adhering to it. The paint, I found, would be rubbed off without staining any place I could discover, which of course, would be the case if it 
was done with the ground surface of the shoe. I have blamed the short turns of a half-mile track-where she has received what little trotting-education she has hadfor doing the mischief. The faulty set of the hocks "may have increased the evil, yet it is certain, that, when driven fast on the road, she never sidles or brushes a hair. I feel positive that if this difficulty can be overcome, she will make a very fast trotter.

Preceptor.-We must not ascribe all to the track. Fast horses, and those with perfect action, have been in the same situation, never having seen anything but a halfmile course, where they received their whole training. The two united have operated badly in May's case, and let us hope, that, having now a full mile, with easy turns, we can shape her into the fast trotter you fancy her capable of making.

PupiL.-I will now drive Delle, and will have to jog her rather longer than May before I can show you her true manner of going. When I purchased her, at three years old, the man who bred her had irritated her so much, that it was quite unsafe to attempt harnessing her in the stable. When she saw any one approaching her with the harness, she would rear as high as the halter rein would permit, flying about the stall perfectly frantic. By taking her out doors, she permitted the harness to be put on with very little trepidation, and in two weeks the uniform kindness she met with eradicated the nervousness acquired from the attempted coercion by her owner. I now direct the boys to harness her some little time before she is required to come out, and I think the wearing of the harness in the stall has had some effect in tranquilizing her.

Preceptor.-She moves beautifully, and has a great deal of speed for a colt that has not had much handling. I can discover no peculiarity in her gait that requires modification. She will make a trotter almost of her own 
accord, the only thing being to keep her in bounds, and teach her not to rush off her feet in endeavoring to go faster than she can. She does not touch anywhere, proving that a horse can be driven on a short turn without necessarily spoiling him,-though I heartily agree with you that a half-mile track ought never to be built, especially where we expect to teach colts to trot. The morning is now too far advanced to see Oriole and Marourneen move. We will wend our way dinner-ward, and after partaking of this important meal, I will recount how I spent my time while in the country.

PupiL.-I have fancied that Delle went too low, and thought that perhaps heavier shoes than she has been accustomed to wear might be of benefit. When there is dust on the track, she will leave the mark of her hind toe for quite a distance after she picks the foot up.

Preceptor.-I noticed she did that, though not when at full speed. The ease and grace of movement she displays, suits me exactly; she would almost carry a tumbler of water on her loins without spilling it. She is so symmetrically formed, that her body is carried along level, without any perceptible motion. The legs and feet do all the work. Count D'Orsay said that a gentleman should never dance higher than his loins; and a horse that either gallops or trots without bodily contortion, certainly does the work easier, and ought to go faster. 


\section{CHAPTER X V .}

JOURNEY TO THE COUNTRY-MR. P. AND HIIS DAUGHTERS.

Preceptor.-As I look back at the time spent in the country, so devoid of excitement, I can hardly hope to interest you by detailing the incidents of my trip. Simple pleasures and pastimes become dull when rehearsed; and I rather fancy you will be disappointed in the recital, wondering at the simplicity of my taste, that could find so much to enjoy in a quiet daily routine. But the repose attending a short residence in the country is delicious to one who has been accustomed to a life of excitement. Long continued, its enervating influence might induce ennui,-a fearful infliction, so I should judge by the description of those who have suffered from it. Thank Providence, my life has been too active ever to becnne acquainted with the countenance of this dreaded demon. But this feeling of repose can only be appreciated by those who have lived long enough to fully understand the art of living. To throw your fishing-rod aside, and lie down on the mossy bank of the woodlawn stream, and there, while peering through the openings in the thick foliage, and watching the light clouds high up in the blue firmament, the liquid murmur of the water and the sough of the gentle breeze in the branches will lull without tiring, for they are not a monotone, but varied as the breathings of the æolian harp, and more silvery in their tones. 
To one whose frame has been racked with pain, the nerves vibrating with a metallic harshness, until the opiate so magically changes the feelings, and the bed of suffering is turned to the couch of the sybarite, without a crumpled rose-leaf to mar its luxuriousness,-to such a one I could ofler a metaphor or two that would portray my feelings. It is as when the child sinks on its mother's breast to slumber, smiling at the rustling of the angel's wing that is to watch it through life, and is whispering bright words describing the beauties of their joint home in Paradise ; or as, when the strong swimmer, vainly wrestling in his agony, till the limit of human endurance is reached, sinks under the gurgling wave, down, down, without pain, the music of the sirens in his ears, and he floats in choral depths fully realizing that he is at last at rest ; or as, when the good Christian throws off the armor in which he has battled, and sees the golden gates open, and the glory that surrounds the awful throne making his final pathway bright, thronged with the loved and lost that have preceded him o'er the "silent river," and the ties that bound nim to this beautiful world become as the glossy flaments that sparkle on the dewy meadow in the morning sunbeams.

The friend to whom I am indebted for the pleasure of my visits-which are made semi-annually-lives in a neat cottage, surmounting a gentle eminence at the foot of the lake which I have so poorly described. I first made his acquaintance in the forests of Northern Maine, where we became associated in a hunting expedition. Many a moose and caribou fell at the report of his rifle, and I never met any one who was so passionately attached to the sports of the field. Small and fragile in form, it was astonishing how nerve and spirit supplied the place of bone and muscle, as he was the hardiest and most untiring of any one in the camp. Day after day, he would don the snow- 
shoe and heavy double-barreled rifle, and when the ardor of all the rest of the party was dampened by a day of ex. treme fatigue, his never flagged. No matter how thick the air was laden with the trembling snowflakes, or how icily the northern blast rushed over the barrens, out he would go, never returning to camp till the shadows were lost in the murky darkness. As I have instanced before, he possessed that unseen power which enables the thoroughbred to race on when the vision has become dim, and the physical machine is kept in motion by the force of the mind that knows not failure. He is the scion of one of those aristocratic Philadelphia families, who, though warm in their adherence to Washington and the country during the struggle for independence, yet kept up the exclusiveness of the nobility they assisted to ostracise. With the manners of the class from which he sprang, he unites a warmth of heart and disposition that prompts him to fraternize with whoever he thinks worthy, no matter how lowly he ranks in the social scale. This grand quality, united to the wondrous nerve power I have mentioned, endeared him to me so much that I sednously cultivated his acquaintance. I am happy to state that he reciprocated the strong friendship, and ever since-for many years - I have been a visitor at his house. In the winter we hunt deer, foxes and rabbits, the baying hound filling the crisp air with music as we stand on the runways; and in the summer, going far into the "pathless woods" of that section, enticing the speckled beauties of the brook, and breathing the pure night air on the hemlock boughs, - a couch you are so well acquainted with, and join with me in extolling. During the winter, we alternate our hunting in the vicinity of the lake-which is famous for being the resort of game-to ground more distant. Thus I have become acquainted with other families who hold the highest place in my affections. Winter, which 
so many dread the approach of, to me is as enjoyable as the more balmy months of summer; and the many happy days and nights I have spent in the most delightful social intercourse with these friends, mark it as a time that will always be green in the tablets of memory, the remembrance being a "joy forever."

During this last visit, my friend's business was so urgent that I could not assent to his absenting himself from important duties to lounge the time away with me; so, when tired of fishing in the Silver Lalse, I would mount a horse, and ride six or seven miles to the house of a gentleman,one of my especial favorites. He is nearly seventy years old, yet with feelings as youthful as many possess when half a century younger. His personal appearance is my beau-ideal of matured, manly beauty. Age has taken away none of the lines that marked him for a model in his younger days, while it has added the glory of silver hair and beard. But I may as well describe him minutely, as I see you are somewhat anxious to know whether my eye is as correct in the knowledge of human perfection, as you admit it was in finding the Falcon the type of whatever is super-excellent in the horse. This old gentleman is by birth English, and his appearance denotes his nationality. His height is a trifle over five feet ten,- the proper elevation for a man, as sixteen hands is for the horse that carries him. His shoulders are broad, conveying the idea of strength, without being disproportioned to the rest of his body. His limbs are long and muscular, terminating in medium-sized feet and hands. There is a little tendency to embonpoint, just giving the waistcoat the right set without any approach to corpulency. You imagine, if taken away from country life and made a bank president or railway director, he would be at least a score of potunds heavier, and your surmises are probably correct. You can see that daily exercise in the open air gives that 
ruddy glow to the cheek betokening buoyant health. The white beard falls in wavy masses on the full chest; a sparkling diamond, in antique silver setting, glows on the ruffled shirt, and shines like a bright star through a broken cloud in a moonlit sky. The moustache is as silken as a boy's, and curves away from lips that are apart enough to show natural, well formed teeth. The nose is slightly aquiline, and shows determination without so much bend as to appear haughty. The eyes are a deep blue,-earnest looking eyes,-exemplifying the strong soul which you can see shadowed in them. The brow is broad and prominent. The hair the same shining hue as the beard, but clinging in close curls to the round, well-formed head. The crown is bald, making the closely curled locks look like an ivy garland. He dresses with consummate taste, and he has the rare faculty of looking well-dressed, even if corduroys and a fustian shooting-jacket envelop his manly frame. It is supererogatory to say that he excelled in all manly sports when younger, and still rides across the country, disdaining to turn for a stake-and-ridered fence, and would nearly as soon be caught in a mean act as to shoot a partridge or pheasant when not on the wing. $\mathrm{He}$ is a graduate of one of England's most celebrated colleges, well versed in modern literature, plays cribbage and whist scientifically, gives me the rook and move at chess, and beats me more than half the time then. His farm is a model in arrangement and management, and his crops and stock show how much skill can accomplish in making a naturally sterile soil look well and pay well.

PupIL.-Really, my worthy master, I am more in the dark than ever. I would have cheerfully wagered quite a large sum, for me, that you had some other object in your twice-a-year visits than calling on the friend with the wondrous nerve force. Hunting, fishing, and camping, are all very pleasant; yet I was ready to swear your 
description would have been that of some bright feminine, in place of a Pennsylvania Squire Osbaldeston, or Sir Tatton. I looked for some dashing Die Vernon,-and though, not long ago, you informed me that a farm and connubial happiness had evaded your grasp in the more exciting whirl of the turf and road, I still thought the idea had a charm which you were loth to give up. Now this old gentleman in the mansion, on the well-stocked farm, ought to have-

Preceptor.-Away you go like an unbroken horse with the bit between his teeth! Having made up your mind that you are wonderfully cute, you start on a scent, right or wrong, and follow it,-like making a trotter of every race horse, no matter whether he ambles or paces.

PupIL.-Beg your pardon : and I promise not to make any more unseasonable interruptions, hoping you will disclose to me in your own good time what I am sure is to follow, and what would do me as much good as to see Della trot in twenty.

Preceptor.-Your interruption, unseasonable or not, came very near causing me to end abruptly the history of my journey. But to finish your sentence, which $I$ made the break in, Mr. P. has not only a daughter, but several of them, as well as sons. By way of punishment, I am almost tempted not to describe the two elder daughters of this interesting family; but feel that, much as you will boast of your penetration in discovering something that has no form save in your distempered fancy, it will be necessary to introduce them, in order that you may understand the numerous enjoyments their talents and education gave me. The eldest, Jane, is even superior to her father in beauty of form, face, and complexion. There is a great resemblance in their appearance. Notwithstanding there is nothing but masculine vigor in every point of the father, yet it is toned down and modified in the daughter, 
till she is as much a type of female loveliness as the famed Medician statue, which so many generations have conceded to be the model. As a preface, I must acknowledge her to be the very handsomest woman I ever saw, with one exception; and this is saying a good deal for one who, for years, was a constant visitor to all of the Southern race courses, witnessing the blaze of beauty that was wont to shine in the grand stands at Charleston, Mobile, and New Orleans. Not knowing how many feet and inches is the proper standard for a woman's height, I cannot even guess how tall she may be, and I can only describe her stature, by saying that I believe half an inch either way would very much lessen the grace of her figure. The deep blue of her parent's eye is intensified in hers, and darkened, till, in some lights, it becomes almost black, taking, with every feeling, a varying expression, hardly needing the aid of words to convey what is passing in her mind. The slight Roman curve in the old gentleman's nose gives way in hers to the purest Grecian; the thin and expanding nostril, cut as finely as was ever seen portrayed in ancient cameo. The upper lip is curved like the bow of Cupid, while the under is rounded, and slightly fuller. The chin is beautifully turned, and the setting on of the head to the finely moulded neck is perfection itself. The complexion, which I have no words to describe, is the finest English and American combined. Burns' "Lilies dipt in wine" is vivid, without picturing the commingling of tints. Those sea-shells, that are brought from the shores of the Mediterranean, in their delicate pencilings, are the nearest approach I can think of. But in her cheeks the changes are many,-now glowing, when ex cited, now subsiding into a clear pearly lustre. Her hair is of the pure golden color, which poets in all ages have rhapsodized about, and which I thought existed only in their fervid and florid imaginings, till I saw Jane P. 
Her taste, in its arrangement, is equal to its marvelous beauty, though what model is followed I am unable to say. Every movement is graceful and lady-like, uniting the polish of high breeding to the native modesty of her every look and gesture. Educated in all the prevalent female accomplishments, she excels so much in drawing and painting that her other excellences are partly hidden. To this fascinating pursuit she is an enthusiastic devotee ; and her portfolio is filled with sketches that would delight an artist, as well as charm one whose æesthetic tastes are no better cultivated than mine.

Her sister Susan is widely different in both appearance and character. Though two years younger, a stranger would think her the elder. Tall, and of majestic form, she has a queenly department that completely awes and takes captive her youthful admirers, and, I must admit, that for some time I thought her the most beautiful of these two handsome sisters. The difference between Minna and Brenda, Rowena and Rebecca, was not so marked; and yet there is a similarity, in Jane and Susan, in both being so transcendentally beautiful. The grey eyes, black -intensely black-eyebrows and hair of Susan, comport well with the chiseled, oval face. Her features are, if anything, the most regular of the two, and there is a haughty look, which marks the indomitable spirit. In the family circle, it is hard to say which is the most agreeable; and when $I$ add that Susan excels as much in music as Jane does in the sister art of drawing, time could not hang heavy on my hands. I will forbear to say anything further at present of them and their pursuits; and as their father brings them down to attend the races at Jerome Park, you will have an opportunity of seeing for yourself. I have taken up so much time that I will have to defer acquainting you with the details of my rustication, which 
I hope will entertain you as much as your account, when you first came, of the breeding-farm, struck my fancy.

PupIL.-I am delighted at the prospect of making the acquaintance of your friends, and have only one request to make-that you will invite them to see a trot on the classic Union, when Miss Jane can have her love for the beautiful gratified by seeing you drive the bob-tailed buck-skin that gained favor by beating the celebrated contraband,-and Mdlle. Susan can hear your musical voice as you shout at him to increase his easy flight of speed.

Preceptor.-I have a great mind to discard you entirely; and if you have the impertinence, even to hint at my mounting a sulky, during the visit of $\mathrm{Mr}$. $\mathrm{P}$. and daughters, I will turn every trotter out of the stable. Thanks to the rough country in which the ladies live, a trotting-sulky is unknown to them, and their ideas of race horses are from paintings of Derby and St. Leger winners sent by their friends in England. I would not, for every trotter on the track, be seen driving the one you mention, when I have described to them, in as glowing terms as I could muster the excitement, of a closely contested race, and felt, as I saw the two beautiful countenances grow animated with my poor description, that the scene was enacted in truth before us. Should they see in realization of this the uncouth, dirty-colored bob-tailed brute, I should never have the heart to see them again.

A sulky is about as unpoetical as a wheelbarrow, and not only hides the figure of the horse, but places the driver in a very ungraceful attitude.

How I would like to see Susan mounted on the Falcon! What a picture it would be, not needing the aid of a grand old tree to make it complete! How grand she would appear enthroned on his back! And I would wager my life that he would disdain to trot. He would 
sweep along at his grandest pace, and all the equestrian statues and specttacles would be far eclipsed by this living display of power, grace, and beauty.

We will now take up our line of march for the track, when we will see how Oriole and Mavourneen deport themselves. 


\section{CHAPTER XVI。}

THE COLTS-MANNER OF PROGRESSING-SWEATING-PHYSICREDUCLNG WITHOUT MEDICINE.

PuprL.-As you are too full of the lines of grace and beauty to look with equanimity on a sulky, I will have the colts hitched to the wagon, frankly admitting that I want them tolstrike you as favorably as their merits will justify. Oriole, being a year the oldest, will have the precedence, and I will drive her first.

Preceptor.-You may not think much of my powers of discrimination, because I do not qualify the praise of your horses with some invidious remark ; but I must acknowledge that I never saw colts that pleased me so well. How general is the desire to be considered a good judge of a horse! I have often been much amused at the efforts of people to appear learned in the scale of points. Many will think that the only way of impressing a general belief in the soundness of their judgment is to pick the animal to pieces, and while learnedly discoursing, will often praise the parts that are very faulty, while they condemn the only good points in the animal.

I must say that the fancifully marked filly is one of firstrate promise, and after the closest scrutiny I cannot see where she could well be bettered. It is quite true that she is far from being a trotter yet, and may never be classed as such, no matter how much eare we use in her education. Her fine size, united to good form and evenness of temper, is a great thing at the outset, while her 
gait is certainly very true and square. The rolling and hitching you spoke of she has not shown yet, and I hope, if we do not hurry her too fast, she will not resume that very annoying habit. Mavourneen I will have to see move again before I venture an opinion, as I fancied there was something in her movement not quite satisfactory. What a beauty she is! Unlike your friend, who thinks no man rich enough to buy her if she could trot in twenty-five, if I owned her, a harness should never ruffle a single pile of her golden hair. Much as I would admire the grand picture Susan and the Falcon would make, I can fancy one I would give more to possess. Imagine a grassy dell where a sheeny brook is "singing a quiet tune." Jane is seated on a violet bank sketching an elm,-its branches rising like the capital of a Corinthian column, in graceful reversed curves, crowned with a wealth of foliage terminating the spray-like branches. Mavourneen is standing by as if watching the transferring of the sylvan monarch to the paper, too much attached to her beautiful mistress to leave her side. The drawing finished, how gayly the fair artist gallops homeward, the shining curls floating in the ambient fluid! But I cry your forbearance, and promise not to let the incidents of the last three weeks interfere with the attention we must now give our horses.

PuprL.-Truly, I am sorry that you have come to that conclusion, and trust we have time enough to talk of something else besides horse. We who make the business of training our chief occupation, are apt to be bored with any other theme, till those who are thrown in our company think that horsemen are fitted for no other place than a stable, or at most, some saloon where races are made, and pools sold. We must educate ourselves, as well as teach the quadrupeds, and much of the obloquy now heaped on us will give way to a proper appreciation of the 
merits we possess. A love for the beautiful is just as compatible with handling horses, as in the professions absorbing the greater proportion of the talent of the country. I sincerely hope the day is not far distant, when a liberal education will be thought essential in the training of a good horseman; and I know that reading and study are rewarded in this profession, as in those where erudition is considered the only foundation to build upon. I am certain that Jane's pictures and Susan's music would have charmed you fully as much, if the artists had been less favored by nature in being themselves so beautiful. But

Preceptor.-We will dispense with the continuation of the sentence, as I do not want to be led into a disputation at present, nor to argue an abstract question of art, further than to heartily agree with you in the necessity of education in our business. We will now attend the evening walk of the horses, and without utterly tabooing the subjects that have been uppermost in my mind, we must give to training the study it so imperatively demands, if we would succeed in getting all of our horses in proper order, so that they may trot their races according to their best ability.

In former conversations, we discussed the effects of walking; and I do not know that much more can be said at present pertaining to that part of the exercise. I always like to see the horses when at their walk, and by closely watching them, can distinguish if anything is going wrong. When a horse is fairly settled in his walk, there is very little variation in the way in which he performs it; and when he does change, I always try to find out the reason that causes him to go differently. Slight strains, that unattended too often result in serious lameness, sometimes show more plainly when a horse is walking than when going at a faster gait. By closely scrutinizing the move- 
ments of a horse when well, the eye will detect changes the most skillful could not see, if not acquainted with the peculiarities of the animal. I have seen the removal of shoes followed by a difference so marked, that the change would be ascribed to something serious having happened; and as an illustration of this, will recount a circumstance that occurred before I adopted the present system of shoeing. I sent a horse to the shop to have his shoes reset. He came back apparently all right, yet, when taken out in the afternoon to walk, I saw a shortening of his step, which soon changed to positive lameness. The most thorough examination failed to discover the cause, though I felt convinced the shoeing was the reason. The job had evidently been done with the greatest care; the shoe fitted exactly, and every nail was driven the same distance above it. I thought that perhaps the clinches had been too closely drawn, hampering the foot with the pressure. It was too late to take him back to the shop that night, so the foot-tub was brought in requisition, and the soaking kept up till bed-time. Next morning he was worse, therefore I went to the shop with him myself. The smith was positive the injury was not caused by the shoeing, and suggested sprains of the coffin-joint, pastern, eibow, or shoulder. He cut the clinches, drawing the nails out separately, when we soon discovered what had caused the difficulty. The nail in making had been split, and, in driving, the parts had divided, one portion coming out where intended, the other, following a straight course, had pressed on the sensitive portion of the foot, and, of course, the hurt increased as the walk was continued. The system of shoeing we are now practicing would, in a measure, guard against the occurrence of this accident-the nails being hardly more than half the customary length, and the point of exit much nearer the shoe, so that the 
liability of their taking a wrong curve when driven is much lessened.

As you remarked, Never Mind has a very queer manuer of progression, and I can hardly think it is his natural walk. If so, it is "werry peculiar," as Sam Weller would. say, and totally unlike any walk I ever witnessed before. May it not be ascribed to the severity of treatment he met with at the hands of the man who worked him so hard, and who sweated him so often, that there was neither vigor nor proper life left in him? As it resembles so much the manner in which a horse would walk when nearly prostrated from exhaustion, the inference is, that he acquired it from having been forced to take long walks, when he ought to have been allowed uninterrupted repose.

As he is more gross than any of the others, he will be the first we should sweat; and as I contemplate putting him through that ordeal in a few days, we will now begin his preparation. Half an hour before the time for the others to come in, he can be stopped and allowed to graze. His hay will be curtailed a little to-night, and the quantity of grain slightly increased. It was formerly my plan, when a horse was in the situation he is, to give him a dose of physic, and I would have thought any one a mere tyro in the business who neglected to do so. Many still follow that plan, and would think it impossible to condition a horse without the use of drastic drugs. Had some one asked me the reason why I used physic, I should have answered that it was to decrease the belly, rectify a disordered action of the bowels, expel parasites, prevent humors and plethora, cure swelled legs, and refresh and enliven the animal. Blood-letting, diuretics and diaphore. ties, were also connected with the violent purgations, and considered prime necessaries in the treatment of horses expected to go fast. If a horse is not healthy, the veterinarian ought to be consulted. But as long as he feeds 
heartily, I would certainly rely on getting him in proper condition with other agents than by dosing him with balls and drenches. The reasons why I advise that Never Mind should graze for half an hour, the amount of his hay shortened, and grain increased, are that the stomach may not be encumbered, the evacuations more pultaceous, and less danger of feverish symptoms following the exudation. I only mention the sweating incidentally, as we will give it the fullest consideration when the time comes to practice it. Physic I have hardly treated as it should be, and we may as well consider now the bearing it has as part of the preparation for fast work, as in the future. Horse training is not the only thing it has been considered important in. Had a man to be "fitted" for any arduous undertaking, it was also held imperative that he should follow a course that was sure to weaken, and needing cordials for him to recover from the effects. And not alone in athletic exercises has its use been sanctioned; but purging and bleeding have been practiced in every department of life. The bolus and lancet depleted the system, outraging nature, whose violated laws were so little understood that the life currents were sapped, and the tone of the stomach injured by the poisons introduced.

The practitioner for the human family has broken away from the old practices, and increased longevity is the result. The course of physic prescribed by the old trainers was three doses, given at intervals of from eight to fourteen days. Twice a year this had to be gone through with; first, when the horse was taken up in the spring after the winter's rest, and again when the season of labor was completed. The first effect of physic is to act on the inner surface of the stomach and bowels. This irritation causes a copious secretion of a water-like fluid, derived from the blood. Thus nature tries to relieve the system 
from the poison by diluting it and extending the surface on which it acts.

The loss of blood is made up by the absorbing vessels. They first commence operations on the fat, which undergoes a change, and acquires a resemblance to blood. This, so far, might be of service by removing the superfluities which are in the way of rapid locomotion; but, unfortunately, it does not end here. The superpurgation, that almost invariably follows this course, is so debiliating that much valuable time is lost in re-establishing the health. As an evidence that there has been injury done, the horse that was in good spirits before, and had a hearty appetite, becomes dull and refuses his food. The sickness and dejection usually passes off when purging takes place, and the intestines have become relieved of the foreign matter. There have been numerous instances of horses being killed by the operation of violent cathartics, though not even then will the practitioner admit his error, and will ascribe the fatal result to the want of constitution in the animal, not to the virulence of the drug. The question may be asked, "How then will you train a horse overloaded with flesh, with legs that are swollen from plethoric habit, and which is naturally not strong enough to stand the work necessary to have him trot fast in a short period of time?" It would be much better not to subject such an animal to hard work until we had taken time to bring him by degrees to where he could endure, without injury, the exertion of getting rid of the superfluities. Blood-letting, purging and sweating, are the means used by all trainers to accomplish the reduction of the subject. If we discard the first two, are we not likely to do as serious injury by depending entirely on the latter? One thing has been received as an axiom by all of those who have the management of horses ; viz., that no curtailment of food is admissible. Admitting the truth of the old adage, that the 
more the horse eats the better condition he will ba in, we must qualify it with the explanation, that his work must be in proportion, so that he continually gains in speed and stoutness. The horse that eats so much, that, with all the work his legs and lungs will stand, he keeps taking on too much flesh, must be restricted in the supply, if even it fall below that which we would like to see him eating. The position then may be untenable although sanctioned by those highest in the profession. One of the great requisites for speed is muscle, and all recognize the fact that a diminution of that article is an injury. Hence the volume has to be kept up; and the argument used is, that food makes muscle, and that the quantity will decrease with any curtailment of the rations. It would be impossible to say how much food would have to be given to form all the muscle a horse could carry.

An idle horse eating, say twelve quarts per day, wouid eliminate from the surplus a good deal more fat, and nothing like as much muscle, as the one eating the same Fuantity and regularly worked. All that the horse eats hove the daily waste is stowed up for future use. When the food is below the requirements, the fat is first seized t.n by the absorbents, and it would take a long time before a very gross animal would become emaciated on a slight decrease of food. When a horse has become inordinately fat, it is distributed both in the interior and on the outside ; and one that is high in flesh, and that flesh acquired while doing a fair quantity of fast work, has his surplus mainly covering the ribs and filling up the interstices between the muscles. In one case the fat interferes with the action of the heart and lungs, completely hindering the working of the machine, and making it totally impossible to go any distance fast; while in the other, though hampered with the additional unnecessary weight, the horse works with far less labor. His legs would become weary, 
which repose would soon restore. Should these two horses be put in train at the same time, both having to trot races on the same day, it is apparent that their treatment could not be alike. There would be no difficulty with the one: his food and work could be given with impunity. With the other, some part of his preparation would have to be hurried, and I would much rather it should be in the last stage than the first. Two-thirds the amount of grain, with not over half the hay, three feeds a day in place of four, and the work given when the stomach was as near empty as possible-before feeding in the morning-would be the variation. The sweats given with less work and heavier clothing would suit me better than sickening him with aloes. The alterative medicine we are giving Clipper is very different in its effects. It is also combined with a tonic, and the intention is to strengthen-not weaken-the stomach.

PupIL.-I have often wondered at the array of bottles, pots, and cans, which some trainers fill their stables with, and have imagined that if all their contents were needed to develop the trotting-speed of the inmates, that chemistry and pharmacy were necessary studies.

Preceptor.-That the study of Hippopathology would be beneficial to trainers, I firmly believe, giving them the power, to detect disease, before it became seated and required the aid of a veterinarian to handle; but when seated, I would much prefer putting the case in the hands of a man who has made that science his whole study and business. To be able to form a correct diagnosis of a malady that is threatening a horse, might be of great service in establishing guards to prevent it. My remarks in allusion to pur. gatives were as a means of furthering condition. I most assuredly would not throw them out as prescriptions for disease. The question is, Is it necessary to give a well horse medicine, thereby making him sick, in order that 
his frame may be brought the sooner to endure great fatigue? I think that other processes are better, yet it is a matter of so much moment, that we ought not to take any one's assertions, unless such assertions are based on good judgment, or have been put to the proof.

PuPIL.-Your former remarks that air, food, exercise, and a strict attention to cleanliness, were the great adjuncts to successful training, appear to cover the whole ground. The variations that can be made with the almost endless varieties of food, and the difference in exercise from the walk to the fast trot, will meet the wants of, at least, a majority of horses. With what little knowledge I have of training, I should never have thought of drenching or balling to hasten condition. If one of my horses were taken with scouring, I should try at once to check it by giving more hay and less grain; sometimes using a drink made with starch or wheat flour, and if the case was bad, using injections of the same material. Oftentimes suckling colts are greatly troubled with this complaint, and if it is not stopped, it will kill them in a very short time. I seldom fail to cure it by restricting the mother to flour and water for drink, with a very little tannin in it. But if it has not been attended to at once, the poison becomes disseminated in the system of the foal, and both have to be treated. In that case I give two or three raw eggs, broken, into the colt's mouth, and should these fail, a strong cup of black coffee will, nine times in ten, effect a cure. I was much amused at a friend of mine who left with me three mares to stay during the season. One of them had a foal by the Falcon, which the man thought very highly of. When ready to leave, he asked me how I treated colts with the scours. I answered as I have been telling you. That would not do for him, and I must accompany him to the town, where he would get me the medicine that I must use, in case his colt should be unfortunate enough to be 
attaclied. I, of course, went with him to the drug store. He got a half ounce vial which he filled with distilled water ; to this he added as much of a white powder as would lie on the extreme point of the small blade of a pen knife. He then directed me to take another vial the same size, fill it with rain-water and put three drops of the liquid of the first vial into it, and should the colt become sick, drop one drop on his tongue, showing me how to hold my finger to guard against any more falling. I could hardly keep my countenance, but managed to restrain myself to ask what would be the result, should more than one drop be given. He answered, two drops will stop the discharge too suddenly, but be very careful that three drops are not given, as that would certainly kill him. I took the vial without any further remarks, and as the colt was well all the time he was at my place, I had no opportunity to test the wonderful efficacy of the eightieth part of a drop of the first solution.

Preceptor.-Such infinitesimal doses, I should think, could not do much good or harm. Still to me there is something very wonderful in homœopathy, and I believe that system carried into horse practice would be beneficial. The cruelty now constantly attending the treatment of horses by those who-boast loudly of their skill, and impose on the credulity of owners, might be abated, if all, not regularly educated in veterinary colleges, followed the homœopathic formula. How much cruelty has been practiced in the treatment of horses for the colic! I have known a pint of soft soap and a pint of vinegar first given, then a pint of whiskey and a tablespoonful of Cayenne pepper, then a quarter of a pound of saleratus dissolved in hot water, and lastly, a gill of spirits of turpentine poured down the nostrill. The men who recommended the last dose were highly indignant when I prophecied it would kill him, and I nearly got myself in a scrape by 
denouncing them as an ignorant, cruel set, unworthy of ever seeing a horse. I have never yet known a case of flatulent or spasmodic colic fail to be relieved by the use of copious injections of warm water, if given in time. While recommending the study of the pathology of the horse, I would still more strongly urge the consideration of his anatomy; at least, so far as to obtain a correct knowledge of the osseous structure. Knowing correctly the position of every joint and articulation, we can arrive with far more certainty at the solution of lameness, which otherwise might be difficult to locate. For instance an enlargement of the coronary ligament is often taken for ringbone; and the effort to reduce this morbid growth in the tissues, is the cause of hundreds being tortured in the vain hope of curing an incurable disease.

Acquaintance with anatomy would also be of good service in determining the structural symmetry and equipoise of the parts that form the well-balanced whole. This might be important knowledge when adjusting the work to the supposed capability of the animal ; of course it would be impossible to demonstrate from the form the work a horse ought to have, and yet knowing the faulty place in that horse's make-up, might lead to a variation in his treatment, resulting favorably, when one might have gone on a wrong track unguided. It is getting rather too late in the day to discuss this question now; at some future time we will have a talk on the proper-frame work for rapid locomotion. Considering the horse as a finished piece of mechanism, it is essential that each part should be in proportion to work in harmony, so that there need be no waste of muscular power in moving it along. 


\section{CHAPTER XVII.}

HARNESSING-DRIVING-COMMAND OF TEMPER-DRIVING ON ICE-

WINTER-TROTTING IN CHICAGo, \&c.

Preceptor.-Good morning, my hopeful scholar. I see you are awaiting my presence to commence operations.

PuprL.-We are all ready. The morning walk is through with, and I have harnessed Jane. I always like to have the harness get warm before hitching to the vehicle. I formerly owned a horse that, if saddled and mounted immediately, would throw off the best rider in the world; but if saddled half an hour before he was brought out of the barn, would go as quietly as desired. I ascribed this to the coldness and dampness of the pad, which had probably frightened him in his first lessons.

Preceptor.- In all likelihood that was the reason. The stuffing of the saddle absorbs a good deal of moisture, which must be exceedingly uncomfortable when pressed down with a man's weight. I have known horses that would not pull freely 'till they had "warmed in the collar," as the grooms say.

Regarding harnessing, nearly every man who uses a horse would say, that he can harness one properly, when the fact is that many professional grooms are not aware when it is rightly done. For trotters, especially, the greatest care should be observed that every strap is in its right place, and every billet buckled in its proper hole. When on, the whole suit ought to fit like a lady's glove, without confining the animal by a pressure of buchles, 
drawn as tightly as the force of the groom will permit. The bridle ought to be so adjusted that the bit will not draw into the corners of the mouth, yet close enough, so that the winkers or blinds will have the right set-the fore-top straightened below the brow band so that the hairs will not be broken. The breast-collar should come above the points of the shoulders, without encroaching on the windpipe. There is just the right place for the back pad on every horse, viz.: where the springing of the withers and the swelling of the ribs make it sit easily; this is, of course, regulated by the length of the crupper strap. The breeching ought to be about level with the stifles.

When the horse has been placed in the shafts-the reins having been run through the martingale rings and terrets-first fasten the traces to the whiffletree, then buckle the false girth. I follow this plan with horses that are restive when being hitched to the sulky, for should they want to start, you are in a situation to humor them. Now buckle the holdbacks, placing them under the traces, which will prevent the breeching flying up, giving, of course, plenty of room. The breeching ought to be so loose that you can draw it several inches away from the quarters. Snubbing-straps I never use, having found that, when the martingale is at its proper length, there will be no undue pull on the girth. I think many are prone to err in shortening the martingale so as to make quite a sharp angle in the reins, reasoning, that because a horse throws his head up in a break, there must be a downward pull to "catch him." It is true, that, with a short martingale, you get something of a pulley purchase, perhaps not greatly augmenting your strength, but allowing you to hold all you get. I am doubtful, however, if the advantage gained is commensurate with the injury done. The horse, unable to keep his feet, either 
from the pace being too rapid, making a mis-step, or becoming tired, breaks. His recollections are of being punished by having the bit twitched about in his mouth, and he throws his head up to bring the bit on the least sensitive part. The fear overcomes his judgment, and he completely loses his presence of mind, making a "terrible bad break." The dead pull the short martingale produces further worries him, and he tries, with short, sudden jerks of his head to free himself from the restraint. With the lengthened martingale there is only a little friction between the rein and ring-not sufficient to misplace the girth. We get far better control of the horse's head, and there is not near the danger of doubling him up, so that he will strike his knee or grab his quarters.

Drivers have generally a favorite way, peculiar to themselves, of recovering a horse from a break. One throws his body back in the sulky, and his whole weight on one rein, drawing the horse's head around till his neck forms the are of a circle, with a very short radius. Another snatches him from one side to the other, while a third yaws him about as far as the width of the track will permit. My plan is varied. If a horse breaks when I have been forced to pull him sharply, to keep him on his feet, I immediately slacken the rein, giving him the free use of his head, as it is possible he may have been partially choking under the pull. Throwing his nose out is a great relief to him under these circumstances. Should he not catch of his own accord after going a few lengths, I give him a little shake with one rein, as a reminder that he is doing wrong, accompanied by a gentle pull, which will always succeed in those horses $I$ have worked myself. If a horse is overtrotting, and flies up excited, a sharp, strong pull, lifting him, as it were, back to his trottinggait is often successful, without the loss of much ground. As soon as you feel him settled, ease away gradually till 
he goes on with as light a pull as is compatible. Horses that are not addicted to pulling, frequently take a very sharp hold of the iron when scoring, or in the first start of a race. With these we will have to be very gentle, ruffling them as little as possible, and yet suffering them to come to the score at their best flight of speed. It is a great thing to have a horse that will go from the score well, enabling you to make choice of the track, and obtaining other advantages that a leading horse always possesses. The pull we were forced to give at the outset can soon be slackened, provided we have been lucky enough not to have made a mistake. Though I find I am again traveling away from the subject, I thought it a good time to say something about harnessing when the union between martingales and breaking presented itself. There is much yet to think about relative to the leathern equipments; and after Jane displays her capabilities, and you jog Falcon and Never Mind, we will resume the consideration of martingales, check reins, and blinders.

PuPIL.-I want to recall your promise, that you would devise a way that I could exercise Jane without danger of her running away. I am not afraid of her absolutely getting away with me, though I am fearful of injuring her mouth in restraining her.

Precepror.-I see you have followed instructions in putting a chain-bit in her mouth. Hitch her to the wagon and I will jog her myself, and my word for it, she goes as quietly as can be expected.

There, you see she did not act badly, only compelling me to bring her to a stop a few times before she learned that all that I required was for her to go slow. It is true, that, when I turned her around to try her the right way of the track, she was somewhat excited. But finding, that I would permit her to walk only, she acquiesced like the well-bred one she is. She must make her mark, if for 
no other reason than the name she wears, and if she should show herself worthy, forgeting all her bad habits, and going "alarmingly fast," we will add the surname, and she shall wear the best suit of clothes that can be bought to deck her ladyship, embroidered by the fair fingers that can do it so well.

The few steps she took, when I first turned her around, convinced me, that she has any amount of power, which we must make available by proper teaching.

I feel safe in guaranteeing, that she will not strike her knee. Still we will let her wear a boot on the one that is slightly enlarged, whenever we permit her to go fast enough to endanger it. I will now see you drive the others.

Pupn.- You must have put some potent charm on the Falcon, as I never knew him to jog so quietly on the track before. This must be one of his white days.

Preceptor.-Or rather say of yours. It is hard to convince a person of the absolute requirement there is to govern the temper when handling horses. You got into the sulky, knowing, that every motion of you and the horse was to be closely watched; so you were constrained to be on your good behavior. You governed him by kind words and gentle tones, in lieu of pulling at the bit. The good effects you have seen. Should you ever feel a little cross-grained, delay exercising till the black fit is off. If you have not an Annot Lyle to charm you out of the sulks, rely on reason to guide you, but above everything else, visit not your wrath on the horses. You cannot always expect them to understand every command, and should they appear disobedient, rely entirely on kindness. It is true that there must be punishments, as well as rewards. Be convinced of your own temper before you strike. Mark me, that we are going to cure these horses of all former bad habits by uniform kindness, and I urge 
on your consideration, more strenuously than circumsíances will warrant, the necessity of uniformity of temper. A blow, a passionate jerk of the reins, even a harsh word, might render nugatory the teachings of weeks. Having once been in rebellion, they will be incited thereto again, by treatment analogous to that which was the primary cause, only it will require less ill usage to spoil them than it did on the start. Never Mind you will drive a trifle faster than you did the Falcon, ending your drive when you have gone five miles. Should the weather be favorable, we will sweat him day after to-morrow, and again in a week from that time. The Falcon and Jane will then also be ready to lose part of their surplus.

PupIL.-You need not apologize for urging the necessity of keeping my temper. Having a fair command of it there are yet times when I find it difficult to keep it in subjection. I feel, that it is more important with those horses that have suffered abuse, than even with the colts, as there is always more danger from a relapse, than from the disease at first.

Preceptor.-The high-headed brown fellow certainly makes a fine appearance; and, to take the motto of his native State as a password, we will try "to guide" him so that he may be no discredit to the land that has turned out several of our best trotters. They were fortunate in obtaining some of the Messenger blood from near the source of the stream, and, having the blood, have made the most of their inhospitable climate, by taking advantage of the frozen surface of their rivers to teach the scions of a noble horse to trot, that otherwise would have been compelled to haul the plough or wagon all their lives. I have heard a good deal of argument whether it was better to drive a horse on the ice or not. Never having tried the experiment, I can only hazard an opinion. It appears 
as if the unyielding thick ice would be rather a dangerous place for the feet and legs.

PuPIL.-I am inclined to think that, in the northern latitudes, the ice might be taken advantage of for teaching colts to trot, without being detrimental to the feet or legs. I have tried it a little, and found by proper shoeing the jar was in a great measure taken off, and they could go with more freedom than on the frozen roads. The shoe I have found best adapted to ice work, has a little resemblance to the flanged one we are now using. The toe-calk is made to extend quite a distance round the shoe, and the heel ones are set parallel with the foot, and nearly an inch long. They are made of steel, and kept very sharp, so that the cutting into the ice not only gives a better hold, but takes off a great deal of the concussion. I had an eye to the benefit of ice driving, when locating the breedingfarm near the Mississippi. The river itself is apt to close up rough, from the running ice pushing huge cakes over one another. On the large island, however, there are lakes not disturbed by the current, where the ice is smooth, and the woods afford protection from the wind.

One season I broke three colts that were of the same age, and very closely matched in speed. Two of these I let run all winter; the third I had shod, and drove her as occasion required-chiefly to the little town a couple of miles off. By making a circuit, I could drive on a bayou where the ice was good, and where I would let her step along. She was taken out at irregular intervals, and driven only when her services were needed. Neither had she any better care than the others. When brought in, a blanket was thrown over her till she became dry, when it was removed. The others were turned out of their stalls into the field every day that was not stormy. All were fed alike. As the spring opened, the colt's shoes were pulled off, and she was allowed to run two or three weeks after 
the other two were taken up. She soon trotted right over the others, and kept her lead all summer. This impressed me so highly with the benefits to be derived from driving on the ice, that I am determined to pursue it when I got back home, and by giving it a fair trial I think I will be able to decide in relation to its advantages. I think the smooth surface gave her confidence, after the novelty of the situation had worn off. Some cold mornings the ice would crackle and rumble as though an earthquake was breaking up the foundations of the river. This would startle the colt, and she would dart away frightened, though she very soon became accustomed to the noise, and paid no further attention to it. I noticed she would bear more urging without breaking than when on the track. There was a marked difference in her action the following summer-keeping her feet under her better, and going more like a trotter in every particular. The treatment for horses trained in this way would have to be very different, of course, than if the weather were warm ; walking would be inadmissible, and much grooming would be an injury, by breaking the hair. Large, soft blankets, to absorb the perspiration, and permit the moisture to evaporate, would be essential. The stable would have to be moderately warm, with plenty of straw to make a bed that would cover their knees as they stood.

Preceptor.-Anything I could say regarding driving on the ice would only be surmise. Though I cannot see any reason why colts would not be benefited by the winter's schooling, I would not like to make the lessons very severe, although when I found the limbs and feet were uninjured, there would not be a great deal to fear otherwise. The rapid inhalation of very cold air might be prejudicial to the lungs, which would be obviated by making the brushes very short. Skating is admitied to be a healthy recreation, provided proper precautions are taken to keep 
the extremities warm ; and of course, the frozen air has to be breathed by the bipid, in, perhaps, as rapid draughts as the young trotter would require. I shall await your further experiments with some anxiety, as it would be a great gaining of time, if we could make the winter months available for continuing our lessons.

PrpIL.-The Chicago River, in the winter months, is frequently a very animated scene. It runs nearly through the centre of the city, its two branches uniting some threequarters of a mile above its confluence with the lake, dividing the town into three compartments, known as the south, west, and north sides. It is one of the main causes of Chicago's greatness, making not only one of the finest harbors in the world, but giving facilities for the handling of grain, lumber, and merchandise, that are unequaled in any place that I know of. There are upwards of twelve miles of docks, with numerous large elevators, whence the grain is taken from the cars, and vessels loaded so rapidly, that millions of bushels are transferred, without causing any more bustle than is apparent every day. Those engaged in the business are the only ones cognizant of any greater degree of activity than usually characterizes the place, although shipping corn and wheat enough in one day to equal the whole amount grown in some of the New England States. Five drawbridges span its turbid wave in the distance of a mile; and when the ice is good, and the scores of fast horses are dashing rapidly below them, throngs of people are congregated to watch the exciting spectacle.

Here is a pair with grand and lofty action, keeping step with the regularity of trained soldiers: the merry bells jingling in cadence to the measured footfalls. The wolf robes are comfortably tucked around the form of one of the fairest daughters of the garden city, and the furred and gauntleted driver seems to be at a loss which to be most proud of, the costly turn-out, or the beautiful lady at 
his side. They are going fast; but a few rods behind thelis a pair of small chestnuts, with flowing manes and nervous step, are rapidly approaching. This sleigh has also two inmates, muffled so closely, that you can only see the blue, good-humored eyes of the driver, contrasted with the small, black and glistening orbs of his companion, that are fairly dancing with excitement at the prospect of a brush. As soon as the leader is aware of their proximity, the tapering whip is allowed to fall lightly on the quarters of his gallant steeds, and they respond by an increased flight of speed. It is in vain : the chesnuts' heads are opposite the cutter as they rush under Clark-street Bridge-as they emerge from the shadow, they are lapped, and in the next one hundred yards are gliding rapidly away, the grand bays pawing frantically in the air. Yonder come two of the fastest, rigged to skeleton sleighs. Many has been the boast of what each could do with the other when they came together; yet neither seems anxious to bring it to a practical test. They are jogging along quietly, when ine driver chirrups at his horse, and he darts away at a forty clip; but he soon pulls him up, and the other goes through the same maneuver. Once more they are in juxtaposition, and away they g'o. How rapidly they overhaul those that seemed to be going so fast! Still they are head and head. The words of encouragement of their respective drivers give place to quick, sharp yells, and the whips are also brought in requisition. How eagerly they strain for mastery! One has got the length of his neck in advance, and seems still to be gaining by a quarter of an inch at a stride, when up he goes; his competitor has a clear length the lead before the other recovers; but when he does regain his trot, he is going faster than ever. 'The people on the bridges are shouting with excitement; and from the decks of the vessels, that are now motionless, wedged in the frigid barrier, come correspouding shouts, 
The other actors in this gliding panorama have pulled their horses to a slow pace, and are intently watching the progress of the race. As the racers pass the victorious chestnuts, a clear, ringing voice, issues from below the sparkling eyes: "A thousand dollars to five hundred tha' MIedoc pops it to him." There are no such odds, for as they make the turn in the bend of the river, they are as closely locked as Grey Eagle and Wagner were in making their final brush, when strong, stalwart Kentuckinns fainted from the excitement of witnessing the continued struggle. We catch the last glimpse of them as they fly by the South Branch, and we are left to imagine which will be crowned the victor. There must be some strange fascination in watching these contests : regardless of the cold, we keep our station on the bridge, till the sun's rays are slanting through the white vapor, and the shadows are falling thick and heavy from the huge warehouses, and lie in patches on the white ice.

Preceptor.-And surely, any one with a spark of mercury in his composition, would endure a good deal of cold to see the trotters of a great city exercising where he could obtain such a view of them. From your description, I judge there is nothing in the way, save the performers themselves.

PupIL.- They have the whole river to themselves, and to get on the ice, there has to be a declined bridge of plank made from the higher elevation of the street. Teams, and those engaged in business, never take the trouble to drive down. I saw a race there once that was thrilling. Two men were coming down the river with horses that were very nearly matched, and the contest was close and exciting. Before arriving at Rush Street, the bit of one of the horses parted in his mouth, and he run away. To ease the labor of driving, the man had knotted the reins around his back, and they had become 
so entangled, that in his excitement he could not undo them. On the horse sped, and of course it would have been madness to have jumped out of the sleigh, only to be hauled along by the firmly twisted reins.

The frantic animal, under no control, rushed madly along; the point, on which the lighthouse stands, was passed, and he made his way directly for the blue water that was surging in the wintry wind. It was yet some distance off, but the fearful rate, at which the scared horse rin would soon carry him over the intervening space. Soon the dashing of the waves, as they curled, foamed, and hissed over the frail barrier, was heard, mingling their sound with the plunge of the horse's feet, and the crisping drag of the runners slightly cutting the hard surface. Only a few more bounds and they would be engulfed in the cold water. The driver had called and shrieked at the horse till he was hoarse, and now sat with the calmness of despair, with no hope that anything could avert the fearful end. He speculated on the time he would have to endure the embrace of the watery shroud, before he became unconscious, and wondered how long it would take him to sink to the bottom and be at rest. He shut his eyes, feeling there would be some relief in not seeing the fatal plunge. There was a shock - he felt the sleigh upsetting, and his recollections were at an end. The horse had at last become aware that he was going to run into the water, and turning just on the brink of the ice, had nearly capsized the cutter. He ran down the lake shore, where he was stopped, the man still being in a swoon. No one could ever persuade him to drive on the ice again.

Preceptor.-He ought to have had more sense, than to jepoardize his life by fastening the reins to his body. I have seen men run their wrists through the hand-pieces, taking a twist in them, to drive a hard puller; it always makes me nervous to witness it. There is danger enough 
in driving, without taling the chance of being fastened to a runaway horse. With such a winter's drive as you speak of, and good summer roads, there will likely be always a market in Chicago for trotters.

PupIL.-There is not much doubt of that. At times I have been fearful that the sharp practice of some-who ought to be below the turf instead of on it-would disgust the men who uphold and give countenance to the sport, and that trotters would depreciate in value, until the price would no longer pay for breeding and training. Should these villainies finally drive the public from patronizing the trotting parks, the inquiry there will be, by those living in the larger towns and cities, for superior roadsters, will tend to leep prices up; but the large prices that are paid at the present day for the fastest trotters, in that case, could not be looked for.

Preceptor.-As long as our wealthy men take the pleasure they now do in fast driving, there will always be a remunerating market. As to the rascalities that are sometimes practiced on the turf, it is a very unpleasant subject even to talk aboul. I hope there will be a joint action of the clubs over the country to eradicate them. A confederation of the different clubs and driving-park associations would be the most effective cure. If ruling off one course included banishment from all, there would be few bold enough to take the chances of detection.

[t is now approaching the time for our noontide meal. After discussing that, we will see if we cannot "know of something for the good" of our horses, and such as will be pleasanter to think of than the knaveries of mankind. 


\section{CHAPTER X VIII.}

THE MARTINGALE-BLINDERS-BLIND AND OPEN BRIDLES-FEED. ING-OATS AND HOMINY.

Preceptor. - Before eating dinner, I felt a little out of humor. The recollections of some transactions worried me. I am pleased to say that I have recovered my equanimity, and after inhaling the aroma of this finely flavored cigar, my brain will be clear enough to discuss any topic with which I am acquainted. By the way, you must have obtained another supply of cigars. I see your favorite clay pipe is laid aside, and you are smoking with evident satisfaction the fellow to this.

PupIL.-The bale of Killikinick, that was flavored so exactly to my taste, has unfortunately been consumed. The visions that have been pictured on my brain, while assisting at its empyreal ceremonies, have not been so evanescent. While you were gone, and I was left to my solitary dreamings, the after-dinner smoke was among the pleasantest moments of the day. I am not going to inflict the recollections of these phantasies on you now, though I watched the decrease of my treasure, much as the castaway sailor would look at the daily diminishing supply of water. I could not expect to get any more, as the fabricators have gone out of the business, and I knew of none others possessing the same cunning skill at selecting the leaves from a year's purchase, having them manufactured with the same care, and apportioning the fragrant spices of the Orient so exactly that the compound became perfec- 
tion itself. The last bright leaf was burning in my pipe, when there came a package by express, all the way from Chicago. I directed it to be left on the porch, quietly deliberating on what it could contain, determined however, that my curiosity should be unsatisfied till I had drawn the last perfumed breath from the fascinating bowl. I looked at the package with some misgivings, thinking that when opened it would disclose some great sell of Capt. $\mathrm{K}-\mathrm{t}$ or Charlie $\mathrm{C}-\mathrm{k}$, who are much given to the perpetration of practical jokes and hoaxes. Both of them would go without sleeping or eating for forty-eight hours, if by that means they could raise a good laugh at the expense of their friends ; and, to catch each other, would even go without drinking for the same period. I looked at the box, and felt convinced it was a hoax; but mustering resolution to know the worst, I got a hatchet, and brought to view such an array of cans and boxes, that I was fairly dazzled. There were half-a-dozen bright canisters marked "Banner," the same number of varnished wood ones, filled with the finest smoking tobacco, almost equaling that so fondly remembered. Boxes-I hardly know how many-of Regalias, Punches, Principes, \&c., and at the very bottom, a card: "From P—, No. 48 Dearborn St., Chicago, nlinois." The present being unexpected, and coming so opportunely, made it doubly acceptable; and though aware - that friend $\mathrm{P}$ — is an enthusiastic admirer of the horse, was unprepared for this liberal demonstration to one who had no claims upon his generosity. I opened one of the boxes of Principes, and they brought back the sunny days of my youth so vividly that I have continued to smoke them ever since, and can only say that no other cigars would have seduced me from my vows of fidelity to the pipe. When I saw the card, I needed no other guarantee of their quality, as I know only the very best ever came out of P—'s store. 
Precepton-You are in great luck in the tobacconists of your acquaintance; and I hope, when sending your acknowledgments for this liberal present, you will also embody my thanks in the epistle. These cigars are, if anything, superior to your first consignment, and would tranquilize the perturbed spirit of a man who had just lost a race.

Before we return to the stable, we will resume the consideration of the harness. The martingale we will commence with, in relation to its use in the training of trotters. The general idea has been that it could not be done away with in their education, or its future services be dispensed with. With saddle horses, it has long been a mooted question, whether it is advantageous or not. In this country, in the region where the best saddle horses are found, it is rare to see it forming a part of their equipment. Those who have written on the subject are divided in their opinion, and while one questions its advantages, another will not admit that it can be prejudicial. I have embodied most of my ideas regarding it in the conversation this morning, adding that there are very few cases in which I would decline using it, but still less frequently can I see any benefit in having it very short. Harry Hieover, in alluding to martingales, says : "They are useful in two ways. With the good rider, they bring and keep the horse's head in its proper place; and with the bad one, they prevent the badness of his hands pulling it into an improper one." He further recommends their use in all cases, even on a horse that has to jump high, or a distance, as crossing a stream. Carl Benson, commenting on this article of Mr. Brindley's, writes: "As to long jumping, I have not the slightest doubt that the martingale is a hindrance to it, especially with green horses. I have seen the experiment tried too often; over and over again I have seen a horse baulking at a ditch, and clear- 
ing it as soon as the martingale was removed. Once I saw one baulk so badly that he ended by throwing his rider, who was a very good horseman, too; but, in the conceit of good horsemanship, he thought he could force the animal over with the martingale on. After this very decided hoist, he took my advice and removed it, and the horse went over at once, and I have seen him clear some very nasty ditches, and ridden him over not a few myself."

These facts instanced by Carl Benson, are of far greater weight than mere theorizing. The horse, knowing the martingale cramped and fettered him, was afraid to try the leap, if even it was within his power to do it easily. But as soon as the martingale was removed, his confidence returned, and he went boldly over. The trotter requires the full use of himself, as well as the steeple-chase horse or hunter, and is much benefited by being harnessed so that he has all the freedom admissible with being properIy secured to the vehicle. My idea, then, is, that ninetynine in every hundred horses require the martingale to be so long that there will be no friction between the reins and rings, as long as his head is carried in a proper position, and will only act when the head is elevated to an improper height. My remarks are, of course, only applicaple to the common or running martingale. To the harness horse, the fixed or standing martingale is a posi.tive injury, as I have never seen a case where one was of service. It is rarely seen except in the harnessing of pairs, and I think is mainly used from the fancied improvement in the team's appearance. Some horses have a habit of tossing their heads up, generally for the momentary reliet afforded, when the bearing-rein is too tight. The sharp blow the bars of the mouth receive from the bit, when fastened with an unyielding strap, cannot do much good. I have heretofore signified my preference for the Kemble Jackson check, when a horse required his head to be much 
elevated, and gave my reasons at the time for estimating it above the common one. It is hardly necessary for me to state that I would prefer a horse that needed no extra appliances to trot at his fastest gait; and if I had an animal that would go under all circumstances better without check rein, martingale, or blinders, I should certainly not put them on him. But, unfortunately, for one animal of this kind, there are very many that need all these appliances, and it will be a matter requiring much study and frequent experiments, to know the best manner of applying them, to meet the exigencies of each particular case.

Fast trotting depending so much on the education, the first lessons are of the greatest moment in determining the habits of a horse ; therefore, if we accustom him to a high check when we commence, the chances are that he will always need its support; or, should we teach him that a heavy pull is an absolute necessity, when he is trotting fast, then the short martingale is an essential part of the harnessing. The tension is steadier, and remedies, in a measure, what Harry Hieover would call "bad hands." If one could retain the natural delicacy of the horse's mouth during the long time the training of trotters requires, a great point would be gained. The admonitions of the bit would be sooner obeyed, and this powerful monitor would have a tenfold greater effect. Fashion and Miss Footetwo of the greatest mares on the American turf-were as easily placed in their races as though they were reasoning beings, permitting their riders to take every advantage the changing scenes of a four-mile contest afforded, and I am positive in my belief that they would not have won half the races they did, if they had been pulled at till all feeling in their mouths was gone. Launcelot, a brother to the celebrated Touchstone, was the very reverse, and his great powerrs as a race horse were almost rendered nugatory by his determination to run away, only restrainable by a 
powerful curb. It is no argument, because some of the best and fastest horses have been great pullers, that it is not a material injury to speed, as it is almost a certainty that they would have gone still faster if easier driven. But even granting that it does not meterially effect the horse, the driver assuredly would be in a better plight to win, if he had been more at his ease when driving the heat.

A great deal has been written and said relative to the use of blinders. While the arguments for their discontinuance are apparently the stronger, I must acknowledge that, in my practice, more horses have gone better with than without them. It is a great point with me to have a bridle "sit well" on a horse's head ; and if it has not been properly constructed, all our efforts to adjust it will be futile; and when well made, the greatest care must be takew that the bit is in the right place, and that the side-pieces, and the strap that is attached to the front part of the blinders, are buckled just where they ought to be. The blind itself should be of sufficient size to completely hide from the horse everything that is behind him, and confine his range of vision so that it will be circumscribed by about sixty degrees, or the sixth part of a circle. This will give the blind flare enough, so that it will merely shade the eye, without the least possible chance of injuring it by presstire, or by want of circulation of air. I find that horses driven with an open bridle are not so attentive to their business, watching everything that comes under their observation, and paying particular attention to every motion their driver makes. While I am willing to gratify this propensity, when it does not interfere with the lessons I am giving, I want to control it when in the harness, and prefer at that time to have the undivided attention of my pupils. Each horse should have his own bridle. To have a harness apiece would still be better, but this would in- 
crease the cost of fixtures so much that in a large stable the amount necessary to equip the horses would be quite onerous. Horses that are nearly of a size can be used in the same harness, without much change. Horses, however, with the same sized heads might not be suited to the same bridle. The angle of the lips might be deeper in the one, and the eyes nearer the poll in the other, thus requiring a change in the length of the billet that holds the bit. The bit itself should also be adapted to the wants of the horse, and the bearing-rein always of the length thought best.

PupIL.-In breaking colts, I have found it advisable to accustom them to both blind and open bridles, and have discovered that while one could hardly be harnessed with his eyes partially blinded, another would go more quickly when he could only see ahead. Extremely nervous or timid colts are more easily broken with an open bridle, while those that shy, I find, are less liable to do so with kilinders. I have a large, strong, thoroughbred colt, three yrars old, that I got from an old friend of mine, who had suffered him to grow to that age without his ever having lieen in a stable. When I saw him, he was tied up with a strong halter; and as I noticed he did not like the approach of a stranger, I contented myself with admiring his well-knit frame, and a general wiriness of form that denoted his breeding and activity. I bargained for half of him, the old gentlemen being determined to retain the other moiety. He brought him to my place when he had finished planting his corn, leading him beside a large mule that had been a playmate of the colt's when both were running out. He had not become much more sociable than when I first saw him, but would trot alongside the mule, showing a gait "that pleased me exceedingly." Having traveled some thirty miles that day, the conclusion was that he would be a little tired, and would not be so 
troublesome to harness as when fresher. I put a blind bridle on him, when not another strap would he permit to touch him, nor would he allow a hand even to be placed on his neck. We took the bridle off, and replaced it with an open one, when we found him no more trouble to harness than colts usually are. He bounced about when first driven on the track, yet it was not long before he became reconciled to the hold-backs and breeching dangling about his quarters. After several days' practice with the harness on, I thought it time to put him in the shafts. He became perfectly frantic at the approach of the sulky. When we pulled it along in front of him, he would rest his nose on the seat, perfectly fearless in that position; yet the moment he was brought before it he became as wild as ever.

Quite a time elapsed before we attempted to put him in the shafts again, practicing him daily by leading him alongside and behind the sulky. When we did, we got him in without a great deal of bother ; I did not think it advisable to fasten him further than merely placing the points of the shafts in the loops, a man on each side holding him by the bit, and with the other hand keeping the shaft in its place, so that, should he become frightened, we could push the shafts back, and he would be free. $\mathrm{He}$ walked very quietly for a couple of hundred yards, and I was congratulating myself that the worst was past, when, without any warning, he bounded as furiously as though he had been struck a severe blow with a whip. We held on, thinking after a leap or two he would become tranquilized; but seeing him lay back his ears on his poll, and being fearful that he would kick, we shoved the sulky back. We again resumed leading him near the sulky, and I made up my mind that when we attempted to hitch him again, I would fasten him to the sulky, as I thought we had made a mistake in not doing so before. So I strapped up 
his fore leg, and took him in a smooth field inside of the track; we could not pull the sullry up behind him, as on its approach he would spring around in spite of the efforts of two men at his bit; so we laid the shafts across his back, and by carrying the wheels around, got him in position. As soon as the traces and false girth were fastened, we secured the kicking-straps, one being placed across the coupling, and the other just above the setting on of the tail, the ends buckled securely round the shafts. On moving him-with the leg still up-he commenced kicking as violently as his cramped situation would permit. It was as much as a man could do to hold the sulky down with all the leverage his grasp of the hind cross-bar gave him. The colt then succeeded in slightly splintering the whiffletree bar. We brought him on the track, drove him on three legis till he ought to have been subdued, but, seeing no sign of it, I became apprehensive of injuring the fore leg that was doing all the work, and let the other down, taking the precaution to fasten a strap to his fetlock and over the shaft, so that the foot could be pulled up at pleasure. It would be tedious to recount the work we gave him for the ensuing three weeks; but we got him so that we could harness and hitch him without difficulty, and he would usually drive quietly.

His education was progressing so very favorably that when leaving home, I directed the young man who assisted me to break him-and who is as good a hand to work with colts as I ever saw-to drive him daily. One very windy day he became frightened, broke the water-hook of the harness, enabling him to get. his head down, and he began kicking so furiously that he threw the driver out of the sulky. The kicking-straps; fortunately, holding, drew the axle up out of the way of his legs. The man was unable to hold him, and away he went. After he ran a short distance, he stopped kicking, and cantered quickly 
up to the gate by the stable, where he suffered himself to be caught. Nothing was broken save the water-hook; so, refastening the check, the man drove him several times around the track, going more quietly than he had ever done before. I learned afterward that, to halter him, they got him into an old log stable, cramped him up in a corner of it with poles, where they had a regular battle royal, the colt coming out victorious, after having been scratched all up with the knots on the poles. His antipathy to the blind bridle resulted from his being severely punished with one on to make him tractable, and I very much doubt whether it will ever be possible to drive him with blinds. His not being able to hurt himself, from the lkicking-straps throwing the sulky out of the way, and the harness and vehicle being strong enough not to break in the fracas, had a beneficial effect, which was shown by his exhibiting less fear at the approach of the sulky afterward.

Preceptor.-Kicking-straps alone will not hold a resolute, strong horse, if he gets his head down. With it up, his power to do mischief is very limited. We will go to the stable, and while you are jogging those you did not work this morning, I will superintend the cleaning and preparation of feed. This has not been necessary heretofore, the horses having all been fed at the same time. When the rattling of the sieve was heard, their uneasiness was soon relieved by getting their respective portions. Now, to get along with the driving as we ought to, we will have to postpone the feeding of those that are exercising near the feeding-time, and it is important that those who are eating should not disturb the others in the stable. With the feed prepared, it can be given without noise. Good, clean, sound oats, one or two years old, that have been kept in the stack long enough, before thrashing, to 
sweat thoroughly, and weighing from thirty-five to forty pounds to the measured bushel, is the first consideration.

We will use a strongly made forty-gallon cask, and put in it two bushels of oats, two of the boys, with shovels or spades, striking alternate blows, or rather chopping, till all the husks are loosened, that can be by this operation. When sufficiently chopped, carry to the green, and, spreading a linsey or sheet, let the oats fall slowly from pans elevated as high as the boys can hold them. The breeze that is now exposing the silver lining of the leaves of that beautiful poplar, is just strong enough to blow away all of the dust and light grains, so the portion retained is both heavy and clean. We will now take six quarts of hominy-the proportion will be greater hereafter-and after fanning all of the mealy particles out of it thoroughly, incorporate it with the oats on the linsey. To efiect this, the boys will take the sheet by the corners, and by tossing it backward and forward, the union is soon accomplished. The work is continued till the receptacles intended for the reception of this mixed feed are filled. Another is filled. with cleaned oats alone, and still another with prepared hominy. A barrel or two filled with bright ears of corn, and a box of bran complete this part of the commissary. We can then feed a horse whatever we desire, without waiting for preparation, and there is no rattling of the sieve to annoy those we do not wish disturbed. The best bran for our purpose is that obtained from winter wheat. The flinty husk enveloping the kernel on this is thinner and more easily separated from the flour. There is less nutriment, of course, than in the bran of spring wheat, but nutriment is not what we want. We will use oat-meal or sago for gruels, the mashes intended to slightly irritate the inner coating of the stomach and intestines, causing: them to secrete more of the watery fluid, thus softening the evacuations. 
The feed room must be kept strictly under lock and key, and the boys never suffered to measure the feed. The foreman will give them the amount each horse is to have ; and if $I$ had not full confidence in his attending to this part of his duty, I should carry the key myself, even if it necessitated my attendance at the stable for every feed. Grooms becoming attached to the horses they are taking care of, are very apt to feed them more than they are told, and this mistaken kindness I have known followed by serious consequences. I will not detain you any longer from driving; by the time you get through, the horses will have to go out for their walk.

PuprL.-The young things are done with. When driving I was cogitating over your manner of feeding, and am anxious to learn why you prefer mixing the hominy and oats together, and why you increase the proportion of hominy as the horses take sharper work.

Preceptor.-We have hardly time now to discuss the effects of the different kinds of grain on the health of the horse. It is a matter I have thought a great deal about, yet I cannot flatter myself that I am capable of throwing much light on the subject. Oats are said to be the nataral food of the horse. Why they are claimed to be their natural aliment would be difficult to tell. If the horse originated in the East, as is generally believed, he must have been dieted on something else, as oats were not grown there at all. Oats have the thickest husk of any of the cereals with which $I$ am acquainted, there being only eight pounds of flour to fourteen of grain, while there are twelve of barley and thirteen of wheat in the same quantity. Corn has still less bran, and if a horse were confined to any one of these grains in a whole state, the greater bulk of oats to their weight might make them easier of digestion.

But I will give you some of the reasons why I mix oats 
and hominy. There is more nutriment in the same bulk; they are easier digested than when fed separately; most horses like the mixture better, and will eat it when then they would mince over oats alone. Corn, being more laxative than oats, has to be used with discretion, and I have known trainers to err in giving it to animals that would have been better without it. Washy, delicate horses, which can hardly take work enough to learn to trot even without going off their feed, with such a fidgety, nervous organization that any noise or change will discompose them, that scour when they are the least excited, that never need to be sweated under any circumstances, ought never to be fed corn or mashes. All will agree with me that bran ought not to be fed to such as these ; but a majority will say, Why, these are the very subjects that ought to have corn ; it will increase their strength, being stronger food, and you can often get them to eat an ear or two of corn when they would not touch the oats. The English practice of feeding beans, universally recommended by their best trainers for the washy, light-waisted fellows, will be instanced; and it will be argued, that, because beans and corn are of about the same specific gravity, they are analogous in their results. Beans have a constipating tendency, which makes them a proper corrective for the lax constitution, while corn increases the evil.

We will have to take a more fitting time, however, to consider the question of aliment, which is a very important one.

I will now leave you, having some business in town which requires my attention. Treat Never Mind as you did last night allowing him to graze half an hour. I will not be here very early in the morning, but I do not want you to drive him till I come. As we have now every prospect of good weather, I do not think there will be 
anything to interfere with the contemplated sweat, day after to-morrow.

Think of all you can that will have a bearing on the question of the utility of this means of depletion, and we will try to obtain mutual advantage from the discussion. 


\section{CHAPTER XIX.}

OBJECTS OF SWEATING-HOW FAT IMPEDES THE ACTION OF THE HEART AND LUNGS-MANNER OF REMOVING IT-RACES LOST BY SUPPRESSED PERSPIRATION.

PreCEPTOR.-I am later in making my appearance this morning than I expected, and came very near being the cause of delaying Never Mind's work longer than would have been politic.

PupIL.-The boy has given him an hour's walk, which I took the responsibjility of ordering.

Preceptor. - That was correct. We can hardly overestimate the importance of being regular in the time of working a horse. Trotters, perhaps, can be allowed more latitude in this particular than race horses, yet the benefit they experience by taking their exercises at a definite hour well repays exactness in dividing our time. There is no business in which regularity and order are more imperatively demanded than that of training horses. It is very true we cannot reduce it to a question of performing a routine of duties at the same hour and minute of the day. If this were the case, training would be a simple concern, capable of being done by every one who is energetic and systematic. Rules could be laid down which, if followed, would certainly result in success, when, in truth, the great art in training is, when to change the work, feed, \&c., according to the wants of the horse. It might be good policy with some horses, indeed, to change the hour of their 
work, the same as we frequently find the benefit of giving them their exercise in a different locality. The brown fellow, I expect, has the harness on. Hitch him to the sulky, jog him quietly twice round the track; the third time let him go about a four-minute gait, till you get half way down the stretch, when you can drive him nearly to the top of his speed to the stand; pull him up on the turn, as I want to see how he breathes. You can then jog him leisurely the reverse way of the track, twice round, and drive him to the barn.

PupiL.-I hope I followed the directions to your satisfaction. He was eager to go when allowed to move faster than was customary, and he did not half like being pulled up after so short a brush.

Preceptor. - Your driving was worthy of commendation, and the horse performed even better than I anticipated. The action of his lungs and heart is very much impeded by inside fat, and to have kept him at the same speed, that you drove the two hundred yards for half or threequarters of a mile, would have overworked him, and caused serious injury. He has speed enough to trot in the very best company ; and with a moderate share of good luck, I think we will be successful in lis preparation. The reasons I had for directing you to open him that short distance, I will give you in the conversation we will have on sweating, its effects and uses. Your presence not being required at the stable till after dinner, we will go to the house, where our seat on the piazza will be more comfortable, and where our attention will not be so likely to be distracted as when in the immediate neighborhood of the horses. Jane and the Falcon, I suppose, worked kindly.

PupIL.-Neither of them gave me any trouble, but I would not like to bet on being able to pull Madam Jane 
up in so short a space as I did Never Mind, after allowing her to get nearly to her best speed.

Preceptor. - We will have her as obedient as any of them, before we call on her to display her speed even for a short distance, and I feel safe in assuring you that she will be less trouble on that score than the one you have just driven. The bay mare's faults are those that have been engendered by bad handling; her natural disposition is better than that of Never Mind, and her phrenological developments are certainly much superior.

PuPIL.-I think the long journey has been an advantage to the Falcon as well as King. He never drove as kindly on the track as he has since he has been here.

Preceptor. - In place of ascribing the improvement to the journey on the cars, is it not more likely to follow your own improved skill in driving him? It is not very flattering to our self-love to admit that we are more to blame than the horses, yet nine cases in ten it will prove so.

Here we are comfortably seated, and have time enough before dinner to say a good deal on the topic we are going to discuss. Should I advance any ideas that are not clearly understood, or that you differ from in opinion, do not hesitate to interrupt me, so as to have the matter stated in a clearer light, or show by argument that the grounds I take are untenable.

The natural outlets of the body are the skin, bowels, and kidneys. With their aid we get rid, of what the old trainers called the waste and spare. We can increase the action of all of them by articles given as food or medicine. The evacuations through the numerous pores of the skin are what we call sweating, the effects of which-when properly used-being to bring a horse into such a state, called condition, that he can do, without injury, what would be an impossibility for him to perform without its aid. I have 
signified my objections to stimulating the bowels and kidneys by cathartics and diuretics as aids of training, and I must, necessarily, show that condition can be acquired without their help. Sweating has two distinct things to perform : the first, to give freedom to the respiratory organs and the action of the heart, which we may call internal relief; the second, to promote the strength and activity of the muscles, and lighten the load to be carried, which, with the same propriety, may be termed external relief. The organs of respiration are the lungs, bronchial tubes, trachea or windpipe, glottis or valve, at the extremity of the trachea, nasal passages and nostrils. Knowing that I am incapable, it would be foolish in me to attempt a lecture on hippophysiology, and in offering the remarks I am going to make, I do not present them as being scientifically correct. I lament greatly the want of a suitable knowlecige of anatomy and physiology, which would have lightened my labor in many instances, and when I have been groping in the dark, uncertain whether the little glimmer I could Jiscover was a scintillation which could be depended on, or a false light that would lead me further astray, the possession of this knowledge would have enabled me to detect. the imposture, and pursue the right course without the loss of time. If it were my intention to continue in the business of training horses I would, notwithstanding my age -which makes it harder work to learn-devote a portion of my time to this study which I have neglected, and by enrolling myself in the class of some competent instructor in veterinary science, try to rectify the want by rigid study, especially in those branches pertaining to respiration.

It requires study to understand the workings of the organs of circulation and breathing, and. I must admit that I am not capable of understanding any of the treatises that I have read on this subject sufficiently to explain them, or to make them even as intelligible to you as they are to 
myself. I would urge you to take the first opportunity of acquiring a scientific education, so far as may be necessary to know the physiological and anatomical structure of tho animals you expect to breed and train. When the winterseason puts a stop to practical training, join a class of veterinary students, and acquaint the teacher of what you want to learn, when he will order a course of study that will be of the greatest importance to you hereafter. Doubtless when you acquire this information you will look back to our present conversation, and see many errors, though the deductions drawn from the statements $I$ am going to make I know to be correct. They have been demonstrated by my practice, and since I have followed my present plan of sweating I have never had a horse become baked or feverish, which was frequently the case when I sweated them without thinking of the causes why it should be done, or was aware of the results that might be expected to follow.

The action of the heart is so much identified with the lungs that both have to be talien into consideration. Quicken the motion of the one, and you accelerate the other, but not in the same proportion. For instance, when a horse is breathing tranquilly, the respirations are from four to eight in a minute, and the pulsations thirty-six to forty. As you increase the motion of the lung's by fast work, the respirations will be multiplied, till the ratio will be as one to two, possibly two to three. Suppose that, in driving Never Mind, you had kept up the rate of speed you took in the brush, until he became distressed. The respirations would probably have been forty or forty-five times in a minute, with the pulsations at seventy-five to eighty. The inspirations at times would be a good deal longer than the expirations, frequently sighing and "blowing out" suddenly. This would arise from the amount of adipose matter interfering with the heart and lungs, restricting the first, and enfeebling the others; and it would 
be a long time before he would recover, and the circulation and breathing be restored to their natural condition. We will also suppose that he became thus distressed in going half or three-quarters of a mile. We get rid of the superfluities, and drive him till he exhibits great fatigue, having gone perhaps two or three miles. The respirations have increased to two-thirds of the throbs of the heart. Still the expirations and inspirations are nearly equal, and there is very little if any sighing. He blows out freely and forcibly, recovering the natural breathing in much less time than before. In the first case he would have been "dead beat;" in the second, by taking a pull, and easing him for a short time, he would "come again," and make another struggle. This would show that rapid respiration and arterial action can be kept up if the organs are in a proper state. The main muscle acting on the lungs, and assisting in respiration, is the diaphragm. In forcible expiration the abdominal muscles act with great power. It will be useless to take much time to show that if an excessive deposit of fat exists, their aid will be much diminished. Fat within the chest is laid in layers beneath the serous coating, and about the base of the heart. It materially affects the breathing by encroaching on the pulmonary chamber, and interfering with the expansion of the lungs, so that the minute air cells cannot be filled to the extent of their capacity as they can when freed from this obstruction. If the heart is healthy, there is room within the pericardium for all of its motions, contraction and expansion not being greatly restricted by the outside coating of fat. But this coating does effect the equalization, or rhythm of the pulsations, when the action is hurried, so it becomes necessary to remove the obstruction here as elsewhere.

The change in the blood, from the time it leaves the heart by the arteries, till it is returned by the veins, after having been aerated in the lungs, is a wonderful provision 
of nature for it to obtain properties from the atmosphere essential to the existence of life. The passage of the blood to the extremities of the vessels that convey it, is accompanied, in sweating, by another phenomenon, viz., the for-cing of the moisture through the pores of the skin, which we call sweat. In the evacuations from the bowels and kidneys there is never a particle of fat, and the emaciation following purging or excessive staling is not due to fat being carried from the body directly, but to causes resulting therefrom. In exudation, however, the oily part of the blood is got rid of, as well as the watery fluid that accompanies it. You will perceive, when a horse takes his first sweats, the moisture is of a thick, unctuous nature, forming a lather like soap when it meets with friction from the clothes or harness. As the horse's body becomes freed from impurities, the sweat becomes thinner and clearer, finally, having the appearance of clean water, as it trickles down his leg:s. The skin, then, appears to be the most direct way of getting rid of the fat, and not only the most direct, but the most natural.

The consequence of the fall of man was, that his bread should be obtained by labor-"the sweat of the brow" was to be the lot of all of the descendants of Adam; and let horse or man be required to exert himself sufficiently, the hindrances to that exertion are got rid of by those natural outlets, the pores of the skin.

The fat, in the first place, having been deposited by the blood, the loss of the oily portion in sweating is replaced by the absorbants working on the surplus in store, removing it from.where the original deposit was made; and as the sweatings are continued, exhausting all that we desire to get rid of. There are probably other changes that take place in the blood, one being a greater degree of fluidity, perhaps occasioned by an increase of heat. - It would appear that the abstraction of the watery particles would 
have a contrary effect, yet I am satisfied that this is counteracted by an opposing force, which I cannot explain, rendering the arteries and veins less liable to engorgement than when the circulating fluid had properties which made it more difficult to propel through them. From the relief afforded by copious and repeated sweatings, we might infer, that the abstraction of the fatty globules in the blood was the means of lessening the labor of the heart, which is of the greatest importance when the blood is sent bounding along more than twice as fast as when the animal is at rest. The theory that the pulsation keeps time to the step, is, I believe, correct when the action is much hurried. Hence, when a horse is making a fraction more than two bounds in a second, the work of the heart is greatly increased, and the labor of that vital force-pump would be much lessened by the blood being easier to urge through the tubing of the veins, as fast as the accelerated pace. required that it should be.

It will readily be seen that nearly all the inside fat will have to be got away before the respirating organs are capable of performing their functions in a manner that will endure fast work. The heart is also facilitated in its operations by the removal, and the diaphragm and abdominal muscles can act with far greater force, the whole. internal economy is in a manner changed, the muscles of the stomach are strengthened, and digestion is better and more rapid. The gastric juices are more intimately blended with the contents of the stomach, and the waste for the bowels to carry off is less acrid and easier expelled. We will also find that the same process will get rid of the external fat, and while the load is lightened for the horse to carry, and the muscular system is brought to a higher state of vigor, it also assists in the expansion of the chest. The intercostal muscles or the muscles between the ribs have a good deal to do with respiration, and the reduc- 
tion of the neck removes the unnecessary load of fat which surrounds the windpipe, giving more room for it to convey the air to the bronchial tubes, and through them to the lungs. I have just said that the same process gets rid of fat, wherever it is deposited, either among the internal viscera, or where it surrounds the muscles. This is so, yet we can modify it in practice, so that the effects will be greater in absorbing the interior than the exterior deposit.

This is the first thing to be done. Till we remove from the lungs and hear' the adipose deposit that hinders their working, we cannot give exercise enough to be of much benefit to the muscles of locomotion. The first sweats, then, will have to be given independent of speed, which these organs are yet unable to endure. In England, it is well known that if a horse used for hunting becomes much tired, he will never after be as good as he was. No matter how long the interval of rest, his impaired powers can never be recuperated. In all probability the injury is to the lungs ; in the excitement of the chase, the symptoms of being exhausted are overlooked, and animals are forced to struggle along till their structure is injured. We are all aware how much more acute the sufferings are from the exhaustion of the lungs, than the tiring of the muscles. Thus nature warns us of the greater danger attending the overworking of them. The sweating of Never Mind tomorrow will be a practical exemplification of the mode I adopt to relieve the respiratory organs, so there will be no need of dilating on the plan to be followed to accomplish this end. We have in a cursory manner glanced at the effects of sweating on the internal organs; we will afterwards discuss its merits in relieving a horse, when in distress from rapid work.

The questions attending sweating for the outward formation are not so complicated. The muscles are masses of elastic fibres, terminated by the tendons on which they 
act by contraction and relaxation. Thus while one set exert their force in one direction by contraction, the opposite are lenghtened so as not to interfere with the power applied. Some run parallel with the tendons, others cross these in an oblique direction, and still others at nearly right angles to the first. The fat is deposited where they overlap each other, filling up the interstices and giving prominence to the muscles by pushing the outside one out. In a very fat horse, there is a further deposit of adipose matter between the skin and the body, sometimes covering the muscles of the ribs to quite a depth. This is entirely useless, while that in the interstices has a duty to perform of great importance, viz., lubricating the fibres so that the friction at the points of attrition is much lessened. The muscles are completely filled with a network of bloodvessels, their ramifications being so extensive that the eye is unable to detect their presence. The muscles become harder and more tendinous as they are made to perform active duty, till what was a pulpy, fleshy mass, becomes fined down to a strong, elastic substance, very different and much more suitable to the necessities of rapid progression. This change takes place as the result of exercise, and does not follow the removal of the fat, when that removal is dependent on other agencies than muscular exertion. While the Roman or hot-air bath would be a very proper and powerful auxiliary in removing interior and exterior fatty matter in the first stages of preparation, its services could never further this change of the muscular system. Exercise is the only means of effecting it, and the amount of work best adapted to effect this end is varied in almost every animal that has to undergo the conditioning process. The first sweats, however, are nearly identical in all horses having the same amount of extraneous matter to remove, so that we will be less likely to err in this stage than when we make a racing pace one 
of the concomitants of sweating. The removal of the fat in the cavities formed by the lapping or crossing of the muscles is a question of time, and much injury would result from attempting to get rid of it sooner than is prudent. It must never be completely eradicated, as there must not only be a sufficiency left for lubrication, but a surplus that will meet any extra call that exertion, protracted longer than we looked for, will entail. As the fat is wasted, there ought to be a proportional increase of muscle, which will invariably be the case if the minutir of training have been carefully attended to.

Sweating under clothes has also a local effect. This is an advantage which no other system of depletion can boast of, and the benefits of which can hardly be overestimated. If it were ctherwise, we would be compelled to bring one part of the horse's body much lower than we would like it, in order that some other part might be in a situation to stand the effects of fast work. To exemplify this, we will instance the effects of sweating on the neck, chest, and loin. The difference in the necks of horses in a natural state is very marked. In one we will find the long, delicate neck, perhaps a little drooping in front of the withers, so small at the junction of the head that you could nearly encircle it with your hands. The next is larger at the shoulders, fuller in the crest, but equally as well cut out in the throttle, and better at the joining of the head. The third is larger everywhere, and short, thicker even at the throat-latch than the first was at the shoulder, with a crest so thick and flabby that it hangs over on one side. The jowls are also covered with meat, and, what is much worse, the space between the jaws is also filled with flesh and enlarged glands.

While size may be a measure of power in other parts of the body, an overgrown neck is a sure mark of inability to sustain a fast pace, not alone from interfering with the 
free passage of air in the breathing-tubes, and the free passage of blood through the jugular veins and carotid arteries, but the extra weight to be carried is in the very worst place for the ease of the horse. It would be a safe estimate that the last described neck would weigh fifty pounds more than the second, and more than double as much as the first. If these horses were identical in every other particular, there would be a vast preponderance in favor of the two with lighter necks on that score alone. But when we come to consider the effects on the breathing apparatus, and the stricture on the return of the blood from the brain, we will be convinced that the large-necked animal is totally unfit to go any distance fast, without artificial aid to diminish the useless volume of matter in the neck. Now, if we were forced to waste all parts of him alike, it would be evident that we would weaken some portions so much that the balance would be equally as much disturbed, and the part that would fail the most would be the loin. A deep chest, swelling barrel, and broad loin are generally looked upon as betokening: strength of constitution.

A severe strain of the loin is followed by partial paralysis of the hind quarters; the legs are drawn feebly along, and the animal moves by dragging himself with his fore feet. The whole propelling power of a horse being in his hind quarters, it is evident that anything that will weaken that force will materially retard the velocity with which he is capable of moving. The back-bone is braced with strong fillets parallel with it and joined to the bony projections, and the large muscles that cover the bony framework are heaped up in masses at this point. If we dimi nish their force by repeated sweatings, we lose much without any corresponding gain; so, to reduce the overloaded neck we have recourse to the local application of clothing, and thus effect the object desired. There is nothing like 
the danger of over-swegating the neck there is even in the chest, which will also bear a great deal of reduction. We may reduce the muscles that cover the shoulder-blade too much, but the intercostal and abdominal muscles will bear a diminution of their tissue, if that is necessary, to get rid of the fat in their immediate neighborhood. Of all your horses, the Clipper is the only one that carries a heavy neck, and his is nothing like so bad as that of many very successful trotters. The "blood" here works to advantage, and I will cheerfully admit that, so far, it is a great and lasting benefit, not only in giving a configuration of neck that is better adapted to speed, but much lessening the work necessary to get the horse in order.

In saying that we would sweat Never Mind to-morrow, and again in a week from that time, I did not mean to be understood that we would fix on a definite time for sweating. The interval between the sweats will not only vary in the different horses, but the same horses will probably go longer at one period than another between them. Causes that we cannot now foresee will affect the animals frequently, and a horse may require to be sweated every few days, or there may be weeks intervening. There is not much use in speculating now on what such causes might be, as undoubtedly we will have a practical illustration of some of them beiore the season is ended. We will find a great difference in the aptitude to take on flesh by the same horse under apparently the same circumstances. The feeding may be alike; the driving and exercising the same,--there may not even be any great dissimilarity in the weather; yet we will find that the horse in an unaccountable manner has accumulated more fat at one time than another. It will be obvious that, in such a case, the sweats will have to be more frequent than they were. I am not fond of drawing a horse "very fine," as it is termed, when 
that fineness consists in a tucked-up flank and an emaciated look.

The day and night previous to a race, a trial or sweat will generally be found sufficient to curtail the contents of the stomach and bowels so that the work can be given safely. The inside of a horse must "be clean," i. e., free from fat. The neck must also be relieved from weight, and the pressure of glandular and muscular fiber must be taken away from the windpipe. The ribs must not be loaded to impede their dilation and contraction as the wants of the lungs require, and the muscles in no part the body must be hindered from acting with full force and celerity. Some horses will have a more robust, fleshy appearance when in condition than others, and it will require much thought and observation to find out the amount of flesh each one should have when best fitted for arduous labor.

There is, of course, a distinction to be made in horses going different distances. A horse, however, may be able to trot three miles in as high condition as when in the best form to trot one, but the flesh will require a good deal more "seasoning" to go the longer distance. This seasoning must be accomplished without getting the system in a feverish state; if that should happen, the flesh will be "baked" and the horse become "stale." There is usually more danger of this occurring when the horse is trotting in races, than in the exercise preceding them. The much harder work a horse endures in trotting a race is overlooked. The three, five, or more heats are perhaps duly kept in mind, but the scoring, which may have been the most trying part of a race, is unthought of. A horse, when being sweated, meets with careful after-treatment, and all that care and skill can accomplish is performed. The distance intended to be gone over is made, and the flow of perspiration encouraged or checked as the trainer 
thinks best. Between the heats of a race there is not the same opportunity. We aim to have the horse ready to resume the contest after a stipulated interval of time, which is greatly prolonged by the difficulty in obtaining a start. The horses rush to the score at their best speed; one is pulled up on the turn; another goes a full quarter of a mile, and others are either overworked or become chilled, waiting for the line to be re-formed.

The duties of men who judge trotting-races are very onerous, and the situation is one of great discomfort, not the least of which is, the trouble of starting the horses, originating from the perversity of the drivers. The judges being anxious to give every one a good send-off, try time after time to start them all so level that there will be no room for censure. The drivers aware of this make a great display of jogging up the stretch, and working for an advantage as they come to the wire. Many of them are not contented with an even start, hoping by delay the patience of the judges will become worn out, and they will finally get an advantage in the send-off. I think some of these fellows like to make a display of themselves before the occupants of the stands, and that vanity is their ruling passion. In days of yore, when gorgeous livery was worn, and satin, velvet, and silk, embroidered with gold and silver lace, shone in the brightest colors, there might be an excuse for wanting to show their new clothes "with buttons all over them." But now-a-days, when the shirt sleeves are considered the most appropriate costume to drive a race in, this cannot be the cause. They must want to show their beauty of face and form, and thereby captivate the fancy of some of the blooming damsels that grace the course with their presence. There are many trotting-horse drivers that I have never seen, yet, if there be an Adonis among them, I will give more to see him paraded than $I$ would to see the eighth wonder of the world. 
A majority of those I am acquainted with would be entitled to the knife "Simon Suggs" carried so long, and there is not one that would divert attention from the superior beanty of the horse he sits behind. If the judges would insist on the warming-up being done before the time for starting-which should be punctually kept-and not allow the drivers to go above the three in five distance to score, place a steward there to marshal them, and in case of not getting the word, compel them to pull their horses up in a certain specified distance, the annoyance would be greatly modified. This would bring the interval between heats nearly to the time the rule gives, would meet the hearty approbation of the spectators, and greatly increase the attendance at races.

PupIL.-You have not yet informed me of the reasons why you wanted Never Mind to make the short brush; and, also, why you required him to be pulled up when he had passed the stand.

Preceptor.-My object was to notice how he breathed when the lungs were first required to act a great deal faster than they had been accustomed to. I also wanted to witness the expirations and inspirations, and try if $I$ could obtain any additional light into the cause of the cough, which you ascribe to a slight irritation of the glottis. I think, from his not showing any undue labor in breathing, that your conjecture is right. If it arises from a chronic disease of the lungs there would have been more abdominal labor in the expirations. The brush was so short that healthy lungs would not show any want of power to perform the task required of them; but restricted as they were by fat, any organic defect would have been apparent. The day before sweating I always like to give fast work in proportion to the condition of the animal to perform it. I think that the lungs being called into action at that time, is favorable to the exertion of them in the sweat, and no 
matter how slowly we work a horse to start a flow of perspiration, you will perceive that the breathing will be very much accelerated.

PupIL.- There is another point I desire much to have explained-the effect of inducing copious perspiration in the interval between the heats.

Preceptor.-And a very important subject that is, as numerous races are lost by a want of knowledge in this particular. There are many things in relation to sweating that I have not touched upon yet, intending to notice them as they actually come in practice. We cannot give the subject too much thought, however, as I have implicit confidence in the benefits of forced perspiration, but which may utterly frustrate the very best management, if not rightly controlled. I have attempted to show that a fast pace is accompanied by rapid action of the heart and lungs. The heart has to beat quickly to furnish the muscles with the blood required for them, in their rapid contractions and expansions. The lungs must move quickly, in order that the blood shall become properly aerated, r,iving off the carbon which is expelled in expiration, and - mbibing the oxygen which inspiration furnishes. In this apid transfer of the blood through the lungs to the extremities, and back to the heart, a great deal of heat is evolved, which ought to be removed to the surface, where it is dissipated in the atmosphere. This must be done by the blood throwing off the watery portion through the pores of the skin. The evaporation reduces the heat of the body, and relieves the internal organs. The change in the blood itself-formerly spoken of-which renders it easier to be driven through the arterial system, also greatly assists in relieving the labored action of the heart. It is evident, then, that if a horse performs the labor that ought to induce free perspiration, and he does not sweat, there must be great internal suffering, and which cannot 
be speedily relieved in any other manner. It would also be evident that if a horse were in this situation, relief would not follow his being kept in a quiescent state. That would aggravate the difficulty, especially if the theory of the synchronism of the pulse and step be correct.

Should a vehicle, that is going at the rate of twenty miles an hour, be brought to a full stop, its contents-if not fastened to it-keeps up the same rate till the force of gravitation arrests the momentum, by bringing the body to the ground. In a like manner, arresting the rapid motion of the blood would be attended with very serious results. Any one can satisfy himself of the truth of this assumption, by running rapidly till his accelerated breathing occasions distress. He cannot sit down and remain passive; the suffering is unendurable in that position, and he is forced by his feelings to keep moving, till the circulation and breathing are moderated by degrees. A horse is pulled up after a heat; the heaving flank, quivering nostril and distended eyelids show distress, while the surface is hardly moistened with perspiration. It would be madness to stop the horse in this situation; he must be clothed-not too heavily-cantered or trotted slowly, till the circulation and respiration are partially restored and then blankets thrown on till a good scrape is obtained.

In remarking that the horse must not be clothed too heavily, I want to have you understand that there is a proper medium to be observed, so as to induce free perspiration. It is a mistaken notion that the more clothes a horse is wrapped in, the more likely he will be to sweat. I presume your western experience has made you familiar with the "fever and ague," and if fortunate enough to have escaped the scourge yourself you have witnessed others overtaken with the "chills." The first stage is the cold, shivering one; the second, the burning fever, in which 
the sufferer drinks a great deal of cold water, which, reducing the heat, finally brings the body to a proper temperature, and copious perspiration follows, relieving the patient from the sharp pains that have been shooting from his head through every bone in his body. Although extreme lassitude is felt, this sweating stage terminates the attack.

When the sweat has fairly broken out, the extra clothes can be put on, which will prolong the flow, and guard against the collapse of the pores. If we do not succeed in inducing a free flow of sweat, there will be no use in pushing a horse to trot another heat. He could not possibly win under the circumstances, and his life or future powers would be in imminent hazard. Should he perspire freely, the relief is almost magical in the suddenness of its operation. The breathing becomes regular, the haggard look is gone, and his eye and ear denote cheerfulness; the rigid muscles are relaxed, and he is soon quite another horse in every particular. The "cooling out," after the flow has lasted as long as is desirable, will be considered when you see it exemplified in practice. That of Never Mind to-morrow will not elucidate it, as we are not limited in time, while between heats of a race we must be ready at the ringing of the bell to "prepare our horses."

PUPIL.-Only a short time ago $I$ witnessed a race that I thought was lost from the neglect of applying this manner of relief, and I believe the only one lost by the animal during the whole season. The race took place over the Chicago Driving-Park, and the contestants were horses of the very first celebrity in trotting-annals. The conditions were mile heats, best three in five. Riders taking the place of the almost inevitable sulky attracted great attention, as both horses were acknowledged to be superior to all others when allowed to don the racing gear, and 
though there might be those that could successfully contend with them when a vehicle was part of the weight, there would .be "no show for them in this rig," and the two would be first and second in a field comprising the picked trotters of the world. Although both thus stood in the front rank, the claims of the one to the championship was so fully acknowledged that extravagant odds were offered on his winning, and the opinion was so generally coincided in that these large odds were not taken.

The attendance was large, attracted by the well-merited fame of the horses, and the desire to see them perform in a way that was favorable to the making of fast time. The favorite had trotted a few days before, making in harness faster time than had ever been accomplished by pacer or trotter on the track previously, and anticipation pictured a still higher flight, one that would excel the most renowned of his recorded feats. The little betting done was on time, and there were not many that liked to back the "Scythebearer" without stipulating that the beatings of the watches should denote considerably less space than had been occupied in the other race. When the horses appeared at the call of the judges loud plaudits welcomed their approach. The favorite was enthusiastically cheered, and the ladies joined in the demonstration with waving handkerchiefs and clapping hands.

There was much to gratify the eye in the whole picture. The ladies' stand presented such an array of bright colors and beauteous faces, that I wondered how Col. Wood, of the museum, had selected the one modeled as the Chicago beauty. I know that it would have sorely puzzled me to have made the selection, as it did not need many glances to discover that there were a score in the stand all wortly of being immortalized in purest Parian marble, while the carriages inside the course were gloriously radiant with beauty in all of its forms. The horses looked well, their 
glossy coats showing that the grooms' duties had been faithfully performed. Your remarks about the absence of good looks in the drivers of trotters would only partially apply here, as the rider of the favorite was a very pleasant looking young man, of clear complexion and tranquil blue eye. There was a tuft of sandy hair on his chin that did not add much to his appearance, yet he was rather above the average in good looks. The other rider would have been fairly entitled to the jacknife from Prentiss or Jonce Hooper; still there was much to be pleased with in his peculiar physiognomy. Notwithstanding a palpable squint, there was a flash in his black and restless eye that surely denoted genius of some kind, and though his seat on the horse was not so graceful as his competitor, he showed a knowledge of the business, and handled his horse, the most difficult of the two to manage, with the greatest skill. While the other might get as much out of a horse in a trial, or, perhaps ride in a race as well, where the competitors were limited, let it come to a close struggle in a large field, and the little round-shouldered, cross-eyed, keen, resolute-looking one should carry my money.

There was not a great deal of scoring to try the patience of spectators or judges, and at the second attempt the bell tapped, and away they went for the first heat. The favorite justified the expectations of his admirers, by gradually drawing away from the other, and at the quarter pole was three or four lengths in advance. He increased his pace on the back-stretch and when the half-mile was done, eight or ten lengths would have scarcely measured the distance between them. By the time the three-quarters of a mile was reached he evidently slackened his speed, for the other, it was supposed, to overtake him, and make the semblance of a race down the home side. The rear horse was gaining fast, and at the distance post his head was at 
the leader's girth. When within thirty yards of the stand they both broke, galloping over the score, and in my opinion, the favorite slightly behind. The time was slow for the horses, a good deal behind what was made in the harness race, and groans and cries of disapprobation met the animals, that but a few minutes ago were hailed with acclamations. How evanescent is popularity! There were many causes conducing to slow time, but not one of these was considered.

A great majority of the vast concourse were disappointed, and when the judges announced the heat as belonging to the favorite, and gave the official time, there were jeers and calls to "bring out_- he can beat that." It was some time before the tumult could be stilled. I told one of the judges, that I thought the other was entitled to the heat, and he replied that they thought of making it a dead heat, but that would only protract the race, as the favorite would win any way. I was laughed at for suggesting that, perhaps, the other might be the victor, as the horse did not live that could beat_- that way of going. From the consultations between the owner and rider, and their request that the judges would be careful not to give the rider the word unless he was moving well and level, it was apparent that they meant to do their best to wipe out the disgrace of the preceding heat, and, by showing time that would satisfy the most exacting, regain the applause they had forfeited. Their wishes were gratified by a capital start for the second heat, both horses trotting very fast as the bell rung the chime that signified onward. There was nothing to describe different from the other heat, only that the favorite was further ahead than before at the half mile. The watches showing a great improvement in the time, and as it was made known in the judges' stand, the vice-president turning to me, his face fairly glowing with 
excitement, and said, "I told you so; he is the only real trotter in the world!"

On entering the home stretch, I could see, from the motions of the favorite, that the rider was urging him to his best pace. He had not come far beyond the three-quarter pole, however, when he broke-recovered-broke again, struck a lumbering, tired gallop, and the thing was out. The other horse made up the long gap, caught him as he commenced trotting again-they stayed together for a few strides, when the gallant black rattled away from him, coming home faster than he had trotted any portion of the road before, his head oscillating from side to side, and his ears gayly playing backwards and forwards, as he came under the wire, many lengths in advance of his tired competitor. There was no smile on the lips of the rider of the victor. The check might be flushed a very little, but the sparkle of the eye told what he concealed in every other feature, - the exultation at conquering the hitherto invincible hero of the trotting-turf.

It was apparent to every one that something was wrong with the quondam favorite. The time of the heat was faster than the other, yet not so fast as he ought to trot nearly every day in the week. The rider ascribed it to the cinders cutting the tender part of the borly, as they were thrown against it by the rapidly moving fore feet. That could not be the cause, as the same thing must have happened in the former race. As soon as he got permission to dismount, the rider took the horse a short distance up the stretch, a light blanket was thrown on him, his body was rubbed, and a man at each leg briskly manipulated the surface of them. I thought then, and am still more confident in the truth of the supposition. now, that if he had been briskly moved under clothes enough to induce free perspiration, scraped, and kept in motion till the order was given to saddle, he would have won the race, 
which he lost by standing still, no matter how many men were trying to keep the circulation to the extremities by hand-rubbing. The next heat was a repetition of the second, when he was very properly withdrawn, and another instance added to the many of the "glorious uncertainties of racing." His rider told me that the horse was well, that he was eating his daily allowance with a good appetite, and that he could not account for his defeat in any other manner than that the cinders worried him so that he would not trot.

Preceptor.- It is hard to determine what the trouble was, if internal disturbance was not the cause, which the sweating would have relieved. We will now go to dinner, resuming our conversation when that has been discussed. 


\section{CHAPTER X}

PRETTY WOMEN-MORE ABOUT SWEATLNG-DRIVING AND SHOEING MAY.

PuPr.-While you are smoking these rough barked cigars, the consideration of other themes besides sweating will, I suppose, be admissible. If you are inclined to listen, I will recount to you the adventure of meeting the next to the handsomest woman I ever saw. By the way, the plan is a good one of characterizing the lady we are describing, as not at the very summit of perfection, and I will follow it, as thereby every pretty woman of my acquaintance will imagine that she is the exception alluded to, whereas, if I said the handsomest, I would have former protestations thrown in my teeth, and a row raised for my insincerity.

Preceptor.-You will please me with the history, though I must take exceptions to your construction of the reasons why I called Miss $P$. the second in point of beauty I had ever seen. The first was so pre-eminently beautifui, that should I attempt to portray her, I could hardly tell you the color of her hair or eyes. It would be like looking on the noontide sun to discover the spots, which astronomers tell us mar its glorious radiance, which should we look for, the eye and brain would be dazed in the vain endeavor to find anything to detract from the bright luminary. You deserve to be well castigated, not alone for the absence of truth in your protestations, but for having 
the impudence to tell more than one lady that you thought her the most beantiful.

PUPIL.-I was just as sincere in the twentieth case as the first, and when telling the last fair one she was the prettiest creature I ever saw, I firmly believed it for the time being; and "why not," as the Spaniards say. If we held to the same opinions formed in boyhood, there would be a small chance for improvement, and we would not be the progressive individuals we claim. As we get more experience, we change the crude opinions formerly entertained, for those we have discovered to be better and nearer the truth; and as to the impertinence of telling a lady she is handsome, in a deferential, proper manner, I have yet to see the first one that was much offended with the impudence. The story I am going to relate partly illustrates this ; and not to waste any more time in circumlocution, I will rehearse it.

Seven or eight years ago I spent the latter part of the summer in St. Louis, stopping at the Abbey Park, then under the charge of the enterprising Charlie - - . There was a perfect round of trotting, pacing, and running, and the stables were filled with animals that were taking part in these Olympic struggles, and with those in preparation for the approaching great St. Louis Fair. The grand Lexington, the handsome Revenue, the fleet Ruric, the powerful Doubloon, France, Waterloo, Princeton, Little Arthur, imp. Barnton, and a dozen other thoroughbred stallions were having the finishing polish put on their glossy coats, and when they were led into the ring, the welcoming shouts from twenty thousand people testified that their merits were appreciated. Much as Charlie had to do in superintending the affairs at the Abbey, his energetic management carried things along so smoothly that there was still time to drive through the pleasant suburbs of the King City. In many of these excursions I accompanied 
him, and on one of the pleasantest Sunday evenings I ever saw, the trotters were hitched to the wagon, and we took our-places in it. The whole turn-out was in good taste, and when I add that Charlie was the handsomest man in the City of Mounds, it is evident we would be very likely to attract our share of attention.

I am not going to trouble you with a description of the beautiful country that environs St. Louis, further than to state that I know of no city that is its superior in beauty of surroundings, especially in the golden harvest time. We were jogging along the Gravois road, when I espied two females a short distance in advance, and as we overtook them I could not refrain from peering under their bonnets. One of them was transcendently beautiful. I nudged Charlie, whose attention was taken up driving the horses, whispering "Look, what a beautiful girl!" $\mathrm{He}$ turned his head, and on the first glimpse, he, with a powerful effort, almost set the horses on their haunches, and broke out with the exclamation, "I'll be__ blessed if she isn't handsome!" There was a transient suffusion of the girl's clear cheek, and something of a toss of the pretty head, yet the sparkling eye and half smile on the lip, showed that she overlooked the impertinence of the very handsome man, that had been betrayed into this enthusiastic acknowledgment of her beauty. When we returned to the Abbey, I was still full of the adventure, and of course must recount it to the rest of the brothers of the spur and snaffle that were assembled in the bar-room. An old gentleman was one of the listeners, who, after patiently hearing all my encomiums on the fair unknown, suid, "Pshaw! I'll bet she isn't half so good looking as my daughter Fanny." A wager of a dozen of wine was accordingly booked, and then the puzzling question arose, how it was to be decided. The old man proposed sending to the stable of Captain M., who had named a favorite 
mare after the Belle of —_, and was the fortunate owner of her picture. I told him the arbitrament would not be just, where a picture had to be taken into consideration, as I knew our umpire, Charlie, would acknowledge that there never was a picture as beautiful as the radiant blonde. Charlie assented, so the decision was indefinitely postponed.

Several days after this the old gentleman came along in his buggy and invited me to accompany him to the residence of his son-in-law, who owned one of the many fine mansions that are situated a mile or two from the Abbey. I went with him, as I had frequently done before, always being much pleased with his reminiscences of former days; which he recounted so admirably that scenes long passed seemed a part of the present time. He hitched his horse to a post, telling me he only intended to stay a few minutes, but insisted on my going into the house. We went into the drawing-room, when he introduced me to a placid, fine looking old lady, his wife. He withdrew, and soon re-appeared with a magnificient looking girl whom he introduced as his daughter Fanny. I was doubly surprised, thinking she was in New Orleans, and my natural bashfulness was greatly augmented by the recollection of the wager with her father. After the ceremony of introduction, he remarked: "What do you think, Fanny, my young friend here had the audacity to bet with me that he saw on the Gravois road the other day a handsomer woman than you!"

Of course I could only stammer out that when I made the wager I had full confidence that I would win it, that never having had the pleasure of seeing Miss __, I did not think there was a woman in the world superior to the one I had seen, and nothing but ocular proof would have convinced me to the contrary; but now I must concede that the bet had been a rash one, and there was no doubt 
of my having lost it by a long way, in turf parlance, being outside of the distance. Still it was one of those ventures where the loss gives more pleasure than would attend the winning. She was very much embarrassed, and I was glad when the old gentleman signified his readiness to return. We had hardly got into the yard when he shouted to Charlie and Captain M. that I had acknowledged the loss of the wine bet; and I had the pleasure of seeing my friends drinking the sparkling champagne, as I cogitated on the two beautiful faces that had been the cause of the flow of the enlivening fluid.

Preceptor.-I am glad the old man trapped you into the loss, though I neither admire your making the barroom of a track the place to expatiate on female beauty, or the want of delicacy in the old man in making the statement in the presence of his daughter. It was a pretty shrewd trick, however, as I doubt whether he would have ever got a decision in his favor in any other manner.

Pupr.-I will engage that I never lay myself liable again to be picked up. It was the second time in my lifo that I would have given boot for a hollow log to crawl in, and it would not have taken a very large orifice to accommodate me if my body was as small as I felt. The cigars being still burning I will recount the other adventure. When I was a young man $I$ had an intimate acquaintance in Dr. L. He was a very highly educated man, and though not a member of the F. F. V.'s he was still a notch or two up, belonging to a Philadelphia family of high social position. From a long series of troubles originating in an unfortunate marriage, his finely organized brain had become crazed, though at this time his madness was in a very mild form. His friends sent him from Philadelphia to that rough part of Pennsylvania, where I was engaged in land-surveying, and which had been a favorite resort of his in his healthy days. He boarded at the 
county seat, and occupied his time with wandering about the neighborhood hunting and fishing. He was very select in forming new acquaintances, hardly ever going beyond the circle of old friends.

He dubbed me Compo, always insisting I was the nephew of an Indian chief with whom he had hunted in the then distant prairies of the far West. At times he was rational, and it was well worth while to listen to his vagaries when the hallucination was upon him, till the interval of sanity, as then his conversation would be of great interest, and he would vividly sketch scenes that had occurred in his eventful life. When the cloud was away, I never listened to a person who could more completely absorb the attention of his hearers; and incidents of foreign travel, and adventures by sea and land, would be portrayed so graphically that they seemed as if actually occurring. When he discoursed of the great men of the world-being personally acquainted with many of themhe showed an acuteness of penetration in discerning traits of character, hidden to an ordinary observer, placing the characters he was describing generally in a more favorable light; and in talking of celebrated poets, he would discover beauties hitherto overlooked, and he would demonstrate his opinions with quotations that showed his intimate knowledge of all their writings. I have listened with admiration to his conversation for hours, as he went over the field of polite literature, giving me ideas that greatly enhanced the pleasure of reading; or he would entertain me with stories of other countries, elucidating life and habit better than I ever saw it done in books. $\mathrm{He}$ would vary this by showing me how to tie the fly that was best adapted for fishing in different waters, explain some intricate problem at chess, set up the rare birds and animals that we would kill in our hunting-trips, his knowledge of ornithology and taxidermy being second only to 
those who made these studies a profession. He was as delightful a companion as I ever had, and had it not been for the "disjointed thoughts" that often shocked you, by proving the wreck of the mind so richly stored, no more fascinating one could be found in any country.

But I find it will take up too much of our time to give an account at present of the scrape he got me in. So I will postpone relating it till to-morrow's nooning, as I do not want to have the recollections of those days of romantic youth to interfere with my understanding the subject-matter now before us, as I am convinced there is nothing of more importance in the training of horses, than fully mastering all the intricacies of swealing.

Preceptor.-You do not overestimate the bearing it has on the welfare of the horse, and if there is any danger that the story you contemplated telling would interfere with your attention, I am glad you have postponed it to another time. I can easily foresee that making a companion of a Iunatic might result in scrapes, as there is none of us any too sane when the equilibrium of the brain is disturbed, which is particularly apt to be the case in that susceptible period of life, from eighteen to twenty-five. In resuming the conversation on sweating, I may go over ground I have heretofore traveled. But though a "twice told tale" may be tedious, there is no royal road to the acquisition of skill in any pursuit, and at the hazard of being tiresome I will further illustrate the effects of the treatment. I have spoken of the change the blood undergoes in its passage through the lungs, and the transmission of some of its constituents through the pores of the skin. There is another function the skin possesses, - that of assisting to decarbonize the blood. There is no other way by which the skin can be so completely purified as by free perspiration. The little seales or dandruff that form are very hard to remove by the currycomb or brush, in fact they 
cannot be thoroughly got rid of by their use, and after patient grooming the removal will only be partial. The constant grooming produces soreness of the extremely sensitive vessels or bulbs at the root of the hair, and we irritate the horse without obtaining a suitable recompense. Washing with soap and water is also ineffectual, and is inadmissible, as the horse's coat will soon show that injury has been done, if the ablutions are continued. The perspiration lifts up the scales, and carries them to the surface of the hair, which is proven by sweating a horse and allowing him to dry, when he will appear as if powdered with flour. The sweating then makes the skin actually thinner and more supple, and of course the air will have a greater effect on the blood-ressels that lie immediately under the surface.

PupIL.-I have become fearful of stating advantages which I believe thorough blood of all others gives to the trotter; but I hope you will pardon me for again calling your attention to it in connection with this question, the decarbonizing of the blood through the pores of the skin. You see a thoroughbred horse after rapid exertion, and there is apparent a perfect network of veins traceablethough in intricate confusion-over the whole of the body. There are not only many more in sight, but they are larger than those of the cold-blooded one. It would be proper to infer that if those you see are larger, it will also be the case with those that are hidden, and if we deduce from this data that the blood is more perfectly decarbonized, our reasoning will be correct. Now, if the blood has lost this detrimental equivalent through the pores of the cuticular covering, there is less labor for the lungs to perform in equal circumstances.

Precepror.-In your ardor for the thoroughbred, you lose sight of all I have said. No one of any sense will argue against the form and characteristics of the blood 
horse being the best for continued fast work, and $I$ have to keep a higher check on you than I would, to prevent you running away-or, rather, blood horses running away with your sense, when you claim to make trotters of them. Their structure, muscular, vascular, nervous, and osseous, excel all others for speed. The only point at issue between us is the possession of the trotting step. We will not argue about it now, and I will admit that if a thoroughbred could trot as fast as a cold-blooded or part-bred one, I would rather pay double the money for him.

The removal of the dandruff from the skin facilitates the action of the air in this purifying process, and, you say correctly, lessens greatly the labor of the lungs. There is much waste from the pores of the skin that is not seen, but which, nevertheless, is going on at all times. This is called insensible perspiration. The evacuations from the bowels and kidneys carry off the more gross residue, and stoppages in their action is always a cause of alarm. When the skin becomes so clogged that it does not perform its share in relieving the internal economy, the injury, though not so speedily observed as from the other stoppages, will ultimately be very serious. The good resulting from sweating is not confined to merely ridding the animal of fat, as it increases the power of the heart, and assists the lungs in performing their duty.

PuPIL.-I have read that, in the great race of five heats of four miles each which was won by Black Maria-the grant aunt of the Falcon-she lost a hundred and twentyfive pounds in weight. I suppose it was as severe a race as ever was run, the fifth heat being only forty-one seconds slower than the first, and the black mare ran for every heat, not having been laid up in any of them.

Preceptor. - It appears almost incredible that a horse could lose so much as that in so short a time, no matter 
how severe the work had been, but if so stated by Mr. Stevens, there is no doubt of its being the case. He was very methodical in all of his business, and his training stable was as perfect as money and skill could make it. There was a weighing-machine connected with it, and the reductions in the weight of the horses, as the training progressed, carefully noted. The results of each sweat and trial could thus readily be seen, and the presumption is, from the success that generally attended his stable, that his horses were usually in good condition. He had a room fitted up with hot-air pipes, and is, probably, the first who used the Roman bath in the training of horses. How it succeeded with him I have never learned, but I believe, from engagements with the government in the construction of a floating battery, and which absorbed his whole time, the training was discontinued soon after the erection of the bath. My intention was at first to show the difference between sweating with hot air and clothing, when hot air might be used to advantage, \&c., but, as I believe, in the training of trotters, that the benefit derived would not equal the expense of construction and the care requisite for its successful use, we will confine our attention to the more simple mode. Scales that we could weigh the horses on would be of great service, and would materially assist us in coming to correct conclusions regarding the effects of the various sweats; and problems in work and feeding could also be demonstrated more effectually.

PupIL.-In preparing the Falcon for a ten-mile race, I reduced him one hundred and twenty-five pounds in three weeks, sweating him once a week, with a great deal more work between them than I would give now. In all the horses I have had to deal with, he is the only one that I could reduce so rapidly without injury. No difference how long the distance, how fast the pace, or how many clothes he was wrapped in, he never exhibited the least 
symtoms of distress, though I am satisfied I worked him too much, and sacrificed his speed without its being necessary.

Precepron.-Very probably you did. Because a horse has that quality we denominate bottom or endurance, with game that does not show distress, if peradventure, he feels it, we are very apt to overwork him. The great difference between training race horses now and in former days, exemplifies the truth of this statement. The trainer, of Haney's Maria - a mare that beat almost everything she ran with-would gallop her, at times, ten or twelve miles. A person who would do so now would be thought crazier than your friend the doctor, and it was only by having a nonpareil that this fellow was enabled to win at all. Horses now run the four miles in time that would have been looked at in her day as an impossibilty, and show as little fatigue as when the time was half a minute slower. Better horses, better tracks, and better training have accornplished this, and the last named has done its full share.

We will now to the stable, where our first duty will be to prepare a mash for Never Mind. I have no great faith in medicated mashes, and usually confine myself to bran, oats, salt, and a decoction of sassafras. The last has, I think, a beneficial effect in making the system less liable to febrile excitement, which is the most to be dreaded and guarded against after sweating. When this is done, I will see you drive the colts. We will make May wear the large roll I spoke of, and see if her action changes any when going round the turn. The effect will be more noticeable when first applied than after she has become somewhat accustomed to it.

I have said nothing yet about the difference between growing and matured horses, both as to the necessity and the effects of sweating. There is a vast difference; so 
muclı so, that the treatment we give an aged horse would nearly destroy a colt. The first will bear a far greater reduction of his bulk than a colt would, when to the cye he would appear to be much in the same order; and a horse will be in proper condition to trot, when his ribs would show to the eye, while the colt's should be covered with quite a coating of flesh. The reason is, that young animals are not so fat inside as the older, and reducing them in size would be accompanied by the wasting of the muscles. Till colts can trot fast enough to fatigue themselves, there will be no necessity for sweating them further than what is required for a complete purification of the skin. I allude to sweating under clothes. As the weather becomes warmer, they will sweat enough in their work to answer all their purposes. I think that reducing May much would further endanger her cutting her pasterns: and she will have to be kept as high as is compatible witr. clearness of wind. Now for the mash, which we will mak: $\theta$ with three quarts of bran, two of oats, a table-spoonful of salt, with boiling water enough (in which is placed the sassafras) to saturate the mass, covering it so there will be no escape of steam. It will become thoroughly cool before it is fed, which is the object in making it so long beforehand. Unless I want to steam the nasal passages, as in distemper, or for the relief of colds, or other medicinal purposes, I prefer giving the mashes cold.

PupiL.-May's shoes have not yet been changed for the ones you recommended, and I have not speeded her since the morning you saw her go.

Preceptor.-I want to watch her closely before her present shoes are removed, and will only keep the roll on long enough to observe the changes it causes in her action. I feel very contident that increasing the weight in her hind shoes will have a beneficial effect, which experiment will either prove to be correct, or confute that presumption, 
when we shall have to discover some other remedy. There is not so much chance to change the action of the hind legs as there is the legs in front, there being no posterior joint, where the motion is so free and as capable of being modulated, as the knee. You can now harness her, jog five or six miles, and by that time I will be on the track to see her move.

PupII.-I have driven the specified distance slow. What will be the next order of exercises?

Preceptor.-Go the next round a three-and-a-half gait, and as you come down the stretch, let it be at her best speed. Pull her up at the stand, and take a medium rate till you come here again, when you can go round the turn as fast as you can drive without her breaking; then turn round at the quarter post and come back.

PuprL.-There is some pleasure in driving her, apart from that sideling motion, which is provoking enough. In every other particular she will do just as you want her. Should anything have been different from what you intended, I am to blame, as the mare went exactly as I directed her to go.

Preceptor.-All was very proper. Throw the blanket and hood on her, and let the boy walk her up the stretch. I saw nothing in her movement to cause me to change the opinion I have heretofore expressed. I think she touched a little when she went round the turn. We will now put the roll on, when you can drive her up the stretch to the three-quarter pole, coming down at speed, which you will keep up half way round the turn. Stop there, and come back as fast as you can.

That will do ; drive her to the barn, unharness. She is not wet enough to scrape ; so have the boys straighten her hair nicely, clothe her with blankets and hood, and walk her half an hour, when she can be rubbed and cleaned, the soles of her feet washed, stuffed with moist. 
tow, and to-morrow afternoon we will have her shod. I am convinced the shoeing and use of this roll will work a cure, as it certainly made a good deal of change in her gait, and that is favorable. As it protects the part where she strikes, she will soon learn not to be afraid of the blow.

You can walk Never Mind the usual time this evening; give him two quarts of water and the mash, in lieu of his regular feed of grain. Give only what hay you can span in your hand, have his bed well prepared, and put the setting muzzle on as soon as he finishes his lock of hay. In the morning, give him one quart of oats when the other horses are fed,--no water; and as soon as he finishes the grain, replace the muzzle. I will be here in good season, to give further directions. 


\section{CHAPTER XXI.}

NEVER MIND'S FIRST SWEAT-PREPARATION, AND METHOD PURSUED-BREEDING TROTTERS-PEDIGREES.

Preceptor.-The morning is all that we could ask. There could not be a better time for the business we have on hand. The air is warm without murkiness, and the breeze is only sufficient to keep it in motion. By the time the sun is a few degrees higher, the vital fluid will be as bland as that ladened with the fragrance of rose and jasamine wafted from the gardens of Ghul. It is a great annoyance to prepare a horse for a sweat, and have the time appointed unpropitious; though if the weather is not too bad I prefer to give it, than to postpone to another time. Should the weather be such that it would be impolitic to attempt the sweating, I should put it off for three or four days, commencing again the preparation from the outset. I do not like to muzzle a horse two nights in succession, though there are some very gross feeders that require the appliance of the muzzle at all times, to keep them from eating the bedding. Even in such a case $I$ would rather substitute some other material for bedding than straw, though there is nothing else so well adapted for the purpose. Sawdust soon heats from the mixture of urine, and is then very detrimental to the horse's feet; anil there is danger to the lungs from the particles of dust that arise whenever the horse moves. In the summer time, I prefer sand to any other substitute. By filling the stall to a depth of six or eight inches, the horse has a very 
cumfortable bed to lie on, and when standing, it gives a uniform support to the sole and frog. It never becomes heated, and whatever portion of it adheres to the skin is easily removed by the wisp or brush. There is nothing" so good for making a "wallowing bed;" and when we see how much pleasure a horse takes in tumbling about in it, we must conclude that it is not an uncomfortable couch for him to repose on. By the way, we will soon have to make a place for the horses to roll, as I hold it is of great service at all times, and we are repaid for the trouble, if only for the satisfaction of seeing them enjoy a good wallow. Have the boy throw a kersey and hood on Never Mind, and walk him in hand for an hour. In the meantime, you can drive Falcon; jog him five miles, and drive one moderately fast, allowing him to go a three-minute gait on the stretches.

PupIL.-I have complied with your instructions, but was disappointed in not seeing you on the track to tell me how well I did it.

Preceptor.-I wanted to watch Never Mind while he was walking, to see that he emptied himself as he ought, and to note the appearance of the evacuations, before any change of color took place from exposure to the air. The excrements are just right, - a bright yellow color, without any hard exterior coating, and of the right consistency. The mash has performed its functions so far admirably. While the appearance of the fœces is as I desire to see them at present, it would not do for them to be of this character if the horse was expected to go in a race. But we must now prepare him further, and have no time at present for the consideration of anything diverse from the business in hand. Have him brought into the stable, lightly wisped over his whole body, and the hair smoothed, when we will clothe him. There, that will do. Now take hold of this long, soft blanket, bring the corners together, 
so that it will be the full length and half the width, throw it over his back and bring the end under his belly; be very careful to have it straight and free from wrinkles. It now laps a little more than a foot; but I perceive there has been a matter neglected that is of moment. There are no strings, and we will have to fasten it with skewers, which I dislike very much. There ought to have been four strings sewed on to the side of the blanket, a little below where it covers the backbone, and the same number on the end that we brought between the fore and hind legs. Then it can be fastened securely, without running any risk of wounding the skin, as there always is from the skewers.

We will now take this lighter and smaller blanket, and after doubling it in the same way, fold it as many times around the neck, enveloping it with several thicknesses from the shoulders to the ears. The next blanket will be similar to the first, only we do not double it, but cover the horse all over, tying it round the breast and under the tail, fastening it every few inches as low as the gaskin. A hood will be the next thing, having no ear pieces, and large enough to cover the shoulders, being tied behind the „ore legs. A heavy kersey suit of clothes carefully adjusted, with the breast-plate loose enough not to interfere with the free motion of the legs; the hood with ear pieces and a flank girth buckled in its appropriate place, and the costume is complete, leaving no part uncovered, excepting the legs from the knees and hocks down, and the eyes and muzzle. The harness has to be enlarged to meet the necessities of the clothing, and rolls are put on above all the fetlocks to prevent bruising of the joints. The horse is now ready to go into the shafts, but before we go to the track we will prepare a drink for him, by taking a handful of linseed, or two of oatmeal, and making a thin gruel, which we temper with boiling water, so that it will be a 
Litle above blood heat. You can now walk him once round, and jog him slowly twice, when you can stop him.

That is very good. Wait till he gets a mouthful or two of the drink. The perspiration is starting, and this hot gruel will facilitate the flow. The next two rounds drive a little faster, when you can bring him to the barn. We are in great luck. The hair is now fully charged with moisture, and you will soon see as "free a delivery" as you could wish for. Turn him around in the stable, so that his head will be at the heel post; close the door and bring plenty of blankets, and we will throw three or four extra ones on him, retaining every particle of heat. See how he begins to labor in breathing, and put your finger on the artery on the inner side of the jaw bone; the pulse is rapid, and the artery so full that it slips, on the least pressure, from under the finger. Give him another swallow of the gruel. The perspiration is beginning to start down the legs. Look at that big drop; it runs an inch or two; stops; takes a diagonal course; here is another one following it, and now three or four little rivulets are running down the arms, and joining in one stream below the knee. Very large globules have oozed through the blanket we first wrapped him in, and the weight of it is so much increased that it bags down as far as the fastenings will permit. Do not be alarmed at this profuse flow; I want it to run a few minutes longer; you can see that the horse does not labor in breathing as much as he did,-and clap your finger once more on the artery. It has an elastic feel in place of the rigid, tense cord, that eluded you at first, while the beatings are not so rapid.

Get the scrapers and rubbers ready. Take a scraper yourself, give Tom another, and let Con and Cooley be prepared with the largest and softest salt sack rubbers. Unbuckle the hood straps and the fastenings of the breastplate. Throw the hoods back on the loin, and turn back 
the clothes so as to expose the chest. Throw that neck wrapper on one side. Use your scrapers carefully, only bearing on enough to force the water from the hair. You, boys, rub him lightly between and around the ears. Your cloths will absorb more moisture if you do not bear on. Now unbuckle the flank girth; throw the clothes over his chest and neck, lay the belly wrapper on one side; it is heavier now than all the clothes were when first put on. Scrape his sides, back, and quarters. How the froth bubbles! We will have different looking and feeling sweat from this in a month or two. Be very careful not to irritate him when you scrape the inside of the thigh and flanks; throw the clothes back : his neck will now scrape again. Go all over him once more, but before you begin throw off these extra blankets. Now you can throw them all off. Tom, you can also take a rubber, and rub his loin briskly.

You, my scholar, get some dry clothes, a pair of those large, fine English blankets, and a hood of the same material. Smooth his hair by running the rubbing-cloths the right way of it, and do not ruffle it as you put the dry clothes on. This time tie the blankets outside of the tail, put your lightest cover over the blanket, and, Con, you can walk him in the ring till you are called in. The rest of you take the outside clothes, and hang them in the air to dry. The neck and belly wrapper place in a tub of water to soak. Get some dry, clean rubbers, the foot tub, hot water, and bring me a small-sized pail, so that I can prepare his drink for the day, which will be eight quarts of tepid water, with a table-spoonful of the best cream of tartar in it. He must not be allowed to drink any more than this till to-morrow morning-given by pouring two quarts of it at a time into another bucket, so that he will not be tantalized by seeing more than we want him to drink, which will also satisfy his thirst better. The object in restricting him in the water is that the absorbents will 
then take hold of the fat, which they would not do if we gave him an unlimited supply of fluid. The tartaric acid not only assists to allay the thirst, but its refrigerating properties are beneficial in guarding against feverish symptoms.

He has now walked a quarter of an hour, so you can call Con to bring him in. He is drying capitally. Take a handful of hay, dip it in the acidulated water, and let him pick it out of your hand, while the boys rub out these damp places. Now throw a linen sheet on him in place of the blanket, put the cover over that, and walk him slowly for twenty minutes. I never saw a horse do better than he has. Look at his eye, it is as bright as those of an eastern Odalisque, and does not need the application of henna to heighten its radiance. Now wash the soles and crust of his feet with cold water, place him in the foot tubs, and after applying castile soap, thoroughly wash with warm water his legs from the knees and hocks down. When that is done, dip a set of bandages in hot water, and swathe his legs from the knee to the coronet. Fix up his bedding, give him two quarts of the drink, as directed, two quarts of the prepared oats and hominy, and two or three pounds of hay, which it will be well enough to dampen. When this is eaten, put on the muzzle, and leave him undisturbed till the next feed. You have now seen the manner in which I give the first sweat to a horse that is robust-iusty, as the English say. If there is a point that is not clear, I am ready to answer any questions.

PupIL.-I think I can see from your former conversations the object of each part of the proceedings. When the horse was laboring so hard, however, as the extra blankets were put on, I should have been uneasy if you had not been present, and, if left to myself, would have been trying some plan to relieve him, especially when I discovered the pulse so high, and the artery so tense. 
Preceptor. - The reasons for throwing on the additional clothing were, that those he wore during the exercise did not sufficiently retain the heat, and the rapid loss of the watery and oily portions of the blood would be followed by the absorbing vessels acting sooner on the fat, than they would otherwise have done if the clothing had not been augmented. By keeping up the flow by their use, we approximated to the benefits derived from the heated air bath, and reduced him more than we possibly could have done with prolonged exercise, which would have endangered his legs. I can only guess at the pounds avoirdupois he has lost; but when you consider the increased weight of the inner wrappings, and the amount of water that flowed from the scraper, it must amount to a considerable depreciation of his former weight. The manner of giving sweats will vary as the preparation proceeds, and the different horses will also require a change of treatment. There will be very little change in the case of Never Mind in the plan pursued to day, until we get rid of a good portion of the inside fat he is encumbered with.

You can now harness Jane, and, while jogging her, follow the previous instructions not to pull at her. If she wants to go faster than you desire, bring her to a full stop, and mind that you do it with a resolute hand, emulating the manner your friend Charlie stopped his team, when thunderstruck with the beautiful female on the Gravois road. The effect of a sudden pull of that description is tenfold greater than when the mouth has become numb from lugging at the bit, and the mare will not only succumb at the time, but the lesson will be a good one to regulate her future conduct by.

PuPIL.-Jane appears to be well contented with the pace you have fixed for her to go, and jogs as quietly as could be asked. I am all anxiety to see her go fast, for if she is 
as amenable then in proportion as she is now, we will certainly have one trotter in the string.

Preceptor.--Unless you have your heart set on a wonderful rate of speed, I think you will be gratified by the possession of more than one trotter. There may be as much profit and pleasure in a horse that can safely trot in thirty, as one that goes eight or ten seconds less. With the very fast horse there are only occasional opportunities of trotting him in races, while others can be trotted as often as we desire. From the greater number of secondrate horses, there is no trouble in making up fields, and the best races-running and trotting-are generalliy those which this class figure in. No further business appearing for the morning consideration, we will take up our line of march for the house.

We will resume a subject that has been dropped for some time,- - the Breeding of Trotters. Without being as enthusiastic as you, in all that pertains to their conception and rearing, I am, nevertheless, greatly interested in it. In former talks I have trod on your corns by underrating " the advantage of racing-blood in trotters," till I am sorry to see that you have become very sensitive whenever the subject is broached. I must confess that I have carried my objections further then I intended. My predilections being strongly in favor of blood, I was induced to follow this course, the better to arrive at a candid consideration of the drawbacks, as well as the advantages, of breeding road horses from the source purified in the alembic of the race course. Throwing aside, as far as lies in our power, all predisposition for or against the thoroughbreds, we may derive benefit from further deliberation; though I had forgotten, when proposing this, that you had promised the denouement of your adventure with the crazy Doctor, and . will be gratified to listen to it. Our time after dinner will only give us space enough to consume a cigar, as I wan's 
to be at the stable when feeding-time arrives; so propel, as the negro minstrels say.

Puprz.-If you leave the choice to me, I shall select breeding as the more interesting topic, now that your thoughts are running that way; the "yarn" will keep cold well enough. As to my enthusiasm, a person of ardent temperament cannot avoid being enthusiastic when engaged in raising colts from farorite stock. The anxiety to see whether his expectations have been realized, causes him to watch the advent of the colt with as much concern as the gambler looks for the appearance of the card on which his last dollar has been staked. With what soli. citude he superintends its awkward attempts to draw nourishment from a source it is yet unacquainted with, till he is finally gratified with hearing the lacteal flui 1 gurgling down its throat, and is more than pleased wit/ the satisfaction it mutely expresses with the sugary draughr. How interestedly he watches it staggering along, leaning; against its mother, not knowing yet how to use those limbs that soon will be so pliant! How much comfort is expressed in the pantomime, when it stretches itself on the green sward, bathed in the warm rays of sunshine, that i:s invigorating its frame so powerfully that only a few day: will elapse before it will be gamboling, with all the grace that it is possible for an animal to show. There is positive affection, akin to the feeling for the dearest of the buman family, for a colt, as it licks the sugar from your hand, and whinnies at your approach, gladly recognizing you as its "next best friend."

Preceptor.-I have no doubt that breeding horses is a very fascinating pursuit, and that the ownership acquired in that way induces warmer feelings than those that result from purchase. The breeding I am going to speak of is retrospective, and the teachings of the past ought to be a guide for the future, in this as well as other pursuits. 
With few exceptions, the trotters of the present day belong to three families or strains, the superior of which is the Messenger. Messenger not only stands at the head of the list, as the remote ancestor of trotters, but it is very hard to find a celebrity, accredited to the other families, that has not some of his blood. Among the very fast ones in lineal descent from him through their sires, are Geo. Wilkes, Dexter, Lady Thorne and Gen. Butler-the two first mentioned having a greater proportion of the blood, through the inbreeding of their sire, a great grandson o the patriarch. Lady Thorne, through her dam, has also a cross of the blood, viz : Gano-Eclipse-Miller's-DamselMessenger. The Bashaws would come next, as they are represented by Lady Emma, Geo. M. Patchen, Jr., and Lucy. The Pilot family have Pilot Temple, Dixie, Tacky, and other good ones. John Morgan, the best of this line, had the Messenger cross through the sire of his dam, Medoc. The once celebrated Morgan has scions, that are superior to any that were on the turf in their palmy days, in the mare by Ethan Allen out of the pacer Pocahontas, and Rolla Gold Dust. The Messenger crops out through the fleet pacer, in the same way as Lady Thorne and John Morgan, she being a great grand-daughter of Eclipse; Rolla Gold Dust has, I believe, the same cross. From the prevalence of Messenger blood in the section where the Bashaws originated-from the imported Barb-there has been a great intermingling of the streams. The stallion Andrew Jackson, a grand-son of the Barb, has been the occasion of their eminence. He was the sire of Henry Clay, Long Island Black Hawk, Kemble Jackson, \&c. His dam was by Why Not, by Messenger, and his grandam also by Messenger.

Again : Jupiter, a son of Long Island Black Hawk, and the sire of Lady Emma, had two crosses, his dam Gipsey being by Almack, a grandson, and her dam by Mambrino 
a son of Messenger's. The best illustration, however, of the breeding of trotters, in the section long celebrated for having the best, is the pedigree of Rysdyk's Hambletonian, universally conceded to be the most successful progenitor of fast trotters, for the truth of which the record is convincing proof :

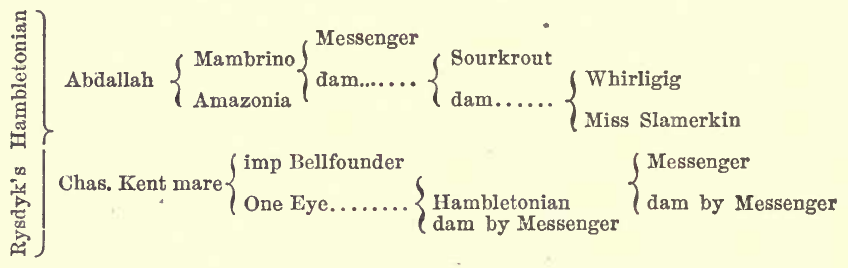

This pedigree shows more inbreeding than that of Lady Suffolk or Ariel, which you instanced as proving that the danger of incestuous crosses might not be as imminent as was generally believed, and this horse will greatly strengthen your argument. His grandam, though only a grand-daughter of Messenger, had five parts in eight of his blood, which would give the Bellfounder mare five in sixteen, and Rysdyk's Hambletonian, therefore, obtained from her five in thirty-two, and from his sire, Abdallah, four in thirty-two, thus giving him more of the blow than his sire, though he was a grandson of Messenger.

The dam of Andrew Jackson was bred the same as Hambletonian, being three-quarters Messenger, so that if the Bellfounder mare had been bred to him, the colt would have more Messenger blood than Rysdyk's Hambletonian, though he would have been called a Bashaw. To carry the illustration further: Suppose One Eye had been bred to Andrew Jackson, the progeny would have been half Messenger, and one-eighth Bashaw, thus : 


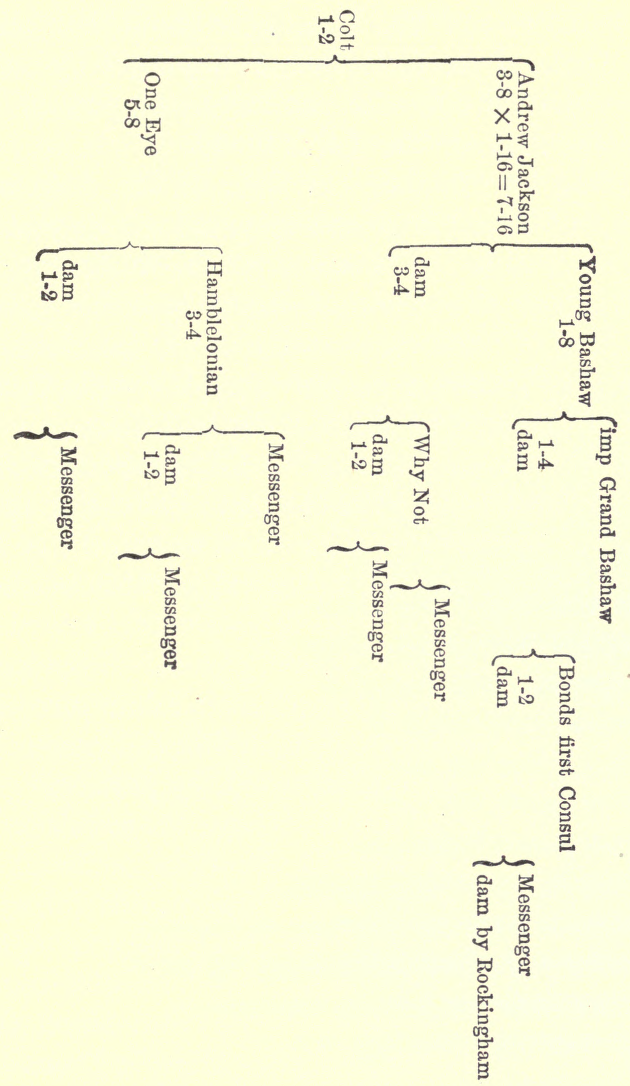

To call this colt a Bashaw, because his sire was in lineal descent from the Barb, would be absurd, and from the fact that Andrew Jackson had one-eighth more Messenger than Bashaw blood, his progeny should be accredited to the dominant strain, especially when we see it further refreshed by another current, as in the case of Jupiter.

I am under the impression that there have been more 
first-class trotters of the Messenger blood than all others put together. I could further exemplify it by numerous examples, but will only cite one more instance, as tending to show the good effects of this blood.

Napoleon, the grandsire of Gen. Butler, descended by both sire and dam from Messenger, and was a great-grandson on cither side. You are given to theorizing, so you can weave from this skein of facts a web that will prove the breeding of trotters, as easily as you can demonstrate that the hypothenuse of a right-angled triangle is equal to the sum of the squares of the other two sides.

PupIL.-I am very glad that breeding cannot be reduced to a geometrical scale, as in that case the charm of uncertainty would be broken. The most we can do is to gain all the wisdom we can from the experiences of the past, and by a course of experiments, add to that knowledge as much as our limited capacity will permit. I am very glad that you have forsaken the French admixture in your composition of a trotter, and hope that the knee action of the thoroughbred can be improved, by judicious crossing of the different families found to have the requisite action, till you will be satisfied that in this point, as in all others, they cannot be excelled. I have been wonderfully pleased with your remarks on the Messenger family, though I was not prepared to learn that inbreeding had been so general. The Falcon has three distinct crosses of the blood, through his sire Camden, Shark, Eclipse, Miller's Damsel, Messenger. His dam was by Postboy, whose dam was Garland, Young Damsel, Miller's Damsel, Messenger. His great-grandam was by Bay Bolton, by Tippo Saib, Messenger. Young Damsel was by Hambletonian, which one I do not know. If the three-quarter bred Messenger of that name, it would increase the proportion.

These three crosses in the Falcon should assuredly be as valuable, from the balance being of the kind that Fanny 
Kemble said "alone did it quite well," as if there were a mixture of French or Bellfounder blood to taint it.

Rysdyk's Hambletonian has been the most successful in nicking with the blood of American Star, as his two fastest sons testify. All that I ever heard of the pedigrees of American Star was, that he was by Henry, though I have seen several of his colts, and they all show a great deal of blood in their appearance, so much so, that I think he must have been thoroughbred, or these colts from very well-bred mares. Clipper is a great-grandson of Messenger, his dam being by Whip, Comet, and her dam by Messenger. Pilot, Jr.'s, dam was a great-grand-daughter of Sir Archy. I have yet to see the first instance of a horse being a successful getter of trotters that was not strongly imbued with racing blood.

If diluted till the proportion of cold blood is greater than the pure, the animal will be a failure, and I would under no consideration breed from even a scion of the Messenger stock, that was impregnated with much mongrel blood. Had the inbreeding of Rysdyk's Hambletonian, been on the Bellfounder in place of the Messenger, I have no doubt that he would have been as pre-eminently worthless as he now is good. Cassius M. Clay takes a front rank as a breeder, and if his renown only rested on the paternity of Geo. M. Patchen, it would be glory enough, as he was, without doubt, the very foremost trotter of them all. His numerous contests with Flora Temple were remarkable, while his private time was such as no horse ever exhibited, and gave a color of truth to the report that he could have trotted much faster in public, if that had suited the "book" of his manager. Cassius M. Clay was by Henry Clay, and out of the dam of John Anderson. I have seen an advertisement in the Old Spirit, that John Anderson's dam was imported Vestris, by Charles the XII. Never having heard before of this highly bred imported mare being claimed as an ancestress for Clay or Patchen, 
I only offer it for what it is worth; if true, the stock would be greatly enhanced in my estimation. Patclien had also a Trustee cross which, without doubt helped him, the get of Trustee having proved themselves trotters able to go both fast and far.

The pedigree of Andrew Jackson shows another Messenger cross which you have overlooked. The dam of Young Bashaw was by Bond's First Consul, his grandam by Messenger, his great-grandam by Rockingham. This would add one-sixteenth more Messenger blood to Andrew Jackson, making seven-sixteenths in all. No wonder, when he was so near thoroughbred as his pedigree shows, that William T. Porter wrote, in the Turf Register of 1840, that "with the exception of Andrew Jackson, for whom $\$ 5,000$ has been refused, Abdallah is the finest limbed and most blood-like trotting stallion we ever saw." The sire of Young Bashaw's dam, Bond's First Consul, was a capital race horse, winning twenty-one races and upwards of $\$ 10,000$ in purses alone, never suffering defeat till he was eight years old. This great progenitor of trotters (Andrew Jackson), having nearly all racing blood in his veins, helps to establish the truth of my theory, that the thoroughbred is the only one to depend on for continuing the species. I will continue Mr. Porter's remarks about Abdallah : "He was got by the celebrated Mambrino (the son of imported Messenger) out of Mr. Treadwell's equally as celebrated road mare, Amazonia, who for ten years, or more, had no superior on the road. Abdallah is a beautiful bay without white, fifteen hands three inches high. He was slightly trained at fours years old, and was considered the fastest horse on Long Island. No purses being offered at that time for trotting, Mr. T. put him in the breeding stud," \&c. \&c. I have read that the Amazonia was a well-bred mare, and that she was a daughter or grand-daughter of Messenger, but cannot recall where $I$ 
saw it. So we will have to be contented to rest on her qualities as a roadster. The breeding of his sire is unquestionable, though I have heard many claim that he was only half-bred. I quote from the Turf Register of 1840, "Pedigree of Mambrino:"

"The following certificate given by his breeder, Col Lewis Morris, leaves no doubt of the purity of his blood :-

'I certify that the bay colt bred by me, three years old the 16th of last month, was got by old Messenger, his dam by Sourkrout, grandam by Whirligig, great-grandam Miss Slamerkin, by Wildair, out of the imported Cub mare.

' Given under my hand at Morrisania.

'June 19th, 1810.

Lewis Morris." "

Mambrino, then, was thoroughbred, and to those who would argue that Abdallah was indebted to the road mare for his trotting qualities, I would say that Mambrino proved his capacity to entail this qualification through other branches of the family, as the many descendants gracing the track at this day abundantly prove.

From this desultory talk you may imagine that the web I am trying to weave is much "tattered and torn" before it leaves the loom. But the trouble is that, amidst the abundance of material for warp and woof, the time is limited to construct even a short piece, and I am throwing the shuttle almost at random, leaving threads of different color in an incongruous mass that would form a very handsome pattern if care and time were taken to get each one in the right mesh of the hiddles.

The deductions drawn from the consideration of the pedigrees and performances of these animals and their descendants would naturally be, that in the Messenger strain there is a manifest tendency to a fast trotting gait, that it is so powerful in this particular that it overbalances contaminating streams, and that those animals having the most racing blood mixed with the Messenger have been 
the most successful breeders ; and I hope to show that if the same care had been taken in keeping the pedigrees of trotters pure that there has been with race horses, the proportion of fast ones would have been materially increased, with much more symmetry of form, and greater powers of endurance. I also expect to show that racing and trotting are not antagonistical qualities, but that the same animal which is so conspicuous as the progenitor of trotters, has been equally famed for transmitting racing qualities to his descendauts. For the truth of this statement we will again bring on to the witness-stand the noted mare Ariel. She ran fifty-seven races, winning forty-two of them-seventeen at four-mile heats-traveling at least three thousand miles in her peregrinatious from one race course to another, nearly every mile on foot. She raced from the banks of the Hudson river, on the classic courses of the Old Dominion, to the flowering plains of Georgia, and inhaled the genial air wafted from orange groves by the breeze that dimpled the gulf at Charleston, S. C., beating the fleetest short stock their favorite distances, and outlasting the gamest of the game in the trying ordeal of four heats of four miles each, scunning a third heat in 7:57, Trumpator beating her only a few feet when she won the fourth in 8:04. This was on the Newmarket (Virginia) Course, where the best time for a first heat was Henry's-7:54-proving those of Ariel the very best on record. In imitation of your example, I will give her pedigree to the fifth generation to show the manner of her inbreeding to Messenger :- 


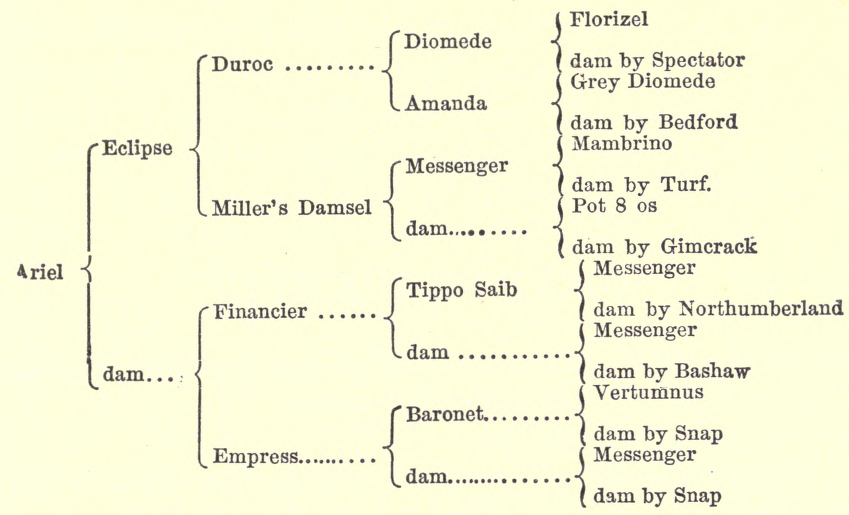

The Bashaw in this pedigree was a brother to Miss Slamerkin, the great-grandam of Mambrino. It will be needless to look for further illustrations of the racing qualities of Messenger's stock-many of them as good as ever answered the bugle's call to saddle and start. Ariel had five-sixteenths of the blood, a thirty-second part more than Rysdyk's Hambletonian. Those two inbred animals being respectively on the topmost round of fame, are apt illustrations of the value of the blood for both gaits. The bell is sounding its welcome invitation to dinner; after we enjoy that, with your permission, I will resume, and further show the plan I believe the best for breeding trotters. 


\section{CHAPTER XXII。}

DELIGHTS OF TOBACCO-FOUNDATION OF THE AMERICAN TROTTER ON THE BLOOD HORSE.

Preceptor.-We will walk leisurely to the stable while smoking, so that the cigars will be finished by the time we get there. Your caution in not permitting any one to smoke in the stable is proper, and whoever would take offence at being requested to observe this rule would have very little sense. The dried and powdered excrements of horses is a material almost as tenacious in holding fire, and as quick to ignite, as tinder. A stump of a cigar is thrown aside; it falls through a crack in the floor which has been the receptacle of the sweepings, where it gives no warning till it breaks out fierce and overpowering. Such a disaster as that which occured at the Riverside Park ought to admonish all when approaching stables, never to smoke even in their vicinity.

As soon as the horses have eaten their feed, we will send May to the blacksmith, to whom I have given the necessary instructions for shoeing, so that we need not accompany her. Never Mind can be brushed, the bandages removed, his legs hand-rubbed lightly for a quarter of an hour, his bed put to rights, \&c. The advantage a loose box possesses over a stall would be of service in this case, as I would much prefer that he should not be disturbed, excepting to take a short walk of a mile or so when the others go out. But as Jane has to be walked two hours 
and Mavourneen driven, we cannot avoid breaking in on his privacy. The practice of going into a stable at all hours of the day and night cannot be too severely reprobated. Horses engaged in fast work should be encouraged to lie down as much as possible, saving both their temper and legs-their temper by not being irritated by needless disturbance, and their legs by not having to sustain the weight of the body when tired or the muscles relaxed, following the tension of hard work. The loose box not only permits of more privacy, but a horse will lie down, when not restrained with a halter, that otherwise would stand.

It would appear, when a horse is lying on a good bed of straw, that for the time being he is safe. There are horses, however, that have a trick of injuring themselves in this situation, by resting the elbow on the shoe, which often results in serious injury, making an enlargement that is extremely difficult to get rid of, and if allowed to run for a length of time, requiring a surgical operation to cure. So inveterate is the habit in some horses that it cannot be cured in any way, save by enveloping the foot with rags, or having a soft cushion to draw over the hoof. I have seen men use a circle of metal six or eight inches in diameter, which they placed around the pastern; this only effected the transfer of the injury to another part. A metal projection is useful when a horse has the habit of standing with one foot on the other, and I have known horses to do this until the coronet has been injured so much as to cause a morbid growth of horn, to the great detriment of the foot. The cushioning should be put on at the very outset, as, after the swelling occasioned by the pressure has got to a suppurating stage, the cushion will irritate it, and prevent the healing. It is a very annoying habit, and the cure is so much more difficult than preven- 
tion, that I always watch very closely to see if any of the horses are likely to acquire it.

PuprL.-Accident discovered to me a manner of preventing this self-inflicted injury, after I had puzzled my brain in every way to find a remedy. I had a large five-yearold stallion that persisted in lying on the shoe, in spite of all my efforts to prevent him. He was tied in a stall, so I removed him to a loose box, plentifully littered with straw, though no benefit accrued from his occupying it. Every movement he heard, he would dart to the window, and paw the dirt floor into deep holes. We were forced to tie him up during the day, which did not stop his pawing, so that he had a depression in front of him of at least a foot deeper than were he stood. One day I saw him lying down with his feet in the hole, and I was struck at once with the favorable position. His halter was tied so that he could not get back on the comparatively level surface sufficiently far to bend his legs under him, and he was forced to remain with his feet in the hole. I immediately dug out his old stall in the same manner, tied him so that he could not go back further than I desired, and had the gratification to find the removal of the swelling-which was as large as the clenched fisttake place. In a short time, he was well. I kept the stall as it was for some time after he was completely cured, and when once more placed on a level surface, he had contracted the habit of lying in a position that did not injure the elbow, and I never had any trouble with him from that cause afterwards.

Preceptor. - Fortune has often been the means of discoveries that had eluded the penetration of those who were renowned for foresight, and the most wonderful efforts of genius have fallen short of the benefits derived from some stroke of good luck. The swinging of a chandelier in a cathedral, the fall of an apple, the laziness 
of a boy whose duty it was to monotonously pull a valve for the admission of steam, are illustrations. The measurement of time, the laws of gravitation, and the usefulness of that power which has done so much for the welfare and civilization of mankind are due to this, and to the observation that saw their eflects, and made them available for practical uses. You deserve commendation for seeing the benefit that fortune had put in your way, and though it is laughable to compare this discovery with the grand results above mentioned, still, little things are of importance, and I am much obliged to you for teaching me a way to cure a habit that has often given me much uneasiness. I cannot see why it would not result as favorably in other cases as in the one you mention, and I cannot perceive any bad results that would be likely to arise. The horse when standing would be on the level, and it would only prevent him from getting his head in an easy position for repose. I should certainly prefer this evil to a capped and ulcerated elbow, which would effectually hinder him from going fast. Favor me with another cigar, and we will take our seat under that spreading, thickleaved oak, when you can continue your disquisitions on breeding. There is danger of these cigars tempting me into an immoderate use of them, and although at the time I considered your description of the enjoyments of smoking in the woods as a raphsody, it seems now none too highly colored, and I can realize the feelings you portrayed.

PupIL.-I might, like the Irishman recommending the mountain dew, urge that there is not a headache in a hogshead of such tobacco. I can assuredly warrant that there is not a deleterious article in the manufacture. When $\mathrm{P}$ __ says cigars are imported, you can safely wager they are from the isle that can alone grow the benign weed in full perfection. If you thought I rhapsodized in 
describing the forest smoke, what will you think of the following lines by the "Gentle Elia:"

"Scent to match thy rich perfume

Chemic art did ne'er presume;

Through her quaint alembic strain,

None so sovereign to the brain;

Nature, that did in.thee excel,

Framed again no second smell ;

Roses, violets, but toys

For the smaller sort of boys,

Or of greener damsels meant ;-

Thou art the only manly scent."

Preceptor.-It strikes me you have broken off rather abruptly in your quotation. Do not the subsequent lines read something like this:

" Stinking'st of the stinking kind, Filth of the mouth, and fog of the mind;

Africa, that brags her foison, Breeds no such prodigious poison;

Henbane, nightshade, both together, Hemlock, aconite."

PUPIL.-Certainly, though he gives his reasons for railing; and how fondly he returns to his first love:

“And a seat, too, 'mongst the joys

Of the blessed tobacco boys;

Where, though I, by sour physician,

Am debarred the full fruition

Of thy favors, I may catch

Some collateral sweets, and snatch

Sidelong odors, that give life

Like glances from a neighbor's wife;

And still live-in the by-places

And the surburbs of thy graces, And in thy borders take delight, An unconquered Canaanite." 
Where would he have found words to express his devotion, if he had been favored with Killikinick, in place of the harsh old "cut and dried," or had a hundred or two of these Principes to awaken reveries. Even then he could not have surpassed his "Dream Children," one of the most exquisite creations of the fancy I am acquainted with. I can hardly bring my thoughts back from wandering after shadowy forms, that melt away like a vision, to the consideration of pedigrees and trotters. Yet Lamb, lame and weakly as he was, appreciated the delights a gallant steed could give. Listen to the description of their uncle to the Dream Children :- "Then, in a somewhat more heightened tone, I told how, though their great-grandmother Field loved all her grandchildren, yet, in an especial manner, she might be said to love their uncle Jno. L_- because he was so handsome and spirited a youth, and a king to the rest of us, and, instead of moping in solitary corners like some of us, he would mount the most mettlesome steed he could get, when but an imp no bigger than themselves, and make it carry him over half the county in a morning, and join the hunters when they were out; and yet he loved the old great house and gardens, too, but had too much spirit always to be pent up within their boundaries; and how their uncle grew up to man's estate as brave as he was handsome, to the admiration of everybody, but of their great-grandmother Field especially; and how he used to carry me on his back when I was a lame-footed boy-for he was a good deal older than me-many a mile, when I could not walk for pain."

I did not find this in the Turf Register which $\dot{I}$ have brought along, but I could repeat the whole of that essay, is I have read it over and over, and always found something new to admire in it. I can see John I_- bounding over hill and dale on the spirited hunter, thereby 
gaining strength to carry the poor lame-footed boy when weary. A true, unselfish love for the horse is always accompanied by strong feelings for those bound to us by the ties of kindred, more especially when they are unable, from bodily weakness, to join in that which gives so much delight. As a prelude to the topic under consideration, I will read from the Turf Register of 1829 a pedigree of Messenger, and also refer to it for proof that the American trotter had his foundation on the blood horse:-

"Messenger was got by Mambrino, his dam by Turf, grandam by Regulus, out of a sister to Figurante, by Starling, out of Snap's dam. He covered in the Middle States, and his colts are the handsomest and finest horses for all uses of any stallion ever imported into this country; but, owing to the prohibiting of racing in Pennsylvania by an act of the Legislature, his stock has not such a chance of distinguishing themselves on the turf. For the saddle, draught, etc., they are unequaled."

According to Mr. Van Ranst-his part owner-he was foaled in 1780-commencing his career on the turf in 1783 where he was quite successful. His first seasons were made in Pennsylvania, and perhaps it was as well that a bigoted House of Representatives should have clogged the enterprise of breeding good horses, as thereby his stock had the opportunity of signalizing themselves on the road in place of the turf. On his removal to New York, the restriction was partly done away with, and he there had the benefit of a few blood mares to perpetuate the qualities that otherwise would have been lost. For proof of this, look at the number of successful sires that have sprung from his location in New York, while I have no knowledge of any of his get in Pennsylvania that are distinguished in that respect. His offspring there were at the top of the tree, as far as performances went, but they had not blood enough to give their descendants the same qualifications. 
Mambrino, Potomac, Eclipse, Lance, Hambletonian, Tippo Saib, Tippo Sultan, Postboy, etc., all give him such a luster, that he could afford to loan to other families a surplus, as you have exemplified in the case of the Bashaws, and still be accredited as the greatest progenitor of trotters.

Before dinner I could not remember the pedigree of young Damsel, the grandam of Postboy. I distincly recall it to mind now, and wonder that I could have been so forgetful. She was by Hambletonian, the son of Messenger, and had, therefore, the same amount of Messenger blood as One Eye, the grandam of Rysdyk's Hambletonian. Messenger's location in the section, that was to be the recognized headquarters of trotting sport, was fortunate for the establishment of a sport, which has made the American roadster superior to those of all other countries; and also fortunate in developing his stock as the best for that purpose. Suppose his location had been in Virginia, Carolina, Tennessee, or Kentucky. The success of his colts on the turf would have been beyond the wonderful performances the record now gives his descendants. $\mathrm{He}$ would have got fifty thoroughbred mares where he had one in Pennsylvania, and the owners of those colts would have felt insulted at a request to make trotters of them, and the very men who have assisted in developing the fast trotting gait of hundreds of Messengers, would have laughed at the idea of making trotters of Messenger's colts. Hence, I say, it has been fortunate, alike for horse and trotting sport, that his location was in New York. His blood was disseminated over the whole eastern country, from Maine to Lake Erie; and not only his, but many high-bred scions of other families, went from the Long Island turf to enrich those places with a valuable stock of road horses.

When I have been arguing with men on the necessity 
of blood in trotters, I have been met with, what they considered convincing proof, that until late years there never was a thoroughbred horse in the New England States. They would ridicule the idea that there ever were any "running races" in Boston, unless of the scrub kind, and, when proven, would only admit a fact they could not longer dispute, but qualify it with the assertion that the horses that ran in them were carried there, and on the conclusion of the races taken back. Tell them that Admiral Coffin imported Barefoot to Boston, or that men purchased blood horses for stud purposes, taking them to their homes on the banks of the Kennebec, or among the green hills that bordered Lake Champlain on the east, and they would be moved to laughter so boisterous that they would almost be in the state of Dr. Holmes' patient, who frightened him from afterwards writing anything "as funny as he could." Mr. Van Ranst sold Defiance, by Wlorizel, to go to Northern N. Y.; Cock of the Rock, by Duroc, out of Romp, by Messenger, to General Barnum, ıf Vermont; Dinwiddie, by Diomede, dam by Wildair, to f company at Utica, N. Y.; Selah, by Bussorah Arabian, - lam by Messenger, to Saratoga County, N. Y.; Callender, hy Eclipse, his dam by Sir Archy, to Washington County, N. Y.; Liberty, by Dinwiddie, dam Miller's Maid, by Duroc, grandam Miller's Damsel, by Messenger, to Brandon, Vermont. At that day, 1825, the blood horse was recognized to be the one to breed from, though twenty-five years later they were carried away by false lights after the splattering little Morgans, and part-bred Canucks, which, by an infusion of racing blood, were redeemed from utter worthlessness; yet if you show me a region where a trotter, worthy of the name, has been bred, I will undertake to prove that, at no distant day, the blood horse was there and prepared the way. There are exceptions, as in everything else, though I am acquainted with but one of any 
weight-St. Lawrence. I will read from the same volume of the Turf Register an account of the horses at the Hunting Park Course, at Philadelphia, where many a hard contest for fame was made by the trotters of the olden time, and a correspondent of the English Sporting Magazine sent this account of the notabilities of that day, appended to reports of the trotting thereon:-

"Top Gallant, by Hambletonian, trotted in harness twelve miles in thirty-eight minutes, and three miles, saddle, in eight minutes thirty-one seconds. He is now nineteen years old, and can trot his mile with one hundred and fifty pounds in 2:45.

"Betsey Baker, by Mambrino, beat Top Gallant, saddle, one hundred and fifty pounds, in 8:16, and when sound, could do her twenty miles within the hour.

"Trouble, by Hambletonian-good bottom-did two miles in harnes in 5:25.

"Screwdriver; dam Bull, by Mound Holly, beat Betsey Baker the last heat by a neck. Time, first heat, 8:02; second, 8:10.

"Sir Peter, by Hambletonian, in 1828, three miles in harness in 8:16.

"WhaLевоne, by Hambletonian, three miles in harness in 8:18. These two, Sir Peter and Whalebone, can be matched either against Rattler or Tom Thumb, now in England, for any amount. Rattler is from an English imported horse out of a Canadian mare, and Tom Thumb is a Naragansett, an excellent breed of trotters, but their origin is unknown.

"ShaKspeare, by Hambletonian, three miles, saddle, in 8:16."

A pretty good "show" of trotters for A. D., 1829. Three miles in 8:02, I think, is equivalent to 7:35 now-adays. One more quotation from the Thuf Register of 1833: "Paul Pry.-This fine trotter, whose performance of 
eighteen miles under fifty-nine minutes we recorded last week, is an exceedingly well-bred horse. He was got by Mount Holly, out of a Hambletonian, bred by Gen. Coles. His grandsire was old Massenger. Paul Pry is now nine years old, bred on Long Island, and previous to his great trotting was only in training five weeks. Those who bet against each quarter, from sixteen and a quarter miles, placed judges at each of them to see in which he would tire out, but the fresh condition in which the horse completed a quarter of a mile more than was needed, saved these gentlemen the trouble of their office. Hiram Woodruff, the boy who rode him, deserved much praise. His seat was beautiful, and his judgment excellent. He was dressed in a new suit in the true jockey style, and the whole affair gave great satisfaction, and proved Paul Pry to be a horse of first-rate bottom. We heartily congratulate his owner on the possession of so fine an animal."

Illustrations showing that the older trotters were generally of good blood, could be multiplied till the consideration would be tiresome. Those of the present day show the same characteristics, or a preponderance of Messenger blood from inbreeding overcoming that of the inferior animals in their generalogy. With a few instances of our time I will close. The horse, Abdallah, which the guerillas captured of Mr. Alexander, was the sire of the famous mare belonging to Mr. Goldsmith. He was by Rysdyk's Hambletonian, his dam by Bay Roman, by Membrino, by Mambrino, his grandam by Membrino. The sire of Squire Bingham-Major Windfield-is by Rysdyk's Hambletonian, dam by imported Margrave, grandam by Trumpator. Open a paper that contaius the advertisements of the trotting stallions for this year, and the most successful in propagating fast animals will be those having the best blood. Probably the largest sum ever paid for a trotting yearling was the amount it took to purchase the Hambleton- 
ian, bred by Mr. Backman-understood to be five thousand dollars - his dam by Waldeck's Messenger, by Wildair, out of a Messenger Mare, and his grandam by Mambrino. Considering these cases-that are taken from the records without exercising much care in the selection, but copied as I came to them-your ground that there have been more trotters of the Messenger strain than all others put together is incontrovertible.

Messenger stood for nearly twenty years in the neighborhood of New York, and from his popularity and low price of service-eight dollars to insure-had all the business he could do. People were so well satisfied with the value of his blood, that they sought so obtain as much of it as they could, even resorting to incestuous crosses to further this end. The fine road horses of the first generation were succeeded by the fast trotters of the second and third, and the numerous progeny in that section were the best they had for the turf, road, and track. The only parallel case in breeding with which $I$ am acquainted is that of Sir Archy. The great age to which he lived-the same as Messenger, 28 years - and the value of his stock, brought him so much patronage that in all probability there never was a living horse with so numerous a family. Close inbreeding produced no ill effects that I could ever discover. Some of the fastest of their day were double Archys. George Martin, by a son, his dam a daughter, conquered those hitherto deemed invincible, and placed himself among the very first for speed and bottom. Fashion's dam, the renowned Bonnets o' Blue, was bred in the same way. To enumerate Sir Archy's victorious descendants, and write their names, would appear like the index of the American Stud Book, as there has hardly been a good, or a very good, race horse on the American turf not related to him, generally in direct descent. It is not improbable that, if Sir Archy had occupied Messenger's place, he would have 
been the Highflyer of the trotting turf, as he now is of the running. Premising that Rysdyk's Hambletonian is now the most successful modern sire of trotters, and that his fastest sons have been the result of crossing with well-bred mares, as instanced by the Stars and others showing good breeding, I would select the very best bred mares I could find with Messenger, Trustee, and Sir Archy blood, to breed to him. But as the present price of his services is beyond the reach of those who breed to make money, I would breed to the son or grandson that had the most blood and the best form.

Now I will probably startle you, and others will look still wilder at what they will consider the gross heresies of my belief. They must grant me the merit of sincerity, as I have no ulterior object in view, and am led to promulgate, what I consider the best system of breeding, from no interested motives whatever. Forty or fifty years ago, in England, to have averred that the thorougbred would make the best hunter to carry weight would have subjected the proposer to as much sarcasm as awaits the advocate of the blood horse for fast trotting, among a certain set at the present day. While it is admitted that the theory has been proved correct, regarding the horse to go across the country, the set that I speak of can see no analogy between that and fast trotting. Essays were written at that time to prove that the configuration of the blood horse was totally opposed to leaping; that the low, daisy-cutting stride would breal the rider's neck on rough ground, while the intervention of ditches, hedges, and high timber fences wonld as effectually stop him, as if anchored with the best bower of a seventy-four. The arguments were reiterated, while the horse himself was improving by further admixtures of blood, till the very best hunters in the kingdom had as fine pedigrees as the Derby or St. Leger winners; and in the face of this, there were still 
those who could not believe anything different from what their grandfathers believed, and would not acknowledge defeat. The improvement in the stamina and pace of the hounds necessitated the change, as it would have been impossible for the best hunters of "fifty years since" to have kept in sight of a pack of the modern flyers for twenty minutes.

With the teachings of the past before us, would not Messenger be as likely to get fast trotters as his renowned inbred great-grandson? Would not Mambrino? Who would not be better pleased if the Chas. Kent mare had been by Trustee, instead of Bellfounder? Has Hambletonian gained from that blood any advantages that are superior to the thoroughbred crosses, of which he has so many? I think no well-informed horseman will claim that he has. Who would not prefer Ariel for a brood mare to breed trotters from, to one with the same amount of Messenger, but French, Bellfounder and Morgan in the place of the purer streams? The wealthy gentleman in Orange County, whose stud of trotters is probably superior to any other in extent, who has spared no expense in everything connected with it to make it the best in the world, who has been so lavish in his expenditures that his farm is a model in everything appertaining to breeding, merits the sincere well-wishes of all who are interested in the development of the American roadster. From an account I read lately, he has twentysix brood mares, a majority of them being by American Star, the others, Long Island; Black Hawk, Bellfounder, General Gifford, Vermont Hambletonian, Canadian, Harry Clay, and one by Old Abdallah, with a colt by Hambletonian. The author of this account saw an inbred Bellfounder mare, displaying the historical characteristics of that breed, which he appears not to value very highly. All these mares had been bred to Rysdyli's Hambletonian, making a bill of thirteen thousand dollars for the horse's 
services alone. I anxiously trust he will be remunerated for the enterprise, but it strikes me that it must have been hard to find that number of mares, which from breeding and form, could all be advantageously bred to the same horse. Had he selected those of the finest blood to breed to Hambletonian, and put the others to a thorougbred that had form, size and a good trotting step, I think the progeny would have been better. Planet is said to show nearly a three-minute gait when allowed to trot in his exercise. A colt from imported Bonnie Scotland, three years old-and I presume the only one of his get that has been trained to that gait-trotted very fast last season. He was in a colt stake at Chicago, but was taken with the distemper, and had to be laid by. The stake was won by a three-year-old, the get of the Falcon, distancing in three minutes her only competitor. She is sixteen hands and an inch high, and had only been harnessed a few times before the trot. Another of the Falcon's get, a four-yearold, won the stake for that age, distancing a granddaughter of Rysdyk's Hambletonian the third heat in 2:47; the track very heavy. I saw the four-year-old trot in thirtysix early in the season, and had he been in hands that knew how to train him judiciously, I think he would have been at the head of the list as a four-year-old trotter.

Now for my heterodox notions. I would prefer to breed from Planet or Bonnie Scotland, having thoroughbred mares of proper form, size, and step, with as much Messenger and Trustee blood as I could get, than from even the famed Hambletonian. I do not want to take away one iota of the well-merited fame of Mr. Rysdyk's horse, and had I a breeding establishment where I could send a mare or two of pure blood to him, and was rich enough to afford the outlay, I should certainly do so in order to get the Messenger blood, of which he has as much as any living horse, and probably more. I should hope that the 
produce would be a filly to breed to the thoroughbred that would suit me, as I think when there is a difference, the male parent ought to be the one without the flaw. But I would be afraid of that coarse Bellfounder cross, trusting however, that it would never make its appearance. I think when the produce of that inbred Bellfounder mare and Hambletonian is old enough to show for itself, these ideas will be verified. It may be thought invidious to say anything against the system pursued in Orange County, which has resulted in producing so many good animals, but "excelsior" must be the breeder's motto, and to get still higher, depend upon it, racing blood will only do. You are undoubtedly enough bored, for the present, with my breeding speculations. With the breeding-farm and the subsequent conversations, I have pretty well exhibited my partialities. Should any one differ with me in my conclusions, the study of trotting pedigrees-some of them mixed up consumedly-will do them no injury. If racing had been carried on without any more attention to horse heraldry than trotting has, the breeding of race horses would have been ten times the lottery it now is. May we not hope that from a like attention being paid to the trotting families, the chances of breeding fast ones will be very much increased, and a genealogical tree, free from stains, be considered as essential to the harness as the racing stallion?

Preceptor.-I will neither assent nor dissent at present from the inferences you have drawn. The trotter, of course, has to be bred before he can be trained, and there is not much danger that our talk on the subject will be a waste o time. It is a subject of interest to those who buy, as well as those who breed trotters. The day has gone by when the remark was thought smart, "I do not care a — for his pedigree; let me see him move," and those consequential gentlemen who could tell at a glance 
just what a horse could do, do not find so many dupes as formerly. Your driving will now fully occupy the time you have to spare. Loan me the book while you are engaged, as I believe I have no particular instructions to give regarding the management of those to be worked. I may go away before you are through. You have the directions what to do with Never Mind. The rest need no change. 


\section{CHAPTER XXIII.}

JEALOUSY OF TRAINERS-AFTER THE SWEAT-RULES TO BE OBSERVED-DIRECTIONS HOW TO PROCEED WITH THE HORSES.

Preceptor.-You look a little wearied this morning. I hope the pedigrees did not keep you from sleeping; I thought you got pretty well rid of them, and had left none to be a burden to you.

PupIL.-Nevertheless they did worry me. When I went to bed thinking of the conversation we held, it appeared as though better illustrations came to my mind than any I had offered; and when I fell asleep, the subject that engrossed my waking hours got a still firmer hold of my mind, now untrammeled by the corporeal frame. Pedigrees of men and horses were mixed up in tangled confusion, and centaurs performed around me in mazy elvolutions, bewildering me with their strange actions, and still stranger speeches. One heavy-made, lumbering, Dutch-looking horse, with a keen human head, every line of which betokened cunning, reproached me for leaving him out, and, pointing triumphantly to an advertisement in the old Spirit, screeched in my ear, "You called us splattering" Morgans: look at that and you will find that we are the true descendants of the children of fire, purer far than those graceful, sleek-coated, fragile-looking things, you have held up for admiration. They cannot make half the display I can;" and he frisked around with short dancing steps, the curly mane flying, and the fat shaking on his sides. The words he pointed to in the paper shone like 
letters illuminated with jets of gas: "North Star, Morgan's dam, was got by Young Diomed, grandsire Old Diomed, greatgrandsire Sir Archy, (a thoroughbred horse.)" "What do you think of that, you cavilling sucker? and look at my Arabian head, my curling tail and mane, my body, modeled in the most perfect form to fly over the sands of the desert-don't they show blood-and I weigh eleven hundred, though six inches lower than some of your dunghill Messengers."

I gazed at this illustrious grandson of Old Diomed, till in the place of one there where hundreds with the same features, contrasting so strangely with the sway back and rolling gait. They grew indistinct and shadowy, until they were partially lost in the hazy atmosphere, which soon became lurid as though there were great prairie fires on every side, and I found myself pinned down in the midst, fastened with lariats, and bound up in cuyote and buffalo robes. I struggled for breath, but could not move. Four stalwart Indians encircled me, with scrapers in their hands heated to a glowing heat, and they forced me to drink a bucketful of molten lava, that was flowing from a cleft in the burning mountain. To heighten my anguish, I heard your voice ordering them to throw some more robes on, and be ready with their rubbers and scrapers. Four more brawny, red skinned, ferocious-looking fiends drew near. They had long scalp locks for rubbing-cloths that were yet red and reeking with blood, as though newly torn from their victims, the gore staining the long silken hair of different colors. I recognized the golden bands of Jane P_, the raven tresses of Susan, and Miss __'s luxuriant locks. I cannot describe the suffering; it seemed more intense than my nerves could bear, and I felt them snapping and torn asunder, giving the same sensation, only tenfold greater than is felt when the bungling dentist rolls a tooth over with the turnkeys. You gave the order to 
scrape me and rub out my poll. The hissing of the perspiration, as it flowed from the red-hot scrapers, and the scorching of the skin, was actually pleasant, when compared with the first touch of the gory scalp-locks. Human nature could not bear it, and with a shriek of anguish I awoke. I lay tossing about the remainder of the night, neither being able or having the inclination to sleep further.

Preceptor.-No wonder you look haggard; want of sleep and such a dream are enough to make the complexion wan and the eye dim.

In all my remembrance I cannot recall a finer season than this has been for the training of horses. The weather has more to do with the conditioning process than many, particularly those who are not engaged in the business, are aware of. A man has a horse he is using on the road, and finding that he possesses a good deal of speed, is struck with the idea that he must have him trained, so he loses no time in making his way to the track, goes to the trainer he has selected to superintend the education, and signifies his wishes. The trainer is, of course, anxious to get another student, the price of whose tuition will assist to pay the heavy bills that are presented at the end of every month, and is unwittingly led to increase the owner's sanguine expectations, by extolling the good form and promising gait of the pupil.

The country dealer who brought him to town had given his full history, his ancestry, near and remote, the little or no work he had to bring out his trotting gait. "He was raised by Farmer such a one, and never had a single harness on unless to plow corn, till so many days ago, when he was purchased out of the wagon that brought a load of grain to the market town." The dealer will add that he was induced to purchase him from knowing his stock, which was first-rate, and which he is likely to repre- 
sent as that most in vogue. The horse is then harnessed, and though a little awkward, shows speed that the buyer is sure is unknown to the seller, and the bargain is closed by paying a round sum, which the dealer knows enough to ask, speed or no speed. Both are pleased, one having made a hundred or two above expenses, and the other, satisfied that he has an embryotic trotter that in due time will be as fast as the best. He has been told that the horse has had no driving, and he will have to handle him very carefully for a while, till he gets used to the shafts. So he jogs him in out-of-the-way places where he will not be likely to have his attention distracted, though he cannot resist the temptation to let him go along a little, whenever a smooth road is gone over. As he and the horse become acquainted, he is gratified with an increase of speed that fully corroborates the dealer's history. The same story is repeated to the trainer, who cannot but agree that the gait of the horse is very fast for one that never had any handling. Should he signify his doubts of that being the case, the matter is set at rest by the conclusive argument that he could not trot in three and a half when first purchased, and now he can go close to three minutes. The facts are that the horse had been driven for two seasons in the country, perhaps not very judiciously, but still so as to develope a good deal of speed. Being sore from the journey when first tried, and not being accustomed to the vehicle, it took a few days for him to get at himself, which resulted in the over-estimation in which he was held. The seller was aware that he would get more for him from this duplicity, than if he took time himself to bring the horse round and show the speed he honestly possessed, as that would be more than would agree with the truth of his narrative, without being fast enough to enhance his value, when considered as a partially trained horse. The trainer takes him under this false estimate, and he is 
mortified that he does not improve as the owner and he expected. After weeks or months are spent, and, perhaps, just as there is a chance for him to improve, the owner becomes disgusted, and takes the horse away, blaming the trainer for not knowing "how to get the speed out of him."

Bad weather has not had much to do with this disap pointment, but there are cases where the trainer is blamed for what he could not control any more than in this instance. A horse has trotted the previous season fast, has been well wintered, and is put into the hands of the trainer in the spring in as fine order to commence work as could be wished. Rain, making muddy tracks, and cold, raw weather, makes it impossible that the horse should have the necessary work. After a lapse of time, which the owner thinks sufficient, a trial is insisted upon, which is, of course, unsatisfactory. The horse is hurried into another with the same result, and the trainer's incapacity seems to be apparent, and the horse is removed into other hands. There have probably been machinations to effect this which are unknown to the credulous owner. I am sorry to say anything against members of the craft, but there is jealousy of each other that prompts them to go to lengths that are contemptibly mean. If a horse is not doing well in the hands of a trainer, his rival's stool pigeons will commence work by telling things that will reach the owner's ears, and such as will surely have the intended effect, if the man is not thoroughly conversant with these nefarious practices. Should the rival manage to have the horse transferred to him, his aim is accomplished. Something is gained if he can only say, "Mr. Blank took his horse from Jones and gave him to me." If the horse does well, there is no end to his boasting of what he has done, which the owner can only repay by giving him all his winnings in addition to his regular training expenses. If he 
does not do well, the fault is entirely in the horse, or something might have been done with him if Jones had not "burned him up" while he had him. An owner should ponder well before putting his horse into any person's hands, and when he does, justice demands that he should give the trainer every opportunity of managing as he desires, and allow him time enough, in all contingencies, to get the horse in order.

You can hitch Never Mind to the sulky and jog him three miles slowly. I once practiced giving a horse sharp work the day after the sweat, in accordance with the condition he was in. My plan now is to let a day intervene, as I think it is better to wait till the debility that follows is removed. Never Mind steps off light and corky, an infallible sign that we did not overdo the sweating.

Pupr.- - He was anxious to go, and I am confident he feels better than he has before. There is an elasticity in his movement that reminds me of a young Highlander, who always walk, with a sort of bound, as though the ground had a spring that propelled him on as he touched it.

Preceptor. - In driving the Falcon, you can jog him four miles, when the rate can be increased to a three-and-ahalf gait for two and a quarter more. Go the reverse way of the track at first, and when you finish at the quarter pole, let him come back a little faster.

You did that as well as possible, not varying five seconds from the time, and each portion of the distance was gone at the same rate. Jane you can jog longer than we would otherwise, to try and wear the wire edge off, so that she will go a trifle faster than she has been accustomed to, without wanting to break away. Drive her slowly a few rounds at the gait she has been going, which you can increase to the same rate you drive the Falcon. Should she rush off, do not attempt to hold her back with a steady 
hard pull, but bring her to a full stop as before; jog her a while longer, and try her again. Should she still prove untractable pursue the same course, and bring her to the barn. At the next trial, we will put the Kemble Jackson check on, and if that does not succeed, she will have to be driven at the same time as the Falcon, when, by putting her behind his sulky, she will be compelled to keep at the rate we want her to go. I do not think it will be necessary to resort to this plan, as, from the kind way she has lately gone in her exercise, I think she will still continue to favor us with good behavior. Be very careful not to pull at her ; the least possible pull on the reins the better, as long as they are kept taut. I find your horses are all obedient to the word whoa, when spoken energetically. Should the mare act like wanting to go faster, talk soothingly to her ; as "gently, my lady ;" "careful, my girl ;" but when the whoa comes, be sure that it is followed by instant submission to the mandate.

PupIL.--One of the first lessons I' give when breaking colts is to stop at the word whoa, and I never use it afterwards except when they are wanted to come to a full stop. To signify to them that they are going fast enough, I say, "steady ;" to slacken their gait, "slower my boy, slower," and I find that a difference in intonation is soon learned, and I can talk to them, and they will obey as if almost human in their understanding. To teach a horse, that has not been taught the importance of the word that signifies stop, I use the small rope that I have spoken of in the allonging process. The loop is put round the lower jaw, and the cord carried over the neck near the withers, running from there through the loop. This gives a donble power, sufficient to place the animal in such a position that he cannot possibly move ahead. You lead him along, and when the word is given, you accompany it by an instant pall on the rope; he cannot move till you slacken 
it, and the stopping and word are ever after associated with being compelled to stop. The value of this lesson must not be subsequently spoiled by using "whoa" to signify several different actions, but for immediate stopping alone.

So highly do I value the importance of this lesson, and the habit of compliance, that I am very careful not to use the word when there is a likelihood of its not being attended to, and if one of my horses were to become suddenly frightened, I would rather let him run a little till I thought he could understand what I said. I can illustrate this by reoounting a circumstance that happened before I left home. I had traded to a friend a large and very promising five-yearold horse, that had only been broken that season. He had been driven on the track, with an occasional trip to the town, before the sulky or skeleton wagon. He was very docile, and I did not hesitate to recommend him as one likely to make a very valuable road horse. My friend drove him on the track, and was very much pleased with him in every respect. After dinner, I hitched him to a buggey, to which the shafts were so short, that, in order to get him the requisite distance from the whiffle-tree, their points came just opposite the shoulder-blade. I apprehended no trouble, relying on the quietness of his disposition. We got into the wagon, and went to town; the steam ferry-boat lay at the landing, where we met an acqaintance, and as we were talking to him, I saw that the horse was becoming frigthened at the boat, and knowing that the pleasure of his new owner in driving him would be much enhanced if he did not see him act badly, I requested him to get out of the wagon, and I would drive on. Before he could get out, the horse became so uneasy as to render alighting difficult, and I undertook to turn him around in the street, so that he would not see the boat. In turning, the end of the shaft hit his shoulder, 
and he became frantic, bounding in the air like a horse that had never been harnessed. We were only a few feet from the bluff-bank of the river, and it appeared as if nothing would save us from taking an involuntary bath in the Father of Waters. I succeeded, however, in turning him in time to save us from going over the bank, and as we got fairly straight in the street, my friend grasped the reins. The instant he took hold of them, I gave up my pull, and said "whoa," the horse stopping immediately. Our united strength would have been insufficient to stop him by pulling, though as soon as he heard the command the former lessons were thought of and obeyed. Shortly after this occurrence, I took him on the ferry-boat, and as soon as his curiosity was satisfied, he was as tranquil as if in the stable.

Precepror.-Perfect acquiescence to our demands can only be looked for when they are not unreasonable, and the habit of using several words to denote one meaning, or one word to denote different actions, will only confuse the horse, who is frequently punished for the stupidity of the driver. I noticed the peculiarity when driving your horses, and congratulate you on the knowledge your pupils display in this essential particular. Yet it strikes me you were a little afraid that Jane would prove zefractory, when you signified your fear that you might be compelled to injure her mouth to stop her running away.

PupIL. - I did not know whether the lessons she learned on the track, or those of a later day, would have the most weight, but was inclined to think the earler impressions would prove the stronger. Colts that I have broken are taught at every subsequent period that this demand must be complied with, and when driven either in or out of the shafts, it is duly kept in their mind.

Preceptor.-There is some sense in your reasoning, 
though I predict Jane will be of very little trouble; so harness her, and let us see. Well, how did she drive?

PupiL.-Admirably, considering her former habits. I onty had to stop her twice, when she took the gait you specified for her to go, and retained it till I thought it was time to bring her to the barn.

Preceptor.-Everything is working very favorably, and ought to impress upon you the value of kind treatment. There are two main ideas to enforce on a horse's mind. The first, that you are his superior, when he will show his loyalty by never rebelling, just as one horse in a pasture field is acknowledged the " boss," till he corners the others where they have to fight; and desperation lending them energy to gain the battle, the quondam monarch is deposed. The second precept is, that you are his friend, taking more delight in rewards than punishment, and thus bring both passions to your aid-fear and love. I want to see Clipper harnessed. I have been making arrangements that will prevent my being with you all the time as heretofore, though $\dot{I}$ will be on hand frequently to notice how you are getting on, and to give such directions as you may need. Whenever a change of work or treatment is required, I will stay long enough to see and note the consequences. The worst thing I feared was that Jane would prove unmanageable; her amiability has got rid of that clog, and you will get along finely.

PuPII.-My sorrow at losing your company is a mark of selfishness that I hope you will overlook. Thanks to your teachings, I feel a great deal more confidence in my ability to manage thou I did, and while I would not have you neglect your own affairs to further mine, I shall be glad to have your aid and support whenever convenient.

Preceptor.-There is great pleasure in assisting those who anxiously strive to learn, and I have been much gratified with the constant attention you have given. The 
training of horses is like all other human affairs-those who think the most will succeed the best. Mental power is as certainly benefited by cultivation as physical power, and one cannot be sustained in full vigor without the aid of the other. As Dr. Johnson remarked, there are only two ways of doing a thing-a right and a wrong wayand we will invariably find that the thinking worker will be nearer right, in a majority of cases, than the man whose mind is not in exercise. Training horses for fast work is a science that has been neglected, so that the best of us have only a very trifling insight into its causes and effects, though I believe the day is not distant when the value of scientific knowledge in this branch will be recognized, and, in order to obtain employment, those who make training their business will have to go through a course of study to fit them for performing their duties understandingly. It is true that there are many whose success merits the encomiums they receive, their industry, application, and energy having mastered the intricacies, without other help than long practice has given them. Yet these exceptions only prove the necessity for a more rigid course of study. Science can never be expected to do-away with practical knowledge, and however much benefit we may derive from its light, it will have to be joined to the art that is acquired alone from daily use. Clinical teachings have been found more effectual than reading, in preparing men to successfully contend against the encroachments of disease; yet both combined will not alone entitle the doctor to confidence. He must have acquired knowledge by his individual efforts, and without this practice, he is unable to form a correct diagnosis, or pursue a proper treatment.

That grey fellow, I see, is ready for you to jump behind him and drive him leisurely twice round the track. He has rather a singular gait when going slow, as if he had rot the free use of his limbs ; this will wear off as he gets 
more exercise. There is a great improvement in the appearansa of his limbs, and they now look as well as though he had gone through the orthodox courses of physic, which would have further weakened the tone of his stomach. The thickening of the integuments can never entirely be got rid of. Firing would be beneficial, but I very much dislike to make a horse undergo the torture of the iron, unless in cases that imperatively demand the application.

PupiL.-With the recollections of the Injuns and their red-hot iron scrapers so fresh in my mind, I could not bear to see a horse fired. Clipper's legs being so much better than I ever saw them, I am in hopes they will now stand the work.

Preceptor.-Percival, in concluding an essay on the strain of the flexor tendons, after recommending the iron in extreme cases, says :- "By the firing-irons have horses, originally worth their hundreds of pounds sterling, been raised from the knacker's price to their former value. By the iron has many a broken-down hunter, and many a racer, been joyously restored to his station and rank in the field where his proudest laurels have been won." Percival is high authority in everything pertaining to horse surgery, and his opinions are worthy of consideration. Before I would have the operation of firing performed, I would consult the best veterinarian within reach, and only resort to it as the last chance. Thanks to the introduction of chloroform, we can do away with the pain attending the application of the cautery, and whenever a painful operation has to be undergone, the relief it gives should be taken advantage of. If it were necessary, I would rather live on one meal a day for a month, than debar a horse from the benefits of this agent, when undergoing a painful operation.

We have yet time, before the feeding hour, to see how 
May will perform in her new shoes. They will induce a higher lifting of the foot now than after she has worn them for some time-so that, if they are going to be of service, they will show it at once. I have mentioned before the great difference in a hor'se's action by a trifling difference in the weight of the shoes. A few ounces added or subtracted, inequality of the sides, lowering either side by a greater reduction of the horn, is often followed by a change that no one would have credited without a trial. By changing the shape of the ground surface of a horse's foot even structural defects may be overcome, and the bias arising from malformation be remedied. You can also buckle the roll on to May's right hind pastern, which will guard it against injury, and will give her confidence as well as protection. We are wonderfully fortunate in our experiments, having been, in a measure, successful in all we have undertaken. May will soon go as straight as any of them. When driving her, in the future, confine her to the stretches when you speed her, and it will be as well to turn her every time you come through, so as only to traverse this part of the track.

Between now and dinner we will consider what is further to be done towards the conditioning of the older horses, and in educating the younger. The Falcon there is no difficulty with. He will take all the work necessary to prepare him for any kind of a race. For the ensuing week, prolong his work to jogging five miles, with a mile or so at a three-and-a-half gait. His feed can be increased to ten quarts of the mixed feed per day. As he has become as tractable on the track as on the road, you can vary the locality of the work of all of the horses, by driving once or iwice in the week on the smoothest, and softest road you can find. In three days you can prepare Falcon for a sweat, the same as we did Never Mind, only he can have his usual allowance of hay until the night before we give 
the sweat. When he is grazing, take him to a secluded part of the field, where he will not be disturbed by the other horses.

Never Mind will not need the same amount of work; jog him three miles, with two at an increased gait; tomorrow morning you can allow him to brush threequarters of the way down the stretch, but be sure you keep him inside his best rate. The preparation for his second sweat will be identical with that for the first. W6 will sweat him and Jane on the same day, so you can prepare her at the same time. You will have to use your own judgment in the work you give her. I would prefer it to be a medium between the Falcon's and Never Mind's. Above everything else, endeavor to keep her going quietly, without anything approaching a hard pull. Keep a strict watch of the boys, that they do not even speak harshly to her. Should any of them have a cross fit, and twitch the horses by the bit, or kick and strike them, discharge them on the spot. Clipper must be jogged very quietly, and his morning and evening walk be curtailed. Watch his leg's very closely, and if you are sure there is not a particle of heat, use cold water to wash them, applying the bandages, drawing them a little closer than before, and have his legs well hand-rubbed, the boy occupying an hour in performing this task. Should there be any heat, use the hot water, put a dry bandage over the wet, and leave them on all night. Let him be grazed for the time his walk is shortened in the evening, and when in the stable, have him kept as quiet as possible. His feed can remain the same as it is now. Never Mind and Jane can have an additional quart at night.

Hirondelle will have to be driven a good deal like Jane. You can give her long, steady work, keeping her well in hand, and endeavoring to keep her high spirit within proper bounds. I think her knee action will be improved 
by wearing the rattles once in a while. These are only to be put on occasionally, as their every-day use would defeat the object we have in view; the novelty would soon wear away, and the only thing gained would be the added weight. Some cover rattles with chamois skins, to prevent them chafing the skin. I would rather protect that by a thin piece of leather or cloth tied on by itself, as the covering injures the flexibility of the rattles, and the noise the beads make striking against each other induces higher action, than would be the case if the noise did not accompany their use.

Oriole had better have her fast work in short brushes, and whenever she shows an inclination to hitch, pull her up, and start her again. I have seen horses that would hitch when going at moderate speed, and when driven faster would go as true, and square as could be desired. Oriole, being anxious to do all, or more than is required, hitches in endeavoring to take a longer stride. This is more favorable than if she had acquired it by pulling heavy weight, which would be harder to set right. Mavourneen will have to be driven according to your discretion. I am afraid she will not repay you as well for the time spent as the others, but one can never prophesy very confidently about trotting colts. Those we think the least of may change in their way of going, and surprise us by beating others that seemed greatly superior. 


\section{CHAPTER XXIV.}

\section{DAY DREAMS-FOOD FOR HORSES IN TRAINING-HAY, CORN BLADES, STRAW, OATS, CORN, LINSEED-MEAL, OA'T-MEAL, SAGO, GREEN FOOD, ETC.-TIME OF FEEDING.}

PUPIL.-I will have to find amusement in following the vagaries of my imagination, when deprived of your company while smoking after dinner. Whether the habit of day dreamıng when the pipe is lit, which my forest life has fostered, will ever be broken, I cannot imagine. It is certain that I cannot read when I am thus engaged. If I attempt to find instruction or amusement in books, I am insuccessful. The book will drop, and I am transported to other times, and far-away places, or am reveling in "scenes that can never be expected to occur. Conversation lispels the phantasies of the brain, and absolves me from whis folly when in company. Should I endeavor to study, when alone, the task is as futile as reading. I am soon lost in reveries, and I have given up all hopes of saving the time occupied in solitary smoking. The half hour thus spent, or thrown away, has become a luxury which I would be loth to part with, if for nothing more than that it is a prolongation of the happy period, akin to the bright days of youth, when the fancy pictured glowing futurities, of which the judgment yet did not show the fallacy.

My countrymen have been characterized as a painstaking, demure, stubborn sort of people, who found in everyday reality, a life more pleasing than any efforts of the jmagination could afford. I am satisfied they are wronged 
in this estimate, and that no other people are so completely carried away with, or live more in, an ideal world. My first recollections are of sitting on an old nurse's lapunder whose fostering care two generations of our family had been nurtured-and listening to the tales she told, still vividly remembered. I am satisfied she did not depend on her memory, as the infinite variety of tales, from which she always selected the one most appropriate to the mood of her auditors, was beyond human recollection. Fairies, brownies, goblins, water-kelpies, and all spirits ever supposed to have an existence in any element, were at her will; the dramatis personce of romances that would take the nights of a winter month to bring to a conclusion. There were ghost stories that, in the horrid ghastliness of her minute descriptions, fairly curdled the blood; legends of castle, town, and lonely cot, and histories of every "ruined wa" in the neighborhood were faithfully recounted; old battles, in which some ancestor had taken a prominent part, were told so heroically that even the child was a mimic soldier, and felt his heart swell in the hopes of imitating those deeds of high devoir; love tales, where the suitor went away in poverty, to dwell in foreign lands, returning rich and distinguished, to find the lassie that had been the magnet which attracted him to conquer every obstacle, some of them seemingly insurmountable was "aye leal"always true-

" 'Away wi' beguiling, cried the youth, smiling,

Off went the bonnet, the lintwhite locks flee;

The belted plaid fa'ing, her white bosom shawing,

Fair stood the loved maid wi' the dark rolling e'e."

The history of "Auld Scotia," so much like a romance, lost none of the brightness of coloring in her hands. From the time the victorious Romans built the celebrated wall to assist in protecting themselves from the valor of 
a people, their superiors in bravery, to the union with England, her knowledge was far beyond that of the books. Of things that happened subsequently to the incorporation of the two countries, she would take no note, as, according to her idea,

“The English, for once, by guile won the day,"

and to join in friendship with their auld allies was a stretch of philosophical forbearance beyond the tenets inculcated in her mind. The framers of the American Constitution, when they added the clause that the chief officer of this country should be a native, were aware of the ties that never can be broken, which binds a man to his fatherland ; and though I left the bleak hills of Scotland when a boy, and a quarter of a century has elapsed since then, I would not renounce the place of my nativity, to be at the head of this powerful government. This is, no doubt, nonsense; as the renunciation would not aid me in climbing one step towards that high position, though the remembrance of the heathery hills, the holms studded with gowans, and the sparkling burns, will always be a warrant for my loyalty.

Peggy's great forte, however, was poetry, and her auditory of "toddlin bairns" was never cloyed by a surfeit, though her repertoire of ballads, love songs, and merry chants was as extensive as her legendary lore. She could not often be coaxed to "wed the words of music," but when she did, the simple grace with which she sung the old Scotch tunes is remembered yet, sounding like the voices I have heard in the woods at midnight-spiritvoices murmuring chimes of another land. The feeling with which she rendered the pathetic ones, like Cumnor Hall, or the lamentations of some of the exiled adherents of the house of Stuart, I have never heard equaled, and 
when the little bosoms were heaving, and the tears could not be restrained by summoning the pride that considered such a display weakness, and derogatory to the character of manliness, which all Scotch boys are taught to believe the first great aim,-and were culminating in a flood of "greeting," she would change the tears to hearty laughter by a grotesque recitation of some humorous song, that would have moved the mirth of the crying philosopher himself. Humor was not as much to her liking as the tender or supernatural, and unless she thought it necessary to remove painful feelings, induced by fear of seeing some spectre wraith flitting by the ivy-curtained windows, or to banish those of acute commiseration, she never resorted to it. I have introduced the old nurse partly as an instance to prove that the existence of deep imaginative feeling among the Scotch is common-as I never heard my nurse was peculiar in this respect-and as possibly accounting for my habits of seeing visions and dreaming dreams at times when the mantle of sleep does not envelop me. I have found the benefit of looking for a "silver lining in every cloud;" though one sink a heavy mass, unrelieved by the slightest penciling of a warmer color, the next one may be bright enough to make amends. The colt gamboling in the sunshine, and which we believed destined to do great deeds, to make the heart bound at the pleasure of having reared it, turns out at the allotted time to be worthless. The visions are dispelled only to be renewed with those of another year, invested with still brighter hopes. The cigars have burned out. Forgive the egotism that has intruded on you the days of childhood, which, however bright in the remembrance, are not exactly the thing to interest others.

Preceptor.-You need not apologise. I feel something of the same kind steal over me when smoking. I assuredly never thought the want of imagination a Scotch characteris- 
tic, and you are undoubtedly wrong in thinking such to be the estimate of the public generally. Scotch history, her romances, traditions, poetry, and music, prove the contrary. I have read-and who has not?-many works of Scotch fancy ; and from James the First of Scotland, in whose King's Quhair there is "Beauty enough to make the world to doat," to Alexander Smith, her poets have been in the front rank. Why, the Ettrick Shepherd could never have had an existence in a country whose people were not highly imaginative. His "Queen's Wake," though read many years ago, and my recollections of it indistinct now, still captivates my fancy ; and passages, thought to have been long forgotten, come freshly to my mind. How completely does he exalt the "Lovely Kilmeny" above earthly life! and when transporting her to the "land unseen,". the transition appears proper, without the aid of death. For

But still and steadfast was her e'e;
Such beauty bard may never declare
For there was no pride nor passion there,
And the soft desire of maiden's e'en
In that mild face could never be seen.
Her seymar was the lily flower,
And her cheek the moss rose in the shower,
And her voice like the distant melodye
That floats along the twilight sea."

But to prove the imaginative power of Scotch poets and romance writers, would be a waste of time, like giving reasons for twice two being four.

We will now divest ourselves of sleeping or waking fancies, and consider the important question of feeding horses in training. In order that a horse may be in proper condition to go fast, the greatest care is requisite in feeding. The food must be of the best quality, and the 
amount regulated to the wants of the animal. Hay, corn blades, and straw are the articles used as the bulky portions of the food, and the different kinds of grain as the nutritious. It would be impossible to get a horse in order if restricted to either class. The hay would not afford nourishment sufficient, while the grain alone would not keep up the tone of the stomach, and indigestion would quickly follow. In my opinion; the best hay is good bright Timothy, cut at the proper time, and cured in a perfect manner. It is better for being two years old, as, when it has become thoroughly seasoned, there seems to be a change that renders it easier of chymification. It does not ferment in the stomach, and is, in every particular, better for the purpose. The hay cut from old meadows is superior to that from those recently laid down, unless the farmer has used a great deal more seed than a majority of agriculturists deem necessary. New meadows, where the soil is rich, and from twelve to sixteen quarts of seed sown to the acre, will grow better hay than old meadows that have become poor from long cropping.

To determine good hay by observation is a very necessary knowledge on the part of the horse owner and trainer. It should be free from dirt or discoloration, the stalks fine, with plenty of leaves on them. When handled, a fragrant aroma should arise, and on examining the heads, the seeds should adhere to the husks that cover them. There is a stage in the growth of this grass when the dust or pollen of the flowers will rise in a cloud, when a puff of wind blows over the field. This is at the time of the first blossoming, and if the grass is cut at this stage, or before, the hay will be bad and dusty. This fine, almost impalpable powder, will be very injurious, though extremely difficult to detect. The seed is the best guide, and in this case the ear will have a shriveled appearance, the seed scarcely formed. The heads or ears should be 
nearly as plump as if the seeds were ripe, which will show that it has not been cut till after this dusty era has passed. If the grass stands too long, the woody fibre predominates, and the hay is brittle, tasteless, with only a small part of its nutritive qualities left. Hay sometimes heats, or mowburns, without showing discoloration enough to detect it from the appearance. To discover this, take up a large handful and hold it to the mouth and nostrils, breathing on it, and if it is injured, a moldy odor will be apparent.

The evils resulting from using foxy, mowburnt hay, are generally known and guarded against. Horses will eat it greedily, the sweet taste it has acquired from the process of fermentation making it palatable to them when they are first fed with it. I have heard people remark, "That hay does not look very well, but my horses eat it first rate;" when it has been almost damaged enough to be poisonous. It soon affects the lidneys, causing an excessive flow of urine, which unchecked, would soon end in debility. This seems to occur before there is much derangement of the stomach, though continuing its use would also disorder that.

A mixture of Timothy and red-top makes very good hay, and would be my next choice after that wholly consisting of the first named. Clover will not do, under any circumstances, no matter how much care has been taken in cutting and curing. It seems to interfere with the action of the respiratory organs, and is inadmissible for horses in training, and can only be used as green food. Corn blades are very valuable as "fodder" for horses in training, and when I wanted a horse in "tip-top-fettle," I would rather pay an exorbitant price than do without them. They ought to be stripped from the stall when the grain begins to glaze, stuck up in small handfuls on the ears to dry, and when thoroughly cured, bound in small bundles, and stored on a scaffolding, formed of poles placed on the 
beams of the barn. It would not do to put many of them together, as the least fermentation spoils them. They have to sweat as well as hay, but the dampness arising must have every opportunity to evaporate. I would feed them alternately with hay, as blades in the forenoon and hay at night, though I have known horses that would do better on the corn blades alone. I also prefer to use them before a race, trial, or sweat, as they seem to be advantageous to the action of the lungs, probably not so much from occupying a smaller space in the stomach, and thus not interfering with the diaphragm, but also by a difference in their chemical constituents.

That there is greater freedom of breathing, when using one kind of food over another, is well known. Mr. Spalding, the celebrated diver, before the discovery of marine armor, found that his diet had a sensible effect on the consumption of air in the diving-bell. I lament the want of a knowledge of chemistry, which would greatly aid me in forming correct oppinions on this point, and in default of that knowledge, can only state the result of experience, without being able to deduce the reasons why the difference should exist. Lord Seymour, who did so much to establish racing in France, trained his horses on straw for forage, and was very successful in gettting them in order. I have tried it with some horses that were habitually costive, with good results. I cut it in a straw-cutting machine and mixed it with the grain, a portion in the feed after the morning's exercise, and the balance at night. By being mixed, the grain was better masticated than otherwise, though this can always be accomplished by making. the horse eat with a large bar bit in his mounth. Prairie hay I have heard highly extolled by some of those who had made trips into the section of country where its use was general, but having no personal acquaintance, I can say nothing about it. 
PuprL.-When I "moved to the West," there was no other kind grown, and it would have been thought folly for a man to seed his ground to Timothy or clover, when he could have thousands of tons of prairie hay for the cutting. The whole country at that time, saving the small proportion in cultivation, was covered with grass. The rolling prairie had a fine growth, that would yield from one to two tons to the acre. The small ravines and little flats lying along the creeks had a thick growth, somewhat like red-top, which would cut two to three tons. The large bottoms bordering on the Mississippi and other rivers were hid by a growth that looked like a diminutive cane-brake, and would cut four tons and upwards to the acre. The variety of large grass thought most highly of is called blue-joint, and I have seen it grow so high as to completely hide a man on horseback, when riding through it.

A few miles north of my place is a bottom at the junction of the Maquoketa river with the Mississippi ; it is some six or eight miles wide between the bluffs on the latter named river, gradually narrowing as it recedes till, some twelve or fifteen miles up, the bluffs come together with just room for the smaller river to run through. These bluffs are an appropriate framework, rising to a height of three hundred feet, their sides nearly perpendicular and rocky, but where their abruptness is not excessive a heavy timber is growing. From the summit of the bluffs one can see almost every acre of this luxuriant delta, and in the month of July to look down on this waving "emerald sea" of verdure is a beautiful sight.

On this bottom I was favored once with the grandest demonstration of the sublimity of a prairie on fire that I ever witnessed. I had seen, hundreds of times, the ruddy streams chasing each other over the rolling prairie, the line extending for miles, flickering and flashing over thousands of acres. This is always a pretty sight, calling 
forcibly for admiration, without exciting a thought of fear. A man could breal through the edging of fire with no greater injury than he would find in stepping over the boxwood border in the garden.

But this bottom, clothed with an immense growth of blue-joint, flags, and weeds, dried till they were as inflammable as pine shavings, when on fire conveyed, while there was abundant room for admiration, an idea of the power of the destructive element, that almost appalled me with its ferocity. The night on the occasion of which I speak was dark and still. Heavy clouds hid every star from view, and there was no wind. The fire originated in the extreme South-east corner of the bottom, and might have been caused by a spark from a passing steamboat. The residents on the verge of the woods seeing the light, at once commenced firing the dry grass in their neighborhood, so as to "back fire" away from doing injury to the timber, fences, and stacks at the foot of the bluffs. Scarcely a quarter of an hour had elapsed before there was a perfect cordon of fires surrounding the whole extent, and, following the irregular outline at the base of the hills, it could be compared to a huge serpent; gliding in glowing folds, and throwing off scintillations from its luminant scales. The advancing columns drew along very placidly, streaming directly upwards in the still air. It was not long ere the smoke began to wave and surge, and the flames to leap higher, and the crackling sound was soon joined to a sibilant, purring noise, and currents of air began to draw through the notches among the bluffs, and strangely moan in the dwarfed red cedars that fringed the rock where I was seated. The murky clouds absorbed the red light from the fire, which had now become extensive enough to illuminate the bluffs, and cause the lesser stream to look like one of blood. The wailing and sighing of the wind increased, the columns of fire swayed, shook 
and twisted themselves into rapid evolutions ; now shooting upward far, far into the lurid sky; now throwing themselves forward till the whole level prairie was absorbed, and burst at once into a tumultuous flaming sea. Looking from my elevated situation, the valley appeared as if transformed into a molten, seething lake, hemmed in with red-hot walls, so that the tormented spirits could not escape.

Burning this hay is not the way to acquaint you with its value for forage. Much diversity of opinion prevails in reference to its qualities, and while some of the Western trainers will not use it, there are others who think it the only kind suitable for horses that work fast. These last will point triumphantly to the fact that when prairie hay only was used, heaves were unknown in the Western country, and that with the advent of Timothy meadows, required by the settlement of the country, this distressing malady also made its appearance. There is no question of the truth of this assertion. When I first went to Iowa the disease was totally unknown, and the absence of it ascribed to a variety of causes. But the prevalence of this affection of the lungs in the same locality now, where the only change has been the substitution of cultivated for the prairie grasses, certainly proves where the cause exists. Notwithstanding this, I do not like it as well as Timothy, the liability of which to injure the lungs would be done away with, if proper care were taken in the cutting, curing, and preserving.

Thick seeding, as you remarked is very necessary to obtain good hay, not only by causing a finer growth of the stalk and an increase of the leaves, but, by getting a thick sward, we also get rid of a good deal of dust. Should there be patches of the grouud uncovered, the fine particles of the soil become disintegrated by the beating of the rain, and, adhering to the plant, are shaken off when fed, and 
carried with the air into the lungs. My objection to prairie hay is, the tendency to produce costiveness ; and if much of it is fed, you will always notice that the excrements are hard, and of a dark color. Of the three varieties I have mentioned, the kind that would seem the least fitted for nourishment I am satisfied is the best, viz: the large blue-joint. I have noticed that stock kept on that have been invariably in the best condition, and the farmers who lived on the margin of the Maquoketa bottom, and who wintered large herds of cattle on this alone, had their animals in better plight in the spring, than the dwellers on the prairie who fed the finer kinds and added a proportion of grain. Some of this prairie hay has a delightful fragrance; this and the bright green color it displays in midwinter, have led people to place too high an opinion on its nutritive qualities. There is frequently a weed mixed with this hay that I am certain is injurious. It is called resin-weed, from a similarity of taste and smell to that substance. It is a very powerful diuretic, and as it is eaten with avidity, it cannot fail to do harm. Some ascribed the immunity from heaves to this ingredient, and extracts were made and recommended as a spectic for most of the diseases of the throat and lungs. I have known two horses injured from giving them this extract, and have no doubt that others have been rendered worthless from partaking of it in its natural and less powerful form. There are undoubtedly other plants cut with the hay that are not proper for a horse to eat, and so, to be sure that I do not give any of them, I would refrain from feeding the hay that contained them.

Preceptor.-Here is a table of the relative value of hay and other foods, compiled from experiments in France and Germany:- 
ONE HUNDRED POUNDS OF GOOD HAY IS EQUAL IN NOURISHMENT TO

$400 \mathrm{ib}$ of green clover.

$275 \mathrm{fb}$ of green Indian corn.

$374 \mathrm{fb}$ of wheat straw.

442 tb of rye straw.

195 th of oat straw.

$400 \mathrm{tb}$ of dried stalks of Indian corn.

$276 \mathrm{mb}$ of carrots.

54 to of rye.
$45 \mathrm{ft}$ of wheat.

$54 \mathrm{tb}$ of barley.

59 tb of oats.

$57 \mathrm{tb}$ of Indian corn.

$62 \mathrm{ib}$ of sunflower seeds.

69 tib of linseed cake.

$105 \mathrm{tb}$ of wheat bran.

$83 \mathrm{fb}$ of dried oak leaves.

This table was the result of experiments conducted by the most eminent scientific agriculturists, and can be relied on as correct, as far as such things can be proven. I am at a loss to know what is meant by the "dried stalks of Indian corn." If they were divested of the blades, I wouid have thought them of no value, and with the leaves on, they would not be so much inferior. Some trainers are so particular as to stem the corn blades when feeding them, but I think that is unnecessary. Neither can I recommend the adoption of the plan of pulling hay, as it strips off the leaves, which are the most nutritive portions. The hay ought to be well shaken up, tossing it lightly with a fork, which will free it from dust as effectually as the boys do by twitching it through hands that have been just picking up the droppings, and which must, in a measure, contaminate the hay, and make it less agreeable to the nice discriminating taste of the horses.

The time for feeding the hay is after the morning and evening exercise, and the amount must be regulated to the requirements of each horse. There are those that will eat so much as to be totally unfit for fast work, while others are benefited by coaxing them to eat all they can. A heavy carcased, craving animal would distend himself with hay if allowed, till he would be in no better plight for rapid exertion than a fat alderman, who had just dined on turtle soup, roasted venison, with a bottle or two of 
heavy port. The light-waisted, delicate, finely organized animal never eats or drinks too much, requiring management to induce him to take more sustenance than he otherwise would. The grain that ninety horses in every hundred are fed with, when in training, is oats, and when bran and corn are added, the variety is complete in a still greater proportion. Oats are to the horse what bread is to man, "the staff of life ;" though, I believe, other articles of diet can be used advantageously. As I have remarked before, oats have more husk than any other grain, causing them to weigh less, according to the bulk, than any of those in common cultivation. That this is an advantage, in some cases, will be admitted, as when the stomach requires more distension than the hay fed gives ; and should we change a horse's feed from twelve quarts of oats a day to half that amount of corn, wheat or barley, the change would necessitate an increase in the quantity of hay used. A majority of horses can be brought into good condition by using oats alone, though I find that "order" is acquired more readily, when I use other articles of food in combination with them. There is an improvement in the health of man by using different kinds of aliment, and this rule will also hold good in the management of horses-fast work requiring scrupulous care, neither to overload the stomach, nor place articles in it that are not nutritious. Thus we cannot avail ourselves of a change that might ultimately benefit the health, if not compatible with these considerations. This may appear paradoxical, yet it is nevertheless true. What Leibig calls the "plastic elements of nutrition," consisting of substances abounding in nitrogen, must be combined with a sufficient quantity of carbon -one to form blood with the proper constituents to promptly repair the daily waste of the tissues, and the other to create heat and assist the respiration. There is nearly as much nitrogen in oats as any other grain, being only 
one-tenth of one per cent. less than wheat, while there is fifty-one per cent. of carbon, wheat having forty-six per cent. Oats having been found superior to any other grain for the food of horses when working fast, it is fair to infer that the proportion of nitrogen and carbon in this grain is the best.

Without doubt, the grain used in the analyses I have quoted, was of the very best quality, and from the results of experiments in England, where the oats are better and heavier than here, shows more nutritive qualities than ours would. I have seen oats that looked plump weigh only twenty-eight pounds to the bushel, and I have used those that weighed upwards of forty pounds. It will readily be granted that a horse would require more quarts of the first, and he will also want more pounds of them to obtain the same nutriment, the lighter ones having so much thicker husks. Good oats are an absolute necessity, and unless they possess the qualities requisite, we will be unable to get a horse in proper condition. I have stated before, that they ought to be heavy, two years old, and remain in the stack long enough to sweat before they are put in the bin. They will sweat there again, and every year they are kept they go through this process, which is probably the reason why old oats are so much better than new ones. To detect mustiness, breathe on them, as I directed for the hay. Observe closely, to notice whether they have sprouted while in the shock or stack. You will discover in this case the dried germ still adhering to the kernel. See that there is no foreign substances mixed with them, as seeds of weeds, gravel, dirt, \&c., \&c.

Poor corn is easier told than inferior oats. The ears should be bright, the kernels solid and plump, and on breaking the ear there should be no dampness or mold. The other articles needed, as bran, linseed meal, oat meal, sago, \&c., \&c., it is needless to say, should be of the very 
best. There is only one use I have for sago, making gruels for horses that have become feverish, and are "baked," as the grooms say. Their coats are dry and have lost their lustre, and the perspiration that should follow their work does not take place. Sago gruels, acidulated drinks, with a reduction of their work, will generally effect a cure, unless the cause is disease which will require the attendance of the veterinarian. I have changed my system of feeding from what I formerly practiced, in relation to the frequency with which I give the meals. When I commenced training, six feeds in the twenty-four hours was thought necessary. After a while I tried five, and thought I observed a benefit from the curtailment, and now I am satisfied that four feeds a day are better than to have them come closer together. The amount conveyed to the stomach requires time to digest before it is replenished, and four hours is a short enough space for the food to undergo this process. I also like to have the stomach distended so as to increase the muscular strength of this organ, which would not be the case if smaller quantities were given with greater frequency. To perform its functions properly the stomach must have intervals of work and repose, proper exercise being as essential to keep it in vigor as for any other part of the anatomy. Our feeds coming at five and ten o'clock A. M., and three and seven P. M., will only be varied in those horses that cannot have their fast work given between the first and second feeds. The time it takes the horses to eat their hay in the evening, will leave them about eight hours for repose, which is none too much.

PUPIL-Do you think sago preferable to green food for inducing perspiration in horses that are "burned"? I have had great faith in the efficacy of allowing a horse to eat plentifully of grass, green corn blades, \&c., when in that fix. 
Preceptor.-As a preventive, I would prefer grazing alone, but when the horse has become burnt, I would rather combine it with sago. When the system has become feverish the sago gruels, taking the place of water alone, have always proved beneficial with me. Yet if I had to forego the use of sago or green food, I would not hesitate an instant in discarding the first, and give the latter the preference over everything else, as an adjunct to correct the injuries arising from fast work, and for the diet of horses in training. If a horse is allowed to graze for half an hour, twice or three times a week, and his work and food are judiciously given, there will very seldom be any necessity for demulcent drinks, excepting when sweating, or after giving extra work, as in a trial or race. The succulent herbage will do away with the necessity for giving so many bran-mashes, which I do not regard with the favor that many do. I use them, but not with the frequency of many of my aquaintances, trusting to the more natural food, which has never failed me yet in doing what I expected. It will not do to give it at particular stages of the training, as there are times when one requires the system to be "lreyed up" to the highest tone. Then only the most nutritious food is admissible. An eminent veterinary writer remarks of green food, that "wounds heal more kindly, inflammatory diseases are not so fatal, and chronic diseases frequently abate, or they entirely disappear under the use of grass. The horse, however, is always soft when fed much on green food. He sweats a great deal, and is soon exhausted with his work." Our aim, therefore, should be to feed enough and at proper times to obtain the benefit of its medicinal properties, without going far enough to debilitate the animal by too free and frequent a use.

PupIL.-You would advise grazing, rather than cutting the grass and conveying it into the stall? 
Preceptor. - At this season of the year I much prefer the animal to pick it himself. He chooses that which suits him the best, and there are no flies to annoy him. In extremely hot weather, or when the flies have become troublesome or in the fall, when the juices are diminished, I would give it in the stable.

Pupil.-Why, I know a man who took advantage of the flies to assist him in exercising. Last July and August there was a great deal of rain, making the track and roads very muddy. This man had a couple of promising colts, and during this muddy time he would tie them in a small yard for two or three hours every day, and let them " fight flies" by way of exercise. He told me this himself, and took much credit for the invention.

PrecePtor.-I wish I could have tied him in an Arkansas swamp, for the same length of time, and let the gallinippers and musquitoes make him dance to the music of their shrill pipes. If his treatment in other particulars was akin to this, he must have ruined his colts.

PupIL.- He was at first very successful in developing their speed, and a month or two previous I thought the two colts were the best I had ever seen. But the fly experiment was not a successful one, as they could not trot as fast in the fall as they did in the early part of the season; but there were other points in his treatment fully as inimical to improvement as the one I have mentioned.

Preceptor. - If he had other notions similar to that, it was no wonder, though I have seen men that knew very little of training very fortunate in obtaining speed from horses. This is no argument against trying to learn all we can, but only shows what fortuitous circumstances will accomplish. It will now occupy the remaining time for you to get through with the colts you have to drive this afternoon. I may be here in a day or two, and perhaps 
not before the end of the week. I believe you know what to do in the interim, and I shall not trouble you with any commands, as I want to see how you will get along by yourself. There is nothing like proving theory by practice, and nothing will improve an individual like having to depend on himself.

PuprL.-I feel much more confidence in myself, which is one point gained, and I hope that I can go along in a manner that will justify my self-laudation. Before you go, I would like to know if there is any difference to be observed in giving the horses their water.

Preceptor.- When you finish driving, and the horse is unharnessed, give him a swallow or two of water, to moisten the lips, throat and tongue, and after he has been clothed and taken out to walk, give a few swallows more, finishing with the usual quantity at feeding time. I have also changed from former practices in this respect. My custom was to "wall the water into a horse," by keeping a bucket at the walking ring, and every few minutes giving a portion of it, till the fifteen minutes' walk and the water came to an end at the same time. I think it is a better plan to wait till the circulation is quieter, before the stomach has much fluid put into it. We will give the subject of drink our attention hereafter, when we will have more time to discuss it. In the brush you give Never Mind to morrow, do not exceed three hundred yards. Watch May's action very closely, so as to report any changes, and should any of them show any symptoms of rebellion, treat them with increased kindness. 


\section{CHAPTER X X V.}

WESTERN CHARACTER-TROTTING IN SNOW-DURECTIONS FOR WATERING.

Preceptor.-Good day, scholar. You will perceive I have dropped in in time for dinner, which, I am free to acknowledge, will come very acceptable. I have "occasion," and shall do justice to the good cheer your hostess always prepares for us. I will also admit that the "pleasures of hope" are likely to be fully realized, as I anticipated "blowing a cloud" with you, for I find no other cigars the equals of those Principes.

Puprx.-I am delighted to see you, and better pleased that you have timed your visit just as you have, when we can have a good talk without being interrupted with the driving. Please to step into my room, as I have another evidence of Western liberality to show you.

Preceptor.-True enough, you have a goodly "lay out," and I would suppose, from the exhibition of this paraphernalia, that you have foregone your strict temperance principles, and become a votary of the vine-clad, jolly god, as well as a disciple of the Indian weed.

PupIL.-I have no intention of indulging in any of these enticements, and my vow of strict total abstinence from spirits, wine, or beer, is no more likely to be broken than if this nectar were a hundred miles off. But test it, fill up a bumper of what you like the best; I will warrant it 
of the true quality, and after you have imbibed, will read you a letter that accompanied it.

Preceptor._- "That good wine needs no bush," is an old and true adage. I hardly ever drink till after dinner, and do not feel capable of giving an opinion that would be worthy of much weight, but that brandy I took the thimbleful of is as smooth as oil, and nearly as fragrant as the breath of the morning.

Pupn.-I want you to try a bottle of that sherry at dinner. If you praise the odor of the brandy, you will be completely carried away with the aroma-but the letter will say better than I what needs to be said:-

$$
\text { “ Chicago, June 1st, 18-. }
$$

"Mr Dear Friend.-Having a little spare time on my hands, I thought I would acquaint you with what is going on in this tight little town. No doubt Hod keeps you much better posted on all pertaining to horses and other \&c's, of which he is so good a judge; but there are things of which I know a little myself, and which I could not help bringing to your notice. In this country where the air is clear, and no salt vapors borne on every breeze, a man can keep healthy as easy as a horse. All that he has 'to do is to eat, drink, laugh, and take his share of exercise to get along first-rate. But down where you are now, there is a vast difference. The sea fogs and the sea winds penetrate everything, and a man can no more be healthy without a drop to repel these insinuating ocean-bred vapors, than a man can keep warm in his shirt sleeves when the wind blows from off the lake. So I send you a variety of my very best, and if you are still too obstinate to take it in moderation yourself, for the sake of the reputation of your Western friends, treat your visitors with more respect than only to be shoving one of John E.'s regalias at them, without a drop to moisten their palates, which would make smoking endurable. Surely, men can- 
not smoke all the while, and what would you have them do when listening to your long-winded stories about horses, and pedigrees, harnesses, and bits, if they have nothing but a trumpery cigar to suck at? Why didn't you stop when you went through, and lay in a supply? as I have no doubt we have all suffered from their taking you for a specimen of Western horsemen. Mind, they do not know you, and will ascribe to penuriousness what your friends are aware is only absence of mind, and not thinking of the wants of others. You talk about the comfort of smoking, and the fine sights you see when the cloud is curling above your nostrils. Arrah na boclish, man! there is more comfort in a whiskey punch of a cold. night, and more fine imaginings in a dozen of them, than there is in all the cigars in 48 Dearborn Street put together. I see you are likely to get acquainted with $\mathrm{Mr}$ P. I know he is of the real sort; and I will be wonder. fully disappointed if he gets there before you have some thing to treat him decently with. Tell him that sherry has been in the wood for fifteen-years, and that I bottled the port myself the same length of time ago. It is now just ripe, and he must on no account leave a bottle, as it will never be as good again. Tell the old man not to be vexed, that I have sent a basket of champagne for Misses Jane and Susan; and I believe you would have been omadhaun enough to have gone to the races at Jerome Park with them, and never have thought of clapping a few bottles in the carriage. The poetry of motion, as you call it, in seeing a half score of thoroughbreds rattling over a dirty track is rather a dry sight; about as bad as smoking with only tasteless water to wash out the gout. If you had only seen the field after the Galway hounds, or wiłnessed a steeple-chase with the Montgomery's, Lord Howth, and the dirty blackguard Tom Ferguson in it! such a skrimmage at the finish, and such a shouting as you 
never can hear anywhere else. Ah! that's worth all your racing, and stirs the blood equal to the best potheen. Well, we all have to be contented with trotters in this country. The two sorrel mares are doing first rate, and with Black Dan and his mate I can give Plowboy and Fine Cut as merry a chase to Hyde Park and back as they want.

"If any of your Eastern acquaintances are coming this way, tell them to step into 112 Randolph Street, whenever anything belonging to me is at their service, and Hod and I will take delight in showing them what is worthy of seeing.

"Don't forget to get a sideboard, and keep the bottles always in sight. Remember, every one does not smoke, and the only good in a cigar is the relish it gives to the drink. There is no use in hoping that you will follow sensible advice yourself ; but I hope that your pride that the character of the West does not suffer, will caution you to take the advice of your friend."

This letter is a fair exemplar of the character of my friend. A liberal Irishman-he has had Western profusion grafted on the kind disposition, till he not only wants to see his friends enjoying themselves, but is determined his friend's friends shall not lack for comforts if he can supply them.

I will now-before we take dinner-give you a history of what I have done for the few days while you have been gone. I have followed the directions as nearly as I could, and have only varied from them with Delle. With her I have gone on the road every day, and after jogging six or eight miles have returned to the track, and speeded her up and down the stretches. Twice she has worn the rattles, and I wish you had been here to see her go. She is going to overtake May, in a very short time. She bends her knees with them on like an old trotter, and in place 
of rushing off her feet in a hundred yards, will go the whole length of the stretch without breaking. I have prepared Falcon for his sweat to-morrow, and intend that Jane and Never Mind shall go through the same operation the day after. Clipper is doing very finely; there has been no heat in his legs, and less swelling than when I commenced driving him. May's action has undergone a change that I did not look for, having lengthened her stride, and she goes sweeping through the stretch a good deal like her sire. Oriole I have confined to very short brushes every other day, when I have let her spirt off for a hundred or two yards. She showed no symptoms of hitching. One of the little boys has ridden Mavourneen along. side of me when I have been driving, and she seems better suited to the saddle than the harness. They are all eating well. Not one of them but is anxious for the feeding hour to come, and as it approaches, are all agog for their rations. Jane works as kindly as when you saw her. Once she appeared a little fidgetty, when I turned her round, going the reverse way of the track, and she became as sedate as I wanted. Should she cantinue as docile when sweating, I do not think we will have any further trouble with her.

PreCEPTOR.-A very good report, only that you should not have speeded Delle every day. Twice a week, threetimes at the outside, is enough for a horse to go at speed, and then the distance should be short. The instructions I gave you about driving the colts were not meant to embrace her; as her rate of going, when at her best speed, is fast enough to work injury if driven every day.

PuPIL.-In saying that I drove her fast every day up and down the stretches, I did not mean that I sent her at her best rate, and only when she wore the rattles did I suffer her to approach it.

Preceptor.-That is better. When the rattles are on, it 
is necessary to let the horse slide along, so as to induce the bending of the knee, which will enable him to go fast, and thus, by associating the necessarily higher action required by speed, and that of the rattles together, the benefit is permanent. I have known a horse's knee action improved by being driven in deep sand, but there are few horses that would not be endangered in other respects, which would not be compensated for by the acquirement of better action in their knees.

PupIL.-Allonging the colts in a deep, light snow, has a good effect in increasing the bending of their knees, and I am in the habit of practicing them through the winter whenever a suitable time comes. I have seen colts that did not exhibit anything of a trotting gait when running in the pasture field, but on a fall of snow take to trotting through it in a manner that could not be excelled. A neighbor of mine bred three colts, which I purchased when they were yearlings. They were by the Falcon, and their dams were half-bred. The one from the fastest trotting mare disappointed me greatly. He did not seem to have the faculty of bending his knees at all when trotting, and would shuffle along at that gait, turning his feet out; the whole motion appearing to be confined to the upper pastern joint. He was very handsome and showed a good deal of breeding. I gave him to a friend of mine, telling: him I was afraid he would prove an exception to the most of his relatives, though I still had hopes that the family charteristics only laid dormant, and would develop themselves in time. From having more colts than I could break, he was suffered to run till after he was five years old, before he had a harness put on him. The winter previous, the snow was very deep, and I had the satisfaction of seeing him trot through it with no fault apparent ii his action. When broken, I drove him on a sandy road for a while, and in less than two months he could trot 
close to three minutes; and I have no doubt that when his training is resumed, he will gain, correspondingly to the work lie gets.

Preceptor.-As I told you before, I have not looked on the allonging process with any favor. There would be an advantage attending it, however, in the case you mention; as the horse would neither have to drag nor carry weight, I have thought that the excessive bending of the knee of most of the French horses, bred in Canada, has been owing to having acquired the habit by being driven chiefly when snow was on the ground, and should that be the case, we may look for improvement in those deficient, by subjecting them to the same work, or something analogous.

PuprL.-Dinner is now ready. Walk in, and I will go up stairs after the bottle of sherry,-or would you prefer port?

Precepror.-No, a half pint of sherry is the most ] indulge in at dinner, and, though I suppose your friend means me when he says the old man, I am not old enough to prefer the heavy, heady port to the more agreeable, nutty-flavored wine. Sherry is the only alcoholic or vinous stimulant that I ever give to a horse between the heats in a race, and I always prefer to get along, if possible, without even that. When it is given, it should be some ten minutes before the start for the heat. I have seen men pour it down just as the horse was starting, which could do no good, as the energy it gives does not arise till the absorbents have time to take it into the system.

PupIL.-Do not be offended at my friend calling you the old man. The term is often used in the West as a familiar manner of addressing a person that is much thought of, and, my life on it, should you go to Chicago and introduce yourself to him, you would be treated with as much respect as if you were the President, and in place of considering you as an old man that needed nursing, 
you would require the stamina and vigor of youth to undergo the round of pleasure-seeking he would insist upon.

Preceptor.-Truly, I must commend his taste and knowledge of wine. I never drank better than this, and the aroma and peach flavor combined is above praise. This will completely spoil me from enjoying what we ordinarily get, and I am inclined to think you have happened on the very best bottle there is. From finding my taste similar to the bon vivants of my acquaintance, my award can be accepted, as in all probability, just; and while I do not want you to neglect the donor's advice in keeping the bottles always in sight, never set this before any one unless you are sure he will appreciate it. It would be a great pity that a drop should be wasted by going down the throats of those who cannot tell New Jersey cider from Johannesberger, or who fancy the odor of "NightBlooming" Cereus" is equal to the perfume of the violet. I anticipate great pleasure in meeting those of your Western friends, who prove the falsity of the idea of "out of sight, out of mind," and whose care of your comfort when away will be sure warrant of a warm welcome when we get on your old stamping ground.

PupIL.-I will say nothing more of Western character and habits, for fear I may over-estimate them, and do injury by causing you to look for perfections, that their universal kindness to me may be the means of my overcoloring. Still, I will wager everything I own against a boy's top, that, for genuine hospitality, warm friendships, and a desire to make every one who comes in their sphere happy, Western people cannot be excelled, and those who have a fondness for the horse, racers and trotters, are the very perfection of even Western manhood.

Precepror.-We ended the conversation, when I was here before, by a few remarks ou watering horses in train- 
ing. We will reconsider it previous to going to the stable. The quantity of this fluid should be as elosely scrutinized as that of the food we give, and from the very clearest holding matter in solution that is detrimental, there is danger in giving water, containing these properties, even if aware of it, and using something to correct the bad effect. Rain, river and spring water are the kinds in use for horses. The first, if it receives no admixture from the roof that collects, or the receptacle that receives it, is pure. This fact has led many to believe that it is superior to others for horses in training. Without absolutely denying that to be the case, I am led to believe that "harder" water may be equally as good, and perhaps better in some instances. When we find the osseous framework of the horse is composed of material which water sometimes holds in solution, and which the animal has to obtain from the food it gets, may not the structure be easier built, or wants repaired, by a proportion of the necessary material being contained in the drink?

I have seen horses in like good condition when trained either on soft or hard water, and more danger arises in a sudden change from the kind accustomed to, if even the change is to that of a better quality, the system having adapted itself to the kind in use. This is so well known that we frequently see a supply of water taken with a horse, when the conveyance has been a good deal of expense and trouble; and this is often used as a very strong argument in favor of rain water. If cisterns were built by the various tracks, the drink would be identical, and the danger of a change done away with. I have found in my practice that, when circumstances compelled me to a change, all danger was obviated by adding a handful of linseed meal, gradually decreasing it as the use of the new kind was continued. I can hardly give satisfactory reasons why this result should be, only that the mucilage 
defends the stomach from the corrosion of foreign matter, and thus neutralizes its effects. Water is benefited by being exposed to the sun and air, and when using from close wells or covered cisterns, I alway allow it to stand long enough to change, and approach nearer the temperature of the atmosphere. The temperature of the water is also of importance, and while attimes that of the blood is the proper heat, there are others when it will not do to be the least tepid, but must be regulated to what will benefit the horse to drink. The acidulating of water by the use of the best tartaric acid, I have found beneficial, as in the case of sweating to guard against fever; and some horses acquiring a fondness for the taste of it, will drink when they otherwise would not touch a drop. This is an advantage in the case of light feeders, as they are generally horses that drink but very little, and if we can coax them to imbibe more fluid, their appetite will be increased in a proportinate ratio, and better condition result.

The amount that each horse can be restricted to can only be told by careful experiment, and the mean between an inordinate drinker, and one whose thirst seems easily satisfied, would be a proper mark to guide us. I have ound in both cases that frequent watering is the best plan. With those that would drink too much, I only put into the bucket the amount they are to have, and not being allowed to distend themselves, they soon become accustomed to the restriction. The others will, perhaps, not drink at all, unless the bucket is full, and some will not touch it unless it is set down, and they can take it unobserved. The same caution must be practiced not to have too much water in a horse's stomach before his fast work is given, as not to fill it with grain and hay. A pailful of water, given a little while before a race, will effectually stop a horse from winning, if his competitors are anywhere near him in speed. This shows that exertion is impeded, and the 
race may not only be lost, but serious injury arise from pushing the animal to do, or try to do, more than he can.

I have spoken of the plan of giving horses water after their work, by small quantities at a time, while they are walking. In signifying my custom of following another plan, I do not decry this entirely, but would follow it under certain circumstances, as when delicate horses would drink better than if we waited till the expiration of the walk. Horses may be very much fatigued after a hard race, and require something to support them while they are taking their walk, which should always be given till the tumult in the blood wholly, or at least partially, subsides. A few swallows of water are very refreshing, but not so good as the same quantity of oatmeal gruel; or, should a horse be washy, I would use wheat flour, which affords nourishment as well as refreshment. We often see a great deal of fuss made sponging and washing a horse's mouth and nostrils after the scoring has commenced. Some grooms pride themselves on the dexterity with which they handle the sponge and bucket, and many a greenhorn watches the process with a good deal of awe, considering it has much to do with the horse's going fast. On a very hot day, and when the track is dusty, it is essential to keep the mouth from parching, and to remove the dust from the nostrils. When these are accomplished, further swashings are unnecessary; and what is needless is wrong.

We will go to the stable, and as you are getting along so well, I think it may be two weeks before I am here again. The difference you should observe in sweating the Falcon to-morrow from what we practiced with Never Mind, is, that you can give him two miles more work, and you need not leep up the flow as long as we did with the other. The pace may be a little faster and the clothing the same. Jane can be treated the same, using every precaution to preserve the tranquillity of her temper. The 
second day after sweating, you can brush the two horses, Never Mind nearly the length of the stretch, and the Falcon two brushes of a couple of hundred yards each, driving a half mile at a good round pace between them. Should Jane be willing to go quietly at three-quarters speed, you can let her go half a mile at that gait, and if you permit her to biush at all, stop her the moment she appears exci ted. The morning before you give the sweats, you can open them according to the former directions I gave. With all these instructions from me, there will be a great proportion of the work, of which you will have to be the judge when you are giving it. But for the ensuing two weeks, more danger will arise from giving too much fast work than not enough. The slow work can also be overdone as well as the other, and you must examine strictly to see that there is no swelling or heat in any of the joints, or any puffiness above the pasterns or in the hocks. Your horses ought to go to their work in a cheerful spirit, and should one appear dull, shorten his work till you find the amount he will undergo without depression. In all of the fast work you give, it will be preferable that they do not go at their very topmost rate, as I would rather they did not break until they were in condition to stand going quite a distance. Giving horses lessons that will accustom them to make good breaks, is often very tiring and trying to the temper of biped and quadruped, and if the horses are in order to take the work without the injury these will entail, much will be gained.

I judge by the time I have fixed to visit you again, the horses will bear quite an increase of work, and you can be gradually preparing them for that event, by giving them what you deem necessary, and by enlarging the feed of those that you think will require it. In making additions to the feed, add to the ten o'clock and to the last in the 
evening. The feeds occuring before the work, cannot be materially enlarged, without causing over-fullness in the stomach just when required to go fast. Clipper should be ready for his first sweat by the time I come back, and you need make no change in his preparation from that of Never Mind, with this variation, of not giving quite so much walk, which his legs would not stand without injury. I have mentioned that I would prefer them not to break for a time yet, and the only way you can keep them from doing that, is to leave quite a margin between the pace you go and their best rate. Horses will break when not near up to their fastest gait. Yet you will find them easier controlled, than when hurried off their legs by endeavoring to have them trot faster than they can. I have known many horses that would "jump up" when going moderately fast, that were honest as could be when going at full speed. The great part of the education of trotters is to teach them to go without breaking, and when they do break, to be able to recover therefrom without the loss of much ground. These lessons however, must be given as much as is possible when the body is in condition to endure extra fatigue; and, necessary as they are, we shall gain by waiting until we can give them safely. These remarks will only apply to the old horses. With.the colts, now is the time to teach them a good system of breaking. The first lessons are of great importance, and if you succeed in making good breakers of them now, it will take very bad handing hereafter to spoil them in this respect.

Every morning before you commence work, examine critically the condition of the horses' feet. Observe if they stand squarely on them in the stable, and see that there are no loose shoes, clinches raised, or breaking of the horn. The replacing of a broken nail may save a shoe coming off, and, perhaps, tearing part of the foot with 
it. Notice the boys when they are cleaning out the dirt from the sole, frog, and under the shoe. The less they use the foot hook, the better, depending on the water and brush to clean out the fissures between the bar and the frog, and the clefts between the bulbs of it. Tearing away at the foot with the picker interferes with the healthy state of the sole, which I find is better by leaving is as much undisturbed as we can, and the ragged portions of the frog, which the boys are so anxious to ppll off, cannot be removed without bringing with them parts that ought to remain.

PUPIL.-How would you arrive at the correct knowledge of the quantity of water a horse ought to have, in one that was inclined to drink too much, and had to be restricted?

Preceptor.-By gradually decreasing the amount; and as long as he looked and fed well, there could be no injury. But if the restriction produced a decline of appetite, it would show that the system required more fluid than he was getting, and the quantity would have to be increased. Habit has.a great deal to do with this, as in everything else, and the force of custom alone may lead a horse to drink more than he needs. When the plan is followed of allowing horses to drink from a trough in a yard, or a running stream or pond, the amount of water can be only guessed at, and is a way of proceding that I do not favor. When adopted, the capacity of swallowing ought to be found out by observing the number of swallows a horse takes in drinking a certain quantity of water, so that we can tell about what he has taken when thus watered. There is a great difference in the swallowing capacity among horses. Some of them will empty a three-gallon bucket in forty swallows, while others will require seventy or eighty "go downs" for the same amount. As in the case of ring watering, I would only allow a horse to drink from a 
trough, stream, or pond, when he could not be induced to drink as well from the pail. This remark, of course only applies to those who do not drink water enough, and require to be humored to induce them to take it.

I will now take my depature, having full confidence that on my return I will find your horses looking and doing well, should no accident happen to interfere with your management. 


\section{CHAPTER XXVI.}

CUTTING THE QUARTERS-APPEARANCE OF HORSES WHEN IN CONDITION-THE MODEL FORM FOR A HORSE-THE BRAIN THE GREAT RESERVOIR OF POWER.

Preceptor.-Why! what is the matter? You have as rueful a look as the Knight of the Sorrowful Coun. tenance.

PUPIL. - I have met with the first bad luck I have had this season. Never Mind has cut his quarter badly.

Preceptor.-It would have been a great deal worse it he had struck his knee. It is rather a bad wound, and I am surprised he could do it with the shoes he is wearing. Get some strong linen or cotton cloth, and tear it into strips, a couple of inches wide. Hand me that bottle of fir-balsam, and we will see if we cannot repair the damage. Wash the wound out clean with tepid water. Now we will draw it close together, and, after applying the bandages for two or three thicknesses, cover them with the balsam, again wrapping them over the coronet until we get several folds, which will completely exclude the air and moisture. The flesh of a horse, in the condition that Never Mind now is, will heal very readily, and I should not be surprised if this heals by the first intention, as the doctors term it. I have had worse cuts than this get well more rapidly than I would have thought possible, by treating them after this simple method. An impervious coating is formed that protects the cut from dust and dirt; and nine times in ten, if applied as soon as the injury is done, it 
will not suppurate, and the horse's work go on the same as if he had not been liurt. You will have to watch that suppuration does not take place, as, in that case, there will have to be an outlet for the matter. You will detect it from increased heat in the foot, and the horse exhibiting pain when you touch it. If this does not occur, the bandage must not be disturbed, until time enough has elapsed for the cure to take place. How did it occur? I was in hopes to have got home before you had driven him, as I wanted to see how he was going; though, from having been away longer than I intended, I presume you thought I had forsaken you entirely.

PupiL.-I have missed you very much, though I have had extraordinary good fortune till this accident took place. I was repeating a brush I had given him of a quarter of a mile, or such matter. In the first, he came down the stretch very fast, when I let him go a threeminute gait till he came to the three-quarter pole again, and on clucking to him, he burst off at a tremendous pace -I am confident it was fast enough to trot in twenty or better-when he made a wild break. I snatched him rather short, and the consequence was that cut.

Preceptor.-Pick up his off hind foot; the shoe must have got out of shape to inflict so much damage, as I never saw the shoe he is wearing do more than bruise the quarter. How is this? What are those large-headed nails in for?

PupIL.-The shoe got a little loose, and in place of sending him to the shop, I pulled out the nails, one at a time, and replaced them by driving these in the same holes. I thought, as all his shoes would need replacing in a few days, I would make it do till he was shod all around.

Preceptor.-I hope this will be a lesson to you, that, if you contemplate shoeing your horses, you will first learn to be a blacksmith, and then provide yourself with proper 
tools. It is great fortune that the injury has not been more serious than it is. I would have imagined that, when you saw these nails sticking out like the callins of a cart horse, you would have taken the rasp and filed them off.

PupIL.-The rasp had become worn, so that the job would have been very tedious. But I will engage that this lesson will be remembered, and if I ever drive a nail in a horse's foot again, I will observe due caution that the head does not arise above the fuller in the shoe. I am very glad that your visit came so apropos, as the balsam dressing is new to me, and I should have bound it up with a solution of copperas and whiskey.

Preceptor.-That is a capital application for ordinary flesh wounds in a horse, and I am not acquainted with anything better, though for a recent injury to the coronet, we want something that will support, and keep the parts in adhesion. You must have commenced early this morning if you are done driving all, except the colts, at this time of the day. I do not approve of taking horses out too early, and would much rather that the sun should be up long enough to dissipate the vapors that collect during the night.

PuPI.-For the last week the weather has been so warm that I have begun earlier than we formerly practiced, so as to have the older horses done up before the heat of the day. I have driven the Falcon first, and I think he enjoys the early breath of the morning, and will welcome the sun as it makes its first appearance over the hills, by signs of delight as unmistakable as though he had the power of expressing his thoughts in words. However, I will defer taking him out in future till the sun's rays fall more askant. Should you be inclined to listen, I will recount what I have done for the three weeks you have been gone. 
Preceptor. - I will hear your story shortly. In the meantime I want to pay a visit to the Falcon, and tender him my regards. I will stay with you until after the horses are all worked to-morrow, when I can give a better idea of how they have done, than by looking at them in the stalls. This noble fellow is certainly looking as well as he could. There is an elastic, firm feeling, when you put your hand on him, that shows his condition is more forward than the length of time he has been in training would lead one to expect. His skin is as pliant as the best chamois leather, and the bloom on his coat betokens that his health is prime. It would take very close examination to detect that he is not in the best condition, as to the hand the muscles appear well seasoned, and he has not more flesh than I think he,ought to carry. The crest is a little thick yet, and the muscles are hardly as distinct as they will be after a few more sweats, given with fast work. These will fine away the material, now partially hiding them, when he will show a covering that will emulate spring steel in its density, and quickness of recoil when the contraction takes place.

It is extremely difficult to determine, from the appearance of a horse, what his condition is. It is true that horses in condition have a similarity of appearance, though condition may seem to be there, without the corresponding capacity to perform. The trainer, who knows the amount of work the horse has received, is the best judge, and even his calculations are oftentimes erroneous, as the result of many a race has proven. One thing he should be "better posted" on than any one else is, the amount of flesh the horse ought to carry, and he must not allow his judgment to be changed by the criticism of any one, no matter how able he may be, if he is not thoroughly conversant with the character of the horse before him.

When horses are in condition, they should, in a great 
majority of cases, have a blooming coat, every hair in its right place, glossy and shining like the feathers on a pigeon's neck. The muscles should be prominent, and, being handled, feel hard and springy. The skin should be loose, so that you can pull it away from the flesh for quite a distance, but, when released from the grasp, fly back like a piece of rubber. The interstices between the muscles should show distinctly, which gives that cordy appearance, like a cable made of wire. The legs should be free from swelling, cool, and the tendons hard, with a sharp outline. The joints should be divested of everything but bone and tendon, the skin on them loose, but firm. The neck is a great guide in determining condition, and though the large muscles running from the shoulder to the poll have nothing to do with progression, the state they are in will be a guide to aid us in arriving at the condition of the other parts. The windpipe should be detached, with nothing to hide the view of it, to where it enters the chest. Near the joining of the head it ought to hang loose, showing three-quarters of its circumference. The muscles of the neck should be clearly defined, and the upper one that forms the crest, should rise to a sharp edge, and be as hard as a cut nail. This sharpness arises from the absorption of the fatty matter that lies immediately below the mane.

The great index, however, is the eye, and though the horse may have all the appearance of condition that I have imperfectly noted, if the eye be dull, or give fitful flashes of animation in the excitement of coming on to the track, he will surely not be able to do what he ought to. It is very hard to describe the appearance of the eye of a horse when in prime condition, as the natural expression varies as much as those of the human family, and we will have to be well acquainted with each individual, to avail ourselves of this as a criterion. I never saw a horse that the 
brilliancy of the eye was not heightened by proper training. It may not show as much briskness, as there is a placid look acquired which might deceive you at the first glance; but as you look again, there is no glassy, unmeaning stare, and you look down into the clear depths till you cannot but resolve that such an organ must belong to more than an animal, and that it is a token of a being endowed with that reason, which we haughtily arrogate as only belonging to man. When the horse is led up to start in a race, this placid look is changed to one as deter. mined as ever flashed from beneath the brow of ancient knight, attempting deeds that would either heighten his renown to that of the great Arthur himself, or consign him to an honorable grave. A fuming, fretty horse, that rears, pitches, and refuses to come to the score when the time to start has been signaled, has rarely the look I have atattempted to describe. $\mathrm{He}$ is either frightened at the remembrance of unmerited punishment, or is so sore from over or injudicious work, that he does not like to start. I have interrupted the recital of your three-weeks' work longer than I meant, and was led into the remarks I have been making, from the appearance of the Falcon, showing, as he does, better order than the length of time he has been in training would warrant.

PupiL.-The day after you left, I gave him the sweat he was prepared for. I drove him the next day the usual distance, as I knew from former experience that no debility would follow in his case. The following day I drove him the same distance, allowing him to brush down the stretch, and he came rattling along without attempting to break. I varied his work as you directed, driving him on the road two or three times a week. I generally drove him five miles out, coming back at a good round pace. The track work has been faster and shorter than you intended, as, from the anxiety he manifested to get along, he 
would go more quietly at a three-minute clip than when driven slower. I have sweated him every week, and increased his feed to tweve quarts of the mixed hominy and oats. The last week I have made his brushes longer, and. he has given me very little trouble breaking, always recovering the trot of his own accord. In his sweats, I have used less clothing, and driven him faster than any of the others. I confined the wrappings in the last one from the loins forward, as I thought his quarters did not need further reduction.

Preceptor.-That his work has been proper his looks testify, and I find that I was right in predicting that he would be got into condition very easily. His form and everything pertaining to his "male-up" are so favorable for speed, that whatever is detrimental is easy of removal. You were right in not covering his loins and quarters, and I am of the opinion that hereafter his neck and belly will only need clothing, the other portions of his body getting into order without the aid of clothes.

PupIL.-Never Mind I have also sweated three times since you were here, and I have been increasing his work, not so much as the Falcon, yet, I am afraid, a little more than was advisable. I have walked him the day after each sweat, and on the following day allowed him to brush from three to five hundred yards, occasionally repeating it. The morning before sweating, I have also "moved him," and in the last week I permitted him to go a forty gait once round the track. He was getting a little nervous and flighty, and I thought an increase of work might sober him without being otherwise prejudicial.

Preceptor.-Being convinced of an error is the surest sign of amendment. His nervousness and flighty demeanor were, no doubt, occasioned by the exercise being more than was proper, and you fell into the very common mistake of attributing it to want of work. He had become 
somewhat sore in the muscles, and though his high temper induced him to burst off when the reins were loosened, the trot was painful to him, which he sought to relieve by breaking into a gait that would exercise the muscles in a different direction, and thus afford him relief. When he broke, you should have given him his head for a short distance, talking soothingly to quiet him, when he might have taken to trotting again himself; or, if he did not, if you had pulled him directly back, in place of snatching him to one side, he in all likelihood would never have touched his quarter. You have not reduced him more than he ought to have shrunk, in the length of time that has elapsed since his first sweat. For the present, we will confine his fast work to once a week, and, by jogging him further, accomplish the necessary exercise, and allow the soreness to subside. We will have the outside of the track harrowed till it is quite deep, and you can give him all the work on that part, making his brushes correspondingly shorter. How about Jane? I am anxious to hear of her doings. She certainly looks well, and from the further diminution of the enlargement on her knee, I would judge she does not brush it any more.

PupiL.-Jane has performed admirably. I have also been working her as much as I dare. She has gone through the same number of sweats as the Falcon, and has never become irritated in the least. I have not " taken her by the head" for as speedy a brush as the others have had, though I have let her stride along at a good round gait. I had proposed to drive her as fast as I could tomorrow, and, if you think it is best, will do so. You can then judge better how she ought to be handled hereafter.

Preceptor. - It will be proper, as she is in condition to undergo it; and as we can never win races without going fast, it is time that all of those which we intend to employ in trotting races should give us a taste of their quality. 
There is nothing like an actual race in training trotters. Exercise, as we give it daily, is a necessary probationary stage; but the teachings of one race are oftentimes worth more than a month's training, and the condition benefited in the same proportion. It will not be long, now, before we will put them to this practical test; and as the trotting-meeting advertised will take place in a month, we must have some of them ready to win, if they can. Now for your report of this grey fellow, who is looking rather coarse compared with the rest.

PupIL.-His work has, so far, been slow only. I have been softening him for a sweat, which I intended to give in a day or two. His legs, you see, are still improving, and none of the colts feel better than he does now. I have jogged him from four to six miles a day, and he has only walked half the time the others did. He appears to wonder that he is never called on to go fast when on the track, and, at first, would become excited whenever he was turned around on it. I think he is beginning to have a more favorable opinion of the graded oval, and the kind treatment proves a specific for him, as well as for Jane.

Preceptor.-With the great amount of speed I have heard he possesses, it well be worth all our care to induce him to forget his former ill usage. A gentleman, who knew him when a colt, informs me that he was superior to Jno. Morgan in that point, which is recommendation enough to those who knew the chestnut in his palmy days. $\mathrm{He}$ is progressing as favorably as we can look for, though I still fear the effects of fast work on his legs, and I am inclined to think the firing iron and a winter's run will be necessary, before we can depend on their standing. The young ones I will see you drive after dinner. I must own that another moiety of your friend's sherry will be very acceptable, and you must be aware 
that my business has been very urgent, when all the attractions you have here could not be attended to till now.

PupiL.-Won't you try a modicum of brandy, as an appetizer before dinner? or, here is some bitters that I will warrant superior to "old plantation," with all the cabalistic signs ever painted on an astrologer's tresselboard, to assist it to attract attention.

Precepror.-No: I thank you for the offer; but it is very rare that I drink anything before meals, and nearly as seldom that I drink at all before dinner. When you see me eat, you will admit that I do not need a provocative ; and repletion is not only injurious to the health, but the flavor of the sherry, and the aroma of the segar, cannot be so highly enjoyed when the stomach is loaded.

I have not eaten a meal that pleased me so well as this we have just partaken, since I have been away; and, though some have been eaten at the headquarters of gastronomical science, I must award the palm to this. By the way, the port and sherry that I took from your supply was pronounced of the first quality by those who are accredited with being the best judges in the country. I was anxious to learn, if I had formed a proper estimate, as I thought it superior to any I had ever drank. Now, if you will "be shoving" one of those Principes to me I will freely forgive your friend for denominating me "the old man," sincerely hoping that he may live till he is old-but not old enough to find life a burden.

PupiL.-Never fear-as he would say-potheen will always have the flavor, and he will feel young as long as he has a friend to benefit. You promised to tell me at some future time, why you considered the form of the Falcon a model of the best for road purposes; and if not too much trouble, I would like to hear the reasons now.

Preceptor.-I will be pleased to acquaint you; and though there have been things that I could not satisfac- 
torily account for, as the effects of different kinds of food, \&c., the advantages of a certain form can be proved on mechanical principles. Considering the bony framework of the horse as a machine, that is set in motion by the action of the muscles, it is very important that their force should be applied in a manner that will effect a certain result with the least expenditure of power. The loin, quarters, and hind legs are the seat of the propelling force. While I have no faith in reducing the form of the horse to a mathematical problem, calculating by a series of angles the extent of stride a certain configuration will give, there is still an adaptability of the parts found in a great majority of good horses. The exceptions only prove the necessity of a form approximating the model; for though we find some points of a good performer not in accordance with this principle, we will discover a counteracting force that overcomes the obstacle. Because English Eclipse had a short, thick shoulder, we must not flatter ourselves that, as our favorite has the same defect, it is not an injury. The powerful quarters that overcame this serious defect in the Eclipse are rarely found; and though the English champion had strength enough in these to overbalance the resistance of the heavy shoulder, it would retard a horse of ordinary power, till he would be useless as a racer.

The hind legs are joined to the body by the upper part of the femur being articulated with the pelvis, the joint forming the connection. The length of that part of the pelvis, which is termed the ileum, constitutes what we call length of hip. In the Falcon, this is of more than ordinary length, which is an advantage in giving more room for the attachment of the muscles that exert their force from this region. A level hip is generally looked upon with the most favor, as the form which will give greater power to the muscles joined to the femur; but I 
am inclined to think that a slight declivity is better, by lengthening the limb this much, and thereby giving a greater reach in the stride. Too much obliquity is a deformity that loses this advantage, by the femur forming too obtuse an angle with the ileum, and, consequently, a waste of the force applied. The length of the femur, or the bone that reaches from the upper joint to the stifle, is also of importance, not only giving better attachment for the muscles, but placing the stifle where it will not be impeded in its motions by the abdomen. The next bone - the tibia-extending from the stifle to the hock, forms just the right angle in the Falcon to please me. It is oblique enough to place the hock at the proper position with the body. When he stands in a natural manner, a line dropped from the point of the buttock will fall a trifle in front of the point of the hock. This increases his stride, without diminishing the force that the muscles exert.

His hock is superb, being both wide and deep. This joint has probably as much to do with fast motion as any other in the frame. From its being the seat of lameness, in nine cases in ten, of the hind extremities, we will rightly infer that any weakness in its construction is soon manifest. By being large, the tendons form strong attachments, guarding against strains, and by the posterior bony process - the os calcos-being long, the tendon, which we call the hamstring, has the advantage of working on a longer lever, doing the business easier, and propelling it further in advance than it could, if this were shortened. The length of this bone also gives the wide gaskin, universally recognized as a mark of speed. Looking at the cannon bone from behind, you would think it was too Iong; but as you step into a position to take a side view, you find it to be very short, and the term "well let down in the hocks" can be applied to Falcon with truth. Long from the point of the hock to the pastern, measuring 
down the tendon, and short from the joint, when following the metatarsal bone, is the true configuration; and I never saw a horse that excelled him in this particular. The pasterns I like to be of good length, in order that there may be elasticity enough to give freedom to the joints in the foot, adding a little to the ground covered by the hind legs; and as every inch gained in the stride is an object to be looked after, this form of the pastern is the proper one. The quality of the muscular covering to the bones we cannot arrive at, though I am inclined to think there is not the difference in them in horses of greater or less speed, as in the manner in which they act, which is determined by the position of the bones. Thus their greater force of action, which enables an animal to stride from two to five feet further with the same outlay of power, is due to their being placed in a position where their contractions and expansions exert a greater force. These wiry, tendinous masses that are so apparent in the Falcon, may exist in an inferior animal; but, owing to their being placed in a wrong position, or encumbered by matter that is a hindance to their motion, they cannot act with the same effect.

The broad, arched loin is a mark of strength; and while a horse that is slack there may have a great deal of speed, it is seldom coupled with endurance. There is considerable motion at this point, owing to the flexibility of the backbone; and I always like to see this flexibility apparent. I do not mean the scringing motion a horse makes, on pinching him, indicating soreness, but a kind of swaying: movement in the walk, which most race horses display. As you stand squarely behind the Falcon, the muscles are developed in harmony with each other. Those on the upper thigh and gaskin are proportioned right, while the inner ones have the same equilibrium. They are long, not covering the tendons, as it were, but merged 
into them by degrees. In taking this rear view, we see the ribs forming a curve, which is not hidden by the quarters, showing that he is good in the carcase or middle piece. This gives room for the internal viscera that are situated back of the diaphragin ; also giving that important muscle room to assist in respiration. His body is that of an elliptical truncated cone, the base at the point I have just mentioned, and the apex where the neck is joined to it. This conformation gives him great depth through the heart, and is much better than if more cylindrical, as the expansion of the chest is greater than if circular. If the chest were a circle, there could be no expansion, while with this form the dilatation is sometimes so great as to burst the girth that confines the saddle. The high and broad shoulder-blade drops back towards the sway, till the distance between it and the anterior part of the pelvis is very short, in comparison to his whole length. This gives the proper angle with the upper arm, permitting the legs to be thrown forward much more than they could be if it were short and upright.

The elbow-joint is parallel with the body. In our former conversation I dwelt at some length on the necessity for this joint being thus truly placed, any divergence interfering with the action. The sloping shoulder not only gives greater stride, but the concussion is less, which is also important. When the weight of a horse's body is propelled with the rapidity which the well-formed quarters and hind legs give, there must be some contrivance to lessen the jar. Thus we see the hind legs are joined to the frame, and tied to it by powerful muscles and sinews, but the fore legs receiving at least three-quarters of the weight, could not be so attached without danger of knocking the machine to pieces. Elastic cushions are placed between the shoulder-blades and the body, and the spring formed by the angular position the humerus and scapula assume 
further guards it. Length in the fore arm is as essential, or more so, than in the corresponding bone in the hind leg. It gives greater leverage, and enables the animal to cover more ground in the stride. The large broad knee is nearly indispensable to a fast horse, by giving more room for a proper fastening of the tendons.

Many hold that a small knee is the proper formation. Eramine Kentucky, Norfolk, or Asteroid, and I will warrant all three of them have broad, lathy knees. The bone that projects from the back part of the knee should be large and prominent. The back muscle is attached to this by the tendon, and of course is more firmly bound to it than if it were smaller. I have heard horses, with the trapezium very prominent, called "cut away below the knee," when their legs could not have been bettered. The knee has a very important duty to peform in a trotter, and unless a horse has the proper action in it, or acquires it, he will never be likely to go fast. I have also heard people ind fault with a broad knee in a harness horse, arguing that he would be more likely to strike it than if smaller. Che position of the limb has more to do with this than the size of the joints, and where the legs are straight, alling from the body as truly as those of the Falcon, it will take very bad handling to endanger them. A short cannon is the usual accompaniment of a long fore arm. The ligaments and tendons that convey the motion from the muscles have an important duty to perform. They should be large, giving the leg the flat appearance so desirable, and no inequalities should be perceivable to the eye, or be felt as the hand is passed down them. Their size renders them less liable to strains, or rupture of the delicate membrane that covers them, and a round, fairsized pastern-joint gives them a better fastening. The long, springy pastern is of fully as much advantage in the fore leg; as in the hind, giving, as I said before, more free- 
dom of motion to the lower pastern and navicular joints, and acting as an additional spring, to preserve those delicate articulations from injury by concussion. The round, medium-sized foot, with proper strength of horn, we have discussed before. While the neck has nothing to do with progression, a proper form is requisite; this we also noticed in our conversation on sweating.

The great reservoir of power is the brain, and, confident as I am that it has more to do with making the successful trotter or race horse the superior of his compeers, than either osseous or muscular formation, yet, as it is not in as tangible a form, I speak of it with delicacy, the fact being incapable of demonstration, and only to be ascertained by inference. For instance, we have seen horses of perfect frame, whose bodies were a type of ninety in a hundred that have shown themselves possessed of speed and endurance, their condition perfect, and brought to the post by those who could manage them in the best manner, yet not worth, as racers, the last feed of oats they eat. Again, we have known instances of the utter prostration of strength from the fumes of a substance that could not possibly injury the stomach, but which acted at once on the brain and nerves. I am acquainted with a man who travels over the country every spring castrating colts. $\mathrm{He}$ never "throws them," merely putting a twitch on their nose, on which he has rubbed something, which he also causes them to smell. They never move while he is performing this painful operation. I ascribed it to the twitch, and laughed at him for deluding people with the idea that the smelling had any infuence. A veterinary surgeon, a graduate of the Royal College, was of the same opinion, and attempted the operation with only the aid of the twitch. At the first stroke of the knife the colt kicked him over, and became perfectly unmanageable. A few snuffs from the bottle, and he stood without moving a muscle 
nutil the job was ended, and the clamps put on. Walking off like a man in a dream, I took the vial, and though cautioned by the man not to smell it, I was anxious to see if I could detect any of the ingredients. A terrible headache was the result. It was generally remarked that the horses he had operated on never had as much spirit afterwards as those treated after the common method.

If motion can be paralyzed thus quickly by something acting on the brain, why should there not be a difference in power transferred thence to the muscles? We will to move our arm, and the motion is performed without our being able to know how it has been done. At times we are aware of having more pewer than at others, and cannot account for it, unless by crediting the brain with augmenting the muscular force. I am so confident that this is the great source of motive force, that I always anxiously look for the signs that make it manifest to the eye. I do not mean to be understood that this lessens the necessity for proper conformation, but that it must be united with it to form the truly valuable animal. How will you determine it from the appearance? is a very pertinent question; and I am afraid I will not be able to answer it as satisfactorily as I could wish. To deduce, from Cranios copy, the peculiarities and qualifications of mankind, has been the pursuit of some of the most gifted of the human family. They have divided and mapped the skull, locating to a specific point what they considered the fountainhead of feeling, taste, and adaptability for certain pursuits. They base this knowledge upon the examination of the heads of men who have been celebrated or notorious for the possession of qualities that made them eminent, and, from prominences found more marked than the generality of the family, argue that this portion of the brain gave such a preponderance.

I have in this spirit studied the head of the horse, and 
without believing a great deal in the science of bumps, am satisfied that close observation will detect this nerve force from the shape of the head, and the expression of the eye and ear. The brain must be large; and, to contain this large brain, the head enveloping it must be large in the cerebral region. A simply large head may not have a great capacity for the brain, on account of the size being lower than where it is situated. Now Lexington has a large head, but its volume is much the greatest at the seat of the brain. I saw him led out of the door of a railway car, and as he protuded his muzzle, he had the appearance of a striped squirrel with his pouches full of nuts; wide between and above the eyes, with a corresponding width at the upper part of the lower jaw, and tapering thence both ways, toward the muzzle, by being scooped out, as if cut with a chisel, and from the jowl and toward the poll, by a gradual drawing in of the lines of curvature, till reaching the ears, which are set not too far apart. The expression of the eye is, if anything, a surer test; but to describe the peculiarity that betokens a resolute will, is a hard task. A person will acquire the power of seeing it, by frequently examining this organ in horses that he knows are distinguished for unconquerable game. No one, who expects to become a judge of the "good points" of a horse, should neglect any opportunity of perfecting himself in the power to detect the different dispositions from the glance of the eye. The shades of expression are so varied, that, if even I could make myself intelligible, it would take more time than we can now spare.

A proper form is usually accompanied with proper action. There are exceptions, however, perhaps arising from local causes, modifying the gait, that should be as unexceptional as the form. From the feet not being looked after when the animal was growing, there may have been a slight bias which cannot be seen, yet still affects the 
action, or the foot has had an irregular bearing from the horn wearing unequally, until the colt has acquired a habit which the correction of the primary cause does not remove. The natural action, which is susceptible of a far greater change by education than many would think, is nevertheless of the utmost importance. There should be energy in all of the paces, especially the trot. I prefer the action that is termed "round" to the very high, the last better than the dwelling stride that often characterizes the horse that covers a good deal of ground at every step. In an untrained horse, more depends on the action of the hind legs than the front ones. Should the hocks be carried the right distance apart, and the hind foot thrown far in advance of where the fore left its impress, I will undertake to leave the supporters to be rolled out of the way, and ultimately make a trotter of the animal that is thus gaited.

This conversation could be carried to an unreasonable length, expatiating on the best form for a roadster, one that is fitted from his configuration to draw a reasonable load fast; and I have very slightly touched where much could be said. It may be enough to set the ball in motion in your thoughts, and by comparing the form of the best animals that come under your observation, you will gain more knowledge than I could impart in a week's talk. I must warn you of the danger of thinking yourself an adept in selecting a winner from appearance alone, as the best judge of form and condition that ever placed his eye on the outline of a racer, is often at fault, and you might find yourself in the condition of the mechanical genius who was going to discover the Derby winner by mathematical principles, which would be an infallible guide. His money ran out supporting those he considered of the best form, before he became satisfied of the falacy of his test. The levers and pulleys were all right, but he had no rule 
whereby to determine the head of steam that was to set them in motion.

PuPIL.-I would like to hear your ideas of long and short horses, which has often puzzled me. While the almost universal idea is, that a horse "as long as a rail" is in the best form, I cannot coincide in that view, which is perhaps owing to my limited experience.

Preceptor.-We have hadtwo striking illustrations, that either form is compatible with a very high rate of speed, Flying Childers and English Eclipse. To have length of stride, a horse must have length of body or of hind leg. When length of body results from a wide, sloping shoulder, a long hip and full quarters, with the middle piece well made and strong, I would have no objections to a horse that is "very lengthy." Should it arise from a long back and slack loin, he might do to run a short distance, but would never go far, drag or carry much weight. I am better pleased with a medium length, and when a horse measures as much from the point of the shoulder to the point of buttock, as he does from the ground to the top of his withers, I am satisfied. Should he be one-tenth longer than he is high, with the requisites $I$ have heretofore spoken of, he would still do. These would form the extremes in my judgment, and I would not like a horse to fall on either side of these measurements. It is now time for you to drive the colts. I am anxious to see how they are getting along, as I have been much pleased with their performances heretofore.

PupIL.-I cannot find fault, as they are all improving; and I fancy that every time I ask one of them to go fast, he gratifies me by going faster than he has done before. The time has worn away till I will have to hurry them up to be done in time for the evening walk.

Preceptor.-You would be difficult to please if you were not gratified with the promising display your colts make. 
The work has evidently been suited to their capacity, as they come on to the track as gayly as a fashionable belle makes her advent into a ball-room when she is satisfied she is looking more than ordinarily well. Colts should always manifest their pleasure at the prospect of the work that is before them. Once get them so sore that every movement is made with pain, and you have done more injury than months of careful training will repair. There is not the necessity for continued long work with them as there is with older horses. Teach them to trot by giving them short brushes, and never inflicting needless punishment because they do not break as well as horses that have been trotted for years, and they will repay you by learning with more alacrity, than those that have been drilled till the buoyant feelings of youth are lost. If they trot fast enough to make it hard labor for them, they are much easier to bring into the necessary condition than horses that are matured. As I have heretofore remarked, they have not so much inside fat, and do not require to be "brought as low" as their elders.

I have often noticed a tendency to overwork those horses that are deficient in bottom-working the length into them, as the trainers say. Overwork a delicate horse, and, my word for it, he will not recuperate in a long time. Colts that are tolerably well bred do not suffer a great deal of fatigue in trotting an ordinary race: therefore the work should not be greater than is adequate to bring them into proper form. We will suppose you have a three-yearold colt that can trot fast for one of his age ; that he has been in regular work for three months, and you expect to trot him in races in a month from this time. We will also imagine that he is a hearty feeder, and predisposed to take on flesh without any curtailment of his work. This would necessiate sweating. It is evident that the policy would be wrong that would follow the same plan that is 
required by an older horse: therefore the sweats should not be so frequent or so severe. Should he show symptoms of his wind not being clear, we would have to increase the sweats, not in severity, but by giving them oftener; and as soon as we found that the respiratory organs were not impeded, it would be evident that we had gone far enough, if even he did look too lusty. We should season the flesh on him with exercise without clothing, and there would be very little danger of legweariness when the lungs performed their part of the labor aright. Should he prove deficient in endurance, there would not be any benefit derived from trying to work him enough to remedy this defect, and it would be better to wait, hoping that another year or two's growth, would make him stouter, than to rin the risk of doing permanent injury. A colt must have condition, though it is acquired with less fast work than is generally thought necessary.

The little beauty Delle is going to make a trotter as sure as you wait for her. "Time and patience" are what make the trotter of the most promising, and very few arrive at a fast gait till they have been subjected to careful, long-continued handling. Oriole is also doing well, and as she learns to bend her knees, she improves in other respects. I have not seen you drive May yet.

Pupil.-I have promoted May into the fast division, and work her with the trotters in the morning. To-morrow I think I will convince you she rightfully belongs to that class. 


\section{CHAPTER XXVII.}

DRESSING CRACKED HEELS-EXERCISING FALCON-DRIVING NEVER MIND-DRIVING JANE-THE STRIDE OF HORSESPOSITION OF FEET IN A TROT AND GALLOPSKILL IN DRIVING.

Preceptor.-The sun's rays have hung diamonds on every bush and flower, transforming the dewdrops into jewels outshining those in a queen's diadam. I have always fancied that there is a sanitive property in the morning dew, and that when a horse's feet are feverish, or the horm brittle, a walk in the "dew-bespangled" grass would be of benefit. I do not know that this distilled moisture is different from that taken from the cistern, and put in the foot tub; and perhaps the idea that it penetrates the foot more quickly is only a fanciful notion. I am not much in favor of these greasy applications called hoof ointments, and think that water is superior to all the compounds that are daubed on the horn. Neither do I believe in the many soakings that some give; the application of water sufficient to keep it clean is generally all that is needed for a healthy foot. Should a horse's heels be inclined to crack, the practice of walking him where the dew will dampen that part of the foot, is bad. For cracked heels, glycerine is the best application with which I am acquainted, and if a little of it is applied when they first begin to open, it will effect a cure, unless the evil arise from a morbid habit occasioned by bad health. Much washing of the legs is prejudicial, by inclining the heels to open, though the use 
of bandages will lessen the liability. Glycerine will incorporate with water, and when I want the bandages to remain damp as long as possible, I always mix it with the water I wet them with. I have had horses that could hardly be worked fast without cracks opening in the heels, till at times the blood would issue. Since using this, I have been successful in curing them by washing the legs with warm water, letting them absorb what moisture could be readily taken up with the sponge, applying plenty of glycerine, and placing a loose bandage from the hoof to the knee. The skin by this treatment acquires more suppleness, which renders it less likely to crack. The bandages must envelop the foot so as to exclude the air, and the folds be numerous though loose.

I see you have the harness on the Falcon, so I suppose he is the first one to be exercised; and as they are harrowing the track, it will be as well not to drive Never Mind until you can give him his work on the soft portion. The Falcon you can jog three miles the reverse way of the track. When you turn him, increase his speed to a threeminute gait, driving him as fast as you can on the back stretch, come round the turn easier, gradually increasing the rate till half way down the stretch, when you can send him along till you get by the stand. Keep up as fast a gait for the next mile as you can drive him without breaking, and this time he can come the whole length of the stretch as fast as he can go, hurrying him till he breaks ; half way round the turn take him up, turn him around, and go the reverse way of the track a three-and-a-half gait, when you can bring him to the barn.

That was very well done. Give him a swallow or two of water to rinse out his mouth, scrape him, rub out his poll, straighten his hair, throw a long blanket on him, and walk him till he is cool. You can continue to give him the same amount of work you did this morning twice a 
week. The mornings that you do not give this work, he can be driven on the road, or slowly on the track, for six or eight miles. In place of the second sweat you can work him now with the long hood on, and after the first mile has been done fast, take him out of the shafts, scrape him, walk fifteen minutes, and repeat with a twomile drive. In preparing him for this move, give him half his usual feed at night, half his water with a small lock of hay, put on the muzzle, and only give a quart of grain in the morning. In place of the mash the preceding night, feed it after he has been done up, in lieu of the grain that this feed would have consisted of. Should we trot him in a race a month from now-and I think that will be good policy, for he is recovering from his breaks admirably, and if he does not find company that is a good deal too fast for him, he will stand a good chance to win - the race will do in place of a sweat, and, as I said before, there is no such school for teaching a horse to trot in races, as races themselves. If a trainer even thinks the work of a three in five race is just what a horse needs to bring him to the mark, he would hesitate very much to give it, unless in the actual combat. How many "green horses" have we seen fail to make good the promise their private trials led one to expect! The race was new ground, and the driver found it out of his power to get them within several seconds as fast as he had often shown them before, with apparent ease. So I always like to make my horses familiar with the place that is going to be the arena where they must display their powers, and if I have a "dark" horse, that I do not want the public to get a line that will be a guide to his capabilities, I try to manage that it shall not be apparent. It is quite as well to win a race by one length as fifty, and people are generally more afraid of a horse that they have never seen go, than one which they have seen win. It is certainly proper that the 
owner of a horse should take pains that his rate is not known sooner than will be of advantage to himself. The public have a claim that must be allowed, viz.:- that a horse must win if he can. Further than this they have none; and if a trainer is foolish enough to tell Tom, Dick, and Harry of some wonderful trial his horse has made, he must not be surprised if they have forestalled him in the market, and he can only get his money on at unfavorable odds, made so by his own lack of judgment. This is not all. Should the horse be unable to come up to the private performance, and be beaten, the driver is stigmatized as a villain who has induced betting for his own profit, or has prevented the horse from winning when he could.

To have the Falcon in order for the race we contemplate putting him in, it will not be necessary, or even advantageous, to strain him up very high. He would trot to-day mile heats with ease to himself. As he increases his speed, which he will be more apt to do under medium than heavy work, he will require better condition. When giving him the move I mentioned, with the hood on, it will be well enough to time him, and five or six days before the race, we can give him a trial of a mile and repeat, which will be some guide to what he can do. After this trial we will "fog him out" by giving a very light sweat under clothes. A half-mile brush the morning after this sweat, and plenty of slow work, will be all that is necessary, in my opinion, to have him trot in proper form.

Never Mind will be benefited by keeping up the sweats. in the same manner as you have been giving them-though you must remove the clothing from his loin and quarters -of course increasing the speed as you drive him. In the meantime, you can jog him on the harrowed part of the track, and have the soil loosened whenever it becomes the least hard. We will also have to give him a trial, 
which will be on the same day as that of the Falcon. Give him the last sweat three or four days before the time of the trial, preparing both of the horses as much as you would for a race. When you speed him, observe due caution, in recovering him from a break, not to increase his tendency to get on his quarters. Give him his head, and after a jump or two, if he does not catch of his own accord, shake him a little by moving the bit through his mouth, giving one rein a slight twich, very tenderly, how. ever, "as though the reins were made of a single thread of silk," which would be broken with a rude pull. If he still runs, pull him directly back, now using a strong hand,-but let this be the last resort. We must have a horse to gallop with the horses in their work, and I know of one that will suit you exactly. I will send him up tomorrow, and, though he has had a good deal of exercise lately, it has not been sufficient to give him condition enough to stand the battering. By the time we make the trial, you can have him in good order to endure going the second mile with ease. It will be as well to have him galloped when you are driving. Instruct the boy that rides him not to lie alongside of you all the while, but vary his position-sometimes head and head, again a few lengths in advance, and part of the time a short distance in the rear.

Now for Miss Jane. As the harrowing is finished, you can jog her on the soft ground. You will be the best judge of how much slow work to give her, knowing what you have accustomed her to, and can give a shrewd guess how she will behave before you start her at speed.

PupIL. - You must not get weary waiting, as I will jog her very slowly for a time. Con is coming out with water sponge, clothes, \&c. I thought it best to put her before the wagon for this her first effort at a real fast gait. I want you to time her down the back side, as I am going 
to drive her there as fast as I can; I will signify my intention of the time I intend to drive when I come by you.

Preceptor.-I would advise you to keep her a little within her rate, unless you find that she is working very kindly, when you can venture to push her as fast as you can. Should she break, handle her very gently. Bravely done! She is tremendous in her stride, and if I had not had the watch in my hand, I would have greatly uncerrated. her. She went down the stretch in thirty-eight seconds, when I did not think she was going any inside of a forty gait. While Con is walling her, we will go across and try to find the length of her stride. I have a tape line, as pacing is only a rough way of guessing, at the best.

PuprL.-I am glad she pleased you, and she certainly went better than I expected. She went very evenly, and luckily did not break until I got by the half-mile pole. ' I had been urging her for the last hundred yards, and when she did leave her feet, she lost a good deal of time, though she was not excited, and did not try to run.

Precertor.-Here are strides that are very distinetmineteen feet to a hundred-pound wagon is some stretching. Tale notice how near they are of a length, not six inches variation amongst them all; and there is another thing I like to see, the regularity in the spaces between each footprint. This is enough to convince any one thát the body of the trotter is in the air part of the time, as the eighteen-hand Magog could not be stretched a great deal over half the distance.

PupIL.-The stretching would require an India-rubber quadruped, or to be something like the harness I heard an old man tell about: he was taking the tanner to task for not making better leather, and to illustrate it, said, that he made a pair of traces of the last side he had tanned, and on a wet, thawing day he went to the woods a quarter of a mile distant to haul up a log. He hitched 
to a smooth beech-not a very heavy draught - and started home, leading the horse by the halter. On arriving at the house he was astonished to see nothing of the log or whiffletree; but the traces were like the "linked sweetness long drawn out" he had heard of, as they were barely visible. As it was nearly night and the chores had. to be done, he had not time to investigate the cause then; so he threw the hames over a hitching post, that stood near the woodyard, to hang for the night. A frost came and checked the rivulets that ran through each ravine, giving promise of being a "good sap day," when the sugar maples would yield a copious flow. He got up early to go to the "bush," when, upon opening the door, he was surprised to see that the log was there. The frost had rried the leather, and the contraction drew the log from the woods.

Preceptor.-A very good Munchausen, and not a whit more wonderful than some stories that are told about horses. Though Jane's gait is very long and open, I do not think it will be advisable to take any means to shorten it, as she does not dwell or point when going fast. I have seen horses that had a very long stride that could not trot fast, as the time it took them to "gather" more than counterbalanced the advantage of covering a good deal of ground. Horses of this kind often go a great deal faster by inducing a shorter stride, and more rapid action. When an animal has both, he must be fast; and though generally not as capable of going as well before heavy weight, or through deep ground, I have known some notable exceptions to this rule, that could do both as well as any short or moderate gaited horse I ever knew. I always fancied that long striders could carry more flesh than if they did not step so far, and always aim to have them feeling as well as a due amount of work will permit. 
They must have condition, as when tired there is a greater falling off in their speed than there is in the short stepper.

You had better get into the wagon and jog Jane slowly a couple of miles before you bring her to the barn. As to her future work, I see no reason for making any other changes than that of requiring her to go, once or twice a week, as fast as she is capable of. The brushes will have to be lengthened as you progress in her training, and you will be the best judge of how much slow work she will need. I think in her sweats it will be well enough only to wrap her neck and chest. When the inside fat is absorbed, and the action of her heart and lungs is satisfactory, it will be needless to reduce her further. When her temper becomes tranquilized, so that we can rely on her performing in a race as well as she does in her exercise, it will certainly take a very good horse to beat her. For should she come well in hand to the entrance of the home stretch, a length or two behind most horses, she would make it very hot for them from that point to the stand. While you are jogging Never Mind, I will watch Clipper walking, and give his legs a close examination.

PupIL.-Never Mind is much pleased with the soft track, and I could not detect any soreness in the foot. I drove him five miles, thinking that distance, on the mellow ground, was enough.

Precepror.- That was sufficient. You can now harness the grey, and, as I am anxious to see him move, you can give him a short brush, just long enough to show me his manner of going. I am very much afraid he will have to be laid up, as his legs have not the appearance I would like to see, and it will be better policy to stop his work than to endanger spoiling them entirely. I am satisfied that the iron, accompanied with proper care the ensuing winter, will result in a permanent cure. The next two or three weeks will be apt to show whether his legs will 
stand or not. If you see any symptoms of their getting worse, particularly if the back tendon becomes bowed, throw him up at once, soak his legs in bran tea, take his feed away gradually, and let him graze an hour every day. In sweating him day after to-morrow, do not drive any further after the hair has become moistened, relying on the additional clothing to give a free flow of perspiration.

PupiL.-Shall I speed him on the outside of the track? Would not that be safer for him to go fast on, as well as slow?

Preceptor.-It would : though, as I want to see how he handles himself, you can pull him to the inside when ready to let him speed. A hundred yards will be far enough. It is as I expected. His way of going is very severe on the legs. He also strides long, and as his action is very high, he necessarily throws a heavier weight on them than if he went lower. We will have him shod with very light shoes, to lessen, as much as we can, this superabundant action of the knee. You had better work him entirely on the outside of the track, varying that with plenty of road work, selecting the sandy one that leads to the cove. His speed has not been overrated, as he certainly went very fast in the short brush. What a pity that he has not such limbs as the Falcon and his colts have! To undergo the battering the hard tracks give, those iron, tendinous ones are the sort. I have heard people argue that large bone is a sine qua non in a trotter. Now, Clipper has bone enough, but there is not corresponding development of tendon. Nine hor'ses in ten that give way in their legs have bone enough, but the tendons are small.

PuprL.-In a conversation we held some time ago, you told me how a horse trotted and ran-that is, how the legs were moved at these gaits. I have known a man claim that a trotter required mose strength in the fore 
legs than a race horse, as one limb did the work of two. It strikes me that his lnowledge of movement was very limited, as I am sure the fast gallop is much more trying than the fast trot.

Preceptor.-There can be no question of that. The greater the velocity of the body, the greater the force with. which it comes to the ground. And not to spend time in argument, I can adduce an illustration that will prove it. Drive a fast trotter on ground that will just receive the impress of the shoe, so that the frog touches the ground. Run a horse over the same, and he will sink much deeper, running in training-shoes similar to those worn by the trotter. I have also heard men state that the fore feet of the race horse struck the earth at the same instant, and that the hind legs followed the same rule. Such ignorance shows a want of common observation, as any person with his eyes shut, and merely listening to a horse galloping past, ought to know better. The foot-prints will show the manner in which a horse runs, more clearly than they do in a fast trot. For instance, the "tracks" are in this form when a horse runs :-

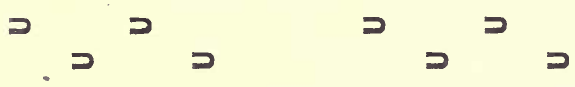

They vary more in the trot, some horses placing the hind foot more in advance of where the fore foot stood, than others, thus :-

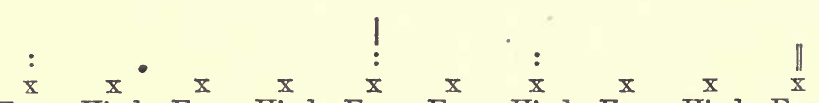

Fore. Hind. Fore. Hind. Fore. Fore. Hind. Fore. Hind. Fore.

The bound is very clearly seen in the shoe marks of the race horse, though it is not so apparent in those of the 
trotter. That there is a time when the body is propelled through the air, is manifest from the length of the strides that Jane made. The tape line showed nineteen feet; extend her feet as far as it is possible, and you will perceive that ten feet is beyond her capacity of reaching, so that the extra nine feet is made by the body being hurled along, before it is again supported by the feet touching: the ground. The length of the stride is from where the foot leaves the ground, to where it first strikes it again. There are four spaces between these two marks. In the trotter they are nearly of a uniform length, while in the race horse, three of these spaces are about equal, while the fourth is as long as all the others. Of course this proportion is regulated by the distance of the stride, there being a great disparity in this particular among race horses. I must acknowledge my partiality for a horse that is a long strider, over a short one, for either running or trotting, as I think the long striders are generally the fastest, and I have known many horses celebrated for their endurance that "covered a deal of ground." It is rare to find this qualification, unless a horse has the oblique shoulder-blade, a point which every judge of a horse's form considers of the greatest importance.

While talking of the foot-prints, I will mention a custom which I always follow, when training horses and making myself acquainted with their length of stride, and I often find it useful as a guide to show the reasons why they are not trotting as well as common. For instance, we give Never Mind a trial, and he trots a quarter of a mile in thirty-six seconds. $\mathrm{He}$ is working and feeling well. We measure the strides for a hundred yards, and find that they average seventeen feet, with very little difference in the length of any of them. At a subsequent period we speed him the same distance, and find that he has been two seconds longer. in accomplishing it. The tape line 
shows there has been a falling off of a foot in the distance covered, and this would show that there has been no diminution in his action, as it is fully accounted for in the discrepancy in the stride. We examine his feet, to see if it is pain there, which has made him fearful of extending them, and if we cannot discover any tangible reason, the foot tub is called into requisition, he is driven on soft ground, with other precautions, that we deem necessary, to remove the difficulty. On the other hand, should the stride prove to be as long as formerly, it will be evident that he must have lost some of his quickness of action. Now there are various causes that may have affected him in this particular. Soreness of the muscles, interfering with the celerity of their action; weakness from oversweating, or an insufficiency of feed-though this would be more apparent in a longer trial ; too much slow, longcontinued jogging, or the carrying the walks to an extreme, making him dull, and without the proper animation to take delight, as he should, in bursting off for the brush. Should there have been a change in the shoeing, that might occasion it-and I never have a different shoe placed on a horse, without scrutinizing closely the effect it has on the stride. It may seem a trivial matter to follow a horse with a tape line, and note the slightest variation in his stride; but I have been benefited greatly by this plan, and I know that you will oftentimes be able to find out the reasons for a falling off in speed, that would have troubled you without this assistance.

I want to see May perform, and hope she will verify your assertion that she is entitled to a place among the trotters. That she will eventually be a good one, I have no doubt, though I did not look for as rapid improvement as you mention.

PuprL.-I may have been deceived, by the rapid change, into placing too high an estimate on her powers; still I 
feel confident that it will not be long ere she will make the older ones "do all they know how," to beat her. I have not driven her at her fastest gait around the turns yet, but will now drive her a mile, and let the watch tell the story.

Preceptor.-Hurrah! 2:41, and she was 1:23 in doing the first half. There is no further difficulty of making a trotter of her, as with proper handling, I do not think she will relapse into her former sideling motion. That is the only thing to fear, and every precaution must be taken to guard against it. It will be as well to confine her fastest work for a while to the straight sides, teaching her to go on the turns by degrees, and always letting her wear the roll to protect the pastern. An unlucky blow, by wounding t sat, would be very detrimental, as likely to re-awaken the fear she formerly had of injuring it, and destroy the confidence she has acquired. I like to have horses capable of going fast on any part on the track-especially the latter end. The advantages are too apparent to need comment. This requires practicing a rapid gait on the semicircles, as well as on the parallel lines, to accustom a horse to go with freedom when "rounding a turn." It will be as well not to hurry May in this part of her education, for if we succeed in curing her by taking the whole season, we will be well repaid for the time occupied. Her neck and shoulders will only need "scraping," enveloping them in a wrapper and long hood, though I would not recommend clothing her farther back than a few inches behind the girth. May is a very handy breaker, so that we can look for her to be a "good moneyed horse"-a safe one to do in a race all she promises in her trials.

I cannot see that you need much further instruction, and now that you have had a lesson in the danger of allowing a horse to wear a shoe that will be likely to do injury, should he "grab," you will not need cautioning on that 
score. You will also be likely to remember the danger there is in snatching a horse sharply, should he break, as more serious results may follow than cutting the quarters. Injury to the knee is frequently the consequence, while the animal may be hurt permanently by a strain of the shoulder or loin. There is nothing gained by this proceedure, as I never knew a horse that would not ultimately be a better breaker, and lose less ground, when the gentler plan has been followed. If a person has so little physical strength that he is afraid of not being able to manage a horse, unless he jerks him at the instant he leaves his feet, he must use some of the safety appliances, which will give him the requisite nerve. But the most successful means of managing a refractory horse is not by main strength; address, or skill, as we may term it, being far more effective.

One of the very best drivers I ever saw has not more strength than a hearty twelve-year-old boy. He never uses hand pieces, or any aid of that kind, depending entirely on skillful management, which I never knew to fail him at any time. If a horse is determined to run away, and is aceustomed to do so whenever he tries, pulling will not stop him. The best way, then, is to retain your selfpossession, when you will be able to guide him, and keep lim running where the ground is the safest. If you have a horse that you feel confident will stop whenever you tell him, and go wherever you direct, you are not alarmed if he does run. It is not the speed, then, that is so frightful, but the consciousness that you are carried along against your will. It is a good many chances to one, that, wheil the horse finds you are not pulling at him, but, if anything, urging him on, and if he is not heeding the suggestions of the bit in going the way you direct, adding to its admonilions a severe reminder with the whip,- - he will not find so much pleasure in the effort, and be as ready to stop as you 
are to have him. This, of course, has reference to horses that run away from willfulness, and not under the sudden impulse of fright. As you have now finished your morning's work I will leave you, and I do not think it will be necessary for me to come again, until the time fixed for the trials. If there is anything you want to know, that I have omitted in my directions, you can subject me to any queries you see fit.

PupiL.-The bump of self-esteem must be a prominent elevation on my head, as I feel very capable of carrying the horses along. The success I have had, so far, I do not ascribe to fortuitous circumstances, but to the result of your teachings, as I should have been sadly at a loss to know what to do in several instances. Your directions have been so minute, that my memory and comprehension would have to be very poor, if they did not serve to guide me for the time you will be gone. $\mathbf{i}$ can assure you that I will not fall into the same error again I did with Never Mind, in either mistaking overwork for rankness, or in twitching him on to his quarters. To fit the horses for the races in four weeks, it will be necessary that their work should gradually approach that which it will be in the race, and with all my assurance, I am not so certain that I will be able to hit the happy medium, and give them neither too little nor too much work.

Preceptor.-You had better keep on the safe side, and have the work rather under what you consider the full amount they can bear with advantage. While there has to be plenty of work given to bring a horse into condition, an over-supply is worse than not having him quite up to the mark in opening a campaign. In fact, I prefer that a horse should not be in the form of doing all he is capable of in his first races, but in that condition that will be benefited by the work he gets in them, and so keep up a steady rate of improvement, until the season is at an end. 
I dislike very much for a horse to become stale, before he has trotted half the races we have marked for him to perform in, and it is better policy not to try to bring him to an "edge" at the start, as I am fearful that, after the first few contests, it would become nicked and broken, from our not having taken time enough to temper the blade so as to hold it. The celebrated trainer, Arthur Taylor, in the commencement of a campaign, had his horses looking. big and bulky, and one of the shrewdest managers on the English turf, Thomas Parr, said that he found it the cheapest plan to sweat his horse in public, meaning that he preferred they should run themselves into condition in actual races, rather than by galloping on the downs. Should the weather not be favorable to give the trials at the time we intend, and the track not be in shape to work on, you will have to go on the road, as it will not do to fail exercising those we trot in the races. If you should happen to need advice or assistance from me, send one of the boys down, and I will come forthwith. 


\section{CHAPTER XXVIII.}

TRIALS-PREPARATIONS FOR THEM-TRIAL OF THE FALCONOF NEVER MIND.

Preceptor.- You will perceive $I$ have come in time this morning, and have been well repaid for my break-of-day drive by the beauty of this bright opening of the dawn. You have been giving fervid descriptions of your Western scenery, and the dry air that enabled you to see distinctly at distances that would require the aid of a telescope in a less favored clime; but I think you will have to aknowledge that even the grand prairie was never enveloped in a purer, more odoriferous, ambient mantle than this. Your. chicago friend would be troubled to find any of those releterious vapors, that he thinks are always brooding on whe ocean's shore, and if his eye is as quick for detecting reauty, as his palate is nice in discovering the exquisite flavor of wines, as shown by his selection, he would be greatly delighted at the prospect presented this morning. Look at the sun rising from its waveless bed, making a glowing pathway, a flooring of radiance glorious in its brightness! The vessels in the offing, which a few minutes ago only caught the refulgence in their topmast sails, now stand out in full relief, a pyramid of whiteness, contrasting finely with the black pennon streaming from the passing steamer. Notice the steamer that is lying by-how the smoke rises in a grand column, with a capital more graceful in its curves than the fluted, acanthus-leaved glory that crowns the elegant Corinthian shaft! And when we 
come to the foreground of this inimitable picture, what perfect keeping there is in the "filling up!" The field of tasseling corn on our left seems a continuation of the coppice beyond it, the broad luxuriant leaves deflecting: from the stalk, and falling back in curves superior to Hogarth's line of beauty, and giving an Oricntal appearance to the view, heightened by the group of sumachs, with their palm-like leaves and scarlet cones. That field of ripening grain appears as if it had retained the yellow sunbeams in which it has been bathed, while the air is filled with the perfume of the woodbines and honeysuckles that drape the cottage porch, and hang in festoons about the windows. The morning is as favorable as we could have for horses to go fast; and if the track is in corresponding condition, the time made will not be a safe criterion to guide us, in estimating the ability of the horses to perform, when things are not so favorable.

PuprL.-The track is good, though not so fast as it might be, as I have had the whole of it harrowed-the inside very lightly-thinking it would be better for the trotters, and I could not bear to see the horse you sent up galloping on ground that had no loose dirt to deaden the concussion.

Preceptor.-You have made a hit in preparing it, as I am very partial to a thin coating of loose earth, even for trotting purposes; and though it is undoubtedly slower than a smooth, hard surface, it is fast enough-faster than many would think who had not tried a horse on a similiar course. There is just the right amount of soil to fill the inner part of the foot, forming a sort of a cushion, which will take a great deal of the jar off, and a horse will therefore extend himself freely, gaining in that way nearly as much as he looses by the added dranght of the wheels running over a yieliing surface. It will be as well that the horses have a short walk before driving, and have a 
mash made for the feed at ten o'clock for each of them. Unless they are costive, this mash can be made of the hominy and oats, and a small proportion of bran. The water must be boiling, and the vessel that is used to make it in must be covered, so that there will be no escape of steam.

PuPI.-In preparing these horses for the trial, I did not give them more than three-quarters of their usual feed of grain, last night half their water, and about a quarter of the hay they commonly receive. This morning I have only given them a quart of grain apiece, and a very few swallows of water.

Preceptor.-I think the amount you have named may not do any injury, though I would not have fed them as much. I am not in favor of "drawing a horse" as closely as many do, who, I think, err in making their restrictions too severe. There is a point to be reached in this preparation which it should be our aim to observe, viz : that the stomach should not be encumbered, and yet the nourishment afforded by the food be sufficient to carry a horse through a race, in which he would "weaken" unless the supply was adequate to meet the demands. Many interesting experiments have been made in France to determine the time it takes for a horse to digest his food, and also the effects of exertion in hastening the process. I do not remember them distinctly enough to quote what the results were; but this $I$ do recollect, that digestion is nearly passive when the animal is in repose, is much hastened with moderate exercise, and suspended when violent exertion takes place. In three or four hours, under the most favorable circumstances, the food is assimilated. Now, last night's feed would only have undergone a partial change before the action of the stomach was suspended by the animal sleeping, and whatever was given this morning, cannot help encumbering the stomach, at 
the time we want him to exert himself. The walk will assist in relieving the horses, and we will postpone the work till after breakfast, which will be a further help. Actual trial is worth far more than theory; and making yourself acquainted with the wants of each horse in this particular, by repeated experiments, is altogether the best method. Horses differ, and while one may require the curtailment in his food and drink to be rigid, others will perform better, by never being forced to wear the muzzle, and only shortened in the meals that immediately precede the race. I have heard a story that an Englishman always fights the best after a good dinner, an Irishman when he has had a sup of whiskey, and your countryman, the Scotchman, when fasting. I presume that this is only a conceit, though it is applicable to the equine family, as I have known different horses that required, one of them the stimulus of the whip and spur; another, the support of the most nutritious food; and the third would do better when drawn till his shape resembled that of a greyhound when in order to run a course. There will be time for you to jog Clipper before we are summoned to the steak and coffee.

PoPIL.-I have observed, when I have been driving him lately, that he has gone with a little halt in his gait, and am fearful that the only cure for him will be the actual cautery, which you have advised as a last resort.

Preceptor.-You need not exercise him, as I can see that the near fore leg gives evident symptoms of not being capable of standing the work. You will see that the outline of the back tendon is not straight as it should be, but is curved outward; and I never knew one in that shape, if the work was persisted in, that did not ultimately break down. Cauterizing has, as Mr. Percival says, restored many when in this condition, and given them renewed strength to perform nearly as weil as they did formerly. 
I know a veterinarian that greatly excels in performing this very painful operation. I have seen legs that he has fired from the knee to the coronet, when the marks of the firing iron have been hardly discoverable, and yet the effect has been equally as good as in those cases disfigured with ugly scars and rigid callouses. By the way, how do the horses like the company of the galloping fellow?

PupIL.-I cannot say whether they consider the acquisition of his company pleasurable or not. The Falcon does not pay much attention to him any more, if he will only stay behind; but the moment he takes the lead, he will exert every nerve to overtake him, and never gives up trying as long as the runner is in advance. I know, as well as if he could tell me in words, what he thinks, and there is no doubt, in my mind, that his cogitations are, if we would only put a saddle on him, there is not a man about the place that he could not carry, and beat that short-gaited fellow, that thought it quite a trick to run ahead of a horse, encumbered with wheels and forced to keep a gait immeasureably slower than his natural one. Never Mind, when the horse laps him, will fairly fly, and keeps him to a good racing pace for a couple of hundred yards, although, when he gets a few lengths clear in the lead, he loses heart, and if still pushed, does not go with the animation that characterizes his efforts when he thinks he is beating him. Jane surprised me with the quietnoss which she displays in his company, and will accommodate her pace to the one the runner goes at, and is prompted more by the command of her driver to go faster, than she is by the desire to leave him. May is like her sire, and cannot bear to be stopped while he is yet ahead. Delle I only tried once, and she was so much excited that I did not repeat the experiment.

Preckptor.-The probable reason for Jane's immobility is that she never yet has been in a race; and the sole cause 
for her former excitement was the drunken driver's lash. I had misgivings that Never Mind would act in the manner you describe, from the narrowness of the skull between and above the eyes, showing the want of the moral force, which, if he possessed, would make him the equal of the very best. Better condition will aid him, and $I$ am in hopes that the work of to-day, and of those intervening, will give him heart enough to win the race we have him entered for. The horses in it are not so fast as he is, or rather those that are known, there being two dark ones that report mentions as having performed wonderfully in some Utopian country, the location of which has not yet been found out. To contend against the Falcon are horses which have gone faster in public than any time we can expect him to make yet; but as it is the only place to put him in, to give him a chance to receive the benefits of a race, he may as well begin there as anywhere else. For all this, I would rather take odds against him than lay them on Never Mind. Both of these races, coming on the same day, will give you and the boys plenty of work; yet, with the help you have, all the attention necessary for the horses can be awarded them. My morning ride has given me a sharp appetite, and I am not sorry to hear the signal that summons us to prepare for breakfast.

PupiL.-I suppose it is useless to offer you anything to drink, and I do so more as a matter of form, than from any expectation that you will accept it.

Preceptor.-Thanking you for the kindness, I must reiterate that I never drink for form's sake, and when I do indulge, it is either to gratify my palate, or for the fancied necessity for the stimulus. I say fancied, as I think nine-tenths of the liquor that is drank is from some fanciful cause. That I take pleasure in drinking I will cheerfully admit, and I appreciate the flavor of good liquor as much as any one. Because ripe peaches are delicions, 
we would be foolish to use them so indiscriminately as to endanger the health, or clog the appetite. My favorite beverage in the morning is coffee, and though I relish a cup of good black tea at times, the decoction of the Arabian berry, when rightly prepared, is the accompaniment I most fancy to the matutinal meal. But I have expatiated so much on the pleasures of good cheer that you will have a right to think I am more of a gourmet than I am. A horse is better for neither being a gross or delicate feeder, and I have always schooled myself not to be over-fastidious about my food, while my hearty appetite causes me to relish almost everything of which people are fond.

PupIL.-Talking of peaches reminds me that their season is close at hand, and they are among the delectables which I prize exceedingly. Strawberries, raspberries, peaches, grapes, and pears I have a fondness for, which almost amounts to a passion, and I gratify this appetite by consuming quantities that appear frightful to some; and I have often been told that I would kill myself, if I devoured such loads; yet I never found any damage to arise from this wholesale consumption. I think fruit is to man what green, succulent herbage is to the horse-a promoter of good.health, and certainly a source of pleasure which does no injury. As I am a pound or two over the standard weight, I suppose it would be as well that I should restrain my appetite somewhat, so that the horses would not have to drag more load than is required.

Preceptor.-The effect of a few pounds' weight in trotters is hardly appreciable; that is, when the extra amount consists in four or five pounds of flesh in the driver. Race horses are different, though I think the disadvontages of a slight excess of weight are over-estimated. The story of the stable key in the pocket of the boy has been told so often, that the belief in the dogma, that an ounce or 
two changed the result in the trials, is very general. 'That weight will equalize horses, is shown by the result of the bandicaps in England; though the difference necessary to bring a good horse and a poor one together should convince people, that the old notion of seven pounds being equal to two hundred and forty yards in four miles is a mistake. Eight or ten pounds, over the regular weight, in a sulky would make a very slight distinction, depending even then a good deal on the state of the track. The additional friction of a vehicle with four wheels, causes quite a gap in a mile with most horses, though I think this depends a good deal on the fact that the wagon covers more ground than the sulky, and therefore is not so easily handled. In going round a turn, the centrifugal force operates prejudicially, and the hind wheels are thrown in such a position that they have to slide as well as revolve. Weight in the wagon there, then, would be more felt, as the heavier the vehicle is, the greater is the tendency to fly from the centre. So I do not think there is much necessity for placing the muzzle on you; and so long as you do not eat too much, so as to effect the free workings of the wheels of the mind, you need not be restricted.

There are other qualifications required to make a good driver, that are fully as essential as skill in handling a horse; one great requisite being coolness of ternper, and another the power of judging quickly, and taking advantoge of circumstances arising from the varying changes of the race. I will not dilate on this point, till I see how you deport yourself next week, when I can give advice that will be appropriate, and better understood, as the exigencies of the case demand our attention.

Now for the trial, which is to determine the chances we imagine the horses will have when pitted against a field, each one comprising it doing his best to win. I must again warn you of the danger there will be in taking the time 
the horses make this morning; as being the measure of their powers in a race. Here everything is advantageous. The air is pure, and not a current to retard the progress through it, the track is in fair condition-much beyond the average for making good time-and the horses will have nothing to trouble them, but will take the inside and keep it, while the horse gallops in such a position as to ensure getting the most out of them. I have known horses that would go faster in a race than at a trial, the excitement of the contest, and the animation induced by the shouts of the multitude, bracing them to do more than was thought to be in their power to accomplish. I suppose you will commence with the Falcon, jogging him two or three miles, opening him as many times by short brushes up and down the stretch. You can drive him past the stand one or twice, stop on the turn, drive back to the distance post, and start for the trial at as good a pace as you can drive him. If he breaks, recover him as quickly as you can, and should he leave his feet immediately preceding the score, I will not start the watch, so you can pull him up and try again.

PupIL.-Shall we gallop the horse with him from the first, or wait for the repeat?

Preceptor.-We will wait till he makes the first mile, as I want to see what difference the company will make, and it would be too much work for the horse to run with both of the trotters through all their trials. Very well. He made the mile in $2: 38$, and the rate was very even for the whole distance. I do not think he has displayed his powers in full, as he appeared to be going too much at his ease, and no one would imagine from his present looks that he had been pressed at all. Throw the blanket on him, and have the boy walk him up the stretch. There is no use in giving him much time, as there is no distress to recover from. 
Now, my boy, I want you to give a practical exemplification of the way to ride a race horse. That fellow is very tractable, and you can place him wherever you desire. You can gallop alongside of the Falcon for a mile, in which he will be driven slow, and when the horse is turned round to start, come a length or two ahead of him, and take your horse up on the turn. The next time, come the same distance behind him, when you can also pull up. The third time let him lead you half a length when I will give you the word; keep this position until you enter the back stretch, when you can go head and head with him to the half-mile pole; then you can run ahead and take the track, keeping a lead of a couple of lengths in the clear till you are within fifty yards of the two-mile distance, when you can pull back gradually, allowing the Falcon to beat you by a neck to the score.

These orders to the boy will govern you in driving. Coming to the score twice before you start will be a short lesson in scoring, and you must make the Falcon go at the very best rate. If he wants to pull, do not gratify him any more than you can possibly help, but talk to him, and in place of a hard pull, try to keep him on his feet by soothing words. Sponge his nostrils, give him a swallow of water, and "mount."

Pupir.-When I conclude the mile, shall I stop, or jog on around the track?

Preceptor.-Go to the half-mile pole, and come back moderately slow, but not slow enough so that he will become the least cool. I am in hopes that he will scrape after this work; and I think he will, as I look for him to work a good deal harder than he did in the preceding mile. I will give you the word when I want you to start, and unless you hear it, you can take him up. If he does not act well, I will delay the send-off.

Bravo!-2:34, and the last half done in 1:16; and from 
the manner in which he accomplished it, I have no doubt of his capacity to make another one still faster. The rush he made to beat the runner, when he found he was gaining on him, was admirable. Should you handle him as well in a race, as you have in this trial, I will certainly have to award you a diploma. Get him out of the harness, scrape him, straighten his hair, and have him walked till he is cool and dry. You can now see the difference in the appearance and feeling of the sweat, from that which exuded through the pores at the commencement. If the heats are broken, this fellow will make trouble for the rest of them, as his bottom and condition are such that he can trot mile heats all day; and I would freely venture that his third heat will be faster than either of those preceding it.

We will now see how Never Mind will go through with the ordeal, and while you are jogging him, the boy can be walking the runner. You will not start him till the repeat -the same as we did before. Twice round will be sufficient for Never Mind to go slow, which you can drive the reverse way of the track, making the last half of the two miles at a pretty sharp pace, and when you come to the stand you can open him for the length of the stretch. Turn round at the three-quarter pole, come leisurely till within a hundred yards of the stand, when you can go as fast as you choose for the mile. You will, of course, have to husband his powers for part of the time, and I would advise taking hirn in hand for the first quarter, and again on the third, so that he will feel like going at his best rate through the stretches. Drive him so that you will feel there is always something in reserve, though I should like to see him hurried at the finish, and thus be able to judge what kind of a brush he will be likely to make at the end of a fast heat.

That is pretty near "trotting-horse time"-2:28, and 
stamina enough to make that last rush with plenty of resolution. As there is a good scrape on him, you can take him out of the shafts, wrap him up warmly, walk him a few minutes, and we will scrape him on the ground. I am partial to scraping a horse in the open air, when the weather is at all favorable, as frequently we have to do so when racing, and if the job is performed expeditiously, there is very little liability of a horse taking cold; none at all such a morning as this. Again, you will perceive that the sweat from Never Mind is dissimilar to that from the Falcon. It shows a little frothy, and has not the same water-like feel that characterizes that of the other. $\mathrm{He}$ needed the work of this trial more than the Falcon did, and the race will be of still more benefit in his case. While I am praying for broken heats for the Falcon, I hope for no such catastrophe where he is concerned. You can pursue the same in the next heat as you did before, and the boy can ride in the same manner, only I do not think it will be advisable to make so many false starts. Should he be going satisfactorily, I will give you the word the second time you come up.

Pupil.-I suppose you want him to show his hand this time, so I must keep him going the whole of the way.

Preceptor. - While I want him to do his best, I do not look for him to be able to keep up his best rate the whole of the time, and in order to have him do the mile fast, it will be necessary to "bottle" him for some of the way. Have him well in hand when I give you the word, and keep him within his rate, till you enter the back stretch. There let him go as fast as he can. When the horse takes the track from him at the half mile, ease him again till you are fairly straightened into the home stretch, and from that point to the stand, get every inch out of him there is. Move the bit in his mouth, and encourage him with your voice, as the whip, severely applied, might cause 
him to "shut up." As the running horse is pulled back for him to collar, keep him on his legs if possible. If he requires something of a pull to accomplish this, you can do so; but try to "hold him level" with the application of as little force as you can get along with.

That fellow is a trotter, if even he did show the white feather. 2:26, and the half-mile in 1:12 is tremendous, considering all things. Still, it is going to require the very acme of condition to enable him to win races among horses that are his equal, or very near his equal, in speed. $O$ for a little more blood! I missed the quarter pole a little, though I am confident he went up the back side better than thirty-five seconds, and had he a moiety of what the Falcon could spare, we would have a trotter that I would not be afraid to "tackle" any person's horse with. Hurry the clothes on him, while I prepare some gruel; he is in a good deal of distress, and will require the best of attention. Observe the tremulous motion of the flanks; and he does not walk as he should. Take the sponge, and shower a little cold water on his poll, and let it run down his forehead. Here, my boy, run and pull a handful of grass for him, which you can let him pick out of your hand as he walks. Have hot water ready to bathe his legs, and apply the warm bandages as soon as you are done. Give him a few swallows of gruel, and after he is thoroughly cooled out, fix up his bed, and leave him to lie down in quiet if he will. Do not offer him the mash until he has had time to recover, which will be some time after the Falcon has had his. It is fortunate that we have been able to give him this work, as without it he assuredly would have tired in the race; and if these dark flyers have the speed that is claimed, I am afraid he will not be sufficiently up to the mark to live through it. They will have to be very fast, however, in order to touch his weak spot, and I think we can flatter ourselves that he will "pull through." 
With a fow hints for your government in future, I will leave you; and as my affairs need close attention, I will not be here again, but will meet you at the track the morning of the race. I have spoken to the proprietor for stalls, so you will not have any trouble on that score. Take plenty of help along, and more clothes than you thinls will be required. Rubbers, scrapers, sponges, buckets, a bottle of arnica tincture, and one of sherry, some oatmeal, and whatever else you think will be needed. Never Mind you had better confine to slow work. with the exception of the half mile more the next morning, but one, after you fag him out. Look to his feeding yourself, and give him all the food he will eat with a good appetite. When the bandages are removed to-day, moisten his legs with the arnica, putting four parts of water to one of tincture, and have the boys lightly hand-rub them till they are dry. The Falcon will almost take care of himself. Work him as you have been doing for the past week, and give him the light sweat at the same time as Never Mind. I am not much in favor of giving a great deal of work, the morning of the race, and, if the animal is not very rank, usually confine him to a walk. The walk from here to the course will be all that is required. Start immediately after breakfast, and in an hour you will be at the course. As the races do not come off till the afternoon, the manner of your feeding last night will be proper. Carry some feed with you, and give two quarts at ten o'clock, with only a swallow or two of water. I will be there in time to have the stalls bedded and fixed before you come, so there will be no necessity for any directions what to do after you get there. 


\section{CHAPTER XXIX.}

NEVER MIND IN A RACE-INSTRUCTIONS FOR DRIVING-THE HEATS-CARE OF THE HORSE AFTER THE RACE.

Preceptor.-You make a brave appearance, with Falcon heading the caralcade. He has "the front and port of royalty," and at the same time he is too well bred to show anything of curiosity in his deportment. Before we put the horses in the barn, we will drive Falcon and Never Mind round the track, in order that they may become somewhat familiar with the ground, and also that you may form some idea of how it lies. It is a trifle unequal on its surface, and this you can take advantage of, by saving Never Mind where the grade is ascending, and make the pace as fast as you think necessary on the descent. The Falcon will bowl along up and down hill with the same facility, and from what I hear of his antagonists, this will be the only way that will enable him to win. There is no question but that two of the horses that are in the first race-the one Never Mind trots inare fast, though I judge we have a couple of seconds' advantage on this score. The pool selling in town was a little mixed, and parties were afraid to take any one for a decided favorite. There was not much difference between the two I have mentioned and Never Mind, the rest of them going for merely a nominal sum. If I am not mistaken, the first heat will rid us of the trouble they will 
occasion, and I would cheerfully give a hundred dollars if they did not start. in the race. They will be a great bother in scoring, which to have as little of as possible will suit us the best. I have put some money on, which you can have a share of, but I must confess that I look on this race with a good deal of suspicion. If even they do beat, I would be glad to wager that they cannot do it again in a week or ten days from now; so there will be this advantage,-they will underrate us, and perhaps give us a "better thing" when we are in proper condition. Your note informed me, that Never Mind recovered from the trial better than you anticipated. How is he feeling to-day?

PupIL.-As finely as possible, and I was indeed greatly surprised at the manner he recovered from the trial. He was in no hurry to eat the mash that was prepared for him, so I only gave him half the amount at two o'clock. He took his walk in good enough spirits, and as soon as he heard the feed room unlocked, he could hardly wait, he was so impatient to get his supper. I have given him a good deal of slow work, and the brush you directed me to give was about as fast trotting as I ever saw. You will see how he will tail the field to-day, provided there is anything in that is fast enough to collar him. I have more hopes of his lasting than you have, as I do not look for him to be kept on his tip-toes in this race, as when he was going with the galloper, and the track is a good deal harder than the one we have been training on, which will lessen the labor, even if it does try the legs and feet.

Precepror.-I hope you will not be disappointed, though I am quite sure you will find more speed to contend against than you at present are calculating on. From the parties who are supporting these horses, I am confident that they are good ones, as they are not the ones to put the amount up they have already invested, unless they have a good thing, and although they fight shy of each 
other, you can depend that they are under the impression that their own horse is the best. They have heard enough of Never Mind to enable them to bring him into the betting, and while they have full faith in beating him, have so far kept him up in the pools, in hopes that the outsiders would continue the support, and that they would thus get more money than if he had only been suffered to bring the small price the others go for. When they discover that your chances are favorable to win, they will play into each others' hand, and by driving one horse at you part of the time, and laying the other one up, get the benefit of a comparatively fresh horse, which will make the task more arduous for you. These tactics will not probably be inaugurated till after the first heat, when we can also better determine the course to pursue. If this black fellow was only a few seconds faster, how I would like to see them cut and slash at him! That would just suit, him by keeping him alive to the size of the job he had on hand. There will be time enough, however, to adopt a suitable defence when we see the plan of attack.

I see that you have taken a wise precaution in bringing Mavourneen to keep Never Mind company, as a little irritation or fretting would be injurious. The boys had better take off the clothes, and give the horses a light brisk brushing, one or two swallows of water, and two quarts of grain. When they have eaten this, put the muzzles on, and do not permit them to be disturbed until an hour previous to the time to start. At that time, give a pint of grain, so that they will not think their customary feed has been neglected, have the harness placed on them, the sulky wheels taken off, the spindles carefully cleaned and oiled, and a rigid scrutiny observed to see that everything is right. These duties, together with having all that will be needed ready to go on the track the moment the signal is given, must be attended to, as I 
understand the managers have signified their intention of having the rules scrupulously enforced. Fifteen minutes before three, the bell will sound to call you out. You will have that length of time to warm up, and as soon as the watch shows that the advertised hour has come, the horses ready will be started, and if there are laggards, they will be left behind. I have seen so many bad consequences result from delaying the time of starting, that I am glad they have come to the conclusion to be thus punctual. Five minutes will disqualify, and when once places are drawn for, no entry that has delayed making an appearance will gain admission. You can depend on Tom and Con keeping a strict watch that no one can obtain access to the horses, so we will wall around the track, in order that you may become as familiar with all its features as there is any necessity for.

PupiL.-Here is a place which cannot be seen from the judges' stand, and though the distance is short, something might be gained by allowing a horse to "take a few jumps" that would help him.

Preceptor.-My plan has always been to drive strictly to rule, and while $I$ took no undne advantage over my opponents, I took care that they should obtain none over me. At this point they may endeavor to interfere with you, one of them carrying you clear to the outside, while the other gets as great a lead as he can. Running would be rather dangerous, as a horse-even if a good breaker -is sometimes a little crochety, and might loose more in recovering than he gained, and should a horse emerge from the shadow in a run, the judges would be very apt to conclude that it was intentional on the part of the driver, which would subject him to the penalty of a distance. The track is certainly in good order for making fast time, and though the afternoon will be warm, the air is not oppressive yet, and I do not think it likely to be- 
come so. We will pay the house a visit, where an early dinner is intended, so that it will be out of the way before the rush comes. We will eat ours, when we can relieve the boys and stand guard while they are taking in their provender. Your boys are certainly models, not only attentive and careful in the performauce of their duties, but they seem to take pride in them, and their appearance is as neat and tidy as those whose business is not near so trying on the clothes.

PuPIL. - I feel proud of them. Formerly they cared for nothing, and when their work was done, would listlessly saunter about. The money they earned was as good as thrown away, and they seemed to have an abhorrence of clean clothes. Since they have acquired a taste for reading-a taste which I have cultivated as far as I could-the change has been marvellous. They now aspire to knowledge that will fit them for any station, pertaining to the management of horses, and are all of them saving money so as to make the winter months the most profitable, by going to school, when I will warrant they will be industrious in remedying the defects the want of education inflicts. Perhaps the partial seclusion of private traininggrounds, has assisted in keeping them away from the temptations they have been accustomed to, though I feel there is no danger of a relapse, and shall look for them to make valuable men, when their education is completed.

Prechptor. - The lessons on order that have been inculcated, have made those boys worth double the money they would have been, if they had not acquired this great quality. Everything about the stable shows the care that has been taken, and the clothes, harness, and vehicles, are not only in better condition, but will last three times as long as if they had been neglected; and the satisfaction of having such well-behaved and good-looking boys is 
more than remuneration, sufficient to repay you for the trouble you have taken with them.

This dinner hardly equals those you are accustomed to, though allowance must be made for the confusion attendant on preparing for a race day. Sandwiches, tarts, doughnuts, \&c., are consumed in such quantities, that it must be as hungry a job to witness the contests as your friend deems it dry.

Pupri.-Shall I limit the Falcon to a pint? His race may be delayed for quite a time after the other, and he is very ravenous in his desires.

Preceptor.-The object in giving the horses any grain now, is to stop them worrying about the want of the feed they have been accustomed to, and not for any actual necessity for the sustenance. Digestion cannot take place, and whatever we give will only be in the way. The two quarts they eat at ten o'clock has probably been assimilated. That, and the vigorous state they are in, ought to carry them through these races without any weakness accruing. Should it arise, we will give temporary relief by using cordials and stimulants, which will not interfere with the capacity to perform fast work. You want plenty of clothes -woolen and linen-scrapers, rubbers, sponges, foot pick, buckets, water, oatmeal gruel, bandages, knee and quarter boots, the bottle of sherry, \&c. I do not think we will require the boots, though it is good policy to have them on hand, and still better luck not to need them. You had better slip a pair of hand-pieces on the reins. You need not pull on them any harder than you would if they were absent, and they are of service by being placed at the right length, which a wrap might not be, making your reins of unequal length.

Now we are ready for the signal, and not a moment too soon, as there goes the first tap. Don't get in a hurry, but hitch up the same as if you were going out to the 
usual exercise. The quarter of an hour before the start you can jog him slowly, going two miles in the time, and not till you have drawn your place and received instructions from the judges, will it be well for you to speed him. There will undoubtedly be some trouble in getting off, which will be warming up enough, and you must use every endeavor not to prolong the start. Do not drive any faster than is neccessary, though if you obtain the inside, do not give it up unless you are forced to. Still, it will be preferable to lose it, rather than get your horse unsteady on the first quarter. You are fortunate in getting the second place, though the horse that has the pole is one of the fast ones. Lie with him until you come to the straight work on the back stretch, when you can take the pole, if you are able. Should you effect this, ease your horse so that he will have to take the outside of you on the lower turn, and thus equalize the advantage he had on the first.

Hurrah! One heat won, and won handily, though here are two spokes gone. How did that happen?

PupIL.-As you noticed, I pulled back on the turn, and as we entered the stretch, I was half a length behind. When I let loose of Never Mind-which was at the place where we were out of sight of the stand-he tried to pull across me and force me to the outside. I would not be crowded, and I rather think he had the worst of it, as I saw a big gap in his wheel.

Preceptor.-You did right. If you had avoided the collision, it would have emboldened him to take further advantages. Now, boys, remove the harness, and one of you wipe the sweat off. Throw on that long blanket and woolen hood, sponge out the horse's mouth and nostrils, and walk him a few minutes. There, that will do; turn his head to the wind and scrape him as expeditiously as you can. Put on the clothes, and walk bim again. You 
can now re-scrape him, give him a mouthful of water, straighten the hair with your rubbers, throw the blanket and hood on, leave off the sway and surcingle, and walk him four or five minutes. He sweats freely, and is cooling and recovering capitally. His breathing has now become natural, so you can dry up these remaining wet patches. Rub lightly: his coat is looking almost as glossy as before the start. Put a linen sheet and hood on: the woollen might cause him to break out again, and the day is so warm that the only clothing required is to keep the sun off. Now walk him about slowly till the bell rings to harness.

Well, my scholar, I feel as proud of you as you do of your boys. You drove that heat admirably, and by giving my old friend that you run into a hint of what he might expect, he will be a little careful of how he tries you again. If you had shown any symptoms of fear, the case would have been different; and when he started to cross you on that part of the track where he knew his motions would be unobserved, he little thought that you would not give way. From his not entering any complaint, he is aware that he was wrong, and though he will do his utmost to win, you can rely on his not attempting that a second time. The next heat will be more desperate, as flyer No. Two has not shown what he is capable of yet, and I noticed he kept about the same relative position until he was stopped inside of the distance. As I predicted, the race is now confined to you three, and you will be relieved of the trouble of scoring with horses that are so much slower. The advantage your inside position gives is a good deal, and if the race could be brought to a closs with this heat, I would feel positively certain of winning it. I judge from the rush to the pool seller's station thit matters have changed somewhat in the betting, and there is an anxiety to get on to the winner of the heat. The 
lack of condition is not apparent yet, though I am fearful it will show before two more heats are finished. All the trouble I look for them to give you now is trying to obtain the best of the start, and as long as they do not get lead enough to take the pole before you reach the turn, I would not care if they had half a length the advantage. Again the signal is given. We must not lose any time in getting ready. By always trying to give the judges as little trouble as possible, we gain their favorable opinion; and a driver who gains a reputation of not being troublesome, will receive more favors than one who is always wrangling. Boys, sponge Never Mind, and allow him one swallow of water. Two to one you win this heat.

Bravo, again! Two of the games towards the long rubber ; thongh that was a harder and faster heat than the other, and Never Mind shows a good deal more distress. His legs are shaky, and his breathing more labored. Wrap him up as soon as you can. Walk him along till you get out of the way of the crowd. He scrapes freely, which is one great thing in his favor. Another swallow of water. Now off with him. You may give him a mouthful of gruel. I think we will not use the sherry yet, as I would much rather he would get along without it. $\mathrm{He}$ does not cool out as well as he did before. Hold his head to the breeze, and shower some water on his poll. That will do: his eye looks a little brighter. Walk him again, when you can finish drying him.

PupIL.- That was a different affair from the first heat; No. Two is a good deal the best horse. I was afraid Never Mind was going to quit when about a quarter of the way down the home stretch, and when the other horse made the rally, he would have given me more trouble than he did if he had not left his feet. Well, I hope it has been as hard for him as it was for me, though from his having an easy heat of the first, it is not likely. 
Preceptor.-No telling. I notice a good deal of commotion among the party, and their horse may not be in a much better fix than ours. We must disguise our weakness as much as we can, and must therefore be prompt at the ringing of the bell. He is now getting along better, and he does not labor so much in breathing, having recovered more rapidly than I expected he would, from his appearance at the termination of the heat. His eye has also regained its animation, so we will endeavor to win this heat, without the aid of anything but a sup of the gruel. Save him all you can consistent with keeping the lead, which you had better retain, your horse being more apt to lose courage, when the others are in advance of him.

Well, our flag is lowered, and that heat is lost. We will not throw up the sponge, however, until compelled. You will observe how differently he breathes now from what he did after the first heat. The respirations were quicker then, but he "blew out" forcibly, and there was not so much abdominal effort. He still sweats freely, which will aid in recovering him from internal difficulty. Rub him dry rapidly, and while the boys are at work, envelop the legs with bandages, putting them on reasonably snug. Pick a little grass for him to be eating. You were only beaten at the very last, and I thought you had the race safe until you were half down the stretch.

Pupic.- - He first tired a little beyond the half-mile pole, and as I could take a pull coming round the turn, I was in hopes he would recover sufficiently to come home. But the driver of the other horse seemed to discover for the first time the difficulty I was in, and kept sending his horse as fast as he could, so there was no chance for me to save him unless I surrendered the inside. I did not think it policy to do so, and Never Mind struggled along with more resolution than $I$ expected. It was a very closo 
thing, and I had hopes of winning to the last, or I should have pulled him up.

Preceptor.-It was well that you kept going, as your antagonist also exhibited signals of distress, and the horse that was saved on the last half mile will now hope to win, which will give us a better chance. If these two will only make fight for this next heat, we will win the race yet.

PUPIL.-I am afraid they will not, as they are evidently in collusion. As you could see, one horse was driven at me for the half mile, when his driver pulled him to the outside, allowing the horse that was trailing to come up, without trotting round the other. This was a great saving to the winner of the heat, and not having been pushed, he could make this brush at the turn, where helapped me with impunity. Perhaps the sherry will revive Never Mind so that he can win this next heat. Is it not time that we were giving it to him ?

Preceptor.- It would be, if I intended to give it this ,eat. But I think there is a better plan to follow. We vill lay him up this heat, and allow the others to struggle or mastery, and before the next, we will give him the timulus. By dropping him inside the distance, he will partially recover, and then, with the aid of the sherry, I think he will trot the fifth heat nearly as fast as he did the third, which will be sure to win. I am confident that both parties are anxious to win, and while they would "double team" on you, as soon as they think your chances are out, will endeavor to gain the race from each other. Never Mind will go comparatively at his ease, when he has the benefit of the eight seconds which he can avail himself of. To get the full benefit, you will have to be very careful to lose the ground gradually. In going the sixteen hundred and sixty yards while the others are making the mile, it will be as well for you to be within twenty 
yards of the leader at the quarter, forty yards at the half mile, and seventy at the three-quarters, when you can drop the balance coming down the stretch, and pull up as soon as you are inside of the red flag. If possible, aid the outside horse in getting the best of the send-off, and drop irrmediately behind the leader. This will aid you in two ways-your own horse will be more likely to go easier, and give the one that has not won a heat the chance to commence the contest at once, without losing ground in going around you. They are very jubilant over winning this trick, and could hardly stop shouting when they knew they had gained it. Never Mind, the advice is good not to balloo till out of the woods, and they will find there is some very tall timber to traverse before the clearing is in view. Delay a little this time-not enough to try the patience of the judges, but sufficient to have them imagine you are more anxious than you are to gain time.

Upon my word, you did it well, and the horse dropped. back so gradually that it appeared as though he was too tired to do more than save his distance, and speculations were rife that he would be "shut out." He is not near so much distressed as he was in the previous heat, and has recovered wonderfully. Barring accidents, I would not give five per cent. to be insured this race. He is now selling for a trifle in the pools, and we must deputise some one to buy him in all of them, provided he can do it without engendering suspicion. You attend strictly to cooling him out. I will go and arrange the pool matter, and take a look at the other horses. I will be back in time to give him the wine. What a fall we could give these fellows if we were only in prime condition so that we could give away mother heat! Each one of them having won one, there would be no danger to let them struggle again as they did in this, and in the following one they could both the distanced. 
They do not give Never Mind a thought, and those who have put a few dollars on him are loud in their denunciations and contemptuous notices, characterizing him as a dunghill, shoemaker, and every opprobious epithet they can think of. We will now give him a little more than half a pint of sherry, mixed with the same amount of water. Give him a swallow of gruel first. I really believe he has a taste for that twenty-year-old juice, as he licks his lips and looks better pleased than he has for some time. Walk him very slowly, and have everything in readiness before the bell rings.

That summons from the judges was to acquaint me that a complaint had been made that you were not trying to win, and praying that they would appoint another driver. It is ten to one that it is the work of those who are betting on the other horses, hoping to have a driver selected whom they can control. Well, the benefit of a good name rarely fails one in an emergency. The judges have known me for many years, and when I assured them we were determined to win, if we could, they required no other guarantee, in spite of the clamors of the complainants. This forcing a change of drivers cannot be too strongly reprobated, and I would recommend that the evil of pulling horses be abolished, by punishing those who do it so severely, that they will not have the opportunity of doing it again, rather than by taking the management away from those who, being more conversant with the horse, know the best manner of handling him to win. I presume the man I sent to buy pools has followed the instructions too closely, buying every one till it was apparent that Never Mind had claims they were overlooking.

In driving this heat you can make a rush at the start, and take the pole at once, or you can lie closely behind till you enter the home stretch. I am satisfied that you 
can win in either way, and would advise you, if you get the best of the start, to adopt the first plan; and if you do not, you can follow the other. If you find that you are likely to have the advantage in starting, get on the very outside of the track, and strike a straight line for the inside at the commencement of the turn. But be very careful that you leave plenty of room for the other horses, so that they cannot have a shadow of reason for entering a complaint. When you get the track, ease him, as I have directed before, and while you keep lead enough to prevent them bothering you, there will be no necessity for opening much of a gap.

There, boys, you can cheer now, if you desire to do so, though I always prefer to see people when victorious exhibit no more excitement than they can help, and accept defeat with the same equanimity. To you, my scholar, I must offer my congratulations on the skill you have shown in driving, when the chances of defeat appeared greatly to overweigh those of success, following my orders when another course might have looked better. You frightened me at first by appearing a little nervous before you took your seat in the sulky, though I saw you were as cool as a veteran when you became engaged in the actual contest.

The judges have announced a postponement of the other trot, so one of the boys can go to the barn, and give the Falcon half a pail of water and a little hay. Never Mind will require and deserves the best attention. Scrape what water you can from his coat, clothe him, walk a few minutes, and bring him to the barn. Con, you go to the house and get a couple of buckets of hot water. When you have him rubbed dry, take both foot tubs and bathe his legs from the knees and hocks to the feet, then put the bandages on and walk him for ten minutes; I will prepare a mash. When the boy is walking him, give him a sup or two of gruel, and allow him to pick a little hay out 
of the hand. The mash must contain ingredients that will act as a cordial and tonic, and the water he drinks can be acidulated with the cream of tartar. I will make the mash with two quarts of the hominy and oats, and the same amount of wheat bran, a table-spoonful of sulphur and ground charcoal, a tea-spoonful of powdered golden seal, and the same amount of fenugreek seed. This mash must be made with boiling water and given when still warm. When the walk is finished, give two quarts of the oatmeal gruel, and while he is being cleaned and brushed, he can be allowed to eat a small quantity of has, and the mash proffered him. Should he appear to have no appetite, make up his bed, and by shutting up the stable he may lie down for an hour or two, when a little of the tepid acidulated drink can be given.

From his appearance, I judge there will be no trouble in getting him to eat; therefore you can give him the mash before he lies down. In three hours more his clothes can be taken off, his body lightly wisped, the bandages removed, and his legs well hand-rubbed. Should there be any swelling or heat perceivable, the tubs must again be used, bathing his legs with hot water for an hour, when dry them, and bandage, after having thoroughly moistened them with tincture of arnica, diluted with twice its bulk of water. His walk to-morrow morning should be for an hour and a half, clothed so that he will be comfortable, but not too warm. He must be gradually returned to his full feed and exercise, and if he does as well as I think he will, two days will be the farthest time that will be required. I forgot to tell you to give him two quarts of the mixed hominy and oats, and three pounds of hay, before shutting up the stable for the night. In the morning give him half his usual feed, and after he has finished the walk, he can be permitted to pick grass for a quarter of an hour. Two hours' walk in the after- 
noon will not be too much, provided his legs, or rather his joints, be not swollen, and the following morning he can be jogged three miles, with a brush the length of the stretch.

Pupil.-Did you observe the amount of leather one of these horses wore? I counted eight boots on his fore legs alone.

Preceptor.-There seems to be a passion amongst some men to cover a horse's legs with boots, and though there are borses that have to wear them to protect some part from injury, more are generally used than necessity requires. I have known people to use them for fear a horse might hit himself, although the animal had never shown any cause for being thus hampered. I prefer to take the pains that will guarantee safety, by looking closely to the shoeing and handling, and find that in nine cases in ten the result is satisfactory. Our best harness-makers now keep a supply of boots, from which the most fastidious can suit themselves, though I must admit a predilection for more simple contrivances, which often prove fully as effectual. Light buckskin rolls, stuffed with hair, or circlets of India-rubber tubes, will guard the pasterns as well as the heavy leathern ones. For instance, a horse rarely hurts the quarters with the outside of the toe of the shoe; the injury is done with the inside of the web or calking, and if this catches on a roll, in place of the heel, the foot slips off without doing injury. The shin is oftentimes better protected with a bandage than by the most elaborately contrived boot that ever was made; while the knee can be clad with strips of strong cloth enveloping the part, and fastened with an elastic tape above tho joint, the upper part being turned over, making a double thickness for the foot to strike against. Should the protection be needed above the knee, on the inside of the arm, the folds are put on thicker, and the cloth not 
turned over, but allowed to extend upwards as far as is required. This does not need to be fastened more than firmly enough, so that it will not slip over the knee, for if it turns on the leg, the protection is still the same. That some of the very fastest trotters are "booted all over," is not a proof that wearing boots is beneficial, as it may be safely laid down that anything unnecessary is an injury. This postponement of the race, while it has favored us by giving us plenty of time to attend to Never Mind, I am afraid will result in a longer delay than we will like. See how quickly the sky is becoming overcast, and the distant thunder and the flashes of lightning are premonitory symptoms that the storm is near at hand.

This long, hot, "dry spell of weather" has culminated, and I will venture the prophecy that we will have a lapse of several days before the "day and track" are both good. We can tell better, however, before bed-time, when the Falcon can either be prepared for to-morrow's race, or the muzzle removed, and he be allowed his usual quantity of fodder. 


\section{A P P E N D I X.}

\section{DEXTER.}

\section{HIS MEASUREMENT AND DESCRIPTION.}

As a further illustration of Dexter, aside from the very correct engraving that forms the frontispiece of this volume, I subjoin measurements taken in Chicago, September 8, 1867 - and comparing them with those of Lecomte, Leviathan, Eclipse, and Doubloon.

I was much gratified to find that these measurements -which were carefully taken-tended to prove the correctness of the positions in Horse Portraiture, and that this noted horse, acknowledged to be superior to all others that had preceded him, was formed after the model recommended as being the best for a fast and lasting trotter.

In instituting the comparison between him and the four noted thoroughbreds included in the tabular statement, I wanted to see whether he "approximated towards the form of the thoroughbred," or whether he had other characteristics, that would prove the configuration of the blood horse-conceded to be the best for racing speedwas not required for fleetness of movement in the roadster. Fortunately, Lecomte and Dexter are very nearly of the same size, in height, length, and girth, the two measurements being identically the same, and the only difference in the circumference of the chest being three-quarters of 
an inch. As the height and length would not be varied by the amount of flesh each one carried, it is safe to assume that these two horses, so noted in their respective classes, were of a size. The estimates arrival at, from a consideration of the data afforded by this detailed measurement, should be nearly correct; and when we find a horse agreeing with them, we may confidently look for a good one, provided he is not deficient in nerve force, which cannot be so accurately measured. Both horses gave evidence of the possession of that, by their performances, and each one displayed it to the eye educated in detecting this wonderful power. These measurements were taken in the stall and with the assistance of Peter Conover, who has had the horse in charge for several years, and I was much pleased with the docility of his charge, who stood very quietly while the tape was placed in the most trying positions to a nervous animal.

The height was arrived at by placing him on a plank, laying a square on his withers in a level position, and measuring with a tape line from point to point. Some of the measurements could not be arrived at with the same accuracy, as the length of neck, back, \&c. But when the corresponding points were definitely fixed, great care was taken that the results should be exact.

Measurearearts of
inches inches inches inches inches

\begin{tabular}{|c|c|c|c|c|}
\hline Height of withers... & 62 & 62 & 64 & 61 \\
\hline Length of head..... & 25 & 24 & 238 & 238 \\
\hline " " neck......... & 25 & 31 & 30 & 25 \\
\hline Round the muzzle........... & 19 & $\cdots$ & $18 \frac{1}{8}$ & $20 \frac{3}{4}$ \\
\hline " swell of jaws. & 33 & .. & 26 & .. \\
\hline Length of back....... & 23 & $21 \frac{1}{2}$ & 18 & 19 \\
\hline From hip to hip over the loin.... & 19 & 24 & 19 & .. \\
\hline Round the body at girth ....... & $68 \frac{1}{6}$ & 69 & 72 & 74 \\
\hline
\end{tabular}




\section{Measurements of}

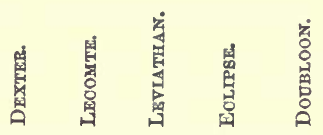

inches inches incles inches inches

\begin{tabular}{|c|c|c|c|c|c|}
\hline Round the flank. over the loin & 65 & 68 & 72 & 74 & 71 \\
\hline 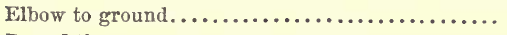 & $36 \frac{3}{4}$ & 36 & $37 \frac{1}{6}$ & $36 \frac{3}{4}$ & 358 \\
\hline Round the arm at swell $. . . \ldots \ldots \ldots \ldots \ldots \ldots . .$. & $19 \frac{1}{8}$ & $20 \frac{1}{8}$ & 22 & $21 \frac{1}{4}$ & 20 \\
\hline " knee ............................ & 13 & $12 \frac{1}{2}$ & $12 \frac{1}{2}$ & $12 \frac{8}{4}$ & $12 \frac{1}{6}$ \\
\hline 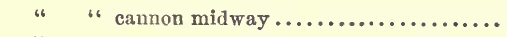 & 8 & $8 \frac{1}{2}$ & 9 & $7 \frac{3}{4}$ & $7 \frac{1}{2}$ \\
\hline 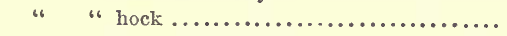 & $14 \frac{8}{3}$ & 16 & $16 \frac{1}{5}$ & $16 \frac{3}{4}$ & $15 \frac{1}{2}$ \\
\hline " cannon, hlnd leg ................... & $8 i$ & $8 \frac{1}{8}$ & $9 \frac{1}{2}$ & $8 \frac{1}{8}$ & 81 \\
\hline From point of hip to point of hock............ & $40 \frac{1}{4}$ & 41 & $42 \frac{1}{2}$ & $37 \frac{1}{3}$ & $38 \frac{1}{2}$ \\
\hline " " hock to ground................ & 23 & 25 & 25 & $24_{4}^{3}$ & 22 \\
\hline From point of shoulder to point of buttock ...... & 62 & 62 & 69 & 65 & 64 \\
\hline 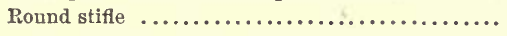 & $39 \frac{8}{4}$ & 39 & 40 & .. & 32 \\
\hline 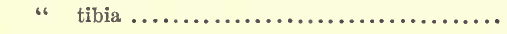 & 17 & .. & 18 & 188 & 17 \\
\hline " neck, at the head $. . . . . . . \ldots \ldots \ldots \ldots . .$. & $31 \frac{8}{6}$ & 29 & 30 & 31 & $30 \frac{1}{6}$ \\
\hline " " body...................... & 421 & .. & 47 & 45 & 53 \\
\hline 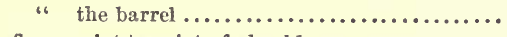 & 71 & 74 & .. & .. & 78 \\
\hline From point to point of shoulder .............. & 13 & 15 & .. & .. & .. \\
\hline " back of knee to the ground............. & 19 & .. & .. & .. & •. \\
\hline " " " " to middle of pastern ........ & 11 & .. & .. & .. & •. \\
\hline$\ldots \ldots \ldots \ldots \ldots \ldots \ldots$ & 22 & -. & .. & .. & •. \\
\hline
\end{tabular}

In looking over the tabular statement of their respective measurements, and comparing those of Dexter with the others, no great divergence is manifest. Dexter's head is long, longer than either of the others, although the thoroughbred characteristics are plainly developed. There is no superfluous flesh, and while the tape line shows him to be larger in the swell of the jaws, he is beautifully carved out below the eyes till the muzzle is finer than Eclipse and in the same proportion to the upper part as Doubloon. In considering the neck and its relative proportions with the others, the disagreement is reconciled from the fact that they were entire, while the emasculation of Dexter would take away from the measurement at its base more than at the setting $\boldsymbol{n}$ of the head. At this point he is finer than would be inferred from his being larger than the others, the thickness being in a horizontal 
direction, while the windpipe is so much detached that the line was carried away quite a distance from the lower part of the neck. The length of a horse's back would. hardly be agreed upon by two men measuring the same animal at different periods. The length given in the table is from the springing of the withers to the "coupling."

A line from the posterior part of the shoulder-blades to the hip would take away enough from the twenty-five inches, to render his back no longer than that of Eclipse or Doubloon. The distance from "hip to hip over the loin" shows that the points of his hips are more elevated than the rest, with the exception of Leviathan, which is also shown by the great distance from the "point of the hip to the point of the hock." The girth depending greatly on the condition of the horse, and the presumption being that Leviathan, Eclipse, and Doubloon were not in training when the measurements were taken, and that Lecomte and Dexter carried about the same flesh, their lower condition would account for the discrepancy in the circumference of the chest.

The same remark will apply to the measurement round the flank, which could he still more varied by the stomach being full or empty, the length of time in training, \&c.

The next distance in the table is the height of the elbow above the ground surface, which is the same as in Eclipse who was an inch lower, one inch greater than Doubloon, two inches being the variation in their height, threequarters of an inch less than Leviathan, and three-quarters more than Lecomte. There is therefore no marked distinction in this point. We now come to a measurement showing the volume of muscle in a place that is acknowledged to have a good deal to do with rapid progression, viz: the circumference of the arm at the swell. These muscles acting on the ligaments and tendons which extend the fore-leg, and the power with which they act, 
and the celerity of their dilatation and construction, govern the length and quickness of the stride. While it is impossible to say from an outside measurement which is the most muscular animal when there is only a third of an inch less diameter in the arm, and when harder or longer continued work had fined down the tissue in one more than the other, and while the effect between galloping or trotting in augmenting the muscular development, cannot be definitely stated, Lecomte was, and Dexter is, a very powerful animal in this particular, which further consideration will certainly show.

"Around the knee" Dexter is larger than any of the others, the place where the measurement was taken being squarely across the bony projection, to which the back muscles are attached by their tendons. The measurement around the cannon, being only exceded by Leviathan and Lecomte, shows that he is the equal of a majority of thoroughbreds in this particular. Not only is the size analagous, but the appearance is similar, and his legs show the preponderance of the racing blood that flows in his veins. Around the hock he is smaller than any that I am comparing him with, and after an hour's critical examination, the most faulty point I could find was the shape of his left hock.

There is a little fullness observable in the lower and outer portion of the joint, which I have no doubt has always existed. The hardest usage might never effect it, as I have seen much worse withstand the wear and strain of several season's racing. Still, in an animal otherwise as well formed as Dexter, it is a great pity that this defect should exist. The off hock is finely shaped, and the width above them is greater than is usually seen. "From point of hip to point of hock" he will compare favorably with the very best, while from the last mentioned point to the ground, the distance is less than any, save Doubloon. 
This configuration has always been recognized as a mark of speed, and many of our best race horses have exhibited this formation. There have been exceptions as was instanced by Don John, a horse of the greatest speed and endurance, and while I would have no objections to greater length in the metatarsal bones, a majority would prefer a horse to be "well let down in the hocks" after the fashion of Boston and Dexter. Both of these horses were comparatively long in the posterior measurement occasioned by the great length of os calcis; and the angles of the propelling limb are such as a good judge would pronounce to be proper for the fulfillment of the duties required of them, moving in a way that would be the least exhaustive of the power furnished by the muscles.

The measurement around the stifle is tremendous, and it was only after several readjustments of the tape that I could be satisfied we had got it correctly. Larger than all except the great horse Leviathan, and then only lacking a quarter of an inch, where the other was seven inches longer in body, is certainly very remarkable. The volume of muscles covering the framework, is the reason for this large girth, and the merest tyro in equine anatomy will readily see the effects of having such a magazine of power to propel the body along.

The lower thigh is larger than usual, and though not equaling Leviathan or Eclipse, yet being the same as Doubloon, a horse that was more than ordinarily powerful, shows that it is in harmony with the muscles located at a higher point. The circumference of the barrel is about in relative proportion with the others, taking the girth of the chest and flank as criteria to be guided by. This gives the wedge-like form, the very best configuration for speed and lastingness. "From point to point of shoulder" the distance is shorter than Lecomte, and to those familiar with both these horses the aid of a tape 
line would not be necessary to point this out. The race horse was "as thick through as a hay-stack" to use an English expression, while the trotter, though showing n. want of substance, is rather more delicately formed.

In giving these various measurements, it is not intended to reduce the characteristics of conformation to mathematical rules, and thus try to fix an absolute guide to perfection of form. But from finding that a great majority of first-class performers on the racing arena are "fashioned after a particular pattern," it is fair to conclude, that the fast trotter also has an outward reason-patent to the observing eye-why he is capable of excelling in his manner of progression.

That Dexter's form "approximates to the first-class race horse" cannot be doubted by any one who will study these comparative measurements, while his general appearance brings the parallel still closer.

I found from a close examination of him in his stall that this highbred appearance was more apparent than when in harness, or when seeing him at speed on the track, and I will now try to convey the idea of "what sort of a looking horse is Dexter," a question I have heard asked a thousand times.

In color he is a brown, with shades of a lighter hue, the more prominent parts being so light as to come under the denomination of bay. This shading is very pleasing to me, bringing into prominence the muscles, and softening down the more angular portions of his frame. The white marking in his face is different from any of the prints or pictures that $I$ have seen. In place of coming round more under the left eye than the right, it narrows alike on both sides, following truly down the nose nearly to the nostrils, where it diverges, covering almost the whole of the upper lip. The white legs are truthfully depicted in the engraving. His coat is silky, th? hair in the mane and tail being 
fine. There are a few small flesh-colored spots under the eye and along the sides. His head is large and bony, very well shaped, and showing in the full rounded forehead, and in the expression of the eye, that the nerve force predominates to an unusual extent. The eye itself is beautiful, prominent, and clear, with a small speck of "glass" in the lower corner of each, giving greater effect to the brilliant hazel of the eyeball. His ears are long, slender, in fact just the ear that is represented as gracing the head of the Falcon, and which adds in my estimation more to the beauty of the horse than any other point of adornment whatever. He carries them well, and whether at rest or in motion, they are sure to attract attention. His neck is of medium length, slightly drooping in front of the withers with very little elevation of crest. The head is finely joined to it, and there is plenty of room for the windpipe between the jaw-bones.

His shoulder is very good, the scapula falling back mbliquely into the sway, while the point is well advanced, and the leg falls tiruly from thence to the ground.

$\mathrm{He}$ "forks" beautifully, and very few race horses equal him in this respect, or are superior in the form of the nrisket. The knee, as shown from the measurement, is large and broad, with the bony projection behind well developed. There is a small splent on the near fore-leg, but far enough from the tendons and joint so that it never can do injury. His pasterns are oblique and of good length, without showing any appearance of weakness; the joints round, and giving no evidence that the many races he has trotted has effected them in the least. Like the race horse there are no long hairs on the upper pastern. His feet, though white, are first-rate, and it is a singular circumstance that the frog in each one is black, though the sole surrounding them is the same color as the wall. His midale piece is good being very deep through the 
heart, with the curvature of the ribs increasing to the centre of the barrel. The spine rises in front of the coupling, giving him an arched loin, yet not high enough to look unsightly. His back ribs might be a little longer, though they approach the hip very closely; and were it not that the stifles are placed unusually low, this would surely interfere with his great speed. This conformation then adds to his endurance, while the speed is not sacrificed, owing to the placing of the stifles. His hip is long and sloping, with the tail set on low. The effect of a sloping hip has been fully considered in the chapter on form, and it would be useless to rehearse it here.

With the exception mentioned about the near hock, his hind-legs are firsi-rate, muscular, with those of the upper thigh and stifle predominating, yet there is a balance kept up and the long firm muscles are appropriately terminated in large tendons.

The hamstring is very large, and the back cords are of fine size and stand out well from the bone. There is no puffiness about the hocks or pasterns, or any appearance to indicate that the work he has had has been prejudicial to them. In this respect his legs look better than when I saw him last year, as then there was a tendency to cracking in the heels, of which there is no symptom now. Standing squarely behind him, a person is astonished at the power shown from the loin to the gaskin. Though the hips are wide and somewhat ragged, the stifles are still wider, and at the hazard of being thought tedious, I cannot refrain from again calling attention to this development. The muscles that run from the ileum to the femur are so large that when the horse walks they become apparent to the eye, ridging the skin as if striving to break through the silky covering, while kindred masses so extend the quarters that he fills up a breeching that would be too long for a much larger horse. 
Forty-two and a half inches was the measurement from stifle to stifle around where the breeching would come. $\mathrm{He}$ is very compactly formed underneath the tail, "well pocketed" as I have heard old horsemen express it, and not divided like a pair of tong:s.

Standing, where a side view can be obtained, the grayhound form is observable. The deep chest, receding flank, sloping hip, long thigh, and short cannon, placed at the proper angle, are after the model of the fleetest of animals, while the hare-formed brisket and perpendicular fall of the front leg, with the elastic spring of the sloping shoulder and pastern, show that the power applied will have no inert mass to move, but the rebound will equal that of the rubber ball when it strikes the ground. The front view shows the mass of brain, the expressive eye and ear, the large nostril, the barrel swelling on each side of the shoulders, and behind that the curved line of the irnmense quarters. Standing squarely on his feet, the toes of the front ones are fairly in line, owing to the proper placing of the elbow, which is parallel to his body, while the hind have a slight outward inclination, due the position they got from the hock. There is nothing in his appearance to show that other than royal blood rums in his veins, and were he placed in a stable of race horses, his pedigree would not be questioned from his looks, sooner, than many that have distinguished themselves on the legitimate turf. One of the great tests of blood is the fine texture of the hoofs : this Dexter has. Another is the thinness of the skin, and prominence of the superficial veins: these he also possesses. Width between the jaw-bones, and the sharpness of their edge, characterize him as well as those that are higher bred. His walk is exactly that of the race horse. From weighing these distinctive marks of breeding, I am led to believe that the only blood in him otherwise than that of the race horse, is that which he obtains 
from his great-grandsire, imported Bellfounder, and that the purer has completely obliterated that and canceled its bad effects.

His manner of going is peculiar to himself, and while his trotting-gait is as even as the movement of a well-constructed watch, he goes with so much power that he fairly makes the track jar with the energy of his motion. This I think is due to the long sweep from the hip to the hock, and the tremendous force of the muscles between these two points. I saw an illustration of this in his late race in Chicago. In coming to the seore with Brown Georgo and running mate, he detached a ball of clay from his shoe; it flew into the air like a bomb projected from a mortar, and describing the same kind of a curve, fell adjacent to the three-in-five distance stand.

The Chicago track is constructed with a coating of clay laid on the natural soil of the low prairie. There is a good deal of elasticity, or rather there is a vibratory motion when the horses pass over it, perhaps more sensibly felt in the judges' stand than any other place. I feel positive that I might have been blindfolded and placed in the stand, and all the horses at the park driven by at speed, when I could have selected Dexter from the throng is dozen times in succession, from the greater jar that ho gave the building.

While other horses on the turf may possess as much speed, as is instanced by the trotting with a running mate, they are incapable of keeping it; while Dexter commences at the outest, and the brush lasts till his anticipated task is completed. There is no faltering, clambering, or dwelling, but the steady rate is persevered in, and the powerful stroke kept up with the same ease with which Kentucky or Asteroid takes his daily exercise. I have not had the pleasure of seeing Kentucky since he was two years old, but have seen the other great horse run in many of his 
races, and I have been struck with the parallel between his racing and Dexter's trotting. Asteroid starts at a sweeping rate, at the tap of the drum, his competitors scraining every nerve to keep up. They do so for a time, and when they fall off, you wonder what has been the cause. You see no change in the son of Lexington and Nebula: he comes in winning "in a big gallop" as the boys say, but that gallop has been enough to break the heart of his adversaries, without actually being a measure of his own powers.

It is almost needless to say that I am gratified to find the form of Dexter agreeing with that recommended in chapter twenty-six, and also his great resemblance to a first-class race horse.

Recognized as being the only type that will answer for continued rapid exertion at the natural fast pace of the horse-the gallop, it is but reasonable to conclude that the perfect symmetry only found in the blood horse, or those nearly allied to him, is an advantage that cannot be overlooked in the trotter. 


\section{N D E X.}

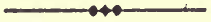

PAGE

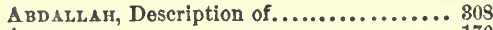

AllongiNG.......................... 170

The colts in the snow...........368

Anatowy, A knowleỏge of, necessary to understand the frame of the lorse .........228 ANDREW JACkson, Pedigree of................ 805 Arier, Pelligree of..................... 311 Preponderance of Messenger blood.. 56 Arteriks and veins.................. 263

BANDAGES, How to apply them after a sweating...................... 299 Jength, breadth, etc........... 111 How to put on............... 114 The duties of, wet and dry, etc.. 113 When they ought to be used for support ................... 114

BAтH, Turkish or Roman, benefit of......... 186 Bearing or check rein, "Kemble Jackson"

check............................ 177 BeDdive, Material of-Straw, sawdust, sand. 294 Benswing........................ 20 Brт, Cnrb, practical exemplification of....... 181 BrTs, Different varieties of............... 175 for sore mouths................... 183 Leather and silk................. 177 Bitting........................... 169 BLANKETING, when giving the first sweats.. 298 Brinvers, their uses.................. 247

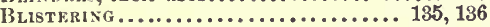

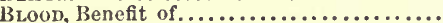

Benefit of, in trotters............. 42 Changes, how a rapid pace affects it.. 261

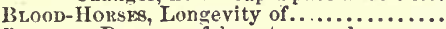
Bolting, Dangers of, how to remedy....... 47 Bоoтs, Contrivance to take thelr place...... 445

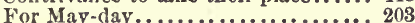

Brain, The seat of nerve force........... 393 Evidence of a large................ 895

Large, necessity of............. 32

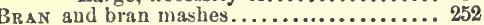
BREAKING from a trot, importance of teaching a horse not to break.......

Importance of obedience to commands..................... 335

Recovering a horse from a break 231

Stallion.................... 71 Breming, Advantages of a mixtrire of French blood............... 46 The Messenger blood........... 303 In, necessary to establish a fixed type.
Brekding, Pleasure of................ 43

Bridues, how they should fit............. 247 Buildings on breeding farms, adornments.. 67

Callusas formed by pulling............. 25

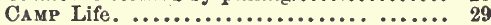

Carrying the tongue out of the moutb..... 182

Cauterizing, The benefits of............. 419

Cilarmer and Betsey Malone.............. 129

Curforey's Instructions................ 177

ClipPEr, Description and history of........ 44

Grazing and alterative medicine for him

His first brush................. 408

How his legs will have to be treated 407

How to cure him of bolting and breaking................... 47

The treatment pursued wit $\ldots . . .386$

Want of condition, ailment, etc... 45

Clothing...................... 114,115

After the sweat, and when cooling out...................... 298

For first sweats, amount of, and how to put it on............ 297

Injury from using it too often..... 20

Couro, Poisoning horses with collc dreuches 227

Cours, Breaking, first lessons............. 166

By Andrew Jackson-One-eye....... 805

Fall and winter-quarters.......... 60

General description of the colts in the

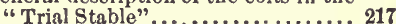

How a wild colt was broken......... 200

How to be treated when yearlings... 124

Learning young colts to eat........ 58

Playing in the field.............. 143

Preparing fall pasturage for the weanlings........................ 59

Proper method of working......... 899

Removal of parasites, mercurial ointment........................ 69

Require cow's milk at tinjes......... 70

Scouring, remedies for........... 226

Should be driven with and without blinds...................... 248

Stakes, the benefits of............. 142 The care of them dluring the winter.. 68

Uses of the check-rein............. 171

Varlety of food necessary ............. 125

When and how to wean............ 59

Winter rations.................. 60

Wrong way of rearing $\ldots \ldots \ldots \ldots \ldots, 27$

Condrion, tests of .................... 8s1 
Corona Ry ligaments, enlargement of, taken

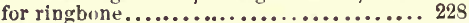

Country Life........................ 207

Cutting, A heavler shoe may remedy it.... 204

Between the hoof and pastern of

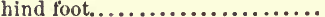

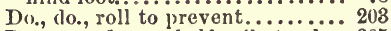

Dangers of, on a half mile track.. 205

llow to determine, by painting the foot ......................204

How to dress the wound......... 380

The quarters.............95, 97, 98

The quarters from bad shoeing. . 379

Decarbonization of the blood. .........256

Decoration of horses................... 116

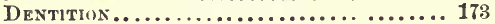

Dexter ..................... 447

Comparison, measurements, etc.... 448

Description...............449-458

Difrerence between trotting and running.. 184

Direction for work in the Preceptor's ab-

sence........................... 174

Distress, internal, how to relieve it........ 278

Drawbacks to training in early days...... 80

"Drawing fine"......................268

Driver, Qualifications for a............. 423

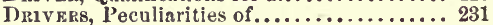

Driving, Bad driving the reason for a horse

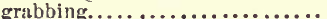

How to handle the reins.......... 24

Necessity of "light hands "....... 25

On the road................... 187

skill in ....................... 413

Elbow, How to prevent injury to......... 314

ENGLisu Colts, Their appearance when yearlings........................... 128

Exercisf, Necessity for it at all times...... 148

EXPERIMENTs to show the effects of a high check.

Falcon, The, His form, description and pedigree........................31-35

Ilis first trial.................. 425

History of.............................. $35-41$

History of work, condition, etc....... 384

Instrnction for driving........... 402

Preeeptor drives him on the road.... 194

Preparatlon for a ten mile race....... 259

Preponderance of Messenger blood in 306

Weight of his shoe............... 9s

FARM, Breeding .................... 52-55

Fat, Diminution of it essential............... 185

Effect of inside fat on the heart and

lungs........................ 260

How it is deposited and absorbed ..... 262

Necessity for, when commencing train-

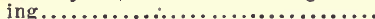

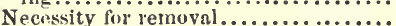

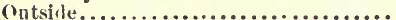

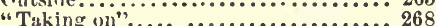

Feed, How to prepare............... 251

Mixture, homlny, oats, bran, etc..... 252

The effects of. in different horses..... 224

Freding, "Poor Feeder," causes wher young......................

The number of feeds, time of giving, quantlty, etc ..............

Ferd-room should be locked, and why.....
FHeT, Care of, picking, washing, etc...... PAGn

Effect of muddy roads on........... 149

Position of the feet in trotting and running, illustrated with a diagram..... 409

Fence for track...................... 164

Fining, Percival's opinion of............. 419

Food, Hay, cornblades, straw, etc......... 349

Table of comparative values......... 356

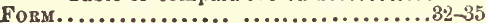

The best form for a trotter, and the reasons why such a configuration is the best............................. 392

Gex. Grant naming a colt at the lllinois fair............................. 153

Govermental aid.................. 149

Grass, Benefits of, why better than bran mashes.......................... 201

Grazing and sago gruel, comparison, ete ... 360 Grooming and rubbing sometimes overdone 11,7 Cruelty in.................. 109 Curryeomb and brush, how to be used...................... 106

Rubbing cloths, wisp, how to use them................... 111

The reasons for, and effects of..... 107

HALF-BRFD, The English definition of...... 127 HA1R Mittens, Benefits of, for a thin-skinnerl

horse........................... 110

Hakn fss, how to adjust................ 2:30

Harnessing, Necessity of, care in......... 229

HAY, Best quality, how to determine it.... 349

Different kinds............................

Prairie hay, medicinal effects of....... 354

Time for feeding, when training...... 356

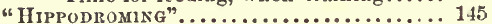

HipPoPATHOLOGY..................... 225

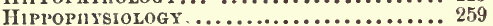

Hikondelle, Pedigree and characteristics... 79

Over trotting herself.......... 7s

Hirondrlue's Manner of trotting......... 205

Homis $x . \ldots \ldots \ldots \ldots \ldots \ldots \ldots \ldots \ldots \ldots \ldots . \ldots 252$

IoE, A race on the ice in Chlcago......... 237

Benefits of driving on the ice.......... 2:5

INJURY from lying on tho shoe................. 813

Iow A, Advantages of, for breeding horses... i4

JANE, Description and pedigree of........ 22

Commencement of her trotting educa-

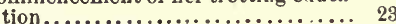

Further instructions for driving..... 44:4

How she should be shod........... 99

How to drive lier................. 233

KEMBLE JACKsox check.............. 179

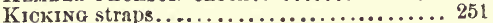

Kindnuss must be enforced.............. $10 \mathrm{~s}$

KixG, Ilis history, etc., extreme wildness... 85

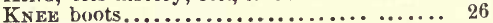

llitting it, caused by wrong set of the

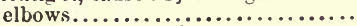

Instrument to cure hitting ...........

Treatment for enlargement of, old standing....................

Do., do., recent injury.............

LFssons in breaking................ 875

Lexington and Sallio Waters ............ 81

At the St. Louis Fair........ 82 
LookJA Ty from PAGE

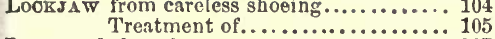

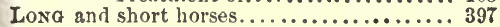

Mambrino Cirme, Pedigree............... 309

Mare that would not stanil, how she was

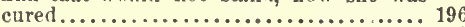

Mares, Accimmolation for brood.......... 58

Breeding in and in............... 58

Gestation and parturition, nursing. 70

How to feed................... 69

Proper manner of feeding brood-

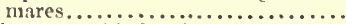

The proper kind to breed from......

Winter quarters for..............

Martingalk, long and short, their effects...

Further remarks on......... 244

Masir, how to make.................... 291

MAY-DAY, Appearance, deseription, etc.... 76

Boots and rollers to prevent cut ting hifol pastern............. 203

Faults of her form............ 77

lleavy shoes, the consequence of.. 341

Hor first drive................ 292

Her manner of going, how to correct, ete................... 202

Time of her first livial.......... 412

Mavournken, Description of............. 81

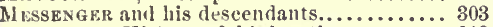

IIistory of, his location.......... 319

Musclas, Reinoval of fat froni the interstices. 265

Naming Farms ....

Narrowness of skull a token of want of

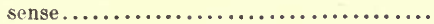

NECK, Effects of sweating on ............ 266

Large neck, why it is prejudicial.....267

Never Mind, Jescription of .............. 19

Care and food after his first sweat....................

Cuts his quarter, what occasioned It................ 380

Examination of him after the

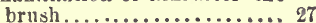

His condition.............4 431

His first brush............. 257

His first race............. 435

His first sweat, how to clothe and treat............... 295

His manner of walking...... 221

Morning of the race.......... 429

Necessity for grazing......... 922

Preceptor's opinion of him after driving him........... 199

The trial of.............. 427

The work given him, appearance, etc.............. 385

Treatment of the night before his first sweat............ 293

Weight of shoe proper for him 97

Wins after a hard struggle and brokell heats.

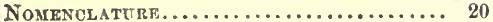

OATs, Amount of husk.................... 357

Description of good, how they should

be prepared.

Mixing hominy, the proportion, etc...252

Ravolns for mixing hominy with them 254

When and liow to feed............. 359

Ond time trotters ................... 821
Order must be enforced in stable duties.... 117

OrIoLr........................... 81

PADDocks, How to construct.

Prrsio, Courses of, in the old system of training.................... 228

Danger of ........................... 48

How it acts .................. 223

How to reduce a horse without physic ........................ 223

Reason for discarding, in training... 229

Pralrif, A western.................. 73

Pulling horses, how remedy the evil....... 176

On one rein................... 180

On the bit detrimental. ......... 246

QUALITy in horses..................... 156

Queen Mary...................... 21

$\mathrm{R}_{\mathrm{ACE}}$ After care, feeding, management, etc. 443

Care between heats............... 437

How to feed, etc., etc............... 435

Morning at .....................441

Never Mind's first race, description of

it.......................... 437

Preparation for a................. 485

RAREY's plan of breaking will not always do 86 Respiration......................... 261

RoAdster, The model for a.............. 387

RUBBERs, Qualification for good................ 109

Benefit of encouraging them to read .................... 109

RubBing cloths, best material for........... 111

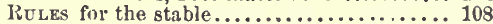

Running, The sound made by horses' feet

when running....................... 204

Rrspyk's Hambletonian, Pedigree of......... 304

S $_{\text {AGO }}$ Its uses....................... 359

Skasoning ........................ 269

Sirakspera's description of a race-horse.... 140

Siroeing, Advantages of a swedgell rim...... 96

Difference of for various liorses... 95

Effects of weight on the actlon.... 98

Form of the shoe, swedging...... 94

How the foot should be pared..... 97

Lockjaw from bal shoeing........ 104

Manner of weighting to avoid hitting the knec.............. 99

Plan of nailing, how to "olinch.". 94

Shoe for the hind foot........... 95

Shoes and plates................ 98

Sole shoulil not be cut........... 97

Singular instance of lameness from a "sulit nait."............... 220

Srlver Lake, Pa., Description of.................. 190

SkIN, How exudation takes place.......... 262

SkEwkrs, How they should be maile, their

uses, etc........................... 111

SмокाN not to be tolerated in the stable.... 31

SPEED ensures bottom.................. 141

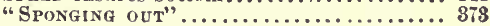

STABLF, Arrangement of the horses in the

"Trial Stable"................ 106

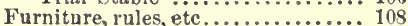

IIow it should look, location, etc.... 50

Interior arrangements for twenty

horses...................... 181

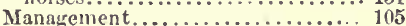

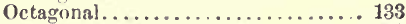

Plan for a training stable......... 130 
STABLR Trieks: crib-blting, weaving, piring, etc...................... 157-159

Stallow, Selection of, for breeding farm.... 70 Teaching him to trot............ 71 The best color for a............ 57 The proper stallion to breed from. 56

Stalla, Arrangement of equipments........ 107 Stimulants between heats.............. 369

Stony Ford, breeding farm............... 325

STRIDE, Realsons for a falling off...........411

"Strides," Advantage of measuring.......4 405

STYLE............................. 172

Sweating, A ppearance after, ............. 299

Between heats............... 272 Change in the appearance of the sweat........................ 262

Design of the first sweats....... 115

Difference of, between colts and aged horses. .................. 291

Dissertation on................ 258

Effects on the skin............ 262

Effects on the blood............ 263

Horses may be too hot to sweat.. 274

How to elethe................. 296

How to feed the night previous.. 269

Injury to the loins from........ 267

Its effect on the respiratory organs 259

Local effect of ................ 266

Mash previous to sweating, how to make it.................. 291

Motion of the lungs and heart.... 260

Necessity for, and how to induce. 278

Of Never Mind, the first one.... 296

Preparation for and care after, necessary................. 117

Purification of the skin from.... 287 Race lost by horse not sweating .. 275

Reasons for the system followed. 800

Recommendation of the plan given.................... 260

Scraping and rubbing dry ........ 297

The benefits of, on the internal econoiny................... 268

The benefits of, to the muscles... 265

The proper elothing for......... 115

Time for, repetition of, etc...... 268

Walk after the sweat............ 299

Walk before................. 295

With hot air; Black Maria's race 289

Work the day after............ 334

TrkTH, How to remedy their cutting the lips. 173 TaMPEt, A horse takes his cue from the driver 233 Importance of docility
PAGT

Theory of breeding...................... 896

Tkacks, The narrow track an advantage in training................... 79

Best form, undulations, etc....... 79

Proper soil for................... 80

The disadvantages of half a mile... 79

TraINER, Benefits of a liberal education. .. 219

Perplexities of................ 331

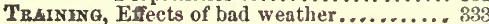

Intention of, definition, ete...... 183

Oats, hominy, corn and beans in.. 254

Old method of ................ 91

Physic.......................... 223

Retrospect of first part.......... 153

The necessity for patience iil.... 42

Water in, sont and hard, etc...... 371

Treateent of the horses in the flrst stige of

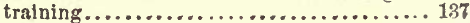

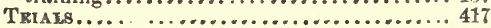

TrotTer, How to feed before a trial... .... 418

The proper form for a........... 359

TrotTERs, Different blood, of what families. 308

Necessity for "blood" in........ 48

Trotring, How a horse moves his feet when trotting.......................... 203

On the ice $\ldots \ldots \ldots \ldots \ldots \ldots \ldots \ldots . \ldots \ldots$

Track; construction of....... 163-165

VELss and arteries.................. 263 Prominenee of, in the thoroughbred.. 2\$7

Superfleial, and their uses.......... 2st

WaLk before the sweat............... 320 W ALKING at the commeneement of training. 98

Can be prolonged too much..... 180

Efrects of, change of location...... 92

Exercise, time occupied in the first stage....................... 137

Importance of................ 92

Old plan of walking horses....... 91

Proper clothing during walking exercise ................... 92

Wallowing BED, advantages of.......... 295 W AtER, Regulating the amount given ...... 376 W Aterine after driving............... 362

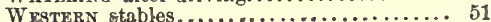
WET banlages, when they should be worn.. 113 WINTER-QUARTRRs for a trotter ......... 48,49 WinteriNG, How to winter a trotter......48,49 Womes, trees and horses................ 156 WoRk, Importance of regularity, change of

loeation, etc................... 256 In the mud, how to protect the horse. 419 

THIS BOOK IS DUE ON THE LAST DATE STAMPED BELOW

AN INITIAL FINE OF 25 CENTS WILL BE ASSESSED FOR FAILURE TO RETURN THIS BOOK ON THE DATE DUE. THE PENALTY WILL INCREASE TO 50 CENTS ON THE FOURTH DAY AND TO $\$ 1.00$ ON THE SEVENTH DAY OVERDUE.

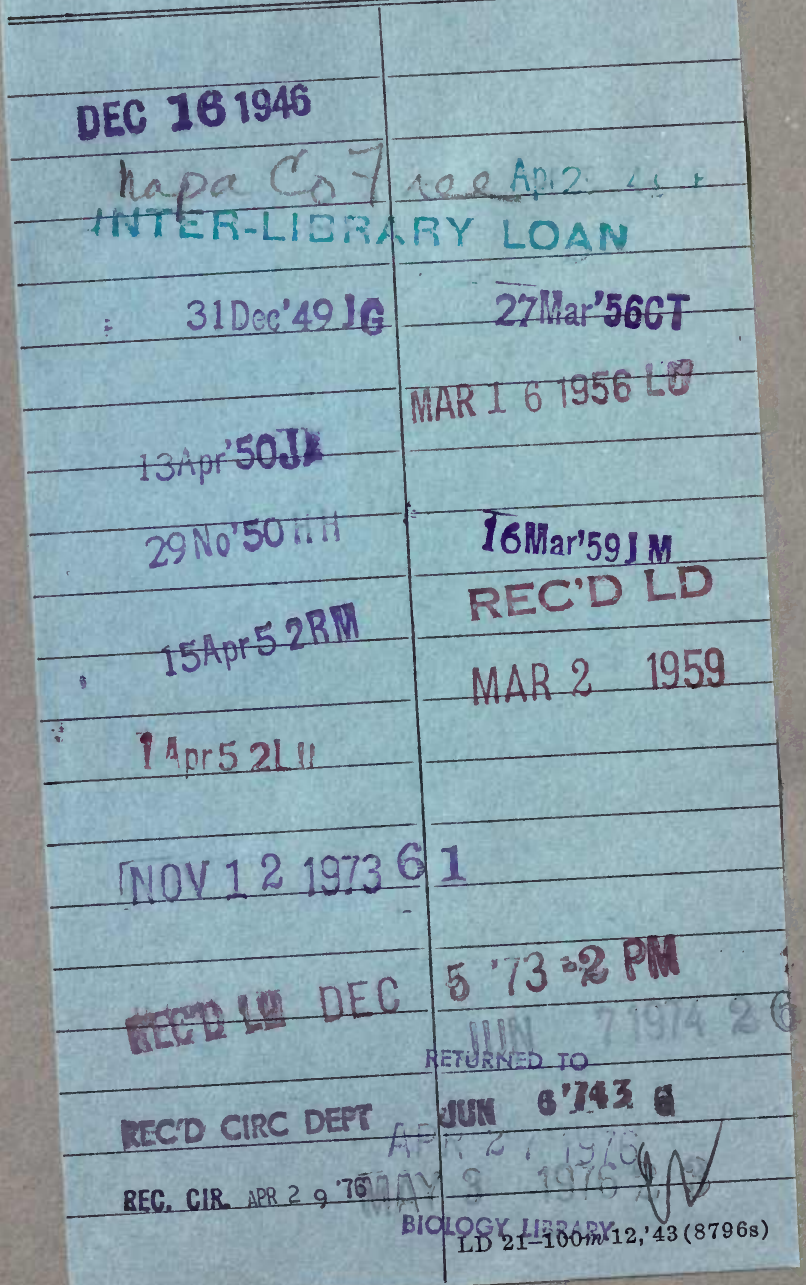




\section{9}

THE UNIVERSITY OF CALIFORNIA LIBRARY 


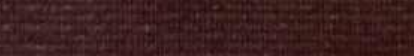

